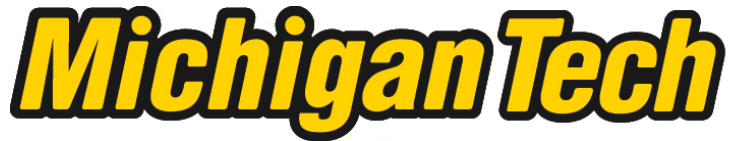 \\ Michigan Technological University Create the Future Digital Commons @ Michigan Tech
}

Dissertations, Master's Theses and Master's Reports - Open

Dissertations, Master's Theses and Master's

Reports

2011

Synthesis of chiral ferrosalen ligands and their applications in asymmetric catalysis

Xiang Zhang

Michigan Technological University

Follow this and additional works at: https://digitalcommons.mtu.edu/etds

Part of the Chemistry Commons

Copyright 2011 Xiang Zhang

\section{Recommended Citation}

Zhang, Xiang, "Synthesis of chiral ferrosalen ligands and their applications in asymmetric catalysis", Dissertation, Michigan Technological University, 2011.

https://doi.org/10.37099/mtu.dc.etds/37

Follow this and additional works at: https://digitalcommons.mtu.edu/etds

Part of the Chemistry Commons 


\title{
SYNTHESIS OF CHIRAL FERROSALEN LIGANDS AND THEIR APPLICATIONS IN ASYMMETRIC CATALYSIS
}

By

XIANG ZHANG

\author{
A DISSERTATION \\ Submitted in partial fulfillment of the requirements for the degree \\ of \\ DOCTOR OF PHILOSOPHY \\ (Chemistry)
}

MICHIGAN TECHNOLOGICAL UNIVERSITY

2011

Copyright (C Xiang Zhang 2011 
This dissertation, "Synthesis of Chiral Ferrosalen Ligands and Their Applications in Asymmetric Catalysis", is hereby approved in partial fulfillment of the requirements for the degree of DOCTOR OF PHILOSOPHY IN CHEMISTRY.

Department of Chemistry

Signatures:

Dissertation Advisor

Shiyue Fang

Department Chair

Sarah A. Green

Date 


\section{Table of Contents}

List of Figures .............................................................................................................................

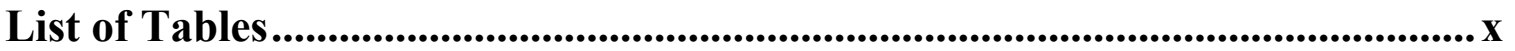

List of Schemes ...........................................................................................

List of Equations........................................................................................................................... xii

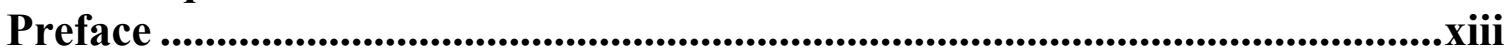

Acknowledgements ............................................................................................................... xiv

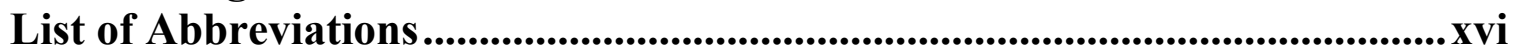

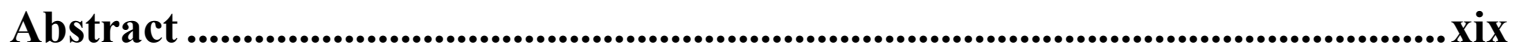

Chapter 1 Introduction .......................................................................................................1 1

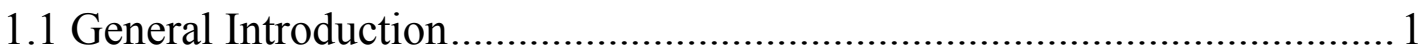

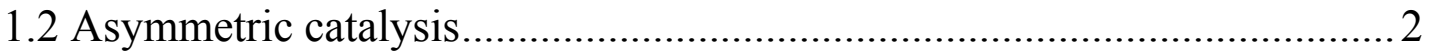

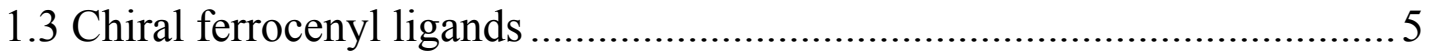

1.3.1 Known ligands and their characteristics..................................... 5

1.3.2 Synthetic routes to chiral ferrocenyl ligands ............................... 7

1.3.3 Applications of chiral ferrocenyl ligands in catalysis ............................ 11

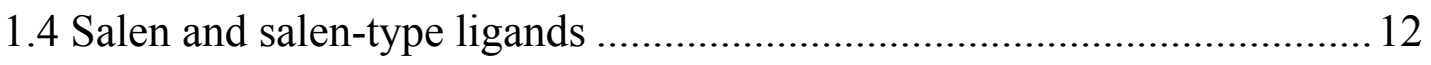

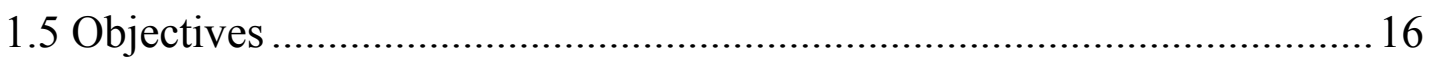

Chapter 2 Stereoselective Synthesis of a Chiral Ferrosalen Ligand Using an Aromatization Strategy ..................................................................................................... 19

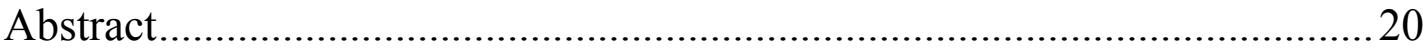

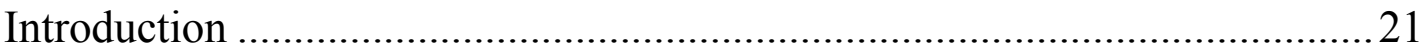

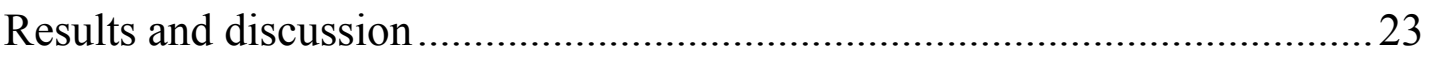

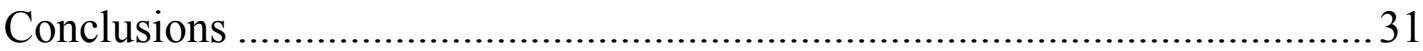

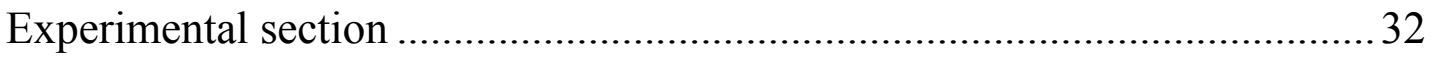

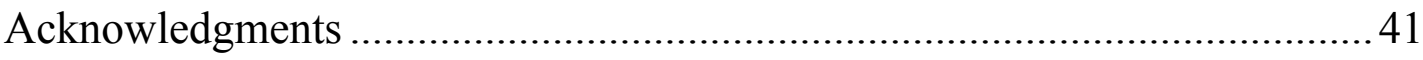

Chapter 3 Ferrosalen and Ferrosalen-Type Ligands: Structural Modulation and Applications in Asymmetric Catalysis .................................................................43

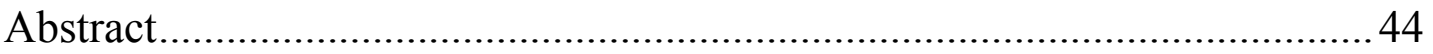

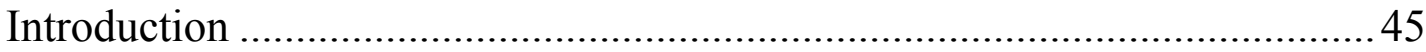

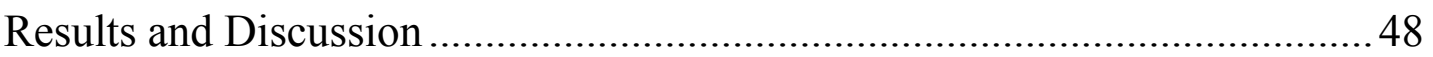




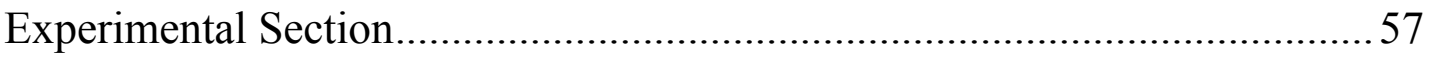

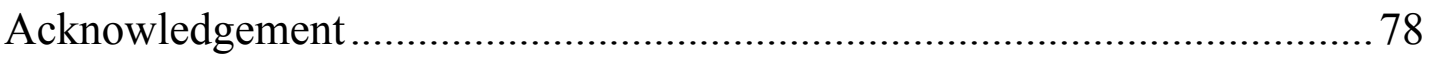

Chapter 4 Applications of Chiral Ferrosalen Ligands in catalysis.................. 79

4.1 Enantioselective Carbonyl-ene reaction ................................................... 80

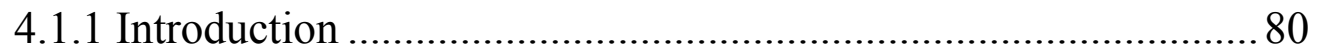

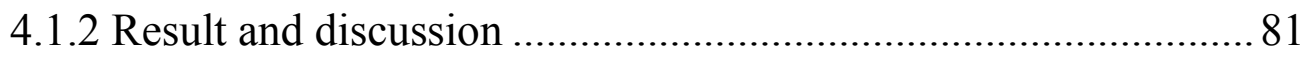

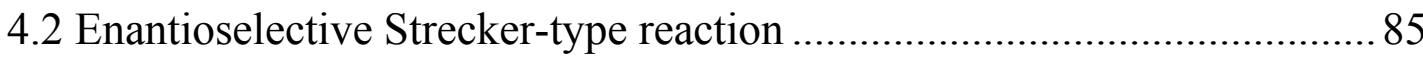

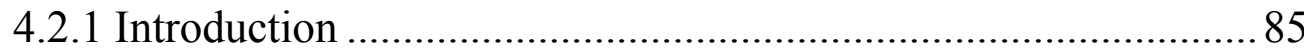

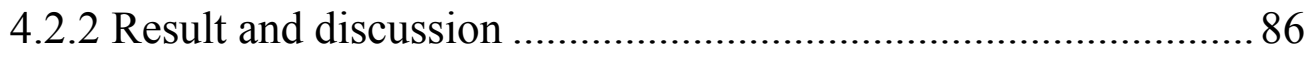

4.3 Enantioselective silylcyanation reaction ................................................. 90

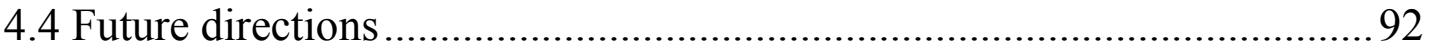

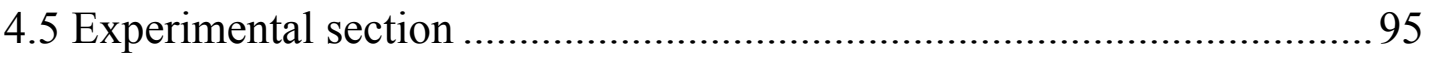

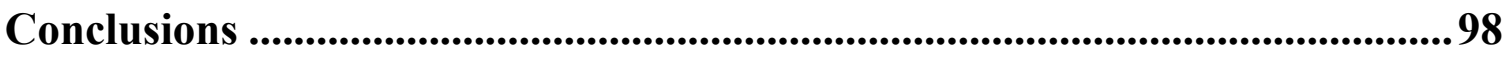

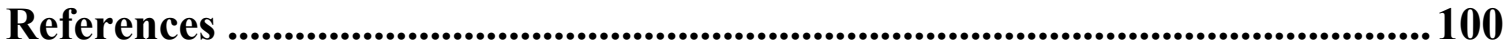

Appendix A Supporting Information for Chapter 2 ............................................. 116

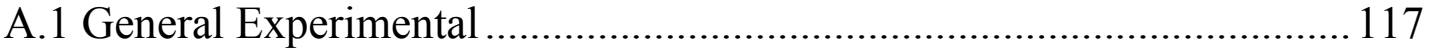

A. $2{ }^{1} \mathrm{H}$ and ${ }^{13} \mathrm{C}$ NMR spectra of new compounds ........................................ 118

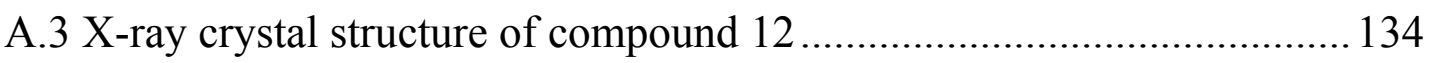

A.4 Low Resolution MS of Ferrosalen-Cu(II) Complex 13 ......................... 135

Appendix B Supporting Information for Chapter 3 .........................................136

B. $1{ }^{1} \mathrm{H}$ and ${ }^{13} \mathrm{C}$ NMR spectra of new compounds ......................................... 137

B.2 High resolution MS spectra of new compounds.................................... 177

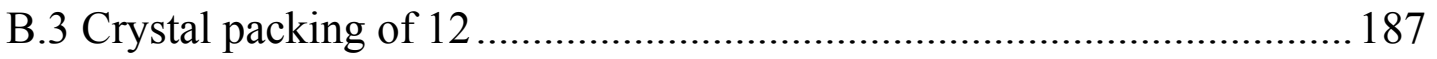

Appendix C Supporting Information for Chapter 4.............................................188

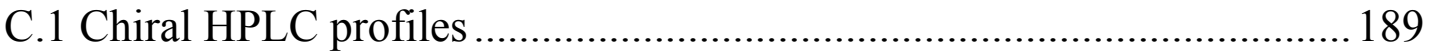

C. $2{ }^{1} \mathrm{H}$ and ${ }^{13} \mathrm{C}$ NMR spectra of new compounds .......................................... 199

Appendix D Permission from the publishers ...........................................................205

D.1 License of reproduction for Chapter 2.................................................205

D.2 License of reproduction for Chapter 3 ................................................206 


\section{List of Figures}

Figure 1.1: Methods of asymmetric synthesis ...................................................... 2

Figure 1.2: General process of catalytic cycle ................................................... 3

Figure 1.3: Example ligands with different types of chirality ..................................... 5

Figure 1.4: Examples of useful ferrocenyl ligands ................................................... 7

Figure 1.5: Examples of "privileged" chiral ligands and catalysts ............................... 12

Figure 1.6: Examples of ferrosalen ligands which can be obtained from $(R)-4 \ldots \ldots \ldots \ldots . .17$

Figure 1.7: Building blocks for the synthesis of methyl- and phenyl- substituted

ferrocenyl salen ligands .................................................................. 18

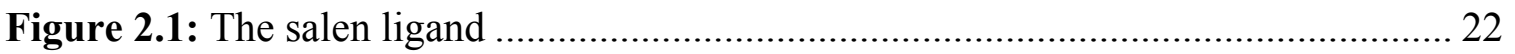

Figure 2.2: Structural motifs of a new class of chiral ligands $(\mathbf{1}, \mathbf{2})$ and a ferrosalen

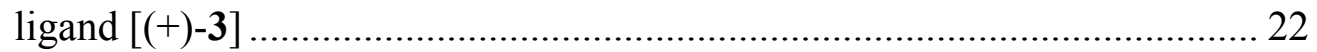

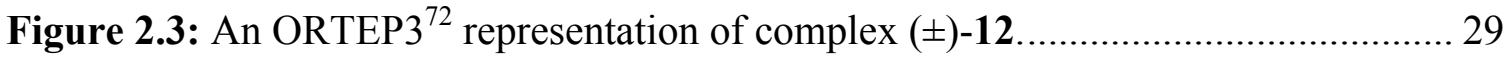

Figure 3.1: The two structural motifs of a new class of chiral ligands ......................... 45

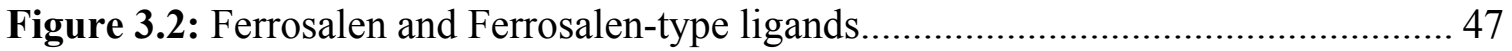

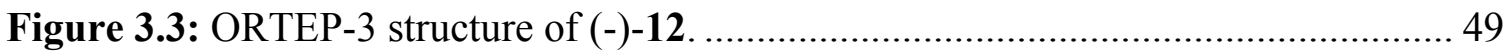

Figure 4.1: Ferrosalen and Ferrosalen-type ligands used in asymmetric catalysis......... 79

Figure 4.2: Example catalysts for enantioselective carbonyl-ene reaction .................... 81

Figure 4.3: Known catalysts for enantioselective Strecker reaction............................. 86

Figure 4.4: Comparison of Jacobsen's salen and ferrosalen framework ........................ 94

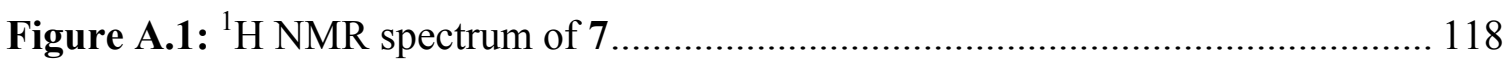

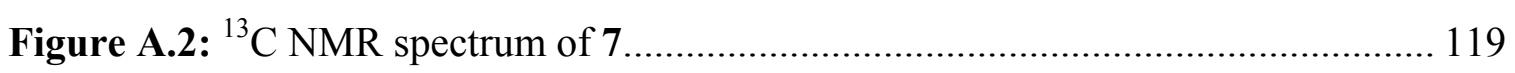

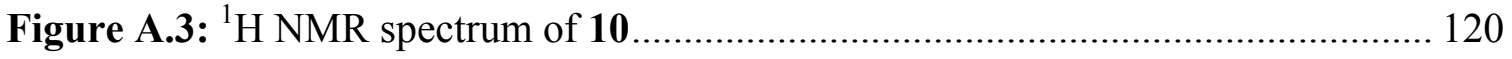

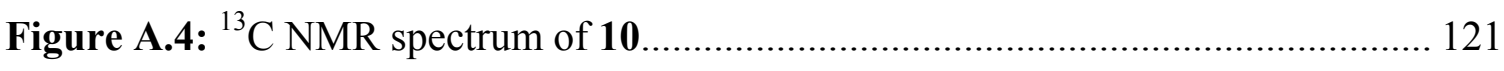

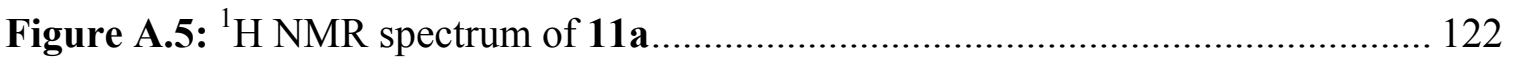

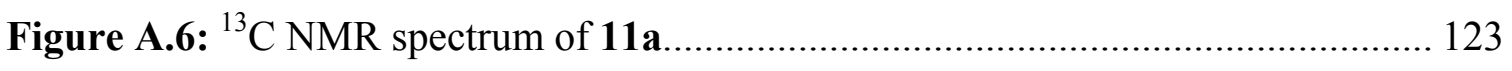

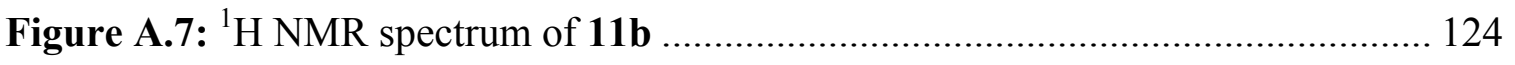

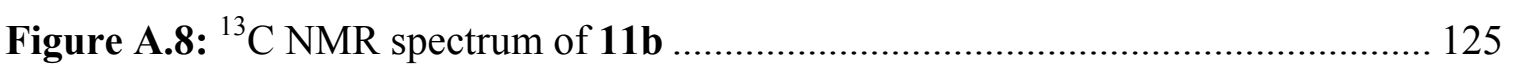




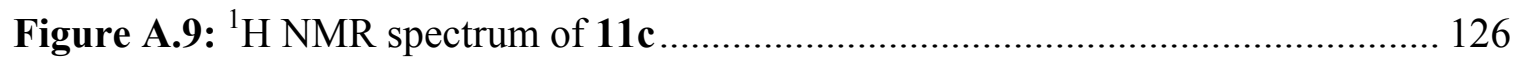

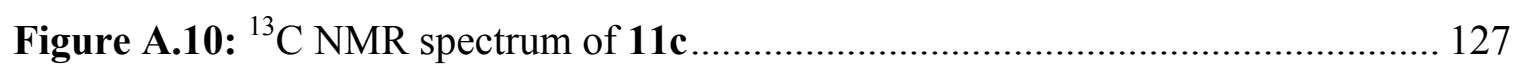

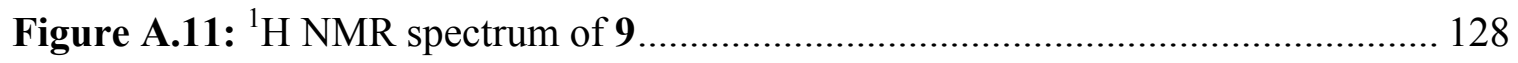

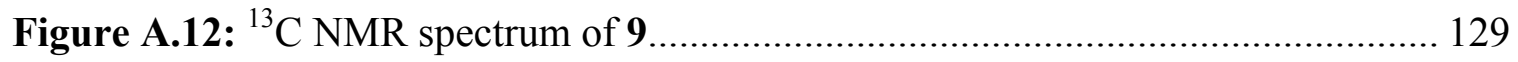

Figure A.13: ${ }^{1} \mathrm{H}$ NMR spectrum of 12 ...................................................................... 130

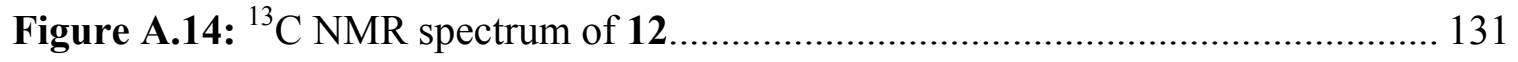

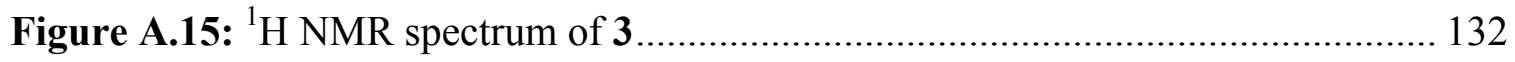

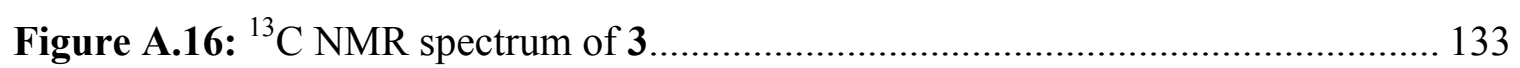

Figure A.17: X-ray crystal structure of compound 12 ………………………........ 134

Figure A.18: Low Resolution MS of Ferrosalen-Cu(II) Complex 13 .......................... 135

Figure B.1: ${ }^{1} \mathrm{H}$ NMR spectrum of (-)-1................................................................. 137

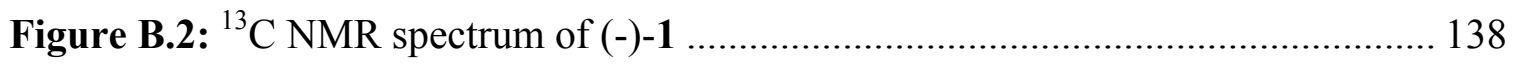

Figure B.3: ${ }^{1} \mathrm{H}$ NMR spectrum of (-)-2

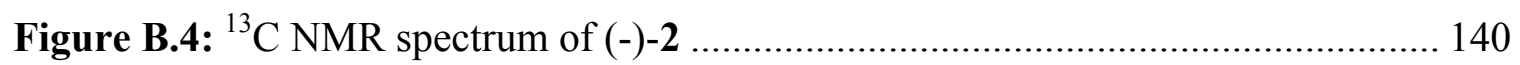

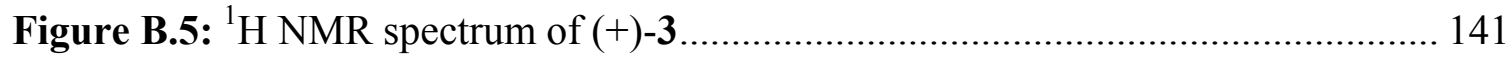

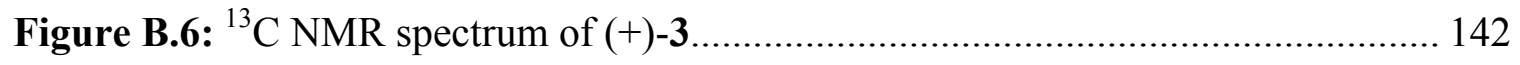

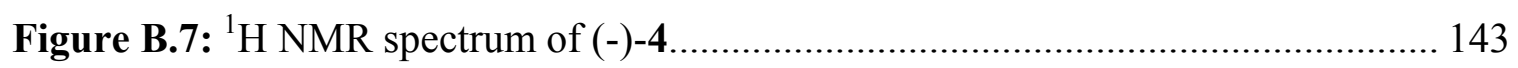

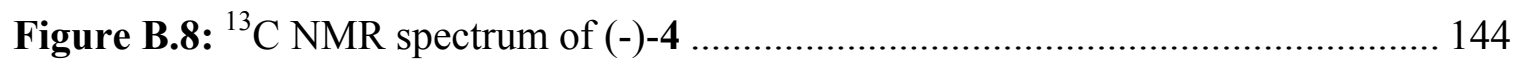

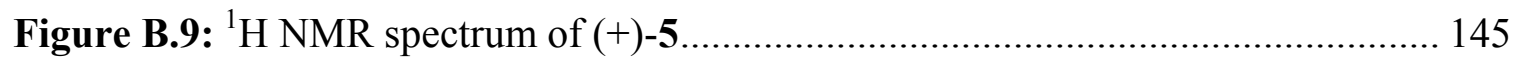

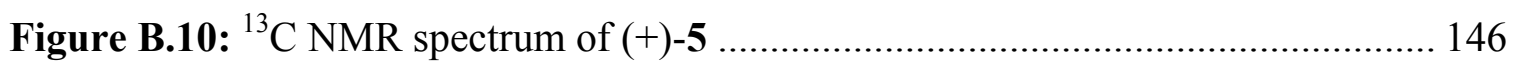

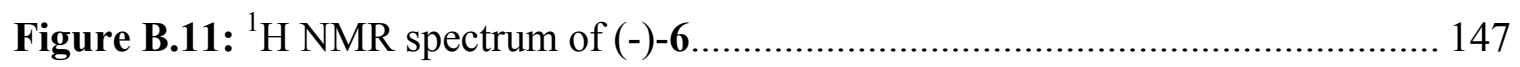

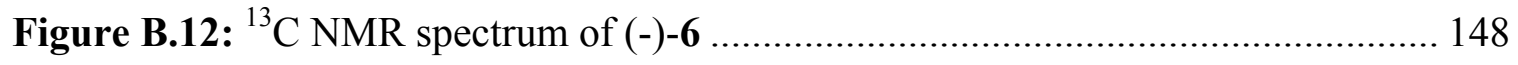

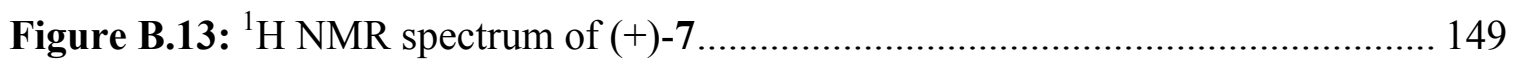

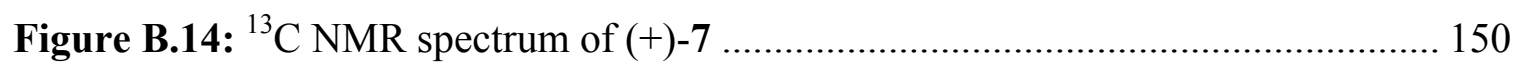

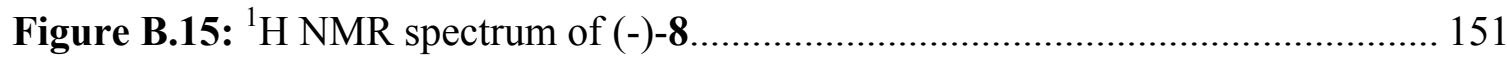

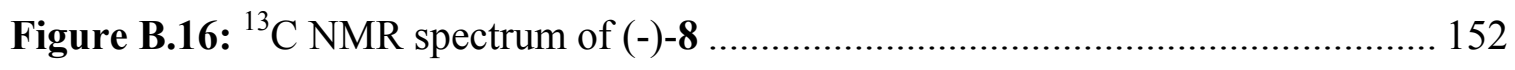

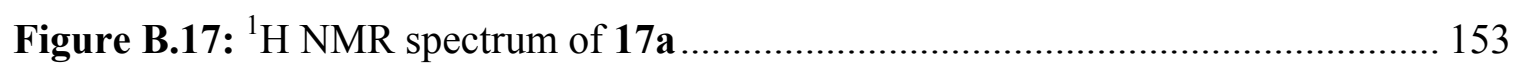

Figure B.18: ${ }^{13} \mathrm{C}$ NMR spectrum of 17a .............................................................. 154

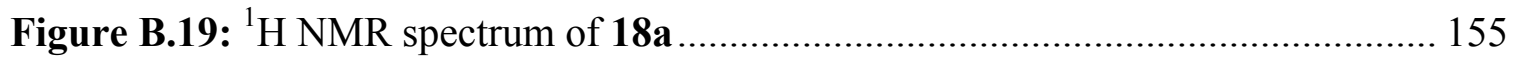

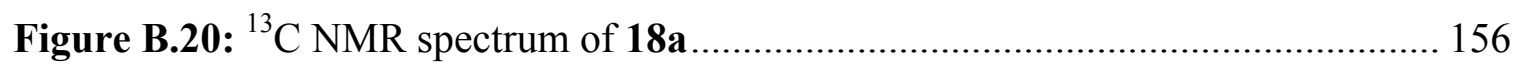




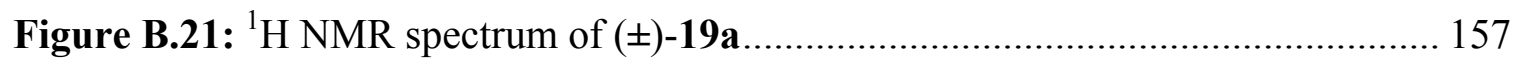

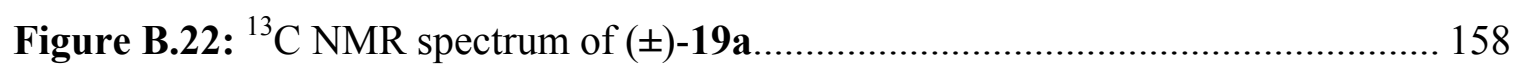

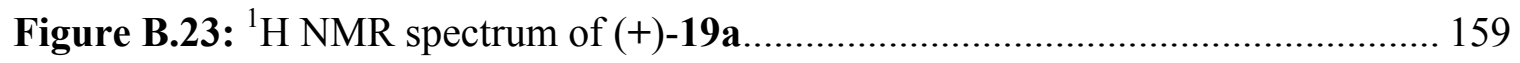

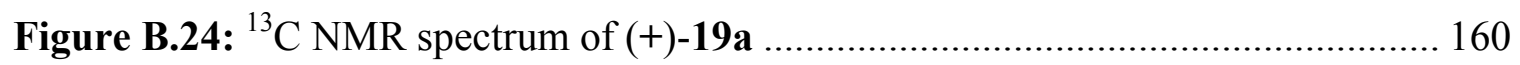

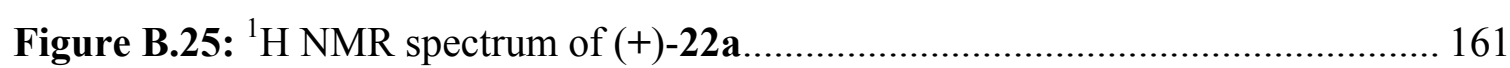

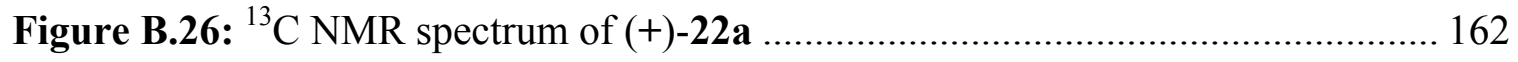

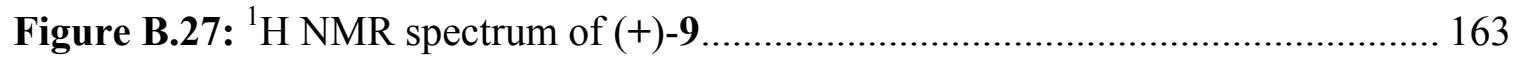

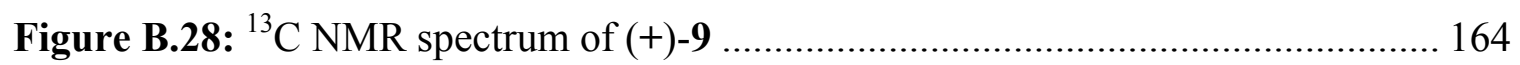

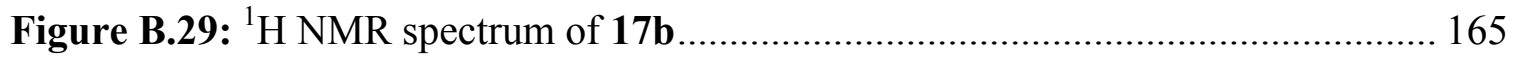

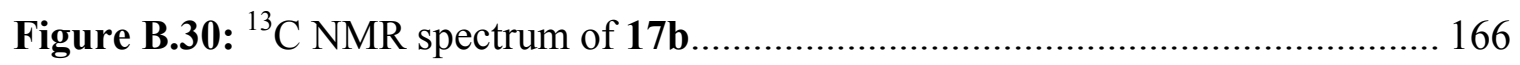

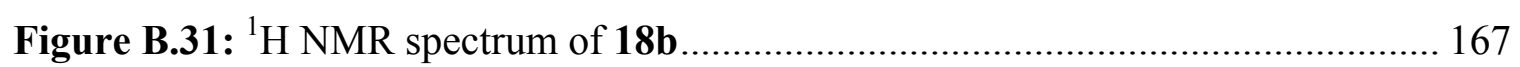

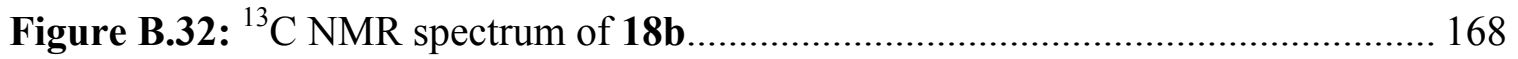

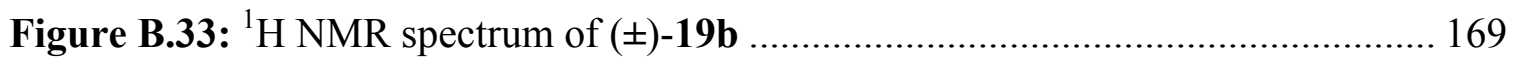

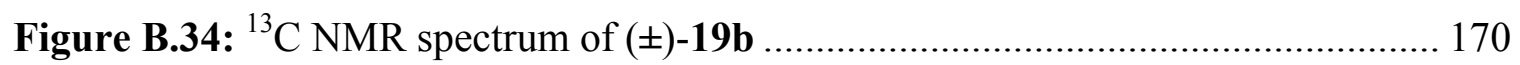

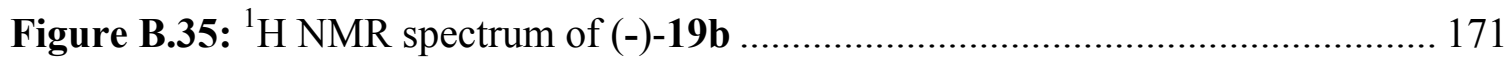

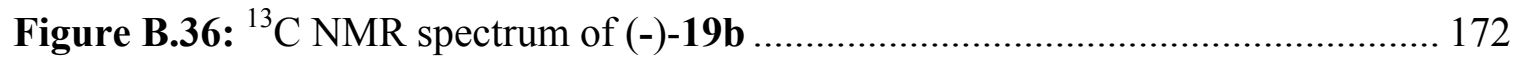

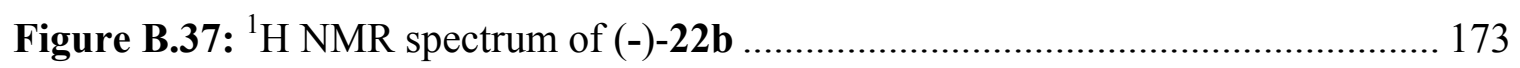

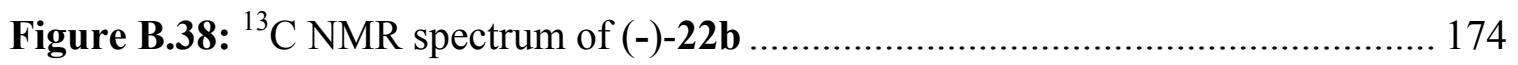

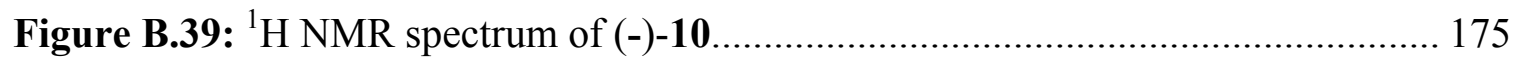

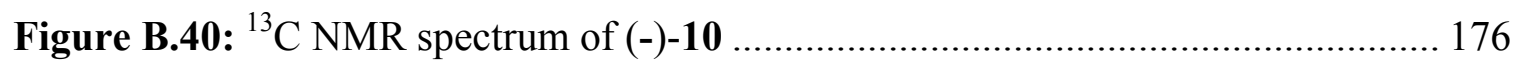

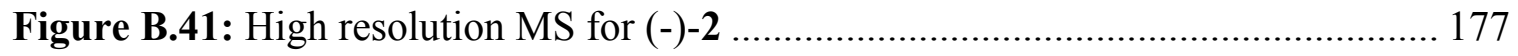

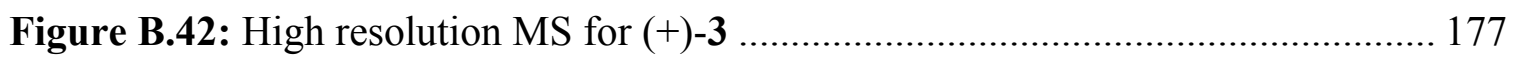

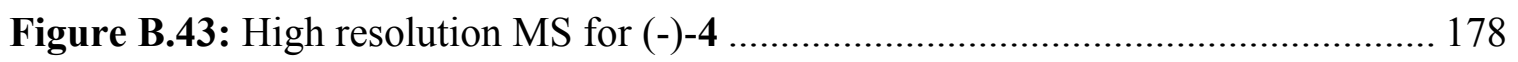

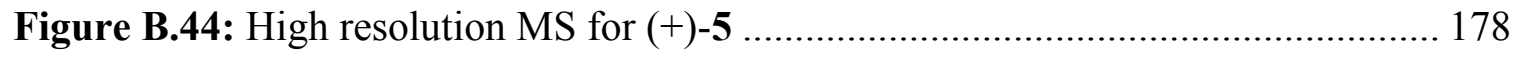

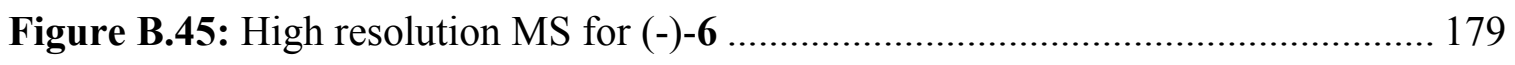

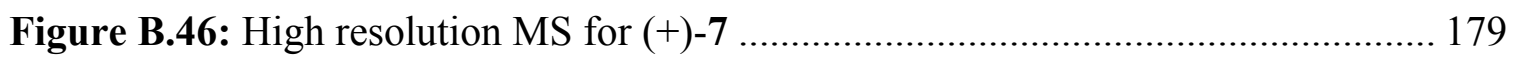

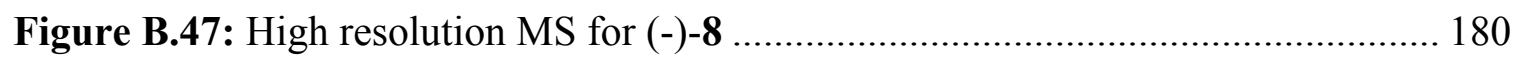

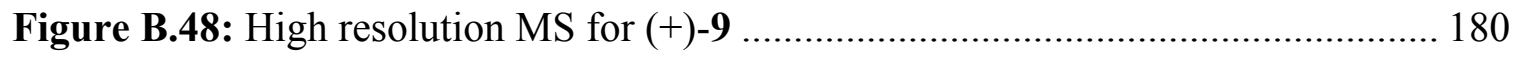

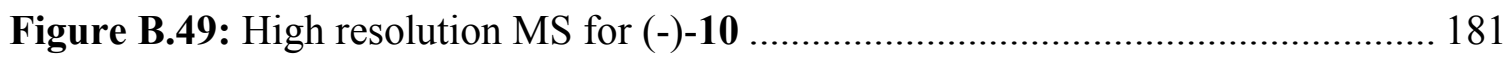

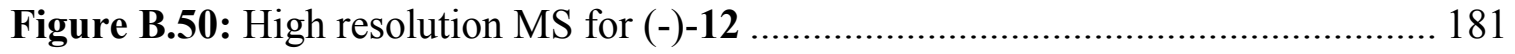




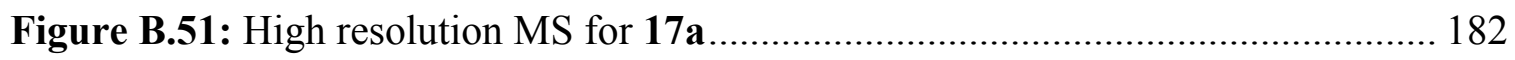

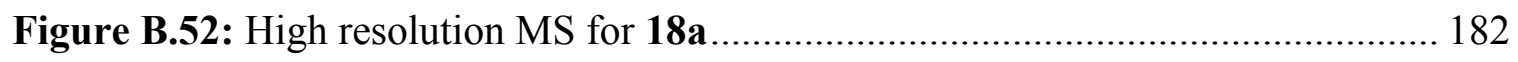

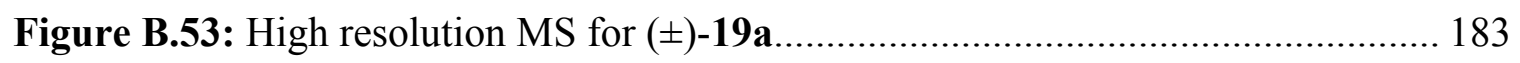

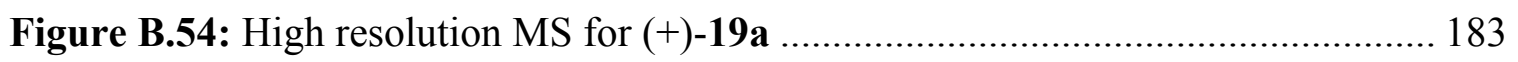

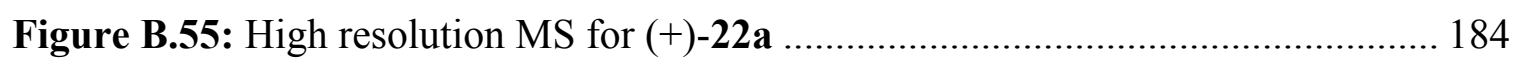

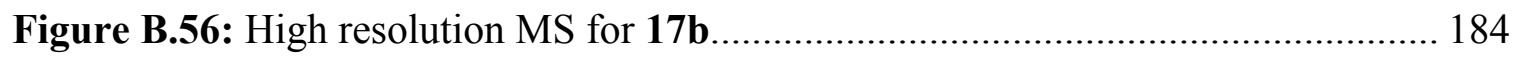

Figure B.57: High resolution MS for 18b........................................................ 185

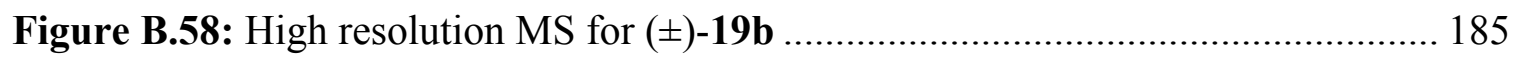

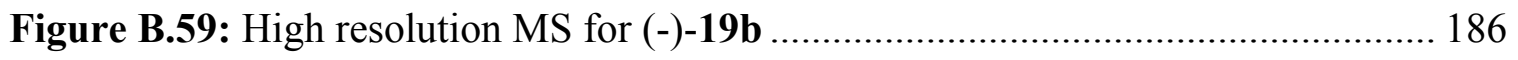

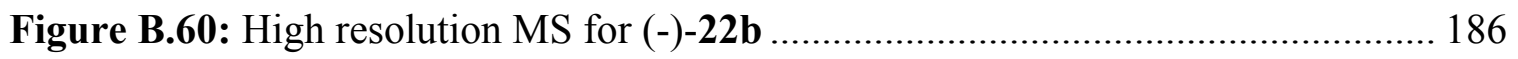

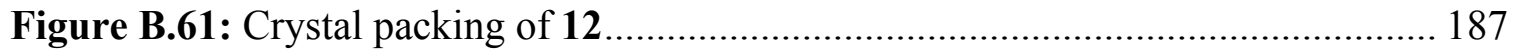

Figure C.1: HPLC profile for 15 using ( \pm )-11-Co(III) as the catalyst ........................ 189

Figure C.2: HPLC profile for 15 using 12-Co(III) as the catalyst.............................. 189

Figure C.3: HPLC profile for 15 using (+)-7-Co(III) as the catalyst ........................... 190

Figure C.4: HPLC profile for 15 using (-)-8-Co(III) as the catalyst ........................... 190

Figure C.5: HPLC profile for 18 using (-)-1-AlCl as the catalyst (rt)......................... 191

Figure C.6: HPLC profile for 18 using (-)-1-AlCl as the catalyst $\left(0^{\circ} \mathrm{C}-\mathrm{rt}\right)$................ 191

Figure C.7: HPLC profile for 18 using (-)-1-AlCl as the catalyst $\left(-78{ }^{\circ} \mathrm{C}-\mathrm{rt}\right) \ldots \ldots \ldots \ldots . . . .192$

Figure C.8: HPLC profile for 18 using (-)-2-AlCl as the catalyst............................... 192

Figure C.9: HPLC profile for 18 using (+)-3-AlCl as the catalyst.............................. 192

Figure C.10: HPLC profile for 18 using (-)-4-AlCl as the catalyst ............................. 193

Figure C.11: HPLC profile for 18 using $(+)-5-\mathrm{AlCl}$ as the catalyst ............................. 193

Figure C.12: HPLC profile for 18 using (-)-6- $\mathrm{AlCl}$ as the catalyst ............................. 193

Figure C.13: HPLC profile for 18 using (+)-7-AlCl as the catalyst ............................ 194

Figure C.14: HPLC profile for 18 using (-)-8-AlCl as the catalyst ............................. 194

Figure C.15: HPLC profile for 18 using (-)-10-AlCl as the catalyst ............................ 194

Figure C.16: HPLC profile for 19 using (-)-1-AlCl as the catalyst ............................ 195

Figure C.17: HPLC profile for 19 using (-)-2-AlCl as the catalyst ........................... 195

Figure C.18: HPLC profile for 19 using (+)-3-AlCl as the catalyst ........................... 196

Figure C.19: HPLC profile for 19 using (-)-4-AlCl as the catalyst ........................... 196 
Figure C.20: HPLC profile for 19 using $(+)-5-\mathrm{AlCl}$ as the catalyst ............................ 196

Figure C.21: HPLC profile for 19 using (-)-6-AlCl as the catalyst ............................. 197

Figure C.22: HPLC profile for 19 using (+)-7-AlCl as the catalyst ............................ 197

Figure C.23: HPLC profile for 19 using (-)-8-AlCl as the catalyst ............................. 197

Figure C.24: HPLC profile for 19 using (+)-9-AlCl as the catalyst: ........................... 198

Figure C.25: HPLC profile for 19 using (-)-10-AlCl as the catalyst:.......................... 198

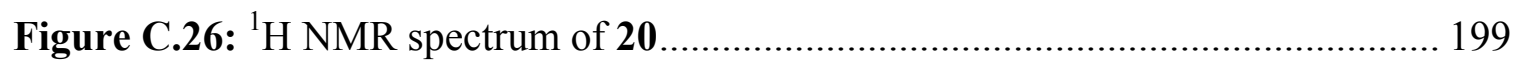

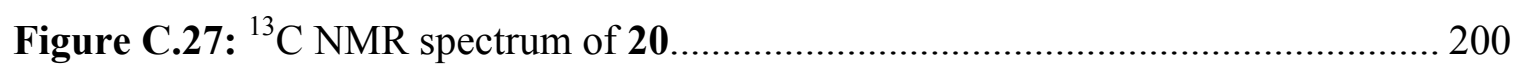

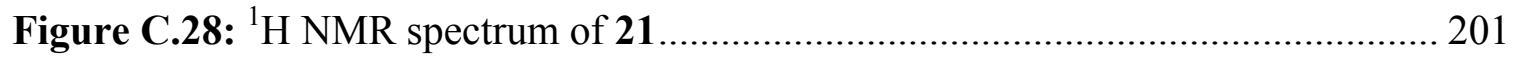

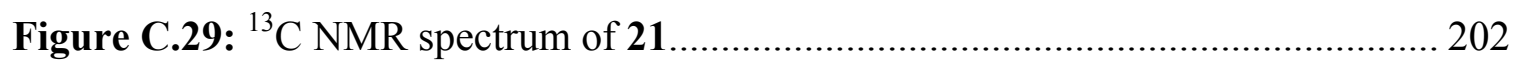

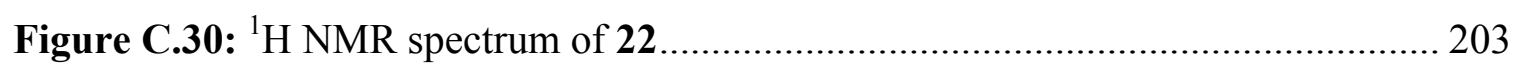

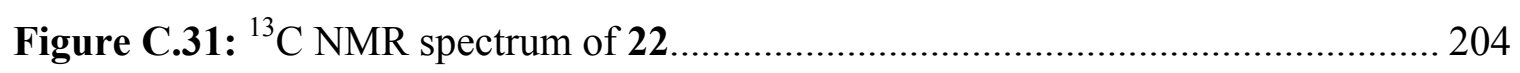




\section{List of Tables}

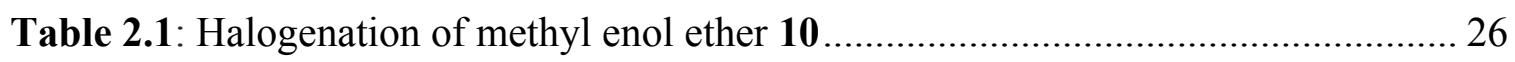

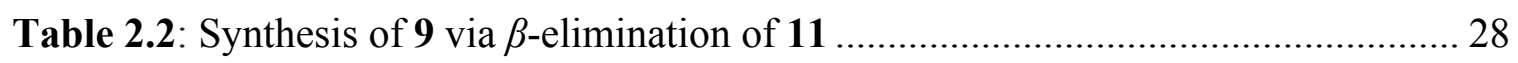

Table 2.3: Crystal data and structure refinement parameters for complex $( \pm)-\mathbf{1 2} \ldots \ldots \ldots . . .39$

Table 3.1: Crystal Data, Data Collection, and Structure Refinement for (-)-12 ............. 64

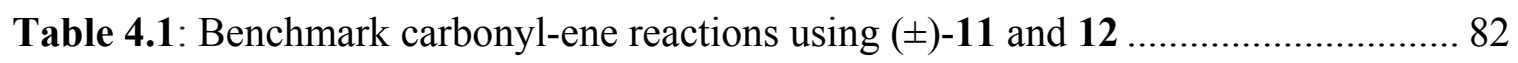

Table 4.2: Ferrosalen complex catalyzed enantioselective carbonyl-ene reaction .......... 84

Table 4.3: Ferrosalen complex catalyzed enantioselective Strecker reaction ................. 89

Table 4.4: Ferrosalen complex catalyzed enantioselective silylcyanation reaction......... 91

Table D.1: License of reproduction for Chapter 2 .................................................. 205 


\section{List of Schemes}

Scheme 1.1: Synthetic routes to $1,1^{\prime}$-disubstituted ferrocene ligands.......................... 8

Scheme 1.2: Examples of 1,2-disubstituted ferrocenyl ligands using Ugi's amine .......... 9

Scheme 1.3: Examples of the synthesis of heterocyclic ferrocene-type ligands.............. 10

Scheme 1.4: Applications of selected chiral ferrocenyl ligands ................................. 11

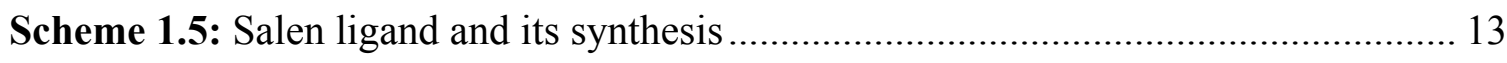

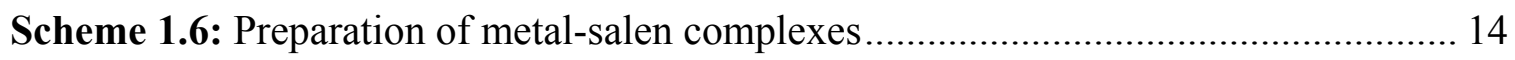

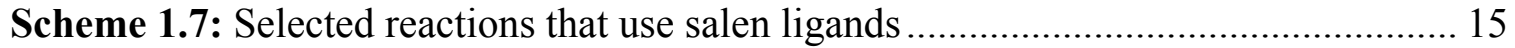

Scheme 2.1: Kuehne's method for the resolution of ferrocenyl ketone $( \pm)-4 \ldots \ldots \ldots \ldots \ldots . . .23$

Scheme 2.2: Early attempts to synthesize $(+)-9$ from enantiopure $(+)-4 \ldots \ldots \ldots \ldots \ldots \ldots \ldots \ldots . . . . . . . .25$

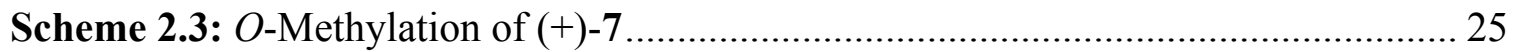

Scheme 2.4: Synthesis of ferrosalen ligand (+)-3 and its $\mathrm{Cu}(\mathrm{II})$ complex (+)-13.......... 30

Scheme 3.1: Synthesis of ligand (-)-2 and the Cu(II) complex (-)-12 …..................... 47

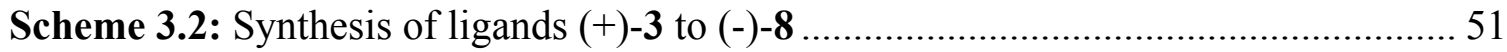

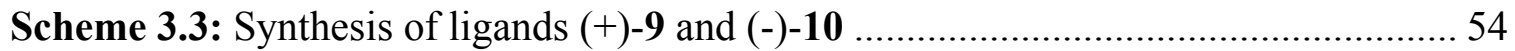

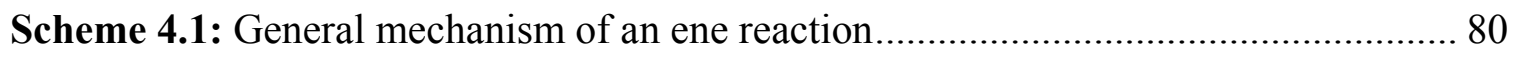

Scheme 4.2: Chirality transfer of enantioselective carbonyl-ene reaction..................... 81

Scheme 4.3: General mechanism of enantioselective Strecker reaction ........................ 85

Scheme 4.4: Benchmark catalytic Strecker reaction using $( \pm)-1$................................ 87

Scheme 4.5: Synthesis of steric hindered diamines 21 and 22 ............................... 93

Scheme 4.5: Retro-synthetic design for the optimized ferrosalen structural motif......... 95 


\section{List of Equations}

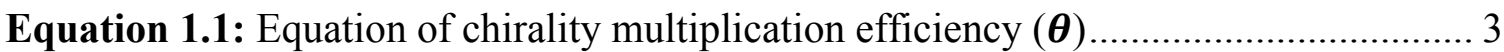

Equation 3.1: Asymmetric reactions catalyzed by ferrosalen ligands (-)-1 to (-)-10 ..... 56 


\section{Preface}

Chapter 2 of this dissertation was accepted as the following publication:

Xiang Zhang, Rudy L. Luck, Shiyue Fang. Journal of Organometallic Chemistry

2010, in press. (doi:10.1016/j.jorganchem.2010.10.064)

Chapter 3 of this dissertation was accepted as the following publication:

Xiang Zhang, Rudy L. Luck, Shiyue Fang. Organometallics 2011, accepted on $03 / 31 / 2011$.

The contribution of Xiang Zhang to these works includes all experimental work in the above manuscripts. 


\section{Acknowledgements}

First of all, I would like to gratefully and sincerely thank my research advisor, Professor Shiyue Fang, for his support and enthusiasm over the past six years. As an advisor, he has always encouraged me to explore my own ideas logically, and he has always guided me in the right direction. No matter how difficult it is for me to understand a mechanism or a reaction procedure, he has been very patient and always gives me an easy explanation. Being a part of the Fang group has been a great honor to me.

I would like to acknowledge Drs. Dallas K. Bates, Marshall W. Logue and Jeremy Goldman for being on my graduate advisory committee. I am very gratifying for their valuable time and advice in reviewing both my research proposal and this dissertation.

The help from all the staff of Department of Chemistry at Michigan Tech University which include Dean Seppala, Don Wareham, Celine Grace, Denise Laux, Margaret Dunsten, Kelly Smith, Shane Crist, Lorri Reilly and Aparna Pandey is gratefully acknowledged. Special thanks to Jerry Lutz for his generous assistance on instrumental training. I would also like to thank Dr. Rudy L. Luck for all the crystallographic studies. It is a true pleasure for me to work with every member of Chemistry Department.

The financial support provided by the Department of Chemistry is highly appreciated. Being a teaching assistant is also a way of learning, and I have learned so much. Sincere thanks are also due to the Biotech Research Center of MTU for their financial support of Finishing Fellowship.

I would like to thank my lab mates and all of my friends in MTU for their help in study and lab work, as well as the memorable moments during my studies. 
This dissertation certainly would not have been possible without the encouragement from my family. My parents and sister have always been incredibly supportive and faithful in me. I am also greatly thankful to my wife Chunbo. Without her patience, love, support and sacrifice, I would have had a tough time making it through graduate school. Finally, I would like to express the love to my 4-months-old daughter Mia. Her innocent laughter provided me with endless encouragement and motivations. She means the world to me. 


\section{List of Abbreviations}

\begin{tabular}{|c|c|}
\hline$\AA$ & Angstrom unit (10-10m) \\
\hline Ac & acetyl \\
\hline $\mathrm{Ad}$ & adamantyl \\
\hline $\mathrm{Ar}$ & aryl \\
\hline BINAP & 2,2'-bis(diphenylphosphino)-1,1' ' -binaphthyl \\
\hline $\mathrm{Bn}$ & benzyl \\
\hline BSA & $O, N$-Bistrimethylsilyl Acetamide \\
\hline $\mathrm{Bu}$ & butyl \\
\hline$c-\mathrm{C}_{5} \mathrm{H}_{11}$ & cyclopentyl \\
\hline $\mathrm{cm}$ & centimeter \\
\hline $\mathrm{Cp}$ & cyclopentadienyl \\
\hline $\mathrm{Cp}^{*}$ & pentamethylcyclopentadienyl \\
\hline $\mathrm{Cp}^{\mathrm{Ph} 5}$ & pentaphenylcyclopentadienyl \\
\hline $\mathrm{Cy}$ & cyclohexyl \\
\hline DMF & $N, N$-dimethylformamide \\
\hline E & Entgegen (opposite, trans) \\
\hline ee & enantiomeric excess \\
\hline equiv & equivalent \\
\hline Et & ethyl \\
\hline
\end{tabular}




\begin{tabular}{|c|c|}
\hline g & gram \\
\hline GC-MS & gas chromatography/mass spectroscopy \\
\hline $\mathrm{h}$ & hour \\
\hline HPLC & high performance liquid chromatography \\
\hline $\mathrm{Hz}$ & hertz \\
\hline$i$-Pr & propan-2-yl \\
\hline$i-\mathrm{PrOH}$ & 2-propanol \\
\hline IR & infrared \\
\hline$J$ & coupling constant \\
\hline $\mathrm{m} / \mathrm{z}$ & mass/charge \\
\hline $\mathrm{Me}$ & methyl \\
\hline $\mathrm{mg}$ & milligram \\
\hline $\mathrm{MHz}$ & megahertz \\
\hline $\min$ & minute \\
\hline $\mathrm{mL}$ & milliliter \\
\hline mmol & millimole \\
\hline mol & mole \\
\hline $\mathrm{mp}$ & melting point \\
\hline$n$ & normal \\
\hline NMR & nuclear magnetic resonance \\
\hline${ }^{\circ} \mathrm{C}$ & degree Celsius \\
\hline
\end{tabular}




$\begin{array}{ll}\mathrm{Ph} & \text { phenyl } \\ \mathrm{R}_{f} & \text { relative mobility } \\ \mathrm{rt} & \text { room temperature } \\ \text { tert } & \text { tertiary } \\ \mathrm{THF} & \text { tetrahydrofuran } \\ \mathrm{TLC} & \text { thin-layer chromatography } \\ \mathrm{TMSCN} & \text { trimethylsilyl cyanide } \\ Z & \text { Zusammen (together, cis) } \\ \delta & \text { chemical shift in parts per million }\end{array}$




\begin{abstract}
A new series of chiral ferrosalen ligands was designed and synthesized. The special feature of the ferrosalen ligands is that the chirality originated from the planar chiral ferrocenyl structure. For most known salen ligands, chirality comes from central and axial chiral centers. The key building block for the construction of these ferrosalen ligands was synthesized stereoselectively by a chiral auxiliary approach. This approach does not consume any chiral material, and does not require chiral HPLC resolution. Using this method, nine ligands were prepared using ferrocene as the starting material. In addition, the steric hindrance was modulated by changing the cyclopentadienyl group to the more bulky pentamethylcyclopentadienyl- and pentaphenylcyclopentadienyl- groups. The structure of these ligands was established by ${ }^{1} \mathrm{H}$ and ${ }^{13} \mathrm{C}$ NMR. The structure of a ferrosalen-Cu (II) complex was determined by single crystal X-ray diffraction analysis.
\end{abstract}

All the chiral ferrosalen ligands were tested in catalytic asymmetric reactions including enantioselective carbonyl-ene reaction, enantioselective Strecker-type reaction and enantioselective silylcyanation. For the carbonyl-ene reaction, up to $99 \%$ yield and $29 \%$ enantiomeric excess (ee) were obtained using ligand-Co (III) as the catalysts; For the Strecker-type reaction, a maximum of $20 \%$ 
ee was obtained using ligand- $\mathrm{AlCl}$ as the catalyst; For the silylcyanation reaction, up to $99 \%$ yield and $26 \%$ ee were obtained using ligand- $\mathrm{AlCl}$ as the catalyst. 


\section{Chapter 1}

\section{Introduction}

This chapter includes an introduction and some background information for all the subsequent Chapters (Chapter 2,3 and 4) of this dissertation. The compound numbers, equations, schemes, figures and tables are restricted to each Chapter and not continued from one Chapter to another.

\subsection{General Introduction}

The synthesis of enantiopure compounds has become one of the most active areas of current chemical research. In nature, most biological molecules such as proteins and sugars are present in only one enantiopure form, which can distinguish the enantiomers of a chiral drug molecule. Different enantiomers of a given drug molecule can exhibit dramatically different bioactivities. The wrong enantiomer may be inactive, or even cause serious side effects. Of the 10 topselling drugs, nine have chiral active pharmaceutical ingredients (APIs) and six are single enantiomers. ${ }^{1}$

The demand for efficient production of enantiopure chiral compounds continues to rise. The increasing trend has led to explosive interests in developing new stereoselective reactions ("asymmetric synthesis"), which is defined as the intentional construction of enantiomers of a given constitutional isomer by means of chemical reaction. ${ }^{2}$ There are three approaches to make enantiopure compounds: 
(1) intramolecular chirality transfer: asymmetric control is achieved by an existing chiral unit from the substrate (Figure 1.1a); (2) intermolecular chirality transfer: chirality is induced by temporarily inserting a chiral-directing group into the original achiral substrate which is removed after synthesis (Figure 1.1b); (3) asymmetric catalysis: a chiral catalyst is used to induce the conversion of achiral substrates to chiral products (Figure 1.1c). Among the three approaches mentioned above, asymmetric catalysis is the preferred method.
a. $\mathrm{R}^{*} \longrightarrow \mathrm{P}^{*}$
b. $\mathrm{R} \stackrel{\mathrm{D}^{*}}{\longrightarrow}(\mathrm{P}-\mathrm{D})^{*} \longrightarrow \mathrm{P}^{*}$
c. $\mathrm{R} \stackrel{\mathrm{C}^{*}}{\longrightarrow} \mathrm{P}^{*}$
*: chiral unit
R: reactant
D: chiral-directing group
P: product

Figure 1.1: Methods of asymmetric synthesis

\subsection{Asymmetric catalysis}

The advantage of asymmetric catalysis is that a small amounts of chiral catalyst produce chiral compounds in large quantity. This advantage can be evaluated with the chiral multiplication efficiency, $\theta$ (Equation 1.1). In theory, the efficiency of asymmetric catalysis can be $\infty$, while those methods using intra- and intermolecular chirality transfer are $0 .{ }^{2}$ The advantages of enantioselective 
catalysis have made the method one of the most explored areas of chemistry in recent years.

$$
\theta=\frac{\text { (major enantiomer })-(\text { minor enantiomer })}{\text { chiral source }}
$$

Equation 1.1: Equation of chirality multiplication efficiency $(\boldsymbol{\theta})$

Most catalysts for enantioselective reactions consist of two major components: metal catalytic center and chiral ligand. Catalytic activity is usually related to the metal catalyst (Figure 1.2). A catalytic cycle starts with bond activation of the substrate by coordination of the metal to the reacting site on the substrate $\left(\mathrm{R}_{1}\right)$, which is usually followed by the attachment of the second reactant $\left(\mathrm{R}_{2}\right)$. The catalytic cycle is finished by detachment of the metal catalyst to form product. Sometimes there might be an additional step to regenerate the catalyst. ${ }^{3}$

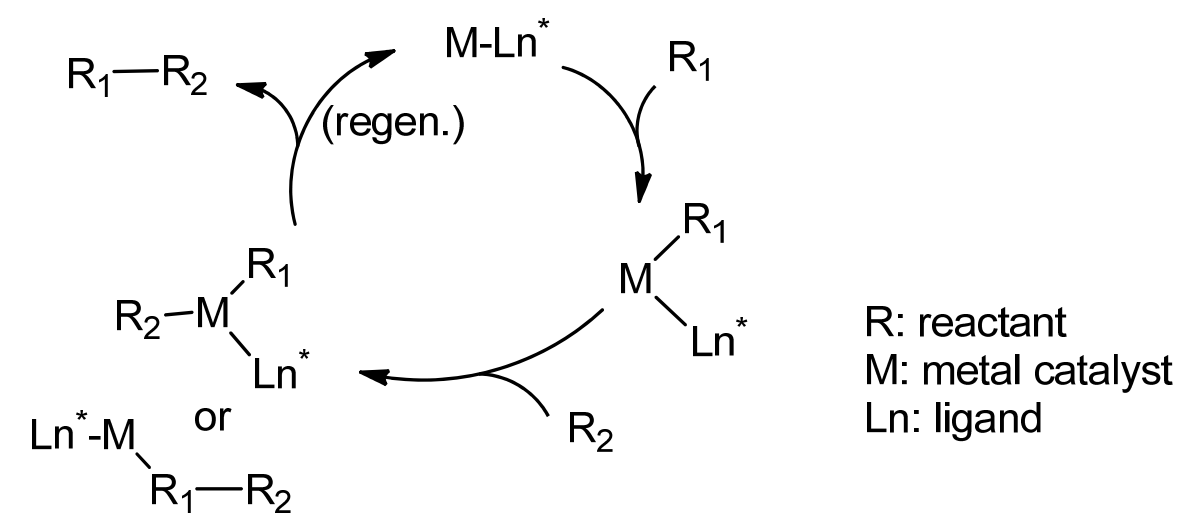

Figure 1.2: General process of catalytic cycle 
For a catalytic asymmetric reaction, enantioselectivity and reactivity are mainly modulated by the chiral ligands. The combined electronic and steric effects should maximize enantioselectivity and reactivity. Proper ligand must be chosen to achieve efficient intermolecular chirality transfer from the catalyst to the substrate, and make one of the enantiomeric products to form predominately.

According to the rule proposed by Cahn, Ingold, and Prelog (the CIP rule), there are three types of chiralities: central, axial and planar. ${ }^{4} \mathrm{~A}$ chiral center is defined as an atom in a molecule that is bonded to four different chemical species, allowing for optical isomerism. Axial chirality is a special case of chirality in which a molecule possesses an axis as the chiral unit - the substituents is held in the way by the axis that is non- superposable with its mirror image. 2,2'bis(diphenylphosphino)-1,1'-binaphthyl (BINAP) is a widely used example of a molecule with a chiral axis (Figure 1.3). Planar chirality is another type of stereoisomerism. It results from different arrangements of out-of-plane groups with respect to a plane. Ligands with central and axial chirality have been explored extensively. In contrast, planar chiral ligands have received much less attention (Figure 1.3). ${ }^{5}$ More recently, due to their unique structures and potential to solve difficult problems in enantioselective catalysis, planar chiral ligands have started to draw interest from the researchers. Most of the planar chiral ligands are based on ferrocene derivatives. 


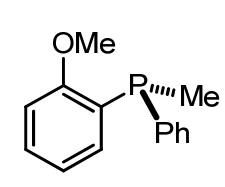

"PAMP"

central

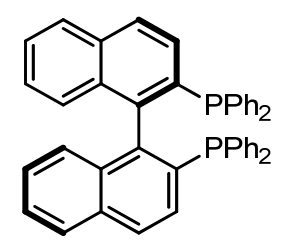

"BINAP"

axial

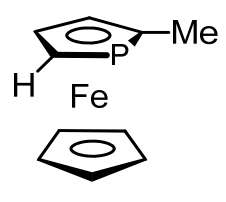

planar

Figure 1.3: Example ligands with different types of chirality

\subsection{Chiral ferrocenyl ligands}

\subsubsection{Known ligands and their characteristics}

Since their discovery in $1951,{ }^{6}$ ferrocene derivatives have been showing more and more utility in organometallic chemistry, materials science, and catalysis. Chiral ferrocenyl structures are the most widely used type of planar chiral ligands in asymmetric catalysis. Many chiral ferrocenyl ligands are known today. Compared to other types of chiral ligands, chiral ferrocenyl ligands mainly have the following characteristics: ${ }^{7-8}$

(1) Rigid conformation: To provide appropriate chiral environment for stereo control, the ligand should not be too flexible. The ferrocene unit is rigid, therefore, it is a good candidate for ligand framework.

(2) Planar Chirality: Planar chiral ligands can provide chiral environments that cannot be achieved by central and axial chiral ligands. Moreover, planar chirality can be combined with central and axial chiralities to solve more challenging problems in asymmetric synthesis. 
(3) Electronic effects: The electron rich $\mathrm{Cp}$ ring gives the ferrocenyl ligand e-donor ability. This is particularly important in some cases. For example, by coordinating the ferrocenyl ligand to a metal center, the reactivity can be tuned by adjusting the electron donating ability of the ferrocene backbone.

(4) Versatility and easy modulation: Through structural modulation, a large number of ferrocenyl ligands with different electronic and steric properties can be easily produced.

(5) Stability: Ferrocenyl ligands are usually thermally and configurationally stable in the solid form and in solution. They are not sensitive to moisture.

Due to the above characteristics, ferrocene-based ligands have been successfully applied in many metal-catalyzed reactions. The most widely used ferrocenyl ligands are multi-dentate chiral ferrocenyl phosphine ligands. Due to their easy accessibility and high asymmetric efficiency (as shown in Figure 1.4), 1,2-disubstituted ferrocene derivatives are especially useful. These multidentate ligands usually coordinate to the metal center using atoms such as phosphorus and nitrogen ( $\mathrm{P}, \mathrm{P}$ and $\mathrm{P}, \mathrm{N}$ ligands). In some cases of oxygen and sulfur ( $\mathrm{P}, \mathrm{O}$ and $\mathrm{P}, \mathrm{S}$ ligands) can also be used. 


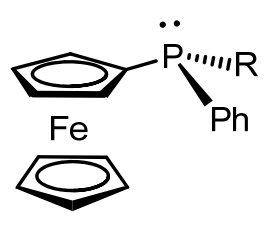

1-Substituted ferrocene

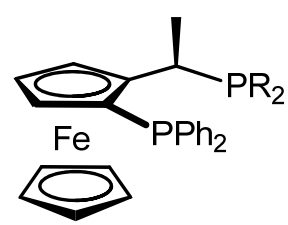

Josiphos
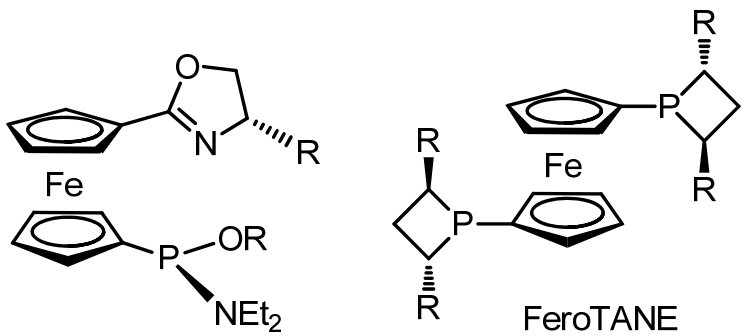

$1,1^{\prime}$-Disubstituted ferrocenes

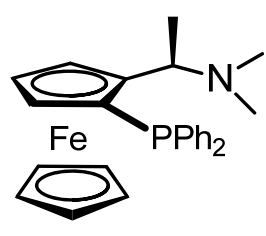

ppfa

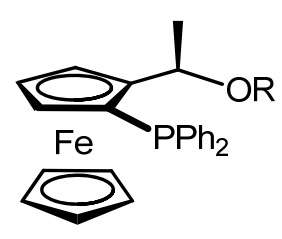

ppf-OR

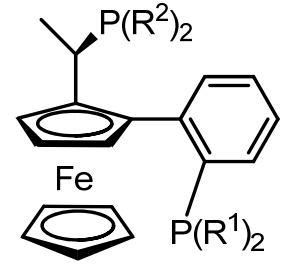

Walphos

1,2-Disubstituted ferrocenes

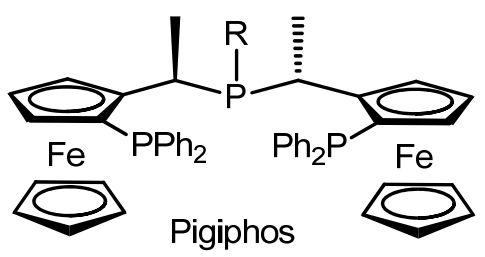

Bisferrocene
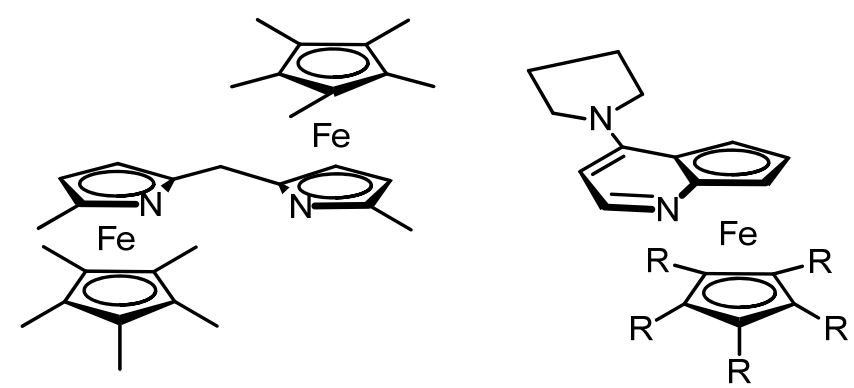

Heterocyclic ferrocene-type ligands

Figure 1.4: Examples of useful ferrocenyl ligands

\subsubsection{Synthetic routes to chiral ferrocenyl ligands}

1,1'-Disubstituted ferrocene ligands are less common than 1,2-disubstituted ones due to side reactions in their synthesis. These include 1,2-substitution and symmetrical substitution on both rings. ${ }^{9}$ The main synthetic methods are 
summarized in scheme 1.1. Cullen's method used the ring opening reaction of 1phenyl-1-phospha-[1]-ferrocenophane 1. The compound was treated with $\mathrm{PhLi}$, the anion intermediate was reacted with an electrophile. Many unsymmetrical 1,1'disubstituted ferrocene derivatives were synthesized using this method. ${ }^{10}$ The other methods include selective transmetallation of $\mathbf{2 a}^{11}$ and selective lithiation of 2b. ${ }^{12-15}$

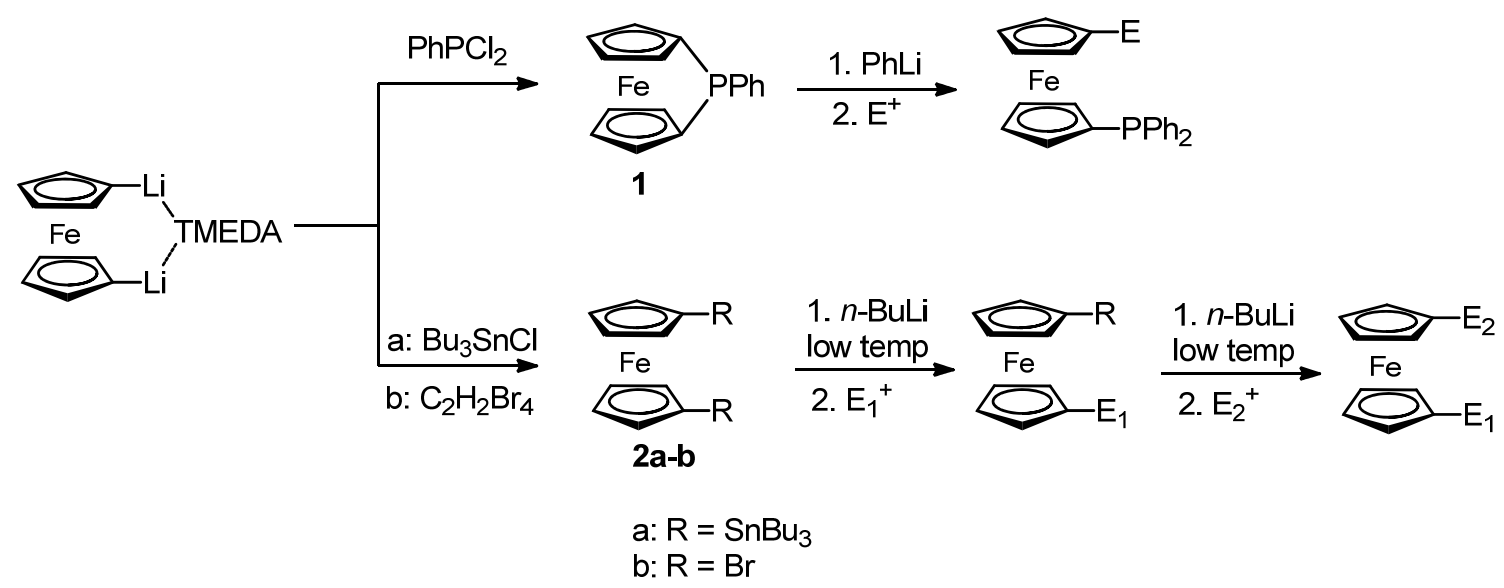

Scheme 1.1: Synthetic routes to 1,1'-disubstituted ferrocene ligands

For 1,2-disubstituted ferrocene ligands, Ugi was the first to report the diastereoselelective ortho-lithiation of $(R)$ - $N, N$-dimethyl-1-ferrocenylethylamine (Ugi's amine). ${ }^{16}$ By reacting the resulting intermediate with electrophiles, some very useful ligands such as the Josiphos and Walphos ligands were synthesized. For lithiation of Ugi's amine, Two equivalents of $n$-BuLi together with TMEDA can lithiate both $\mathrm{Cp}$ rings to give a dilithiated intermediate. The ligand ppfa ( $N, N$ dimethyl-1-[2-(diphenylphosphino)ferrocenyl]ethylamine) was the first chiral 
ferrocenyl phosphine ligand synthesized by Ugi's method. ${ }^{17}$ Up to now, the Ugi's amine method is still one of the most widely used strategies in synthesizing enantiopure 1,2-disubstituted ferrocenyl ligands (Scheme 1.2).

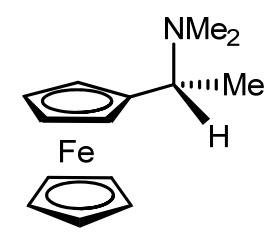

$(R)-3$

Ugi's amine

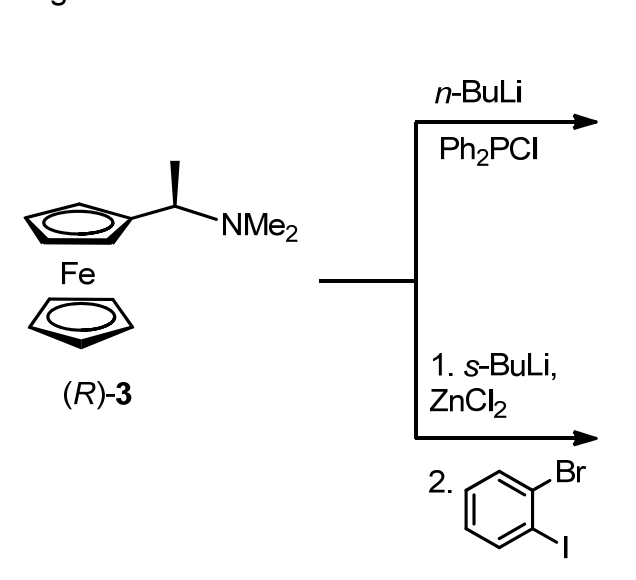

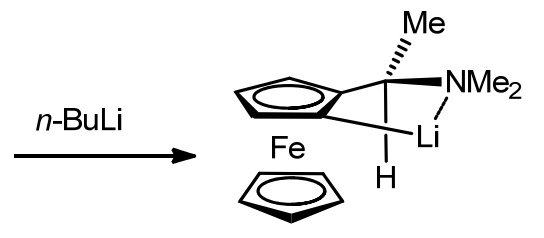

$(R)-(R) 96 \%$

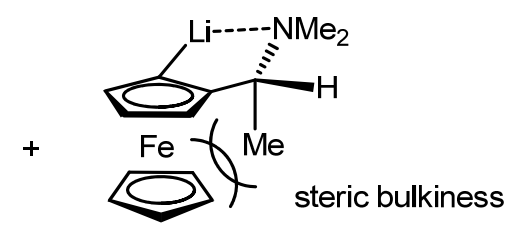

$(R)-(S) 4 \%$
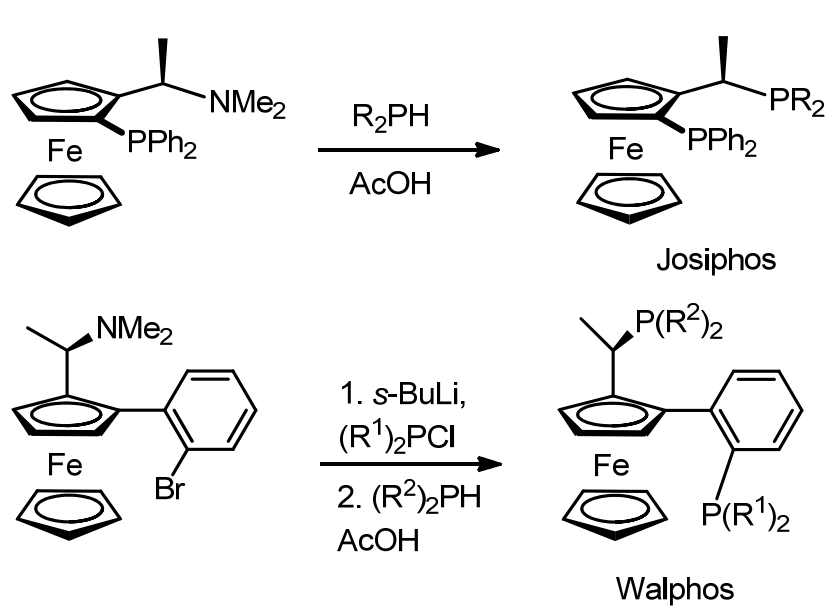

Scheme 1.2: Examples of 1,2-disubstituted ferrocenyl ligands using Ugi's amine

In addition to multi-substituted ferrocenyl ligands, some interesting heterocyclic ligands were also synthesized (Figure 1.4). These ligands are useful in some reactions. For example, Fu developed an efficient method to prepare a series of heterocyclic ferrocene type ligands. His group treated $\mathrm{FeCl}_{2}$ with $\mathrm{Cp}{ }^{*} \mathrm{Li}$, and the intermediate was reacted with the lithium salt of the second planar ring (Scheme 1.3). ${ }^{18-19}$ This method broadened the structural scope of ferrocenyl ligands and made possible tuning enantioselectivity by inserting functional groups 
on the cyclopentadienyl $(\mathrm{Cp})$ ring with different bulkiness such as methyl and phenyl groups. This type of ligand was found to be highly enantioselective towards a variety of processes, such as isomerization of allylic alcohols, $\mathrm{O}-\mathrm{H}$ insertions, and cyclopropanation. ${ }^{18,20-27}$ However, the method has a drawback. There is no selectivity in the ferrocene-building step, and racemic structures are obtained. Most of the ligands made using this method need HPLC resolution on a chiral column, which increases the cost and limits their applications on a large scale.

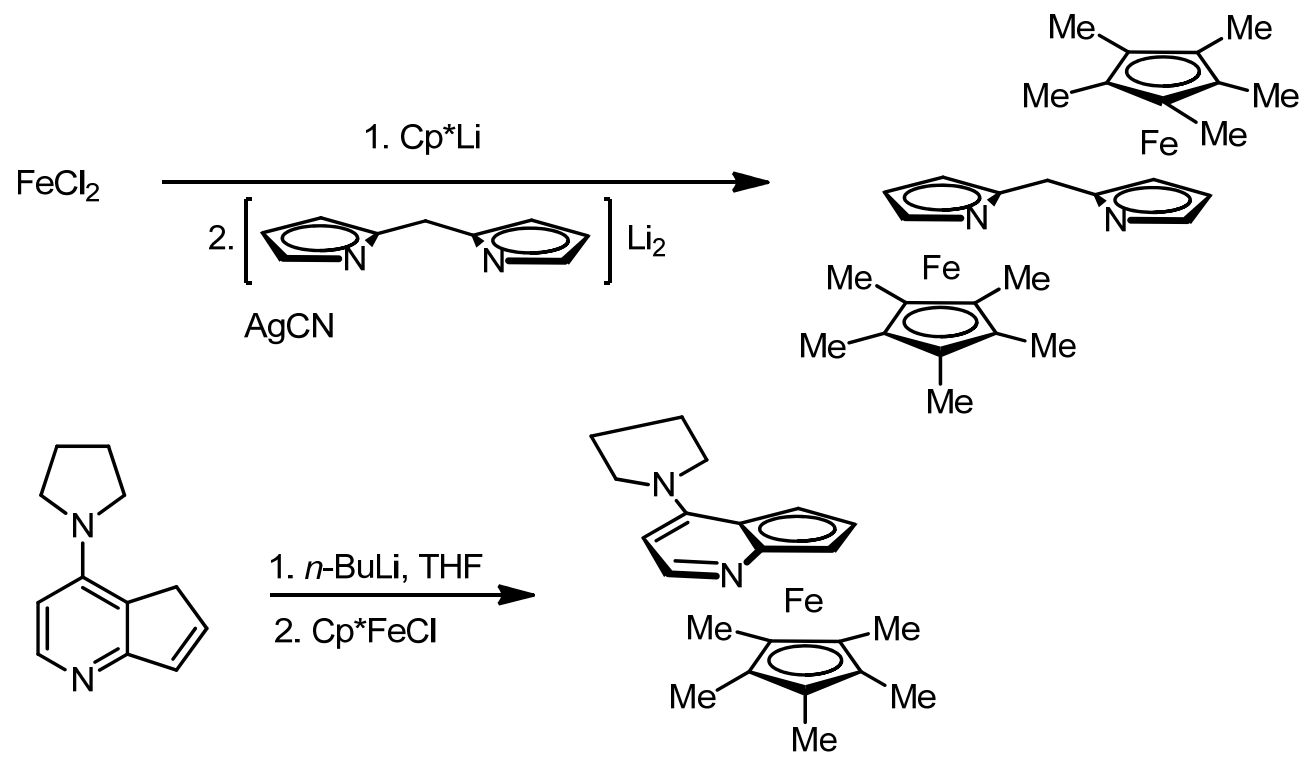

Scheme 1.3: Examples of the synthesis of heterocyclic ferrocene-type ligands 


\subsubsection{Applications of chiral ferrocenyl ligands in catalysis}

Due to their excellent chemical and stereochemical features, planar chiral ferrocenyl ligands have found wide applications in enantioselective catalysis. Scheme 1.4 listed some examples of the applications, which include asymmetric hydrogenation, ${ }^{28}$ asymmetric allylic alkylation, ${ }^{29}$ and asymmetric cyclopropanation. ${ }^{18}$

Asymmetric hydrogenation:
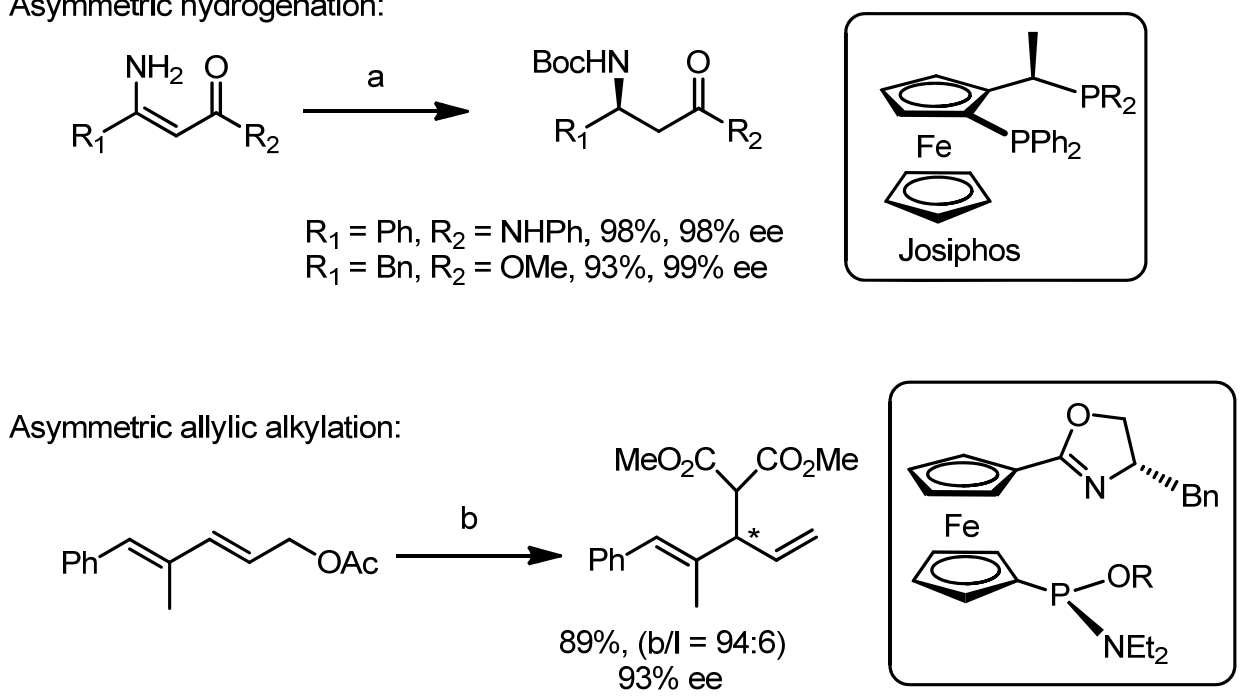

Asymmetric cyclopropanation:
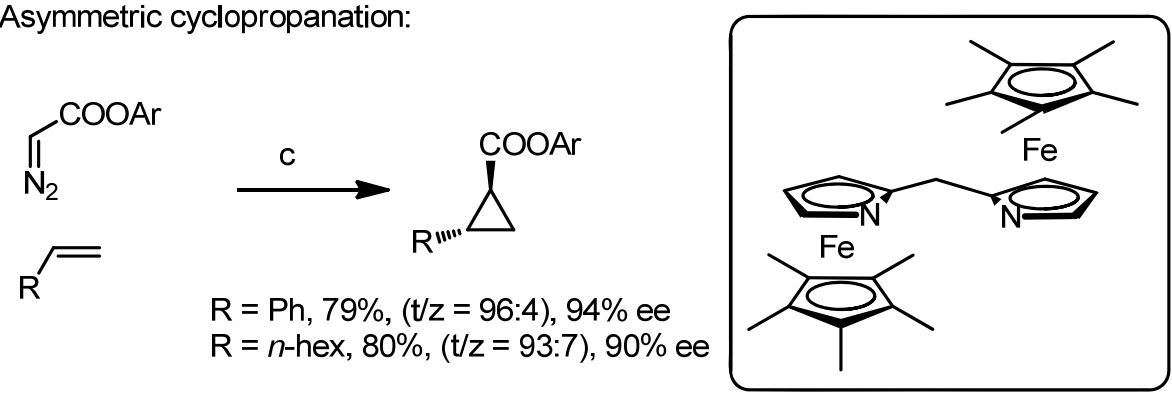

Conditions: a). $\left[\mathrm{Rh}(\mathrm{cod})_{2} \mathrm{Cl}_{2}(0.2 \mathrm{~mol} \%) \text {, ligand (0.41 mol\%), (Boc) }\right)_{2} \mathrm{O}$ (1.1 eq), $\mathrm{H}_{2}(90-100$ psi), $\mathrm{MeOH}$. b). $\mathrm{NuH}$ (3.0 eq), [ $\left[\mathrm{Pd}\left(\eta^{3}-\mathrm{C}_{3} \mathrm{H}_{5}\right) \mathrm{Cl}_{2}\right]$ (2 mol\%), ligand (4 mol\%), BSA(3.0 eq), $\mathrm{KOAc}(6 \mathrm{~mol} \%), \mathrm{CH}_{2} \mathrm{Cl}_{2}$, rt. c). CuOTf (1.0 mol\%), ligand (1.2 mol\%), $\mathrm{CH}_{2} \mathrm{Cl}_{2}$, rt.

Scheme 1.4: Applications of selected chiral ferrocenyl ligands 


\subsection{Salen and salen-type ligands}

Salen ligands are a class of ligands that have $\mathrm{N}_{2} \mathrm{O}_{2}$ as electron donors. They can form tetradentate metal-salen complexes. The name salen was the abbreviation of salicylaldehyde and ethylenediamine, which are substrates used for the synthesis of the simplest salen ligand. Although the metal-salen motif has been studied for over 60 years, the catalytic applications of chiral salen derivatives began in the 1990s. After being extensively explored in the last two decades, the salen framework has now been established as one of the most "privileged" chiral catalysts: catalysts which are enantioselective over a wide range of different reactions. ${ }^{30}$ Figure 1.5 listed some examples of "privileged" catalytic groups.

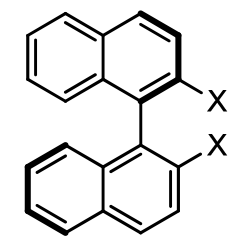

$X=\mathrm{OH} \quad$ BINOL $\mathrm{X}=\mathrm{PPh}_{2}$ BINAP

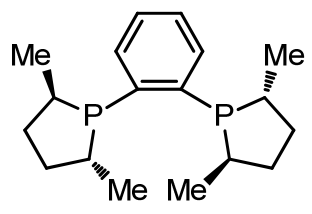

MeDuPhos<smiles>CC1(C)OC(C(O)(c2ccccc2)c2ccccc2)C(C(c2ccccc2)(c2ccccc2)C(O)(c2ccccc2)c2ccccc2)O1</smiles>

TAADDOLate

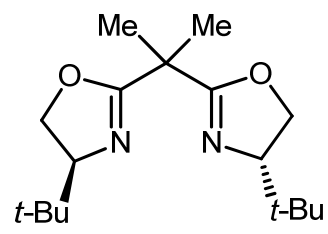

Bis(oxazoline)

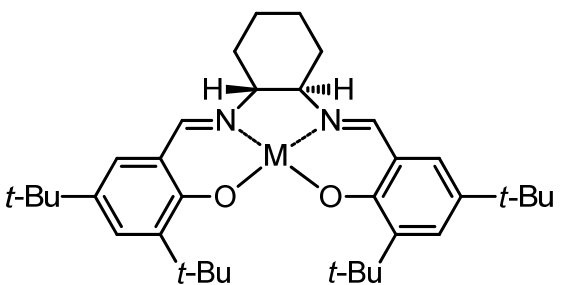

Salen complexes<smiles>C=CC1CC2CCN1CC2[C@H](O)c1ccnc2ccc(OC)cc12</smiles>

Cinchona alkaloid derivatives

Figure 1.5: Examples of "privileged" chiral ligands and catalysts 
The major reason that salen ligands have gained such success in asymmetric catalysis is due to the following features:

(1) Salen ligands are easy to synthesize. Preparation of salen ligand is straightforward. They were usually obtained by the condensation of two equivalents of a salicylaldehyde with one equivalent of a diamine. Quantitative yield can usually be obtained (Scheme 1.5).
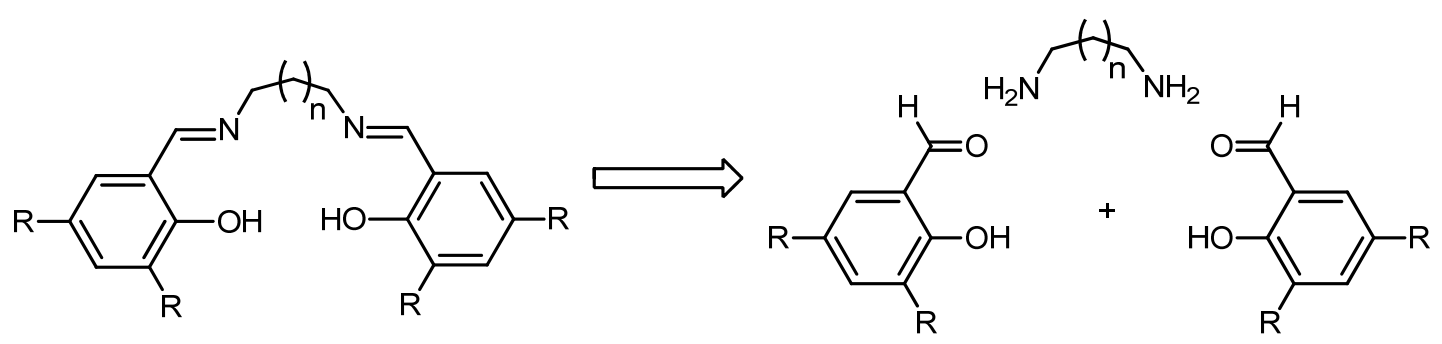

Scheme 1.5: Salen ligand and its synthesis

(2) The C-2 symmetry of salen ligands: The concept of C-2 symmetry in chiral ligand was first introduced by Kagan in $1971 .{ }^{31}$ The advantage of a C-2 ligand is that it reduces the number of possible catalyst-substrate arrangements in the transition state by factor of two. Among the "privileged" ligands, ${ }^{30}$ many of them including salen complexes possess $\mathrm{C}-2$ symmetry (Figure 1.5). ${ }^{32}$

(3) The ability of salen ligands to chelate with a wide range of metal ions: For most of the transition metals, the corresponding metal-salen complexes have 
been reported. Scheme 1.6 lists five different synthetic routes for the preparation of metal-salen complexes. ${ }^{33}$
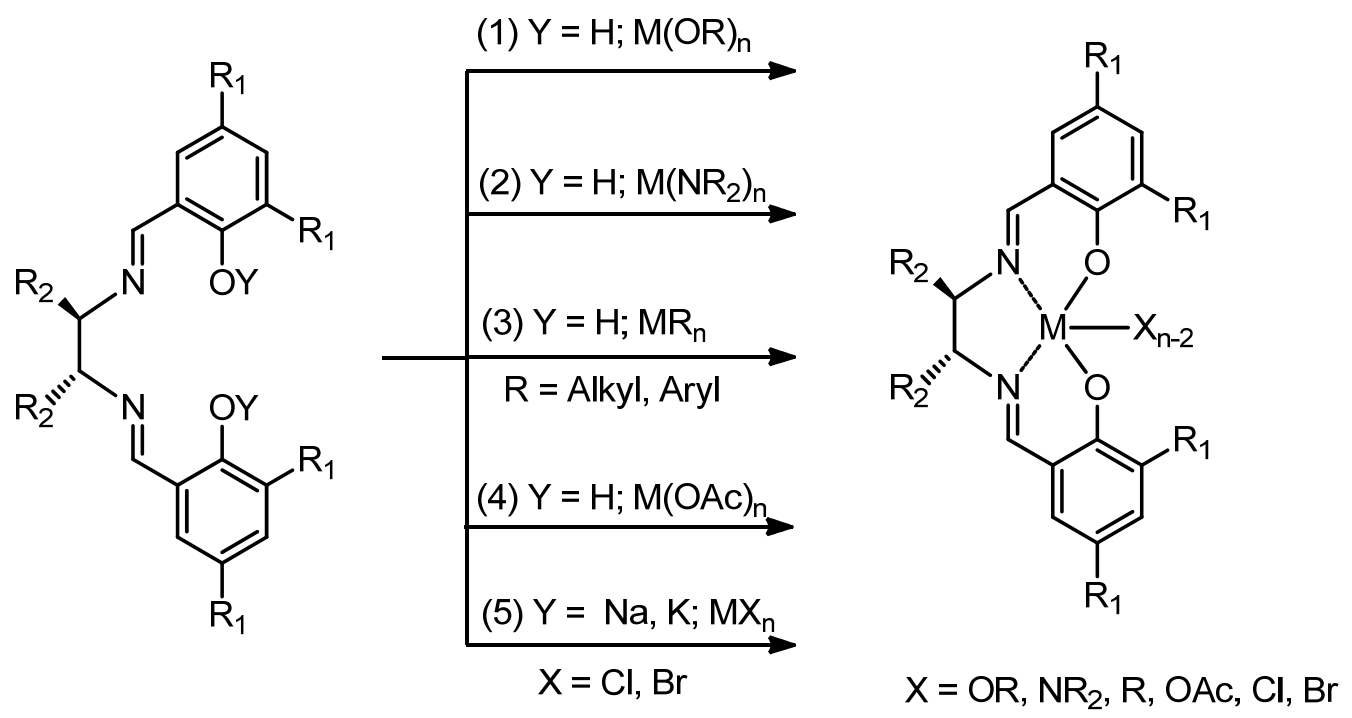

Scheme 1.6: Preparation of metal-salen complexes

(4) Structural diversity of salen ligands: Once the appropriate metal is identified for a required activity, the structure of the salen ligands can be easily modified by modifications of the electron donors, using different chiral diamines as the backbone, and modulations on the aldehyde component in some cases, which allows systematic tuning of stereo and electronic effects to obtain increased stereoselectivity.

Salen ligands were first reported in early 1990s for Sharpless enantioselective epoxidation of simple alkenes lacking allylic hydroxyl groups. ${ }^{34-}$ ${ }^{42}$ Later, they found numerous applications in other reactions. Scheme 1.7 lists some well-developed reactions that use salen ligands. They include asymmetric 
epoxidation, ${ }^{43}$ asymmetric Strecker reaction $^{44}$ and asymmetric Diels-Alder reaction. ${ }^{45}$

Asymmetric epoxidation:<smiles>CCOC(=O)/C=C\c1ccccc1</smiles><smiles></smiles>
3.5:1 cis/trans<smiles>N[C@H](c1ccccc1)[C@@H](O)C(=O)O</smiles>

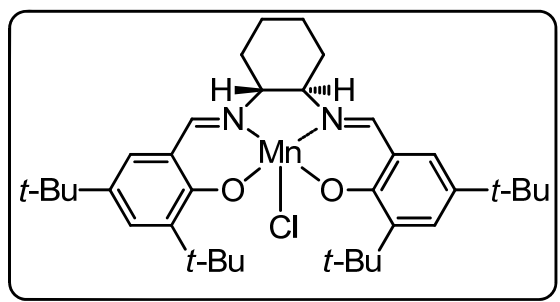

Taxol side chain

Cyanide addition to imine (Strecker reaction):<smiles>C=CCN=Cc1ccccc1</smiles>

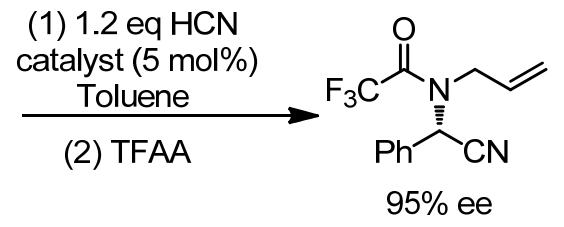

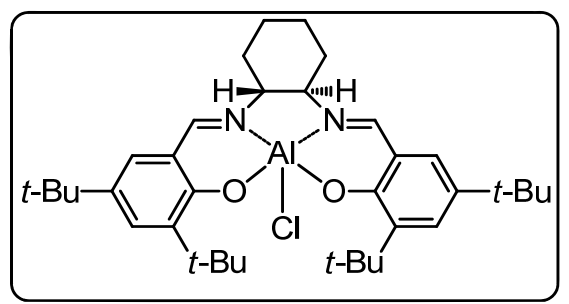

Asymmetric Diels-Alder reaction:<smiles>C=C/C=C/C(Cc1ccccc1)C(OC)OC</smiles>

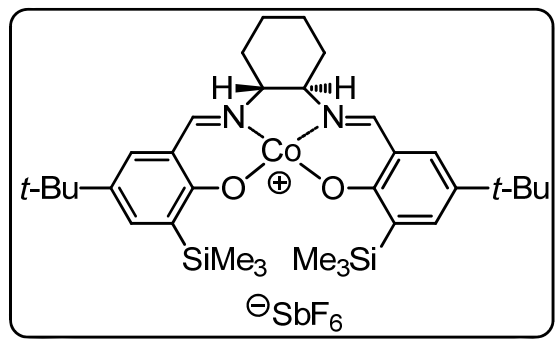

Scheme 1.7: Selected reactions that use salen ligands 


\subsection{Objectives}

By combining the ideas of ferrocenyl structure and chiral salen ligands described above, we designed a new type of chiral ferrosalen ligand. It is based on the salen framework. An enantiopure form of ferrocenyl structure was used to build the ligands. It is worthy to mention that the stereochemistry effect can be enhanced by using a chiral backbone on the salen structure. Because it is convenient to change the backbone, enantioselectivity can be easily optimized.

As shown in Figure 1.6, using the ferrocenyl prototype $(R)-4$ or $(S)-4$, different C-2 symmetric ferrosalen ligands can be easily prepared by their reaction with different achiral and chiral diamines. The synthesis of $(R)-\mathbf{4}$ and $(S)-\mathbf{4}$ were achieved by a synthetic route using ferrocene as the starting material, and the stereoselective synthesis was completed by a known chiral auxiliary approach, followed by a three-step aromatization. This synthetic route will be described in Chapter 2 of this dissertation. These results were published in the following article:

Zhang, Xiang; Luck, Rudy; Fang, Shiyue. Stereoselective Synthesis of a Chiral Ferrosalen Ligand Using a Novel Aromatization Strategy. Journal of Organometallic Chemistry, 2010, in press. (doi:10.1016/j.jorganchem.2010.10.064) 


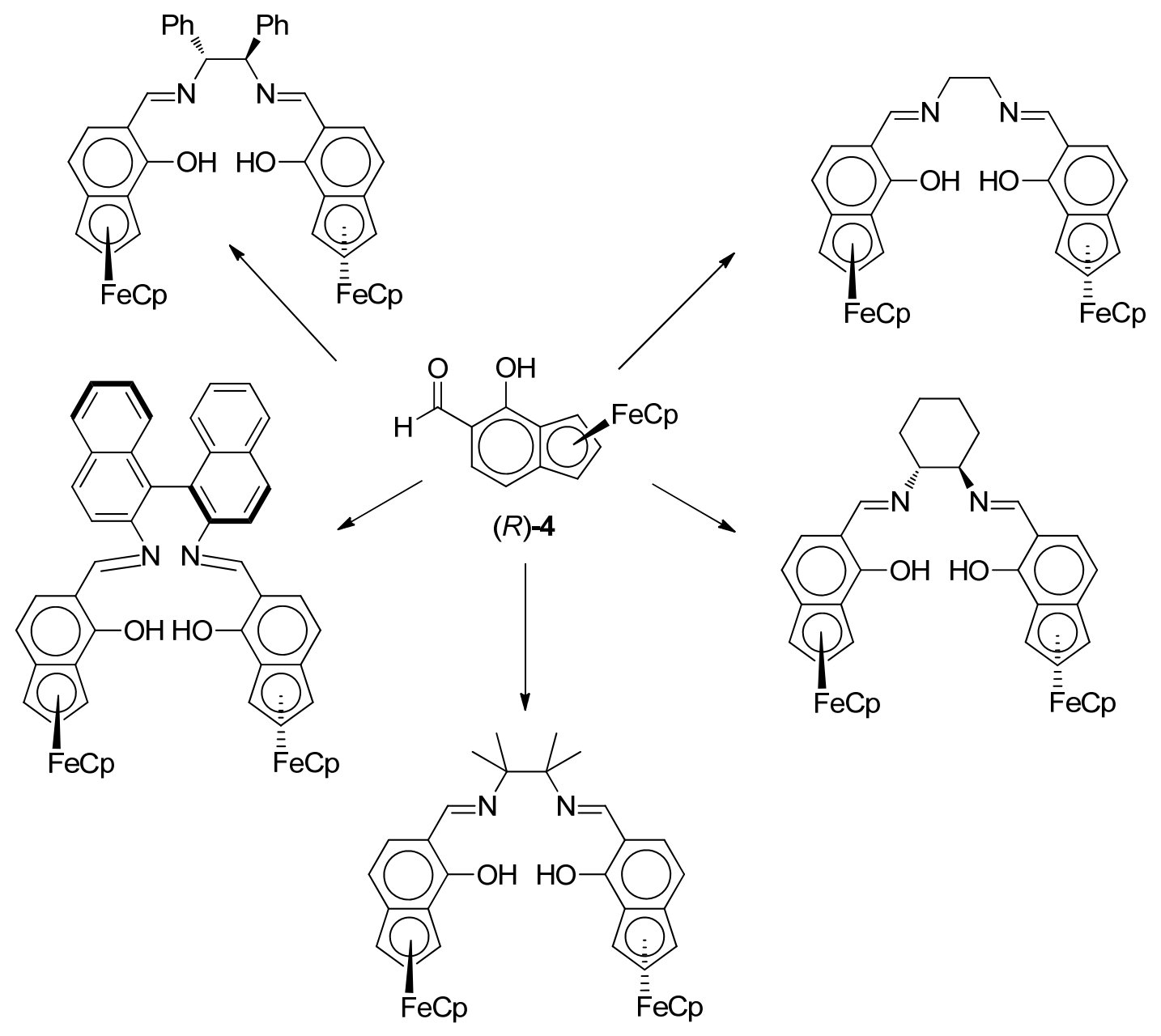

Figure 1.6: Examples of ferrosalen ligands which can be obtained from $(R)-4$

Using the strategy described in Chapter 2, eight ligands based on the ferrocene motif with different backbones were synthesized and fully characterized. Besides ferrocene-based chiral salen ligands, more sterically hindered chiral salen ligands with methyl- and phenyl-substituted $\mathrm{Cp}$ rings were also designed. The corresponding structure motifs $(R)-\mathbf{5}$ and $(S)$-6 for ligand synthesis are shown in Figure 1.7. These ligands were synthesized with pentamethyl and pentaphenyl substituted ferrocene as the starting materials, followed by the similar synthetic 
route as described in Chapter 2. The increased steric hindrance of these ligands is expected to increase enantioselectivity of asymmetric reactions. This research will be described in Chapter 3 of this dissertation, and results were submitted as the following article:

Zhang, Xiang; Luck, Rudy; Fang, Shiyue. Ferrosalen and Ferrosalen-type Ligands: Structural Modulation and Applications in Asymmetric Catalysis. Organometallics, 2011, accepted for publication.

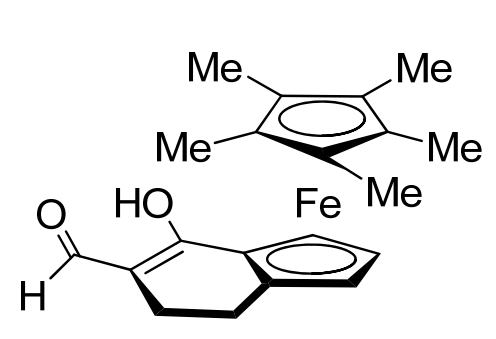

$(R)-5$

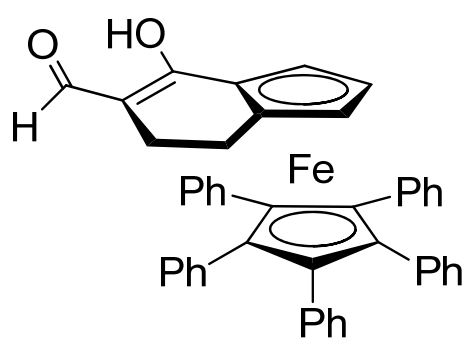

$(S)-6$

Figure 1.7: Building blocks for the synthesis of methyl- and phenyl- substituted ferrocenyl salen ligands

In Chapter 4 of this dissertation, we will examine the catalytic activities of the chiral ferrosalen ligands in three reactions: enantioselective carbonyl-ene reaction, enantioselective Strecker-type reaction and enantioselective silylcyanation. 


\title{
Chapter 2
}

\section{Stereoselective Synthesis of a Chiral Ferrosalen Ligand Using an Aromatization Strategy}

\author{
Xiang Zhang, Rudy L. Luck, Shiyue Fang \\ Journal of Organometallic Chemistry, 2010, in press.
}

(doi:10.1016/j.jorganchem.2010.10.064)

Reproduced with permission from Elsevier Science. Copyright (C) 2010 Elsevier B. V., see Appendix D.1. 


\title{
Stereoselective Synthesis of a Chiral Ferrosalen Ligand Using an Aromatization Strategy
}

\author{
Xiang Zhang, Rudy L. Luck, Shiyue Fang* \\ Department of Chemistry, Michigan Technological University, 1400 Townsend \\ Drive, Houghton, Michigan 49931 USA
}

Tel: +001 (906) 487-2023; Fax: +001 (906) 487-2061; E-mail: shifang@,mtu.edu

\section{Abstract}

A new chiral salen ligand based on two ferrocenyl groups is designed. Unlike known salen ligands, of which chirality originates from central and axial chiral centers, the chirality of this ligand comes from the planar chiral ferrocenyl groups. The ligand is synthesized stereoselectively using a novel aromatization strategy starting from a ferrocene derivative, which was readily prepared using a known chiral auxiliary approach.

Keywords: Ferrosalen, Planar chiral, Salen, Ferrocene, Ligand 


\section{Introduction}

Most chiral ligands have narrow reaction scopes and can only be used to control the stereoselectivity of a specific reaction. Salen (Figure 2.1) and salentype ligands are among a few exceptions including BINAP and bisoxazolines that have wide applications. ${ }^{46}$ For example, salen ligands have been used for enantioselective alkene epoxidation, aziridination and cyclopropanation; DielsAlder reactions; and kinetic resolution of racemic epoxides. ${ }^{46}$ In addition to applications in enantioselective catalysis, salen and salen-type ligands are also useful building blocks in supramolecular chemistry. For example, Zn(II)-salen complexes can self-assemble into useful supramolecular architectures. ${ }^{47} \mathrm{Mn}$ (II)salen complexes are being used for the construction of superparamagnetic single molecule magnets. ${ }^{48-51}$ Due to the wide applications of salen and salen-type compounds, a large number of salen analogs have been synthesized. ${ }^{46,52-56}$ Chirality of most salen ligands is attained by rendering chiral the two central carbon centers at the 8 and $8^{\prime}$ positions. To solve additional problems, central and axial chiral centers were introduced at the 3 and $3^{\prime}$ positions. These new generation salen ligands have been found to give higher ees in some reactions. ${ }^{39,41,57-58}$ In addition, chiral salen ligands based on ferrocene have also been reported recently. ${ }^{59-62}$ 


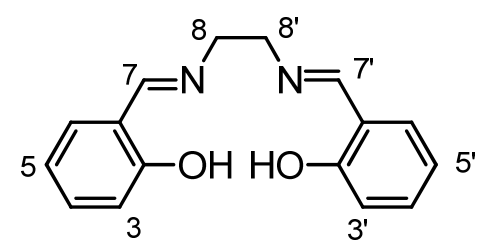

Figure 2.1: The salen ligand

In 2007, our research group initiated a project, which was aimed at developing a new class of chiral ferrocenyl ligands based on the structural motifs 1 and 2 (Figure 2.2). ${ }^{63-66}$ In order to assess the stability of ligands containing 2 , we synthesized several model racemic compounds and resolved some of them using chiral HPLC. These compounds were used successfully as ligands in several reactions, which suggests that they are chemically and configurationally stable. ${ }^{63-}$ ${ }^{66}$ In this article, we report the construction of a salen ligand (+)-3 (Figure 2.2) using 2 as the building block.

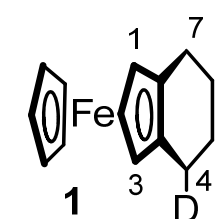

D: Electron donating heteroatoms such as $\mathrm{P}, \mathrm{N}, \mathrm{S}$ and $\mathrm{O}$

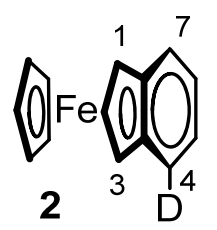

Figure 2.2: Structural motifs of a new class of chiral ligands $(\mathbf{1}, \mathbf{2})$ and a ferrosalen ligand $[(+)-3]$ 


\section{Results and discussion}

Having demonstrated the stability of ligands containing motif 2, a stereoselective method for the synthesis of building blocks of such ligands, which does not rely on chiral HPLC resolution, is highly desirable. In 2001, Kuehne's group developed a method for the preparation of enantiopure ferrocenyl ketone 4 (Scheme 2.1). ${ }^{67}$ They reacted $( \pm)-4$ with the anion of $(+)-5$ to give diastereoisomers $\mathbf{6 a}$ and $\mathbf{6 b}$. These isomers were readily separated with flash column chromatography. Heating $\mathbf{6 a}$ and $\mathbf{6 b}$ in toluene gave enantiopure (+)-4 and (-)-4 in quantitative yield. Because $( \pm)-4$ and $(+)-5$ can be readily prepared on gram scales, and (+)-4 is easy to functionalize, we decided to access enantiopure ligands containing 2 through aromatization of $(+)-\mathbf{4}$ and its derivatives.

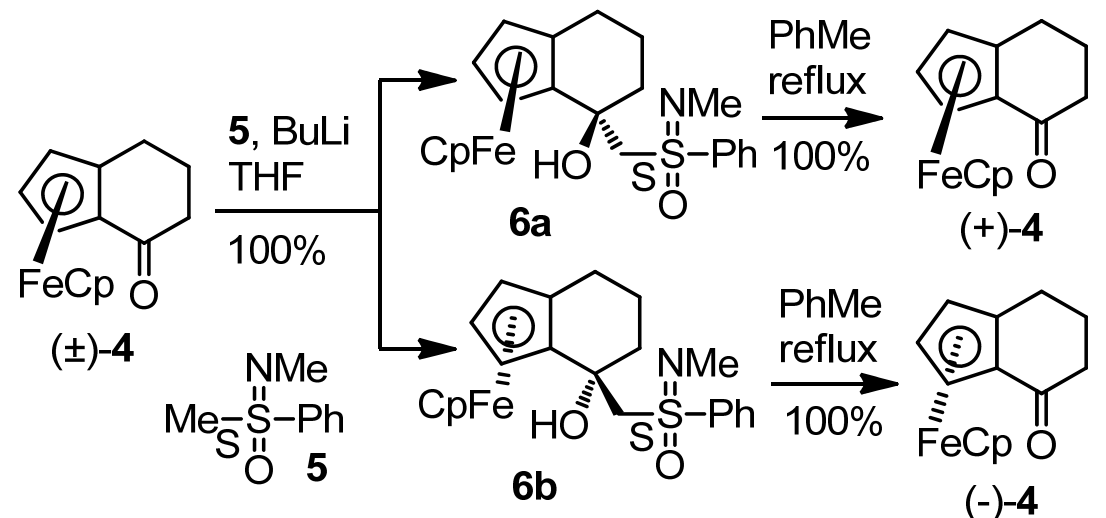

Scheme 2.1: Kuehne's method for the resolution of ferrocenyl ketone $( \pm)-4$

In order to prepare ferrosalen ligand (+)-3, the building block (+)-9 is required (Scheme 2.2). Enantiopure (+)-4 was easily formylated to give (+)-7. 
Installation of a double bond at the position $\alpha, \beta$ to the carbonyls of $(+)-7$ would give (+)-8, which would tautomerize to $(+)-9$ under slightly basic or acidic conditions. However, we found that this double bond installation was difficult to achieve. A simple method would be heating (+)-7 with benzeneseleninic acid anhydride in toluene. ${ }^{68}$ Under these conditions, we were able to synthesize a compound resulting from nucleophilic substitution of the anhydride with the enol of $(+)-7$. Unfortunately, heating the adduct gave an intractable mixture instead of $(+)-8$ or $(+)-9$. Attempted induction of $\beta$-elimination by $O$-alkylation of the selenoxide with allyl bromide followed by base treatment also failed. In this case, we could isolate the alkylation product, but when this was treated with bases such as $\mathrm{NaH}$ or $t-\mathrm{BuLi},(+)-7$ was obtained. Other experimental conditions involving selenium chemistry ${ }^{69-70}$ and the $\beta$-hydride-elimination process of palladium chemistry $^{71}$ also failed. Further, the use of stoichiometric amounts of $\mathrm{Pd}(\mathrm{OAc})_{2}$ did not produce $(+)-\mathbf{8}$ either. Because all the methods using selenium and palladium chemistry involve an intramolecular concerted or close to concerted elimination step, it is possible that the steric hindrance and conformational rigidity of the intermediates for the elimination prevented the formation of the cyclic transition state required for the reaction. Based on this hypothesis, we next employed a twostep elimination process. To this end, $(+)-7$ was converted to the methyl enol ether $(+)-\mathbf{1 0}$ in $89 \%$ yield by stirring with dimethyl sulfate and cesium carbonate in warm DMF (Scheme 2.3). 


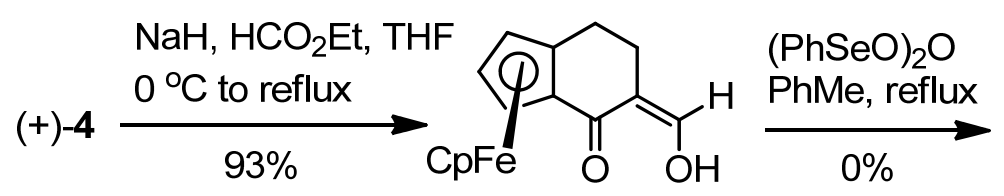

(+)-7

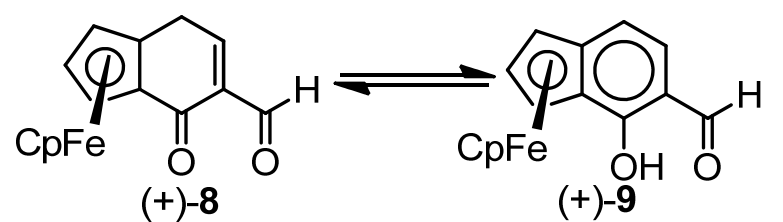

Scheme 2.2: Early attempts to synthesize $(+)-9$ from enantiopure $(+)-4$

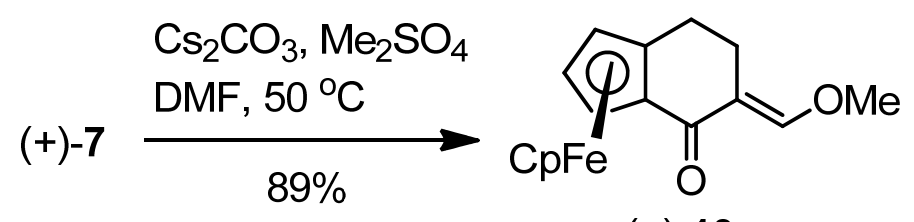

$(+)-10$

Scheme 2.3: $O$-Methylation of $(+)-7$

Next, compound $\mathbf{1 0}$ was subjected to halogenation in methanol using different $N$-halosuccinimides. In entries 1,2 and 5, $( \pm)$-10 was used as the substrate to test the reaction which was obtained from $( \pm)-4$ following the procedure similar to that of $(+)-\mathbf{1 0}$. With NIS as the reagent, at $0{ }^{\circ} \mathrm{C}$ the halo dimethyl acetal product $( \pm)$-11a was obtained in 52\% yield (entry 1, Table 2.1 ). Performing the reaction at room temperature increased the yield to $68 \%$ (entry 2 ). When the halogenation agent was changed to NBS, at both $0{ }^{\circ} \mathrm{C}$ and room temperature, product $(+)-\mathbf{1 1 b}$ was isolated in 71\% yield (entries 3 and 4). 
Halogenation with NCS resulted in a 57\% yield of $(+)-11 \mathrm{c}$ under similar conditions (entry 5).

Table 2.1

Halogenation of methyl enol ether $\mathbf{1 0}$

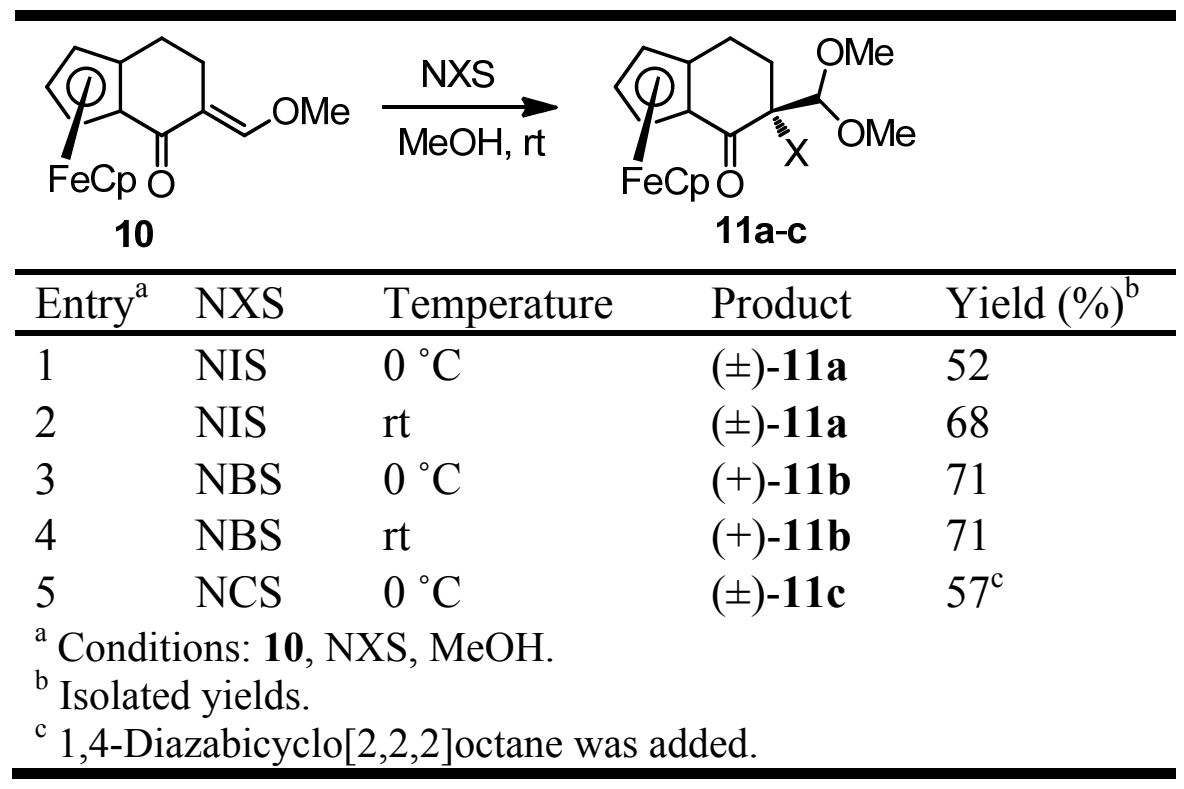

These $\alpha$-halo ketone compounds were then subjected to various base initiated $\beta$-elimination conditions. When $(+)-\mathbf{1 1 b}$ was treated with potassium carbonate in DMF at $80{ }^{\circ} \mathrm{C}$, the enol ether $(+)-\mathbf{1 0}$ was isolated (entry 1, Table 2.2). Under similar conditions at room temperature, the stronger base cesium carbonate resulted in small amounts of $(+)-\mathbf{1 2}$ (entry 2 ); at $80{ }^{\circ} \mathrm{C}$, the product was $(+)-\mathbf{1 0}$ (entry 3). We then employed the strong and less hindered base sodium methoxide for the reaction. In DMF at room temperature, $(+)-\mathbf{1 1 b}$ was consumed in 1 hour as evident in a TLC test, and the desired product $(+)-9$ was isolated in $68 \%$ yield along with small quantities of (+)-12 (entry 4). To see if a stronger and less 
hindered base could give a higher yield, $(+)-\mathbf{1 1 b}$ was stirred with sodium hydride in DMF at room temperature; however, the yield of $(+)-9$ was lowered to $54 \%$, and $(+)-\mathbf{1 0}$ and $(+)-\mathbf{1 2}$ were also produced (entry 5). Treating $( \pm)-\mathbf{1 1 c}$ with either sodium methoxide or sodium hydride at room temperature did not yield $( \pm)$-9 (entries 6 and 8). Upon heating to $70{ }^{\circ} \mathrm{C},( \pm)-12$ was isolated in $40 \%$ yield in the case of sodium methoxide (entry 7); in the case of sodium hydride, $( \pm)-9$ was formed in $35 \%$ yield along with $20 \%$ of $( \pm)-\mathbf{1 2}$ (entry 9). Based on these results (entry 6-9), ( \pm )-11c is not a useful substrate to prepare ( \pm )-9. Treating the iodo substrate $( \pm)$-11a with sodium hydride at room temperature did afford $( \pm)-\mathbf{9}$ in $38 \%$ yield but most of the substrates were converted to $( \pm)-\mathbf{1 0}$ (entry 10$)$.

The structure of (+)-9 was readily established with NMR and high resolution MS. The structure of (+)-12 was first established by X-ray crystallography (Figure 2.3), and then confirmed with NMR and MS. Suitable crystals of the racemic $( \pm)$-12 which was obtained from $( \pm)-\mathbf{4}$ following the same procedure were grown because the pure enantiomer did not crystallize. Even though compounds (+)-9 and (+)-12 are tautomers, we could not accomplish their interconversion under either basic or acid conditions. For example, when treated with $\mathrm{NaH}$ in THF at reflux temperature, $(+)-\mathbf{1 2}$ was unreactive. Other basic conditions such as $\mathrm{Et}_{3} \mathrm{~N} / \mathrm{THF} / 50{ }^{\circ} \mathrm{C}, 10 \% \mathrm{~K}_{2} \mathrm{CO}_{3} / \mathrm{THF} / 50{ }^{\circ} \mathrm{C}$, and $\mathrm{NaOMe} / \mathrm{DMF} / \mathrm{rt}$ gave similar results. With $10 \% \mathrm{KOH} / \mathrm{THF} / 50{ }^{\circ} \mathrm{C},(+)-12$ partially decomposed after 12 hours, and (+)-9 was not formed. Stirring solutions of (+)-12 in THF with 
acetic acid at room temperature returned the starting material; when heated to 50 ${ }^{\circ} \mathrm{C}$, the compound started to decompose after $5 \mathrm{~min}$. Without any added base or acid, heating (+)-12 in toluene in a sealed tube to $195{ }^{\circ} \mathrm{C}$ to induce a thermo 1,5 hydrogen shift gave an intractable mixture after 12 hours. At lower temperatures $\left(170{ }^{\circ} \mathrm{C}\right),(+)-12$ was stable. Under similar conditions described above, attempts to convert (+)-9 to (+)-12 also failed.

\section{Table 2.2}

Synthesis of $\mathbf{9}$ via $\beta$-elimination of $\mathbf{1 1}$

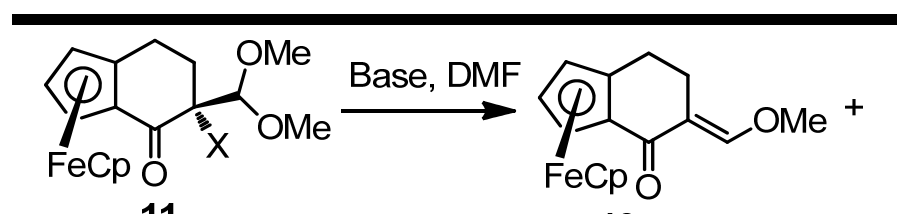

11<smiles>O=C([OH2+])C12C=CC=C1C=CC(=CO)C2=O</smiles>

12<smiles>O=Cc1ccc2ccc(F)c(O)c2c1O</smiles>

9

\begin{tabular}{|c|c|c|c|c|c|c|c|}
\hline \multirow{2}{*}{ Entry $^{\mathrm{a}}$} & \multirow{2}{*}{ Substrate } & \multirow{2}{*}{ Base } & \multirow{2}{*}{$\mathrm{T}$} & \multirow{2}{*}{ Time } & \multicolumn{3}{|c|}{ Yield $^{\mathrm{b}}$} \\
\hline & & & & & $(+)-10$ & $(+)-12$ & $(+)-9$ \\
\hline 1 & $(+)-\mathbf{1 1 b}(\mathrm{Br})$ & $\mathrm{K}_{2} \mathrm{CO}_{3}$ & $80{ }^{\circ} \mathrm{C}$ & $12 \mathrm{~h}$ & $40 \%$ & $0 \%$ & $0 \%$ \\
\hline 2 & $(+)-\mathbf{1 1 b}(\mathrm{Br})$ & $\mathrm{Cs}_{2} \mathrm{CO}_{3}$ & $\mathrm{rt}$ & $4 \mathrm{~h}$ & $0 \%$ & $8 \%$ & $0 \%$ \\
\hline 3 & $(+)-\mathbf{1 1 b}(\mathrm{Br})$ & $\mathrm{Cs}_{2} \mathrm{CO}_{3}$ & $80{ }^{\circ} \mathrm{C}$ & $12 \mathrm{~h}$ & $46 \%$ & $0 \%$ & $0 \%$ \\
\hline 4 & $(+)-\mathbf{1 1 b}(\mathrm{Br})$ & $\mathrm{NaOMe}$ & $\mathrm{rt}$ & $1 \mathrm{~h}$ & $0 \%$ & $9 \%$ & $\underline{68 \%}$ \\
\hline 5 & $(+)-\mathbf{1 1 b}(\mathrm{Br})$ & $\mathrm{NaH}$ & $\mathrm{rt}$ & $12 \mathrm{~h}$ & $10 \%$ & $10 \%$ & $54 \%$ \\
\hline 6 & $( \pm)-11 \mathrm{c}(\mathrm{Cl})$ & $\mathrm{NaOMe}$ & $\mathrm{rt}$ & $12 \mathrm{~h}$ & $0 \%$ & $0 \%$ & $0 \%$ \\
\hline 7 & $( \pm)-11 \mathrm{c}(\mathrm{Cl})$ & $\mathrm{NaOMe}$ & $70{ }^{\circ} \mathrm{C}$ & $1 \mathrm{~h}$ & $0 \%$ & $40 \%$ & $0 \%$ \\
\hline 8 & $( \pm)-11 \mathrm{c}(\mathrm{Cl})$ & $\mathrm{NaH}$ & $\mathrm{rt}$ & $12 \mathrm{~h}$ & $0 \%$ & $0 \%$ & $0 \%$ \\
\hline 9 & $( \pm)-11 \mathrm{c}(\mathrm{Cl})$ & $\mathrm{NaH}$ & $70{ }^{\circ} \mathrm{C}$ & $12 \mathrm{~h}$ & $0 \%$ & $20 \%$ & $35 \%$ \\
\hline 10 & $( \pm)-11 \mathbf{a}(\mathrm{I})$ & $\mathrm{NaH}$ & $\mathrm{rt}$ & $12 \mathrm{~h}$ & $54 \%$ & $0 \%$ & $38 \%$ \\
\hline
\end{tabular}




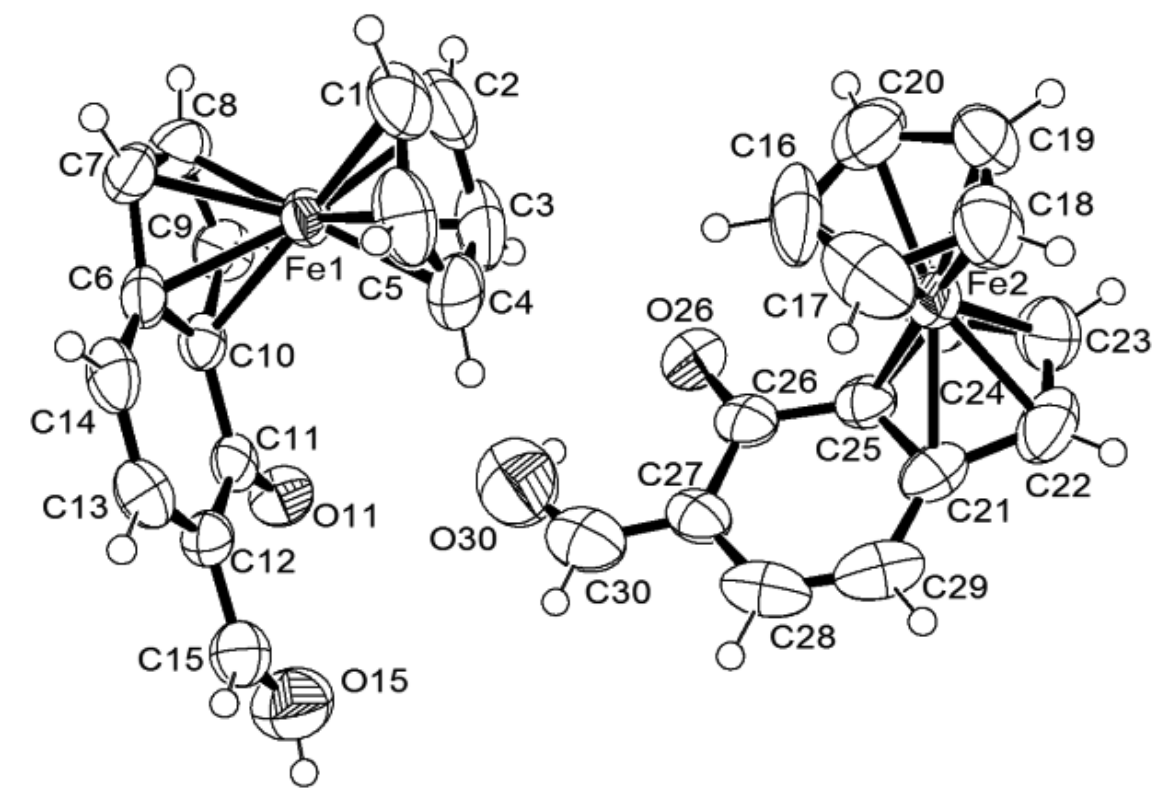

Figure 2.3: An ORTEP $3^{72}$ representation of complex ( \pm -12. The FeCp bond distances range from 2.025(5) to 2.039(5) $\AA$, average of 2.031(5) $\AA$ and 2.019(5) -

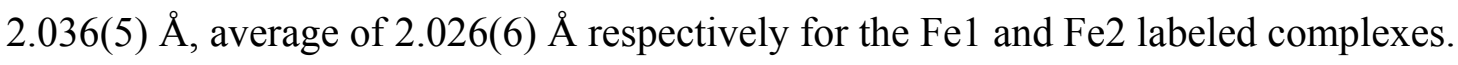
The corresponding Fe distances to the substituted indenyl C-atoms range from 2.034(4) to 2.063(4) $\AA$, average of 2.05(1) $\AA$ and 2.026(5) to 2.083(5) $\AA$, average of 2.05(2) $\AA$ for the $\mathrm{Fe} 1$ and $\mathrm{Fe} 2$ labeled complexes respectively. $\mathrm{Fe} 1-\mathrm{C} 6$ and $\mathrm{Fe} 2-\mathrm{C} 21$ were the largest distances suggesting a skewed arrangement of the indenyl ligand. The corresponding $\mathrm{C}=\mathrm{O}$ ketone and alcohol C-O distances were 1.258(4), 1.352(5) $\AA$ and 1.250(5), 1.343(6) $\AA$ for the $\mathrm{Fe} 1$ and $\mathrm{Fe} 2$ labeled complexes respectively.

Now that a stereoselective method for the preparation of building block $(+)-$ 9 was developed (Table 2.2, entry 4), the synthesis of ferrosalen ligands and their 
metal complexes can be achieved using reported procedures. For example, stirring (+)-9 with 1,2-ethanediamine in anhydrous methanol at room temperature for 5 hours gave (+)-3 in $71 \%$ yield. ${ }^{73}$ Complexation of $(+)-\mathbf{3}$ with $\mathrm{Cu}(\mathrm{II})$ to give $(+)-\mathbf{1 3}$ was achieved by stirring with cupric acetate in ethanol and water at room temperature for 2 hours (75\%) (Scheme 2.4) ${ }^{74}$

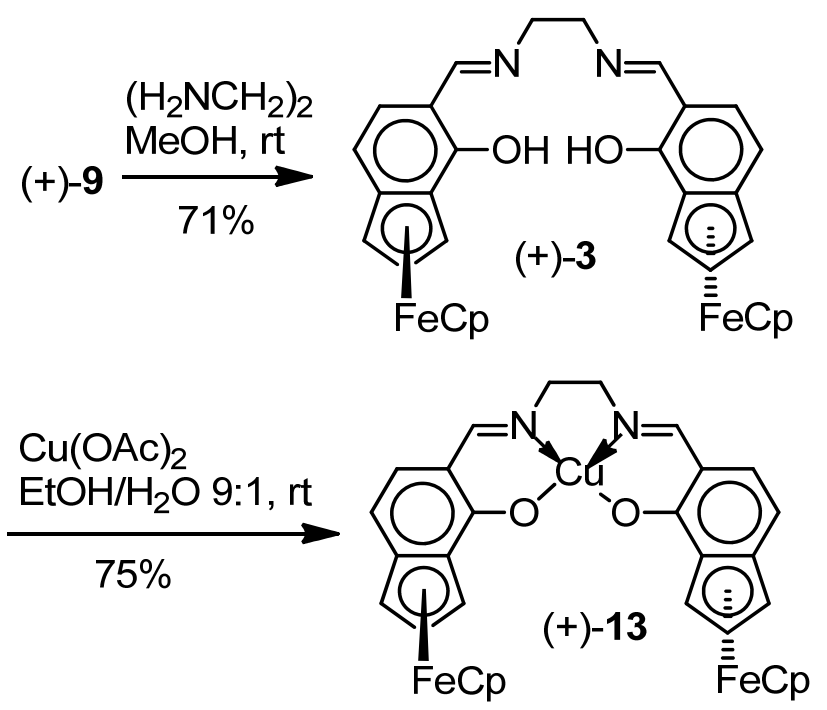

Scheme 2.4: Synthesis of ferrosalen ligand (+)-3 and its $\mathrm{Cu}(\mathrm{II})$ complex $(+)-\mathbf{1 3}$

Many reported methods for the synthesis of non-racemic planar chiral ferrocenyl ligands consume stoichiometric amounts of chiral starting materials. ${ }^{75-76}$ For example, the widely used 2-ferrocenyloxazolines and 1,1'bis(oxazolinyl)ferrocenes were synthesized from enantiopure amino acids. ${ }^{75}$ Additionally some highly useful planar chiral ligands and catalysts were made non-stereoselectively and enantiomers were resolved using chiral HPLC. ${ }^{77}$ 
Although Fu's group recently made significant progress on the resolution of two such catalysts, ${ }^{19}$ the yields of enantiopure products were still low, and the method is not applicable to compounds that are unstable in acid or unreactive with acid, a direct measure of the difficulties in the field. Recently, Kündig's group developed a catalytic enantioselective method to access planar chiral building blocks through the desymmetrization of meso precursors. ${ }^{78-79}$ However, adapting this technology to synthesize (+)-9 is not straightforward.

The method described in this paper does not consume any chiral starting materials and the synthesis is stereoselective. The chiral auxiliary (+)-5 used for resolution of $( \pm)-4$ is commercially available, and can be prepared on multigram scales. ${ }^{80-81}$ In addition, when used for resolution of $( \pm)-\mathbf{4},(+)-\mathbf{5}$ could be recovered quantitatively and be reused repeatedly. For the installation of the double bond in $(+)-7$ to synthesize $(+)-\mathbf{9}$, we used a three-step method. Compared with methods involving selenium and palladium chemistry, this route has the advantage of using less toxic and inexpensive reagents.

\section{Conclusions}

We have designed and synthesized a new ferrosalen ligand. This ligand has unique structural features that are expected to be beneficial for improving enantioselectivities of some catalytic reactions. The key benzoferrocenyl building block (+)-9 for the preparation of the ligand was synthesized stereoselectively. The 
aromatization of enantiopure $(+)-7$ to benzoferrocene derivative $(+)-9$ represents an unprecedented strategy for the synthesis of chiral ferrocenyl ligands. This strategy may be applicable for the preparation of other planar chiral ferrocenyl ligands and catalysts that have previously found wide utility. ${ }^{77}$ Research on structural modulation of the ligand and the use of such ligands to solve problems in asymmetric catalysis is underway.

\section{Experimental section}

4.1. (+)- $(R)-\eta^{5}-[5-(E)-H y d r o x y m e t h y l e n e-4-o x o-4,5,6,7-t e t r a h y d r o-3 H-i n d e n y l]-$ $\eta^{5}$-cyclopentadienyliron [(+)-7]. A two-neck round-bottom flask charged with enantiopure (+)-4 (1.63 g, $5.78 \mathrm{mmol} ; R$-enantiomer is used as an example) and THF $(20 \mathrm{~mL})$ was cooled on an ice bath. NaH $(0.694 \mathrm{~g}, 17.34 \mathrm{mmol})$ was added under positive $\mathrm{N}_{2}$ pressure. After heating the mixture to reflux for $0.5 \mathrm{~h}, \mathrm{HCOOEt}$ (1.28 g, $1.40 \mathrm{~mL}, 17.34 \mathrm{mmol})$ was added via a syringe. Reflux was continued for an additional $2 \mathrm{~h}$, and the reaction mixture was allowed to cool to $\mathrm{rt}$ and then to 0 ${ }^{\circ} \mathrm{C} . \mathrm{Et}_{2} \mathrm{O}(30 \mathrm{~mL})$ was added, and the mixture was transferred to a separation funnel. The organic phase was washed with $5 \% \mathrm{HCl}$ solution $(50 \mathrm{~mL})$. The aqueous portion was extracted with ether $(25 \mathrm{~mL} \times 3)$. The organic phase and extracts were combined, washed with brine, dried over anhydrous $\mathrm{Na}_{2} \mathrm{SO}_{4}$, and filtered. Solvents were removed under reduced pressure. Purification by flash column chromatography $\left(\mathrm{SiO}_{2}\right.$, hexanes/Et $\left.2 \mathrm{O} 2: 1\right)$ gave $(+)-7$ as a red oil (1.68 g, 
93\%): $R_{f}=0.40\left(\mathrm{SiO}_{2}\right.$, hexanes/Et $\left.2 \mathrm{O} 1: 1\right) ;[\alpha]^{22}{ }_{\mathrm{D}}=+21^{\circ}\left(c=0.010, \mathrm{CHCl}_{3}\right) ;{ }^{1} \mathrm{H}$ $\operatorname{NMR}\left(\mathrm{CDCl}_{3}\right) \delta 7.35(\mathrm{~s}, 1 \mathrm{H}, \mathrm{CHO}), 4.76($ br s, $1 \mathrm{H}, \mathrm{H}-1$ or 3$), 4.50(\mathrm{t}, J=2.4 \mathrm{~Hz}$, 1H, H-2), 4.42 (br s, 1H, H-1 or 3), 4.19 (s, 5H, Cp), 2.83 (td, $J=14.0,5.6 \mathrm{~Hz}, 1 \mathrm{H}$, H-5), 2.88-2.25 (m, 4H, H-6 and 7); ${ }^{13} \mathrm{C}$ NMR $\left(\mathrm{CDCl}_{3}\right) \delta 196.6(\mathrm{C}-4), 163.7$ (CHO), 109.0 (C-5), 92.4 (C-3a or C-7a), 75.3 (C-3a or C-7a), 70.9 (C-1 or 2 or 3), $70.3(\mathrm{C}-1$ or 2 or 3), $70.1(\mathrm{Cp}), 64.1(\mathrm{C}-1$ or 2 or 3), 25.2 (C-6 or 7), 22.7 (C-6 or 7); HRMS (ESI) $m / z$ calcd for $\mathrm{C}_{15} \mathrm{H}_{14} \mathrm{FeO}_{2}[\mathrm{M}]^{+}$283.0421, found 283.0413 .

\section{2. (+)-(R)- $\eta^{5}-[5-(E)-M e t h o x y m e t h y l e n e-4-o x o-4,5,6,7-t e t r a h y d r o-3 H-$}

indenyl]- $\eta^{5}$-cyclopentadienyliron $[(+)-\mathbf{1 0}]$. To a two-neck round-bottom flask charged with (+)-7 (6.48 g, $22.98 \mathrm{mmol} ; R$-enantiomer is used as an example) and DMF $(40 \mathrm{~mL})$ was added $\mathrm{Cs}_{2} \mathrm{CO}_{3}(15.0 \mathrm{~g}, 45.96 \mathrm{mmol})$ under positive $\mathrm{N}_{2}$ pressure. The mixture was heated to $50{ }^{\circ} \mathrm{C}$ for $1 \mathrm{~h}$ on an oil bath. $\mathrm{Me}_{2} \mathrm{SO}_{4}(4.38 \mathrm{~mL}, 45.96$ mmol) was then added via a syringe. Heating was continued for an additional 20 min, and the reaction mixture was cooled to rt. $\mathrm{N}_{2}$-bubbled $10 \% \mathrm{~K}_{2} \mathrm{CO}_{3}(100 \mathrm{~mL})$ was added slowly to the flask via a syringe. The mixture was then transferred to a separation funnel, and was extracted with $\mathrm{Et}_{2} \mathrm{O}(40 \mathrm{~mL} \times 4)$. The ether extracts were combined, dried over anhydrous $\mathrm{Na}_{2} \mathrm{SO}_{4}$, and filtered. Solvents were removed under reduced pressure. The mixture contained product $(+)-\mathbf{1 0}(4.39 \mathrm{~g})$ and the starting material $(+)-7(1.78 \mathrm{~g})$, which were separated readily with flash column chromatography $\left(\mathrm{SiO}_{2}\right.$, hexane/Et $\left.\mathrm{E}_{2} \mathrm{O} 1: 2\right)$. Product $(+)-\mathbf{1 0}$ was obtained as a red oil in $89 \%$ yield (based on recovered starting material): $R_{f}=0.35\left(\mathrm{SiO}_{2}\right.$, 
hexane/Et $\left.{ }_{2} \mathrm{O} 1: 2\right) ;[\alpha]^{22}{ }_{\mathrm{D}}=+30^{\circ}\left(c=0.013, \mathrm{CHCl}_{3}\right) ;{ }^{1} \mathrm{H}$ NMR $\left(\mathrm{C}_{6} \mathrm{D}_{6}\right) \delta 7.42(\mathrm{~d}, J$ $=2.4 \mathrm{~Hz}, 1 \mathrm{H}, \mathrm{H}-\mathrm{COMe}), 4.95(\mathrm{~m}, 1 \mathrm{H}, \mathrm{H}-1$ or 3$), 4.04(\mathrm{t}, J=2.4 \mathrm{~Hz}, 1 \mathrm{H}, \mathrm{H}-2)$, $3.99(\mathrm{~m}, 1 \mathrm{H}, \mathrm{H}-1$ or 3), 3.88 (s, 5H, Cp), 3.09-3.02 (m, 1H, H on C-6 or 7), 3.04 (s, $\left.3 \mathrm{H}, \mathrm{H}_{3} \mathrm{C}-\mathrm{O}\right), 2.70-2.60(\mathrm{~m}, 1 \mathrm{H}, \mathrm{H}$ on $\mathrm{C}-6$ or 7$), 2.21-2.15$ ( $\mathrm{m}, 2 \mathrm{H}, \mathrm{H}$ on $\mathrm{C}-6$ or 7$)$; ${ }^{13} \mathrm{C}$ NMR $\left(\mathrm{C}_{6} \mathrm{D}_{6}\right) \delta 191.7$ (C-4), 155.1 (C-OMe), $114.9(\mathrm{C}-5), 92.5$ (C-3a or C-7a), 78.0 (C-3a or C-7a), 70.1 (C-1 or 2 or 3), $70.0(\mathrm{Cp}), 69.7(\mathrm{C}-1$ or 2 or 3), $65.5(\mathrm{C}-1$ or 2 or 3), $60.4\left(\mathrm{OCH}_{3}\right), 23.1$ (C-6 or 7), 22.4 (C-6 or 7); HRMS (ESI) m/z calcd for $\mathrm{C}_{16} \mathrm{H}_{17} \mathrm{FeO}_{2}[\mathrm{M}+\mathrm{H}]^{+}$297.0578, found 297.0569. The $E$ geometry of the double bond of the methyl enol ether was established by NOE. NOE was observed between hydrogens on the methyl group and those on C-6.

4.3. ( \pm )- $\eta^{5}-[5$-endo-Dimethoxymethyl-5-exo-iodo-4-oxo-4,5, 6, 7-tetrahydro-3Hindenyl]- $\eta^{5}$-cyclopentadienyliron $[( \pm)-\mathbf{1 1 a}]$. A two-neck round-bottom flask was charged with racemic $( \pm)-\mathbf{1 0}(0.80 \mathrm{~g}, 2.71 \mathrm{mmol})$ and $\mathrm{MeOH}(20 \mathrm{~mL})$, and wrapped with aluminum foil. To the flask was added $N$-iodosuccinimide $(0.82 \mathrm{~g}$, $3.62 \mathrm{mmol}$ ) in 5 portions in a 20 min period under positive $\mathrm{N}_{2}$ pressure. The reaction was complete in 10 min after addition as indicated by TLC. The mixture was partitioned between water $(40 \mathrm{~mL})$ and $\mathrm{CH}_{2} \mathrm{Cl}_{2}(40 \mathrm{~mL})$. The aqueous phase was further extracted with $\mathrm{CH}_{2} \mathrm{Cl}_{2}(200 \mathrm{~mL} \times 3)$. The combined organic phases were washed with brine, dried over anhydrous $\mathrm{Na}_{2} \mathrm{SO}_{4}$, and filtered. Solvents were removed under reduced pressure. Purification by flash column chromatography $\left(\mathrm{SiO}_{2}\right.$, hexane/Et $t_{2} \mathrm{O} 8: 1$ then $\left.3: 1\right)$ gave racemic $( \pm)-\mathbf{1 1 a}$ as a red solid $(0.84 \mathrm{~g}$, 
68\%): $R_{f}=0.70\left(\mathrm{SiO}_{2}\right.$, hexane/Et $\left.\mathrm{E}_{2} \mathrm{O} 1: 1\right) ; \mathrm{mp} 138-140{ }^{\circ} \mathrm{C} ;{ }^{1} \mathrm{H}$ NMR $\left(\mathrm{CDCl}_{3}\right) \delta$ $5.25\left(\mathrm{~s}, 1 \mathrm{H}, \mathrm{H}-\mathrm{CO}_{2}\right), 4.82($ br s, $1 \mathrm{H}, \mathrm{H}-1$ or 3$), 4.49(\mathrm{t}, J=2.4 \mathrm{~Hz}, 1 \mathrm{H}, \mathrm{H}-2), 4.44$ (br s, $1 \mathrm{H}, \mathrm{H}-1$ or 3$), 4.18(\mathrm{~s}, 5 \mathrm{H}, \mathrm{Cp}), 3.65\left(\mathrm{~s}, 3 \mathrm{H}, \mathrm{OCH}_{3}\right), 3.63\left(\mathrm{~s}, 3 \mathrm{H}, \mathrm{OCH}_{3}\right)$, 2.56-2.50 (m, 1H, H on C-6 or 7); 2.34-2.24 (m, 3H, H on C-6 or 7); ${ }^{13} \mathrm{C}$ NMR $\left(\mathrm{CDCl}_{3}\right) \delta 197.3(\mathrm{C}-4), 108.9(\mathrm{C}-\mathrm{OMe}), 90.3$ (C-3a or C-7a), 72.6 (C-3a or C-7a), $71.4(\mathrm{C}-1$ or 2 or 3$), 70.3(\mathrm{C}-1$ or 2 or 3$), 70.2(\mathrm{Cp}), 66.4(\mathrm{C}-1$ or 2 or 3$), 59.6$ $\left(\mathrm{OCH}_{3}\right), 59.1\left(\mathrm{OCH}_{3}\right), 55.8(\mathrm{C}-5), 31.4(\mathrm{C}-6$ or 7$), 23.0$ (C-6 or 7); HRMS (ESI) $m / z$ calcd for $\mathrm{C}_{17} \mathrm{H}_{20} \mathrm{FeIO}_{3}[\mathrm{M}+\mathrm{H}]^{+}$454.9807, found 454.9797. The reaction was also performed at $0{ }^{\circ} \mathrm{C}$ for $1 \mathrm{~h},( \pm)$-11a was obtained in $52 \%$ yield.

4.4. (+)-(R)- $\eta^{5}-[(5 S)-5-$ Bromo-5-dimethoxymethyl-4-oxo-4,5,6,7-tetrahydro-3Hindenyl]- $\eta^{5}$-cyclopentadienyliron $[(+)-\mathbf{1 1 b}]$. Following the same procedure used for the preparation of $(+)-\mathbf{1 1 a}$, compound $(+)-\mathbf{1 0}(6.09 \mathrm{~g}, 20.6 \mathrm{mmol} ; R-$ enantiomer is used as an example) was reacted with $N$-bromosuccinimide (7.32 g, $41.2 \mathrm{mmol})$ in $\mathrm{MeOH}(50 \mathrm{~mL})$ at $\mathrm{rt}$. The product was purified by flash column chromatography $\left(\mathrm{SiO}_{2}\right.$, hexane/Et $2 \mathrm{O} 8: 1$ then $\left.4: 1\right)$, and compound $(+)-\mathbf{1 1 b}$ was obtained as a red solid (5.93 g, 71\%): $R_{f}=0.65\left(\mathrm{SiO}_{2}\right.$, hexane/Et $\left.2 \mathrm{O} 1: 1\right) ; \mathrm{mp} 120$ $122{ }^{\circ} \mathrm{C}(\mathrm{dec}) ;[\alpha]^{21}{ }_{\mathrm{D}}=+194^{\circ}\left(c=0.010, \mathrm{CHCl}_{3}\right) ;{ }^{1} \mathrm{H} \mathrm{NMR}\left(\mathrm{CDCl}_{3}\right) \delta 5.14(\mathrm{~s}, 1 \mathrm{H}$, $\left.\mathrm{H}-\mathrm{CO}_{2}\right), 4.84(\mathrm{~d}, J=1.6 \mathrm{~Hz}, 1 \mathrm{H}, \mathrm{H}-1$ or 3$), 4.52(\mathrm{t}, J=2.4 \mathrm{~Hz}, 1 \mathrm{H}, \mathrm{H}-2), 4.48$ (br s, $1 \mathrm{H}, \mathrm{H}-1$ or 3), $4.19(\mathrm{~s}, 5 \mathrm{H}, \mathrm{Cp}), 3.67\left(\mathrm{~s}, 3 \mathrm{H}, \mathrm{OCH}_{3}\right), 3.65\left(\mathrm{~s}, 3 \mathrm{H}, \mathrm{OCH}_{3}\right), 2.77-$ $2.71(\mathrm{~m}, 1 \mathrm{H}, \mathrm{H}$ on $\mathrm{C}-6$ or 7), 2.57-2.53 (m, 2H, H on C-6 or 7), $2.41(\mathrm{dt}, J=14.4$, $2.8 \mathrm{~Hz}, 1 \mathrm{H}, \mathrm{H}$ on $\mathrm{C}-6$ or 7$) ;{ }^{13} \mathrm{C} \mathrm{NMR}\left(\mathrm{CDCl}_{3}\right) \delta 196.1(\mathrm{C}-4), 107.6(\mathrm{C}-\mathrm{OMe})$, 
90.8 (C-3a or C-7a), 72.7 (C-3a or C-7a), 71.7 (C-1 or 2 or 3), 70.5 (C-1 or 2 or 3), $70.3(\mathrm{Cp}), 66.9(\mathrm{C}-5), 66.3\left(\mathrm{C}-1\right.$ or 2 or 3), $59.4\left(\mathrm{OCH}_{3}\right), 59.2\left(\mathrm{OCH}_{3}\right), 29.8(\mathrm{C}-6$ or 7), 20.6 (C-6 or 7); HRMS (ESI) $m / z$ calcd for $\mathrm{C}_{17} \mathrm{H}_{20} \mathrm{BrFeO}_{3}[\mathrm{M}+\mathrm{H}]^{+}$ 406.9945, found 406.9942 . The reaction was also performed at $0{ }^{\circ} \mathrm{C}$, the same yield was obtained.

4.5. ( \pm )- $\eta^{5}$-[5-exo-Chloro-5-endo-dimethoxymethyl-4-oxo-4,5,6,7-tetrahydro3 H-indenyl]- $\eta^{5}$-cyclopentadienyliron $[( \pm)-\mathbf{1 1} \mathbf{c}]$. Following the same procedure used for the preparation of $( \pm)-\mathbf{1 1 a},( \pm)-\mathbf{1 0}(0.60 \mathrm{~g}, 2.02 \mathrm{mmol})$ was reacted with $N$-chlorosuccinimide $(0.81 \mathrm{~g}, \quad 6.06 \mathrm{mmol})$ in the presence of $1,4-$ diazabicyclo[2,2,2]-octane $(0.23 \mathrm{~g}, 2.02 \mathrm{mmol})$ in $\mathrm{MeOH}(15 \mathrm{~mL})$ at $0{ }^{\circ} \mathrm{C}$. The product was purified by flash column chromatography $\left(\mathrm{SiO}_{2}\right.$, hexane/Et $\left.\mathrm{Et}_{2} \mathrm{O} 4: 1\right)$, and $( \pm)-11 \mathrm{c}(0.35 \mathrm{~g})$ was obtained as a red solid in $57 \%$ yield (based on $90 \mathrm{mg}$ recovered starting material): $R_{f}=0.65\left(\mathrm{SiO}_{2}\right.$, hexane/Et $\left.{ }_{2} \mathrm{O} 1: 2\right) ; \mathrm{mp} 118-122{ }^{\circ} \mathrm{C}$; ${ }^{1} \mathrm{H} \mathrm{NMR}\left(\mathrm{CDCl}_{3}\right) \delta 5.03\left(\mathrm{~s}, 1 \mathrm{H}, \mathrm{H}-\mathrm{CO}_{2}\right), 4.83$ (br s, $1 \mathrm{H}, \mathrm{H}-1$ or 3), 4.53 (t, $J=2.4$ Hz, 1H, H-2), 4.49 (br s, 1H, H-1 or 3), 4.19 (s, 5H, Cp), 3.67 (s, 3H, $\left.\mathrm{OCH}_{3}\right), 3.64$ (s, $\left.3 \mathrm{H}, \mathrm{OCH}_{3}\right), 2.86-2.78(\mathrm{~m}, 1 \mathrm{H}, \mathrm{H}$ on $\mathrm{C}-6$ or 7$) ; 2.68-2.58(\mathrm{~m}, 1 \mathrm{H}, \mathrm{H}$ on $\mathrm{C}-6$ or 7); $2.56-2.49$ (m, $1 \mathrm{H}, \mathrm{H}$ on $\mathrm{C}-6$ or 7$), 2.44-2.36$ (m, $1 \mathrm{H}, \mathrm{H}$ on $\mathrm{C}-6$ or 7$) ;{ }^{13} \mathrm{C} \mathrm{NMR}$ $\left(\mathrm{CDCl}_{3}\right) \delta 196.3(\mathrm{C}-4), 107.4(\mathrm{C}-\mathrm{OMe}), 91.1$ (C-3a or C-7a), 72.6 (C-3a or C-7a), $71.7(\mathrm{C}-1$ or 2 or 3), $70.6(\mathrm{C}-1$ or 2 or 3), $70.3(\mathrm{Cp}), 70.2(\mathrm{C}-5), 66.1(\mathrm{C}-1$ or 2 or 3), $59.5\left(\mathrm{OCH}_{3}\right), 58.9\left(\mathrm{OCH}_{3}\right), 29.18$ (C-6 or 7), 19.38 (C-6 or 7); HRMS (ESI) $\mathrm{m} / \mathrm{z}$ calcd for $\mathrm{C}_{17} \mathrm{H}_{20} \mathrm{ClFeO}_{3}[\mathrm{M}+\mathrm{H}]^{+}$363.0450, found 363.0464. 
4.6. (+)-(R)- $\eta^{5}-\left[5-\right.$ Formyl-4-hydroxy-3H-indenyl]- $\eta^{5}$-cyclopentadienyliron $[(+)-9]$

and (+)-(R)- $\eta^{5}-\left[5-(Z)\right.$-hydroxymethylidene-4-oxo-4,5-dihydro-3H-indenyl]- $\eta^{5}$ cyclopentadienyliron $[(+)-12]$. A two-neck round-bottom flask was charged with $(+)-11 b(821 \mathrm{mg}, 0.975 \mathrm{mmol}$; $R$-enantiomer is used as an example) and DMF (8 $\mathrm{mL}$ ). $\mathrm{NaOMe}\left(574 \mathrm{mg}, 4.87 \mathrm{mmol}\right.$ ) was added at $\mathrm{rt}$ under positive $\mathrm{N}_{2}$ pressure. TLC indicated that the reaction was complete in $1 \mathrm{~h}$. To the reaction mixture, $\mathrm{N}_{2^{-}}$ bubbled saturated $\mathrm{NH}_{4} \mathrm{Cl}$ solution $(20 \mathrm{~mL})$ was added via a syringe. After stirring for an additional $30 \mathrm{~min}, \mathrm{~N}_{2}$-bubbled $\mathrm{Et}_{2} \mathrm{O}(25 \mathrm{~mL})$ was added via a syringe. The mixture was further stirred for $30 \mathrm{~min}$. The contents were then transferred to a separatory funnel, and the organic and aqueous layers were separated. The aqueous layer was further extracted with $\mathrm{Et}_{2} \mathrm{O}(20 \mathrm{~mL} \times 5)$. The combined organic phases were washed with brine, dried over anhydrous $\mathrm{Na}_{2} \mathrm{SO}_{4}$, and filtered. Solvents were removed under reduced pressure. TLC indicated that the mixture contained two major spots, which corresponds to compounds (+)-9 and (+)-12. These two compounds were purified with flash column chromatography $\left(\mathrm{SiO}_{2}\right.$, hexane/Et $2 \mathrm{O} 8: 1$ then $2: 1)$. Compound $(+)-9$ was obtained as a red solid (384 $\mathrm{mg}, 68 \%): R_{f}=0.63\left(\mathrm{SiO}_{2}\right.$, hexane/Et $\left.\mathrm{Et}_{2} \mathrm{O} 1: 1\right) ; \mathrm{mp} 39-41{ }^{\circ} \mathrm{C} ;[\alpha]^{24}{ }_{\mathrm{D}}=+749.3^{\circ}(c=$ $\left.0.010, \mathrm{CH}_{2} \mathrm{Cl}_{2}\right) ;{ }^{1} \mathrm{H} \mathrm{NMR}\left(\mathrm{CDCl}_{3}\right) \delta 9.57(\mathrm{~s}, 1 \mathrm{H}, \mathrm{CHO}), 6.95(\mathrm{~d}, J=9.2 \mathrm{~Hz}, 1 \mathrm{H}$, H-6 or 7), 6.83 (d, $J=8.8 \mathrm{~Hz}, 1 \mathrm{H}, \mathrm{H}-6$ or 7), 5.21 (br s, 1H, H-1 or 2 or 3), 5.01 (br s, $1 \mathrm{H}, \mathrm{H}-1$ or 2 or 3), 4.42 (br s, $1 \mathrm{H}, \mathrm{H}-1$ or 2 or 3 ), $3.89(\mathrm{~s}, 5 \mathrm{H}, \mathrm{Cp}) ;{ }^{13} \mathrm{C}$ NMR $\left(\mathrm{CDCl}_{3}\right) \delta 192.8(\mathrm{CHO}), 175.8(\mathrm{C}-4), 123.2(\mathrm{C}-6$ or 7$), 117.8(\mathrm{C}-6$ or 7$), 110.8(\mathrm{C}-$ 
5), 91.0 (C-3a or C-7a), 75.0 (C-3a or C-7a), 73.1 (C-1 or 2 or 3), $69.6(\mathrm{Cp}), 65.3$

(C-1 or 2 or 3), $62.2\left(\mathrm{C}-1\right.$ or 2 or 3 ); HRMS (ESI) $m / z$ calcd for $\mathrm{C}_{15} \mathrm{H}_{12} \mathrm{FeO}_{2}[\mathrm{M}]^{+}$ 280.0187, found 280.0181. Compound (+)-12 was obtained as a red solid (51 mg, 9\%): $R_{f}=0.20\left(\mathrm{SiO}_{2}\right.$, hexane/Et $\left.2 \mathrm{O} 1: 2\right) ; \mathrm{mp} 151-155^{\circ} \mathrm{C}(\mathrm{dec}) ;[\alpha]^{24}=+93.3^{\circ}(c$ $\left.=0.005, \mathrm{Et}_{2} \mathrm{O}\right) ;{ }^{1} \mathrm{H} \mathrm{NMR}\left(\mathrm{CDCl}_{3}\right) \delta 10.52(\mathrm{br} \mathrm{s}, 1 \mathrm{H}, \mathrm{OH}), 7.37(\mathrm{~d}, J=11.2 \mathrm{~Hz}, 1 \mathrm{H}$, HC-OH), 6.30 (s, 2H, H-6 and 7), 5.08 (br s, 1H, H-1 or 3), 4.68 (br s, 1H, H-1 or 3), $4.35(\mathrm{t}, J=2.4 \mathrm{~Hz}, 1 \mathrm{H}, \mathrm{H}-2), 3.95(\mathrm{~s}, 5 \mathrm{H}, \mathrm{Cp}) ;{ }^{13} \mathrm{C} \mathrm{NMR}\left(\mathrm{CDCl}_{3}\right) \delta 192.4(\mathrm{C}-$ 4), 153.4 (CH-OH), 126.7 (C-6 or 7), 113.2 (C-6 or 7), 108.0 (C-5), 89.2 (C-3a or C-7a), 78.1 (C-3a or C-7a), 70.8 (C-1 or 2 or 3), $70.1(\mathrm{Cp}), 66.3(\mathrm{C}-1$ or 2 or 3), $64.4\left(\mathrm{C}-1\right.$ or 2 or 3 ); HRMS (ESI) $m / z$ calcd for $\mathrm{C}_{15} \mathrm{H}_{12} \mathrm{FeO}_{2}[\mathrm{M}]^{+} 280.0187$, found 280.0197. Attempts to use enantiopure (+)-12 to grow crystals were not successful. The crystal of $( \pm)$-12 used for X-ray diffraction analysis was obtained by slow evaporation of pentane into a solution of $( \pm)-\mathbf{1 2}$ in $\mathrm{CH}_{2} \mathrm{Cl}_{2}$ under a $\mathrm{N}_{2}$ atmosphere at rt. Crystallographic data are listed in Table 2.3. The crystallographic data (excluding structure factors; CCDC no. 771464) have been deposited to the Cambridge Crystallographic Data Centre. Copies of these data can be obtained, free of charge, on application to CCDC, 12 Union Road, Cambridge CB2 1EZ, UK; fax: +044 1223336033 or via e-mail: deposit@ccdc.cam.uk or via www.ccdc.cam.ac.uk/conts/ retrieving.html. The structure can also be found in the supporting information. 


\section{Table 2.3}

Crystal data and structure refinement parameters for complex ( \pm )-12

\begin{tabular}{|c|c|}
\hline Empirical formula & $\mathrm{C}_{30} \mathrm{H}_{24} \mathrm{Fe}_{2} \mathrm{O}_{4}$ \\
\hline Formula weight & 560.19 \\
\hline Temperature & 291(2) K \\
\hline Wavelength & $0.71069 \AA$ \\
\hline Crystal system, space group & orthorhombic, $\boldsymbol{P} c a b$ \\
\hline Unit cell dimensions & $\begin{array}{l}\mathrm{a}=12.528(2) \AA \\
\mathrm{b}=13.067(2) \AA \\
\mathrm{c}=30.419(5) \AA\end{array}$ \\
\hline Z, Calculated density & $8,1.494 \mathrm{Mg} / \mathrm{m}^{3}$ \\
\hline Absorption coefficient & $1.200 \mathrm{~mm}^{-1}$ \\
\hline $\mathrm{F}(000)$ & 2304 \\
\hline Crystal size & $0.35 \times 0.25 \times 0.15 \mathrm{~mm}$ \\
\hline Theta range for data collection & 1.34 to $22.47^{\circ}$ \\
\hline Limiting indices & $0<=\mathrm{h}<=13,0<=\mathrm{k}<=14,-1<=1<=32$ \\
\hline Reflections collected / unique & $3385 / 3242[\mathrm{R}(\mathrm{int})=0.0267]$ \\
\hline Completeness to theta $=22.47$ & $100.0 \%$ \\
\hline Max. and min. transmission & 0.8405 and 0.6788 \\
\hline Refinement method & Full-matrix least-squares on $\mathrm{F}^{2}$ \\
\hline Data / restraints / parameters & $3242 / 0 / 325$ \\
\hline Goodness-of-fit on $\mathrm{F}^{2}$ & 1.060 \\
\hline Final $\mathrm{R}$ indices $[\mathrm{I}>2 \sigma(\mathrm{I})]$ & $\mathrm{R} 1=0.0375 ; \mathrm{wR} 2=0.0768$ \\
\hline $\mathrm{R}$ indices (all data) & $\mathrm{R} 1=0.0836 ; \mathrm{wR} 2=0.0911$ \\
\hline Largest diff. peak and hole & 0.288 and $-0.290 \mathrm{e} / \mathrm{A}^{3}$ \\
\hline
\end{tabular}


The synthesis of 9 was also carried out under other reaction conditions using compounds 11a-c as the starting materials. Results have been summarized in Table 2.2.

4.7. (+)-N,N'-Bis\{(R)- $\left[\eta^{5}-\left(\eta^{5}\right.\right.$-cyclopentadienylironyl $)$-4-hydroxy-3H-5-inden-5ylmethylidene]\} ethylenediamine $[(+)-3]$. The solution of $(+)-9$ (200.9 mg, 0.718 mmol) and 1,2-ethanediamine $(21.6 \mathrm{mg}, 0.36 \mathrm{mmol}$; $R$-enantiomer is used as an example) in $\mathrm{MeOH}(10 \mathrm{~mL})$ was stirred at $\mathrm{rt}$ under a $\mathrm{N}_{2}$ atmosphere. After $5 \mathrm{~h}$, the solvent was removed under reduced pressure. Purification of the residue by flash column chromatography $\left(\mathrm{SiO}_{2}, \mathrm{Et}_{2} \mathrm{O} / \mathrm{MeOH} / \mathrm{Et}_{3} \mathrm{~N} 40: 3: 2\right)$ gave $(+)-3$ as a red foam $(150 \mathrm{mg}, 71 \%): R_{f}=0.30\left(\mathrm{SiO}_{2}, \mathrm{Et}_{2} \mathrm{O} / \mathrm{MeOH} / \mathrm{Et}_{3} \mathrm{~N} 40: 3: 2\right) ;[\alpha]^{22}=$ $+566.7\left(c=0.001, \mathrm{CHCl}_{3}\right) ;{ }^{1} \mathrm{H} \mathrm{NMR}\left(\mathrm{CDCl}_{3}\right) \delta 7.13(\mathrm{~s}, 1 \mathrm{H}, \mathrm{HC}=\mathrm{N}), 7.10(\mathrm{~s}, 1 \mathrm{H}$, $\mathrm{HC}=\mathrm{N}), 6.21(\mathrm{~d}, J=9.6 \mathrm{~Hz}, 2 \mathrm{H}, \mathrm{H}-6$ or 7$), 6.20(\mathrm{~d}, J=9.2 \mathrm{~Hz}, 2 \mathrm{H}, \mathrm{H}-6$ or 7$), 5.04$ (br s, 2H, H-1 or 3), 4.63 (br s, 2H, H-1 or 3), 4.30 (t, $J=2.0 \mathrm{~Hz}, 2 \mathrm{H}, \mathrm{H}-2), 3.91$ (s, 10H, Cp), $3.48\left(\mathrm{~s}, 4 \mathrm{H}, \mathrm{CH}_{2}-\mathrm{N}\right) ;{ }^{13} \mathrm{C} \mathrm{NMR}\left(\mathrm{CDCl}_{3}\right) \delta 191.1(\mathrm{C}-4), 155.5(\mathrm{C}=\mathrm{N})$, 126.1 (C-6 or 7), 113.0 (C-6 or 7), 107.3 (C-5), 89.1 (C-3a or C-7a), 77.9 (C-3a or C-7a), $70.7(\mathrm{C}-1$ or 2 or 3), $70.0(\mathrm{Cp}), 66.1(\mathrm{C}-1$ or 2 or 3), $64.1(\mathrm{C}-1$ or 2 or 3$)$, $50.0\left(\mathrm{CH}_{2}-\mathrm{N}\right)$; HRMS (ESI) $m / z$ calcd for $\mathrm{C}_{32} \mathrm{H}_{28} \mathrm{Fe}_{2} \mathrm{~N}_{2} \mathrm{O}_{2}[\mathrm{M}]^{+}$585.0928, found 585.0936 .

4.8. (+)-N,N'-Bis\{(R)- $\left[\eta^{5}-\left(\eta^{5}\right.\right.$-cyclopentadienylironyl $)$-4-oxido-3H-inden-5ylmethylidene]\} ethylenediaminato copper (II) [(+)-13]. A two-neck round-bottom 
flask was charged with $(+)-3(27.6 \mathrm{mg}, 0.047 \mathrm{mmol} ; R, R$-enantiomer is used as an example) and the solvent mixture EtOH$/ \mathrm{H}_{2} \mathrm{O}(9: 1,3.3 \mathrm{~mL})$. Cupric acetate $(9.5 \mathrm{mg}$, $0.047 \mathrm{mmol}$ ) was added under positive $\mathrm{N}_{2}$ pressure. After stirring at $\mathrm{rt}$ for $2 \mathrm{~h}$, volatile components were removed under reduced pressure. The deep red solid was suspended in EtOH $(2 \mathrm{~mL})$ and poured onto a pad of Celite. The solid on the Celite was further washed with cold EtOH $(1 \mathrm{~mL} \times 2)$. Then, to the Celite was added $\mathrm{CH}_{2} \mathrm{Cl}_{2}(3 \mathrm{~mL})$. The red solid was dissolved and was filtered into a clean round-bottom flask. The Celite was further washed with $\mathrm{CH}_{2} \mathrm{Cl}_{2}(3 \mathrm{~mL} \times 2)$. The combined red solution was evaporated under reduced pressure giving compound $(+)-13$ as a red crystalline solid $(22.8 \mathrm{mg}, 75 \%):[\alpha]^{24}{ }_{\mathrm{D}}=+2551.0(c=0.004$, $\mathrm{CH}_{2} \mathrm{Cl}_{2}$ ); HRMS (ESI) $\mathrm{m} / z$ calcd for $\mathrm{C}_{32} \mathrm{H}_{26} \mathrm{CuFe}_{2} \mathrm{~N}_{2} \mathrm{O}_{2}[\mathrm{M}]^{+}$644.9989, found 644.9971. This compound is paramagnetic, and was not characterized with NMR. The image of its LRMS is shown in Figure S2 in the supporting information.

\section{Acknowledgments}

Financial support from US NSF (CHE-0647129), Michigan Universities Commercialization Initiative, and MTU Chemistry Department is gratefully acknowledged.

\section{Supplementary data}

Images of ${ }^{1} \mathrm{H}$ and ${ }^{13} \mathrm{C}$ NMR spectra of all new compounds, X-ray crystal structure data of $( \pm)-\mathbf{1 2}$, and image of the LRMS of $(+)-\mathbf{1 3}$. Supplementary data asociated 
with this article can be found in online version at doi:10.1016/j.jorganchem.2010.10.064 


\title{
Chapter 3
}

\section{Ferrosalen and Ferrosalen-Type Ligands: Structural Modulation and Applications in Asymmetric}

Catalysis

\author{
Xiang Zhang, Rudy L. Luck, Shiyue Fang \\ Organometallics, Accepted for publication.
}

Reproduced with permission from Organometallics, in press.

Unpublished work copyright (C) 2011, American Chemical Society. See Appendix D.2 


\title{
Ferrosalen and Ferrosalen-Type Ligands: Structural Modulation and Applications in Asymmetric Catalysis
}

\author{
Xiang Zhang, Rudy L. Luck, Shiyue Fang* \\ Department of Chemistry, Michigan Technological University, 1400 Townsend \\ Drive, Houghton, Michigan 49931 USA \\ Tel: +001 (906) 487-2023; Fax: +001 (906) 487-2061 \\ E-mail: shifang@mtu.edu
}

\begin{abstract}
Several ferrosalen and ferrosalen-type ligands, (-)-1 to (-)-10, were prepared and fully characterized. The structure of one of these ligands ligated to $\mathrm{Cu}$ (II) was determined by single-crystal X-ray diffraction analysis. In comparison with the parent ligand (-)-1, the two six-membered rings of ligand (-)-2 are not aromatized and the synthesis was more facile. Diastereoisomers (+)-3 and (-)-4, containing substituents on the ethylene chain, were synthesized. The aromatized versions of (+)-3 and (-)-4, namely (+)-5 and (-)-6, were also prepared. Further modulation of the ethylene backbone produced ligands (+)-7 and (-)-8. Replacing the $\mathrm{Cp}$ ligands with $\mathrm{Cp}^{*}$ and $\mathrm{Cp}^{\mathrm{Ph} 5}$ gave ligands (+)-9 and (-)-10, respectively. All these ligands were tested for catalytic asymmetric reactions, including the Co(III)catalyzed carbonyl-ene reaction, Al(III)-catalyzed Strecker reaction, and Al(III)catalyzed silylcyanation of aldehydes.
\end{abstract}




\section{Introduction}

Salen and salen-type ligands have been widely used in asymmetric catalysis. Most of these ligands were rendered chiral by introduction of two central chiral centers at the 8- and 8'-positions in their backbone. To solve certain selected problems such as enantioselective epoxidation of conjugated cis-olefins and unfunctionalized olefins, Katsuki's group designed and synthesized salen ligands that contain central or axial chiral centers at the 3 - and $3^{\prime}$-positions. ${ }^{39,41,57-58}$ Recently, salen and salen-type ligands that contain the planar chiral ferrocenyl moieties were also reported in the literature. For example, Ballistreri and coworkers used ferrocene-containing diamines for salen-type ligand synthesis. The resulting ligands contained one or more ferrocenyl groups in their backbone. ${ }^{59}$ Bildstein's group incorporated one or more ferrocenyl groups into the front part of salen-type ligands. ${ }^{60}$ Erker's group used hydroxyferrocene as the building block for salen-type ligand synthesis. In this case, the bulky FeCp groups are very close to the catalytic center, which may be beneficial for stereocontrol. ${ }^{61-62}$
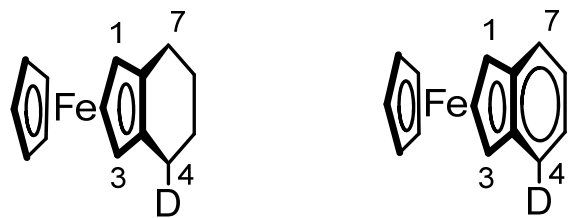

D: Electron donating heteroatoms such as $\mathrm{P}, \mathrm{N}, \mathrm{S}$ and $\mathrm{O}$

Figure 3.1: The two structural motifs of a new class of chiral ligands 
Three years ago, we started to develop a new class of chiral ferrocenyl ligands based on two common structural motifs (Figure 3.1). Our preliminary results showed that such ligands are chemically and configurationally stable, and are compatible with several catalytic reaction conditions. ${ }^{63-66}$ More recently, we have successfully developed a stereoselective method to access this class of ligands such as (-)-1 (Figure 3.2). As a result, we no longer need to rely on chiral HPLC resolution to obtain them in enantiopure form, and gram-sized quantities can be synthesized conveniently. ${ }^{82}$ In addition, this synthetic route provided an opportunity to modulate the steric hindrance at the ethylene backbone and at the FeCp groups. In this paper, we wish to report the synthesis and characterization of ligands (-)-2 to (-)-10 (Figure 3.2), and their use for the Co(III)-catalyzed carbonyl-ene reaction, $\mathrm{Al}(\mathrm{III})$-catalyzed Strecker reaction, and $\mathrm{Al}(\mathrm{III})$-catalyzed silylcyanation of aldehydes. 

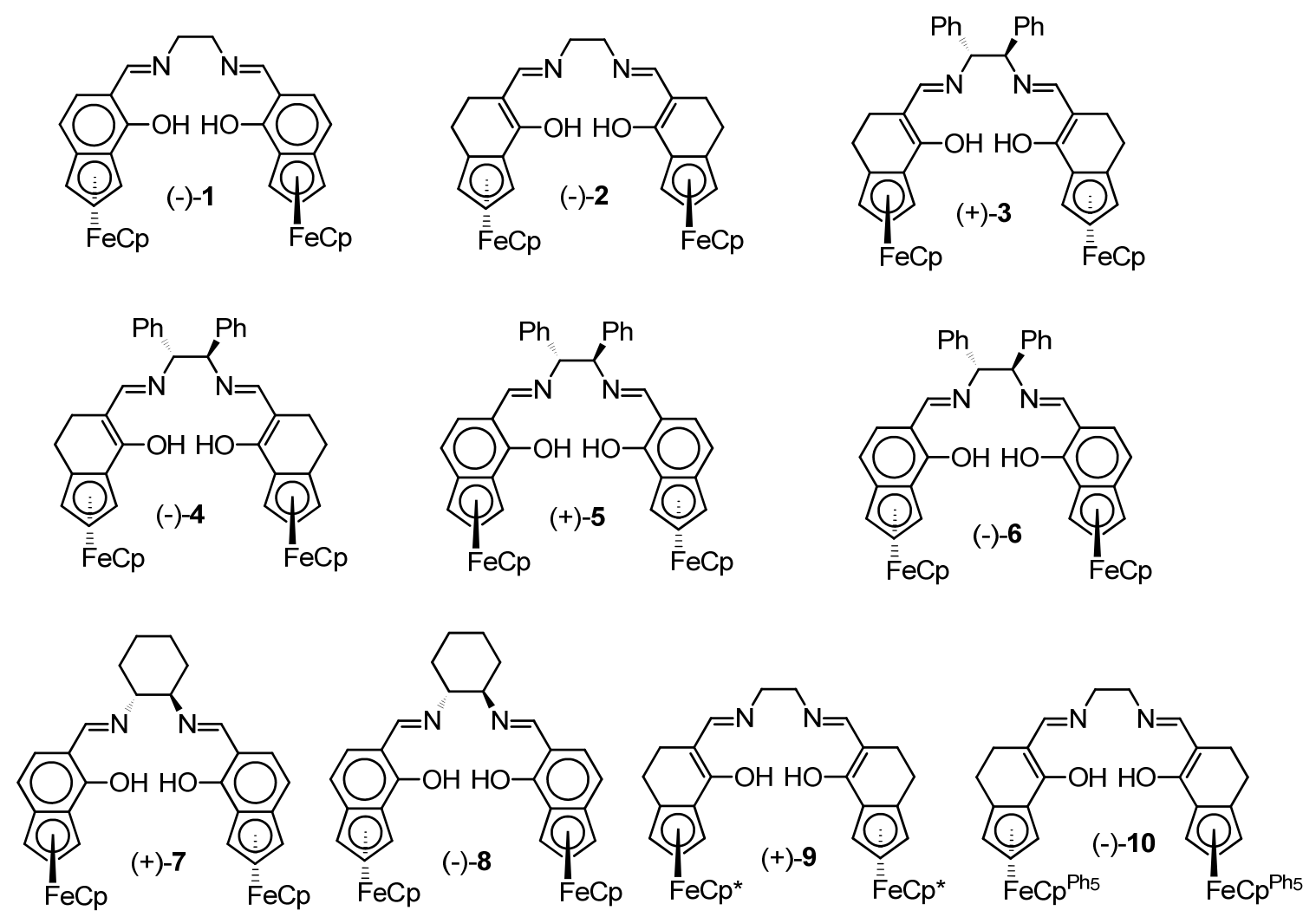

$$
\mathrm{Cp}=\mathrm{C}_{5} \mathrm{H}_{5} ; \mathrm{Cp}^{*}=\mathrm{C}_{5} \mathrm{Me}_{5} ; \mathrm{Cp} \mathrm{Ph}^{\mathrm{Ph}}=\mathrm{C}_{5} \mathrm{Ph}_{5}
$$

Figure 3.2: Ferrosalen and Ferrosalen-type ligands

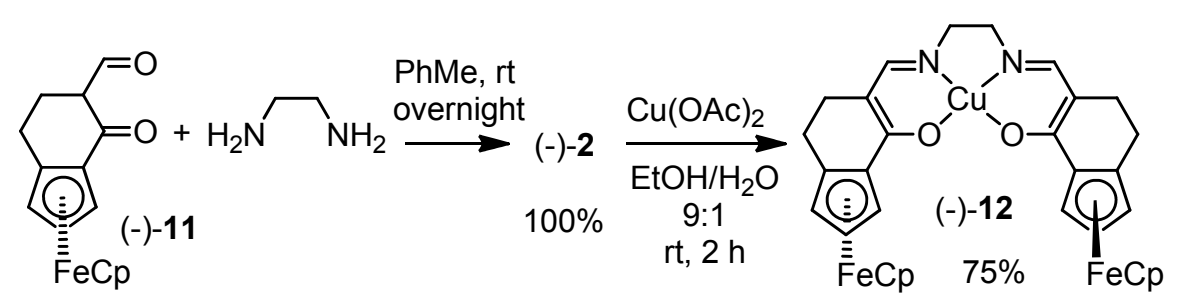

Scheme 3.1: Synthesis of ligand (-)-2 and the Cu(II) complex (-)-12 


\section{Results and Discussion}

The synthesis of ligand (-)-1 (both enantiomers are accessible) has been reported previously. ${ }^{82}$ Ligand (-)-2 is the unaromatized version of (-)-1. As the synthesis of (-)-2 is several steps shorter, it was prepared to evaluate usefulness in asymmetric catalysis. This unaromatized ligand may also display useful electronic and steric properties in catalysis. As shown in Scheme 3.1, enantiopure (-)-11(both enantiomers are accessible; the $S$ enantiomer was used $)^{82}$ was condensed with 1,2ethanediamine in anhydrous methanol at room temperature. ${ }^{37}$ Ligand (-)-2 was obtained in quantitative yield as a red foam. Stirring (-)-2 with cupric acetate in a solvent mixture of ethanol and water at room temperature gave the $\mathrm{Cu}$ (II) complex (-)-12 in 75\% yield (Scheme 3.1$).{ }^{74}$ Compound (-)-12 is paramagnetic and was not characterized by NMR, but HRMS contained a peak equal to the calculated molecular weight. We were also successful in growing crystals for X-ray diffraction analysis (Figure 3.3). In the solid-state structure, like most metallosalen complexes in the absence of multidentate ancillary ligands, (-)-12 adopts a trans configuration. Although there is no substituent at the 1,2-ethanediamino backbone, the five-membered ring containing $\mathrm{Cu}(\mathrm{II})$ and two nitrogen atoms are in a halfchair conformation. This produces an overall stepped conformation for the metallosalen complex. ${ }^{54}$ 


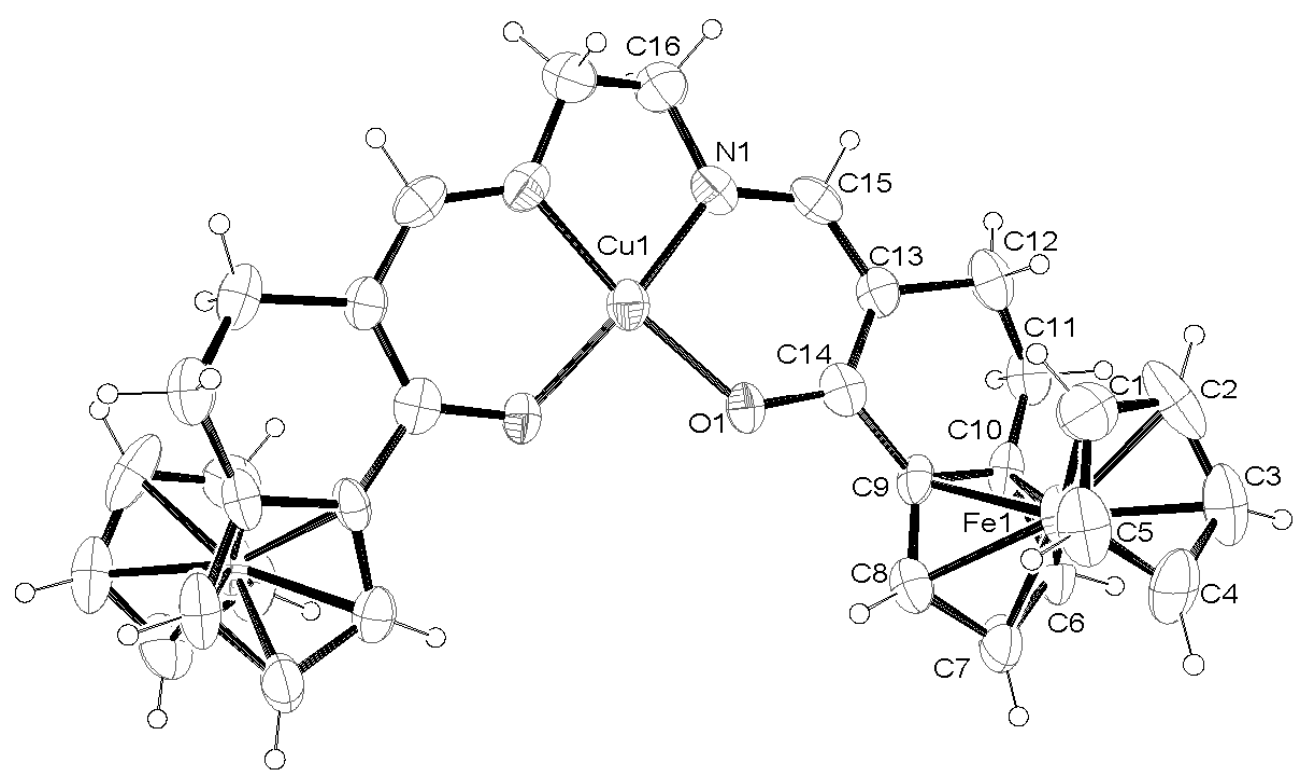

Figure 3.3: ORTEP-3 structure of (-)-12. ${ }^{72}$ Displacement ellipsoids are drawn at the $30 \%$ probability level, $\mathrm{H}$ atoms are represented by circles of arbritary radii. Selected bond lengths ( $\AA$ ) and angles (deg) for 12: Fe1-C1 2.012(12), Fe1-C2 2.041(14), Fe1-C3 2.006(14), Fe1-C4 2.024(11), Fe1-C5 2.028(11), Fe1-C6 2.023(11), Fe1-C7 2.009(12), Fe1-C8 2.037(11), Fe1-C9 2.067(10), Fe1-C10 2.082(11), Cu1-O1 1.927(7), Cu1-N1 1.936(8), N1-C15 1.326(14), N1-C16 1.453(13), O1-Cu1-O1' 91.8(4), O1-Cu1-N1' 165.6(3), O1-Cu1-N1 93.9(4), N1'-Cu1-N1 83.7(6) equivalent atoms generated by -x+2,$\mathrm{x}+\mathrm{y}+1,-\mathrm{z}+1 / 3$

Ligands (+)-3 and (-)-4 are diastereoisomers. In catalytic applications, they should display different efficiencies in stereocontrol. Their syntheses were 
achieved by condensing the commercially available enantiopure (+)-13 with $(+)$ and (-)-11 in anhydrous methanol, respectively (Scheme 3.2). Good isolated yields were obtained. Ligands (+)-5 and (-)-6 are also diastereoisomers. They are the aromatized version of compounds (+)-3 and (-)-4. Their syntheses were accomplished under similar conditions for the synthesis of (+)-3 and (-)-4 using (+)-13 and the two enantiomers of compound $\mathbf{1 4}$ (Scheme 3.2). ${ }^{82}$ The ethylenediamine backbone of ferrosalen (+)-5 and (-)-6 was changed to 1,2cyclohexanediamine (-)-15 to give ligands (+)-7 and (-)-8 (Scheme 3.2) utilizing similar synthetic conditions. Ligands (-)-3 to (-)-8 were fully characterized by ${ }^{1} \mathrm{H}$ and ${ }^{13} \mathrm{C}$ NMR and HRMS. They are stable deep red crystalline solids, and in solution, they are stable under inert atmospheres. Upon exposure to air, the solutions turn green, indicating oxidation occurred; this is typical for ferrocenyl compounds. One would predict that the aromatized compounds (+)-5 to (-)-8 would be less stable than the unaromatized ones (-)-2 to (-)-4 due to the reduced aromaticity of their ferrocenyl units. However, we did not observe any obvious difference in their stabilities in the solid state as well in solution. Our attempts to obtain crystals of these ligands chelating to metal centers such as $\mathrm{Cu}(\mathrm{II}), \mathrm{Co}(\mathrm{II})$, and $\mathrm{Ru}(\mathrm{II})$ complexes for $\mathrm{X}$-ray diffraction analysis have not been successful so far. 


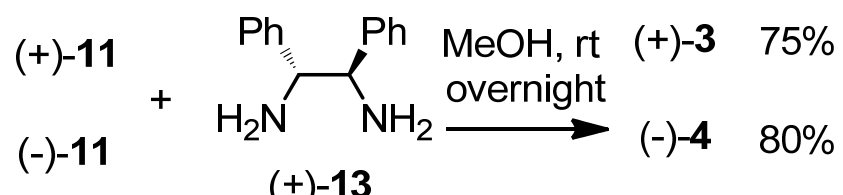

$(+)-13$
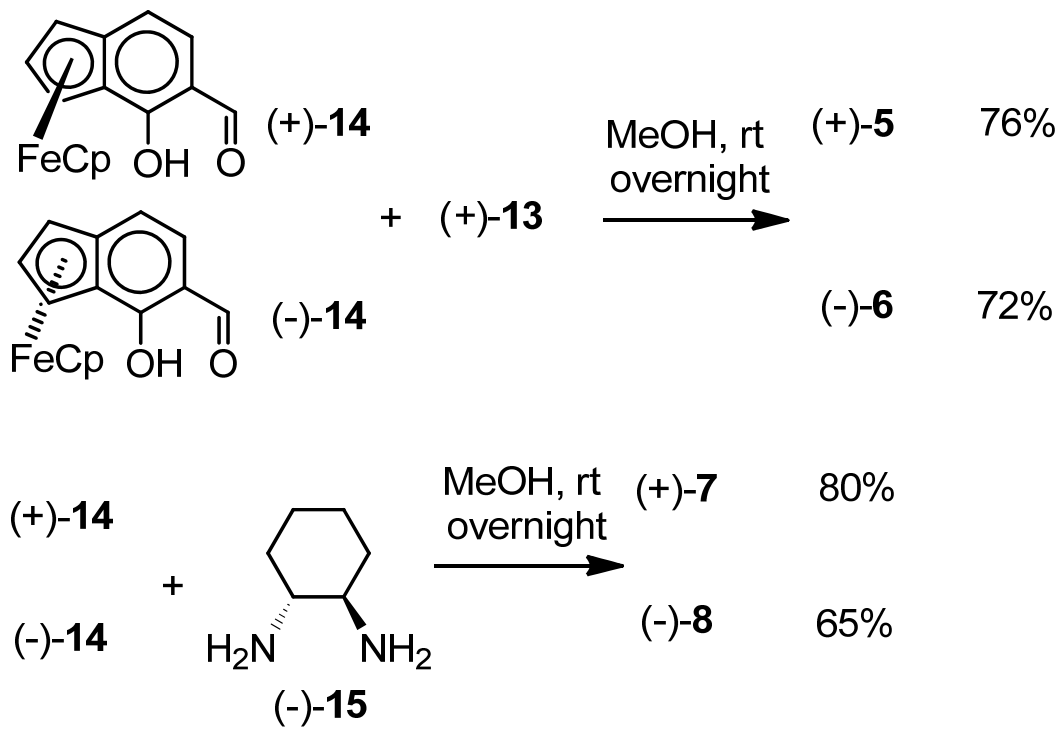

Scheme 3.2: Synthesis of ligands (+)-3 to (-)-8

A significant advantage of using the $\mathrm{FeCp}$ group in ligands to control stereoselectivity of catalytic reactions is the ability to modulate its size. For example, the $\mathrm{Cp}$ group can be changed to $\mathrm{Cp}^{*}\left(\mathrm{C}_{5} \mathrm{Me}_{5}\right)$ and $\mathrm{Cp}^{\mathrm{Ph} 5}\left(\mathrm{C}_{5} \mathrm{Ph}_{5}\right)$. With these more bulky groups, the apical positions of the catalytic center of the ferrosalen-metal complex may be shielded to varying degrees, which may only allow substrates to react through one specific pathway. In order to evaluate this, enantiopure (+)-9 and (-)-10 were synthesized (Scheme 3.3). For the synthesis of $(+)-9$, compound $\mathbf{1 6 \mathbf { a } ^ { 8 3 }}$ was reacted with succinic anhydride in the presence of 
$\mathrm{AlCl}_{3}$ to give the ferrocenyl ketone 17a. Reduction of the ketone with $\mathrm{Zn} / \mathrm{HgCl}_{2}$ resulted in compound 18a. Compound 18a was cyclized through an intramolecular Friedel-Crafts reaction using trifluoroacetic anhydride as the activation agent to give the racemic ferrocenyl cyclohexanone $( \pm)-19 a$. To resolve the enantiomers, commercially available enantiopure (+)-20 was deprotonated with $n$-BuLi and the resulting anion reacted with ketone $( \pm)-19 \mathbf{a}$ to give diastereoisomers 21xa and 21ya. These isomers could be resolved on TLC with $\mathrm{R}_{f}$ values being 0.55 and 0.40 , respectively, when the developing solvent mixture was hexanes/ether $(1: 1)$. However, we only obtained 21xa in pure form. During flash column chromatography, 21xa and $21 \mathbf{y b}$ slowly decomposed to give (+)-20, and the parent ketones (+)- and (-)-19a; the other diastereoisomer 21ya was contaminated with ketones and could not be purified. Pure 21 xa was decomposed in refluxing toluene to give enantiopure $(+)-\mathbf{1 9 a} \cdot{ }^{67,82}$ Formylation of $(+)-\mathbf{1 9 a}$ with ethyl formate in the presence of sodium hydride gave $(+)-22 a$, which was condensed with 1,2ethanediamine in anhydrous methanol to give ligand (+)-9.

For the synthesis of (-)-10, compound $\mathbf{1 6 b}$ was prepared according to a modified literature procedure. ${ }^{84}$ This compound was converted to $( \pm)-\mathbf{1 9 b}$ following the same sequence of reactions used for the preparation of $( \pm)-19 a .( \pm)$ 19b was then resolved using (+)-20 according to the procedure described for resolution of $( \pm)-19 a$. The two diastereoisomers $21 \times b$ and $21 \mathrm{yb}$ have $\mathrm{R}_{f}$ values of 
0.35 and 0.20 , respectively, when the developing solvent mixture was hexanes/ether (2:1). Similar to compounds 21xa and 21ya, these two diastereoisomers were not stable; they decompose slowly, resulting in (+)-20 and the parent ketones (+)- and (-)-19b. Because $\mathbf{2 1} \mathbf{x b}$ has a $\mathrm{R}_{f}$ value similar to that of ketone 19b, we were only able to obtain pure $21 \mathbf{y b}$. Removal of the chiral auxiliary (+)-20 from 21yb in refluxing toluene gave enantiopure (-)-19b (Scheme 3.3). At this time, we were not able to obtain enantiopure (+)-19b. With enantiopure (-)-19b in hand, the synthesis of (-)-10 was straightforward, even though the highly bulky $\mathrm{FeCp}^{\mathrm{Ph} 5}$ group could have hindered the synthesis during the formylation and imine formation reactions. For formylation, compound (-)-22b was obtained in $77 \%$ yield. Condensation of (-)-22b with 1,2-ethanediamine gave ligand (-)-10 in 68\% yield (Scheme 3.3). 


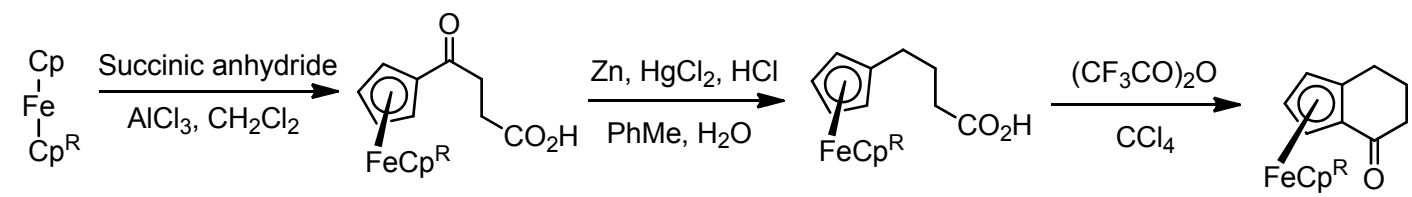

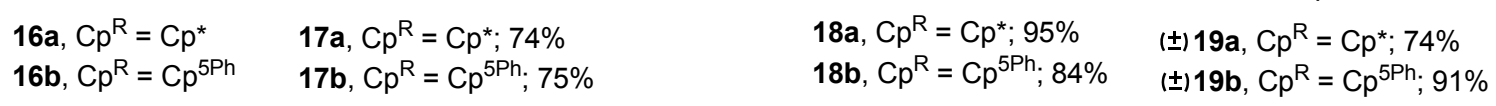

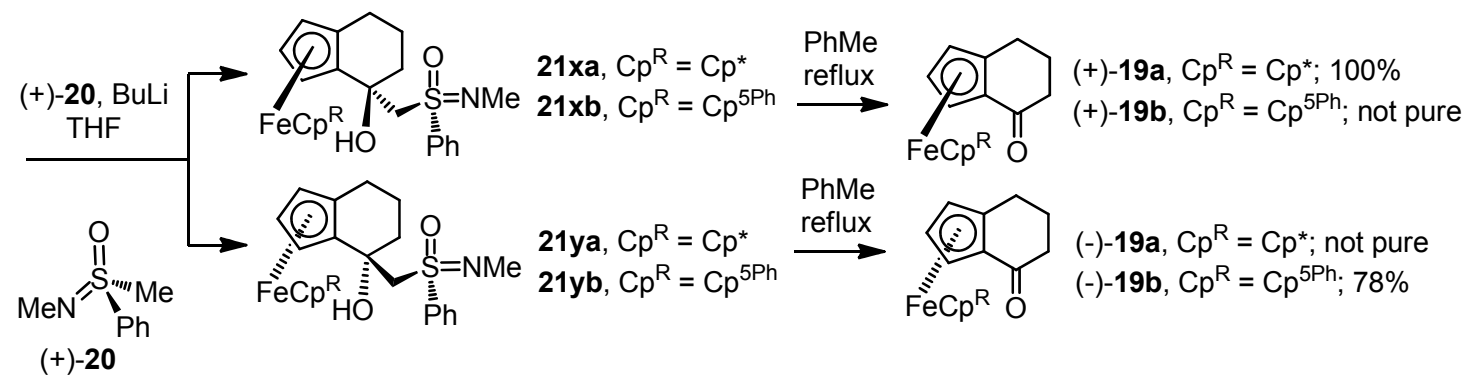

$(+)-19 a \underset{\mathrm{THF}, \text { reflux }}{\stackrel{\mathrm{NaH}, \mathrm{HCO}_{2} \mathrm{Et}}{\longrightarrow}}$

$(+)-22 a, 93 \%$

$(-)-19 b \underset{\text { THF, reflux }}{\stackrel{\mathrm{NaH}, \mathrm{HCO}_{2} \mathrm{Et}}{\longrightarrow}}$

$(-)-22 b, 77 \%$

Scheme 3.3: Synthesis of ligands (+)-9 and (-)-10

All the ligands (-)-1 to (-)-10 were tested in the Co(III)-catalyzed carbonylene reaction (Equation 3.1a), Al(III)-catalyzed Strecker reaction (Equation 3.1b; for ease of isolation, the product was acylated with benzoyl chloride), and Al(III)catalyzed silylcyanation of aldehydes (Equation 3.1c). Under the conditions we have investigated, all reactions resulted in good yields but unsatisfactory enantioselectivity. The best selectivity we achieved for the carbonyl-ene reaction was $29 \%$ using (-)-8-Co(III) as the catalyst with a 5 mol \% loading and with a 
$78 \%$ yield. The major enantiomer has an $R$ configuration. Using (+)-7, a diastereoisomer of (-)-8, as the ligand, under the same conditions, the ee was $10 \%$ but the yield was higher at $99 \%$. In this case, the major enantiomer had an $S$ configuration. For the Strecker reaction, the best ee we obtained was $20 \%$. The catalyst used was (-)-1-AlCl generated in situ with $10 \mathrm{~mol} \%$ ligand and $9 \mathrm{~mol} \%$ $\mathrm{Et}_{2} \mathrm{AlCl}$. Under these conditions, the yield was quantitative. For the aldehyde silylcyanation reaction, the best ee was $26 \%$ in an $89 \%$ yield. This was achieved using (+)-3- $\mathrm{AlCl}$ as the catalyst at a loading of $5 \mathrm{~mol} \%$. The configuration of the major enantiomer is $S .{ }^{85}$ With $(+)-5-\mathrm{AlCl}$ as catalyst and under similar conditions, the selectivity and yield were lowered to $18 \%$ ee and $84 \%$ respectively. We believe that the low ees obtained with ligands (-)-1 to (-)-10 can be attributed in part to the lack of steric hindrance at the 5 and $5^{\prime}$ positions. Without any bulky groups at these positions, a large area at the side opposite to the FeCp group is open. Assuming that there are no secondary interactions between the substrates and the catalysts, the conformations of the transition states are flexible. 


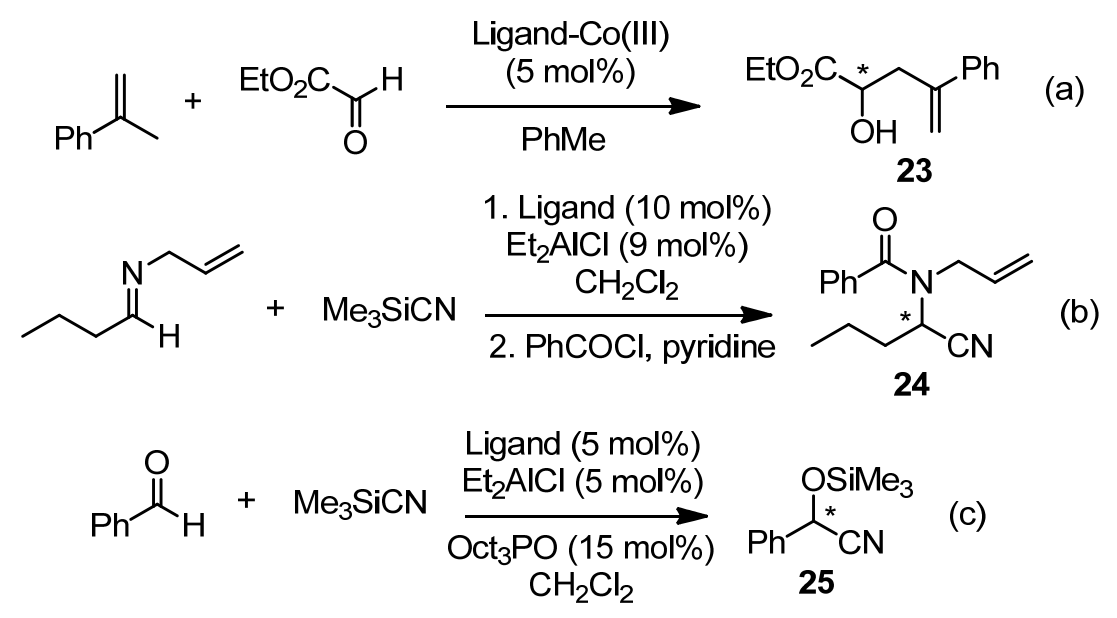

Equation 3.1: Asymmetric reactions catalyzed by ferrosalen ligands (-)-1 to (-)-10

In conclusion, we have synthesized and fully characterized nine enantiopure ferrosalen ligands and investigated their applications in enantioselective carbonyl-ene, Strecker, and silylcyanation of aldehyde reactions. All the ligands are compatible with these reaction conditions, and high yields were obtained. However, the enantioselectivity was low under the conditions we tested. The low selectivity may be a result of the lack of steric hindrance at the 5- and 5'positions of the ligands. Future work will be directed to the modulation of steric hindrance at these positions and to the evaluation of the resulting new ligands for catalytic enantioselective reactions. 


\section{Experimental Section}

General. All reactions were performed in oven-dried glassware under a nitrogen atmosphere using standard Schlenk techniques. Reagents and solvents available from commercial sources were used as received unless otherwise noted. THF was distilled from $\mathrm{Na}$ /benzophenone ketyl. $\mathrm{MeOH}, \mathrm{CH}_{2} \mathrm{Cl}_{2}$, and toluene were distilled over $\mathrm{CaH}_{2}$. Thin-layer chromatography (TLC) was performed using plates with silica gel $60 \mathrm{~F}-254$ over glass support, $0.25 \mu \mathrm{m}$ thickness. Flash column chromatography was performed using silica gel with a particle size of 32-63 $\mu \mathrm{m}$. ${ }^{1} \mathrm{H}$ and ${ }^{13} \mathrm{C}$ NMR spectra were measured at $400 \mathrm{MHz}$ and $100 \mathrm{MHz}$, respectively; chemical shifts $(\delta)$ were reported in reference to solvent peaks (residue $\mathrm{CHCl}_{3}$ at $\delta$ $7.24 \mathrm{ppm}$ for ${ }^{1} \mathrm{H}$ and $\mathrm{CDCl}_{3}$ at $\delta 77.00 \mathrm{ppm}$ for ${ }^{13} \mathrm{C}, \mathrm{C}_{6} \mathrm{D}_{5} \mathrm{H}$ at $\delta 7.16 \mathrm{ppm}$ for ${ }^{1} \mathrm{H}$ and $\mathrm{C}_{6} \mathrm{D}_{6}$ at $\delta 128.4 \mathrm{ppm}$ for ${ }^{13} \mathrm{C}$ ). GC-MS were measured on a Shimadzu GCMSQP5050A instrument: column, DB-5MS; thickness, $0.25 \mu \mathrm{m}$; diameter, $0.25 \mathrm{~mm}$; length, 25m; MS, positive EI. HPLC was performed on a JASCO LC-2000Plus System: pump, PU-2089Plus Quaternary Gradient; detector, UV-2075Plus; chiral analytical column, Chiracel AS-H $(5 \mu \mathrm{m}$ diameter, $100 \AA$, $250 \times 4.6 \mathrm{~mm})$. All profiles were generated by detection of UV absorbance at $260 \mathrm{~nm}$ using a linear gradient solvent system: $1 \%$ to $10 \%$ 2-propanol in hexanes over $30 \mathrm{~min}$ at a flow rate of $1 \mathrm{~mL} / \mathrm{min}$. 
Ferrosalen (-)-2. A solution of enantiopure (-)-11 (213 mg, $0.755 \mathrm{mmol})$ and 1,2-ethanediamine $(22.7 \mathrm{mg}, 0.378 \mathrm{mmol})$ in dry toluene $(5 \mathrm{~mL})$ was stirred under a nitrogen atmosphere at rt overnight. The solvent was removed under reduced pressure. Pure product (-)-2 was obtained as a red foam (222 $\mathrm{mg}, 0.376$ mmol, 100\%): $\mathrm{R}_{f}=0.1$ (hexanes $\left./ \mathrm{CH}_{2} \mathrm{Cl}_{2} / \mathrm{Et}_{3} \mathrm{~N} 1: 1: 0.05\right) ;[\alpha]^{21}{ }_{\mathrm{D}}=-308.2^{\circ}(c=$ 0.0036, $\left.\mathrm{CH}_{2} \mathrm{Cl}_{2}\right) ;{ }^{1} \mathrm{H} \mathrm{NMR}\left(\mathrm{CDCl}_{3}\right) \delta 9.54$ (br s, $\left.2 \mathrm{H}\right), 6.48(\mathrm{~s}, 1 \mathrm{H}), 6.45(\mathrm{~s}, 1 \mathrm{H})$, 4.67 (br s, 2H), 4.31 (t, $J=2.4 \mathrm{~Hz}, 2 \mathrm{H}), 4.23$ (br s, 2H), 4.12 (s, 10H), 3.34-3.10 (m, 4H), 2.94-2.82 (m, 2H), 2.39-2.02 (m, 6H); ${ }^{13} \mathrm{C} \mathrm{NMR}\left(\mathrm{CDCl}_{3}\right) \delta$ 193.0, 149.8, 101.8, 91.6, 78.7, 69.5, 69.2, 68.8, 63.8, 50.0, 28.5, 23.6; HRMS (FAB) $m / z$ calcd for $\mathrm{C}_{32} \mathrm{H}_{32} \mathrm{Fe}_{2} \mathrm{~N}_{2} \mathrm{O}_{2}[\mathrm{M}]^{+}$588.1163, found 588.1160.

Ferrosalen (+)-3. Following the procedure for the preparation of $(-)-2,(+)-$ $11(176 \mathrm{mg}, 0.624 \mathrm{mmol})$ and $(+)-13(66.3 \mathrm{mg}, 0.312 \mathrm{mmol})$ in $\mathrm{MeOH}(6 \mathrm{~mL})$ were stirred at $\mathrm{rt}$ overnight. The product was purified with flash column chromatography $\left(\mathrm{SiO}_{2}\right.$, hexanes/ $\left.\mathrm{Et}_{2} \mathrm{O} / \mathrm{MeOH} 1: 1: 0.03\right)$, and $(+)-\mathbf{3}$ was obtained as a red foam (168 mg, $0.227 \mathrm{mmol}, 73 \%): \mathrm{R}_{f}=0.25\left(\mathrm{SiO}_{2}\right.$, hexanes $/ \mathrm{Et}_{2} \mathrm{O} / \mathrm{MeOH}$ $1: 1: 0.03) ;[\alpha]^{21}{ }_{\mathrm{D}}=+105.6^{\circ}\left(c=0.011, \mathrm{CH}_{2} \mathrm{Cl}_{2}\right) ;{ }^{1} \mathrm{H} \mathrm{NMR}\left(\mathrm{CDCl}_{3}\right) \delta 10.50$ (br s, 2H), 7.20-7.10 (m, 6H), 7.02-6.92 (m, 4H), $6.71(\mathrm{~s}, 1 \mathrm{H}), 6.68(\mathrm{~s}, 1 \mathrm{H}), 4.74(\mathrm{br} \mathrm{s}$, 2H), $4.36(\mathrm{t}, J=2.4 \mathrm{~Hz}, 2 \mathrm{H}), 4.28(\mathrm{br} \mathrm{s}, 2 \mathrm{H}), 4.21(\mathrm{~s}, 10 \mathrm{H}), 4.15(\mathrm{~s}, 1 \mathrm{H}), 4.14(\mathrm{~s}$, 1H), 3.10-2.98 (m, 2H), 2.47-2.16 (m, 6H); ${ }^{13} \mathrm{C}$ NMR $\left(\mathrm{CDCl}_{3}\right) \delta$ 193.4, 148.7, $138.4,128.5,127.7,127.4,102.7,91.9,78.9,69.8,69.6,69.4,69.0,63.9,28.8$, 
23.6; HRMS (ESI) $m / z$ calcd for $\mathrm{C}_{44} \mathrm{H}_{40} \mathrm{Fe}_{2} \mathrm{~N}_{2} \mathrm{O}_{2}[\mathrm{M}+\mathrm{H}]^{+}$741.1861, found 741.1840.

Ferrosalen (-)-4. Following the procedure for the preparation of (-)-2, (-)$11(359 \mathrm{mg}, 1.27 \mathrm{mmol})$ and $(+)-\mathbf{1 3}(108 \mathrm{mg}, 0.508 \mathrm{mmol})$ in $\mathrm{MeOH}(15 \mathrm{~mL})$ were stirred at $\mathrm{rt}$ overnight. The product was purified with flash column chromatography $\left(\mathrm{SiO}_{2}\right.$, hexanes/Et $\left.2 \mathrm{O} / \mathrm{MeOH} 1: 1: 0.03\right)$, and (-)-4 was obtained as a red foam (300 mg, $0.405 \mathrm{mmol}, 80 \%): \mathrm{R}_{f}=0.25\left(\mathrm{SiO}_{2}\right.$, hexanes $/ \mathrm{Et}_{2} \mathrm{O} / \mathrm{MeOH}$ $1: 1: 0.03) ;[\alpha]^{21}{ }_{\mathrm{D}}=-541.3^{\circ}\left(c=0.009, \mathrm{CH}_{2} \mathrm{Cl}_{2}\right) ;{ }^{1} \mathrm{H} \mathrm{NMR}\left(\mathrm{CDCl}_{3}\right) \delta 10.32(\mathrm{br} \mathrm{s}$, 2H), 7.22-6.97 (m, 10H), $6.58(\mathrm{~s}, 1 \mathrm{H}), 6.55(\mathrm{~s}, 1 \mathrm{H}), 4.71(\mathrm{br} \mathrm{s}, 2 \mathrm{H}), 4.33(\mathrm{t}, J=2.4$ Hz, 2H), 4.21 (br s, 2H), 4.14 (s, 1H), 4.13 (s, 1H), 4.09 (s, 10H), 2.85-2.72 (m, 2H), 2.26-2.09 (m, 4H), 1.92-1.79 (m, 2H); ${ }^{13} \mathrm{C} \mathrm{NMR}\left(\mathrm{CDCl}_{3}\right) \delta$ 193.1, 148.3, $138.1,128.4,127.6,127.0,102.5,91.7,78.8,70.7,69.6,69.5,69.3,68.7,63.7$, 28.3, 23.4; HRMS (ESI) $\mathrm{m} / z$ calcd for $\mathrm{C}_{44} \mathrm{H}_{40} \mathrm{Fe}_{2} \mathrm{~N}_{2} \mathrm{O}_{2}[\mathrm{M}+\mathrm{H}]^{+}$741.1846, found 741.1846.

Ferrosalen $(+)-5$. Following the procedure for the preparation of (-)-2, $(+)-$ $14(107 \mathrm{mg}, 0.382 \mathrm{mmol})$ and $(+)-\mathbf{1 3}(36.9 \mathrm{mg}, 0.174 \mathrm{mmol})$ in THF $(5 \mathrm{~mL})$ were stirred at $\mathrm{rt}$ for $10 \mathrm{~h}$. The product was purified with flash column chromatography $\left(\mathrm{SiO}_{2}\right.$, hexanes/EtOAc $\left.2: 3\right)$, and (+)-5 was obtained as a red foam (53 mg, 0.072 mmol, $76 \%$; recovered $54 \mathrm{mg}$ of ferrocenyl aldehyde): $\mathrm{R}_{f}=0.20\left(\mathrm{SiO}_{2}\right.$, hexanes/EtOAc $2: 3) ;[\alpha]^{21}{ }_{\mathrm{D}}=+2380^{\circ}\left(c=0.002, \mathrm{CH}_{2} \mathrm{Cl}_{2}\right) ;{ }^{1} \mathrm{H}$ NMR $\left(\mathrm{CDCl}_{3}\right) \delta$ 
$7.41(\mathrm{~s}, 1 \mathrm{H}), 7.38(\mathrm{~s}, 1 \mathrm{H}), 7.23-7.08(\mathrm{~m}, 10 \mathrm{H}), 6.28(\mathrm{~d}, J=8.8 \mathrm{~Hz}, 2 \mathrm{H}), 6.24(\mathrm{~d}, J$ $=8.8 \mathrm{~Hz}, 2 \mathrm{H}), 5.11(\mathrm{br} \mathrm{s}, 2 \mathrm{H}), 4.65(\mathrm{br} \mathrm{s}, 2 \mathrm{H}), 4.61(\mathrm{br} \mathrm{s}, 1 \mathrm{H}), 4.60(\mathrm{br} \mathrm{s}, 1 \mathrm{H}), 4.34$ $(\mathrm{t}, J=2.4 \mathrm{~Hz}, 2 \mathrm{H}), 3.98($ br s, $10 \mathrm{H}) ;{ }^{13} \mathrm{C} \mathrm{NMR}\left(\mathrm{CDCl}_{3}\right) \delta 191.7,154.7,136.8$, $129.1,128.6,127.5,126.3,113.8,108.0,89.4,78.1,71.2,70.9,70.5,66.6,64.5$ HRMS (ESI) $m / z$ calcd for $\mathrm{C}_{44} \mathrm{H}_{36} \mathrm{Fe}_{2} \mathrm{~N}_{2} \mathrm{O}_{2}[\mathrm{M}]^{+}$736.1470, found 736.1455 .

Ferrosalen (-)-6. Following the procedure for the preparation of (-)-2, (-)$14(96 \mathrm{mg}, 0.343 \mathrm{mmol})$ and $(+)-\mathbf{1 3}(33.1 \mathrm{mg}, 0.156 \mathrm{mmol})$ in THF $(5 \mathrm{~mL})$ were stirred at $\mathrm{rt}$ for $10 \mathrm{~h}$. The product was purified with flash column chromatography $\left(\mathrm{SiO}_{2}\right.$, hexanes/ $\left.\mathrm{Et}_{2} \mathrm{O} / \mathrm{MeOH} 1: 1: 0.03\right)$, and (-)-6 was obtained as a red foam (53 $\mathrm{mg}, 0.072 \mathrm{mmol}, 72 \%$; $40 \mathrm{mg}(-)-14$ was recovered): $\mathrm{R}_{f}=0.25\left(\mathrm{SiO}_{2}\right.$, hexanes/Et $\left.{ }_{2} \mathrm{O} / \mathrm{MeOH} 1: 1: 0.03\right) ;[\alpha]^{21}=-2635^{\circ}\left(c=0.003, \mathrm{CH}_{2} \mathrm{Cl}_{2}\right) ;{ }^{1} \mathrm{H}$ NMR $\left(\mathrm{CDCl}_{3}\right) \delta 7.30-7.09(\mathrm{~m}, 12 \mathrm{H}), 6.12(\mathrm{~d}, J=9.2 \mathrm{~Hz}, 2 \mathrm{H}), 6.07(\mathrm{~d}, J=8.8 \mathrm{~Hz}, 2 \mathrm{H})$, 5.09 (br s, 2H), $4.62($ br s, 2H), $4.54($ br s, $1 \mathrm{H}), 4.52($ br s, $1 \mathrm{H}), 4.32(\mathrm{t}, J=2.4 \mathrm{~Hz}$ 2H), $3.86(\mathrm{~s}, 10 \mathrm{H}) ;{ }^{13} \mathrm{C}$ NMR $\left(\mathrm{C}_{6} \mathrm{D}_{6}\right) \delta 191.4,154.3,136.5,128.8,128.3,127.2$, 125.9, 113.4, 108.0, 89.2, 77.8, 70.8, 70.0, 66.2, 64.1; HRMS (ESI) $\mathrm{m} / z$ calcd for $\mathrm{C}_{44} \mathrm{H}_{36} \mathrm{Fe}_{2} \mathrm{~N}_{2} \mathrm{O}_{2}[\mathrm{M}]^{+}$736.1470, found 736.1463.

Ferrosalen (+)-7. Following the procedure for the preparation of $(-)-2,(+)-$ $14(275 \mathrm{mg}, 0.983 \mathrm{mmol})$ and (-)-15 (56 mg, $0.492 \mathrm{mmol})$ in $\mathrm{MeOH}(10 \mathrm{~mL})$ were stirred at $\mathrm{rt}$ overnight. The product was purified with flash column chromatography $\left(\mathrm{SiO}_{2}\right.$, hexanes/Et $\left.{ }_{2} \mathrm{O} / \mathrm{MeOH} / \mathrm{Et}_{3} \mathrm{~N} 10: 10: 1: 1\right)$, and (+)-7 was 
obtained as a red foam $(252 \mathrm{mg}, 0.394 \mathrm{mmol}, 80 \%): \mathrm{R}_{f}=0.20-0.25\left(\mathrm{SiO}_{2}\right.$, hexanes $\left./ \mathrm{Et}_{2} \mathrm{O} / \mathrm{MeOH} / \mathrm{Et}_{3} \mathrm{~N} 10: 10: 1: 1\right) ;[\alpha]^{21}{ }_{\mathrm{D}}=+5605^{\circ}\left(c=0.005, \mathrm{CH}_{2} \mathrm{Cl}_{2}\right) ;{ }^{1} \mathrm{H}$ $\operatorname{NMR}\left(\mathrm{CDCl}_{3}\right) \delta 7.25(\mathrm{~d}, J=11.2 \mathrm{~Hz}, 1 \mathrm{H}), 7.09(\mathrm{~d}, J=12.0 \mathrm{~Hz}, 1 \mathrm{H}), 6.22(\mathrm{~d}, J=$ $9.2 \mathrm{~Hz}, 1 \mathrm{H}), 6.18(\mathrm{~d}, J=9.2 \mathrm{~Hz}, 1 \mathrm{H}), 6.09(\mathrm{~d}, J=9.2 \mathrm{~Hz}, 1 \mathrm{H}), 6.01(\mathrm{~d}, J=9.2 \mathrm{~Hz}$, 1H), 5.07 (br s, 1H), 5.04 (br s, 1H), 4.63 (br s, 1H), 4.62 (br s, 1H), 4.32 (t, $J=$ $2.4 \mathrm{~Hz}, 1 \mathrm{H}), 4.30(\mathrm{t}, J=2.4 \mathrm{~Hz}, 1 \mathrm{H}), 3.92(\mathrm{~s}, 5 \mathrm{H}), 3.90(\mathrm{~s}, 5 \mathrm{H}), 3.14-2.94(\mathrm{~m}, 2 \mathrm{H})$, 2.31-2.10 (m, 2H), 1.96-1.76 (m, 2H), 1.66-1.28 (m, 4H); ${ }^{13} \mathrm{C} \mathrm{NMR}\left(\mathrm{CDCl}_{3}\right) \delta$ $191.5,191.4,155.2,126.5,126.4,113.3,113.1,107.3,107.0,89.7,89.5,78.3$, $71.1,70.9,70.3,70.2,66.4,66.2,64.9,64.6,64.3,64.1,32.6,32.3,24.7,24.5$; HRMS (ESI) $m / z$ calcd for $\mathrm{C}_{36} \mathrm{H}_{34} \mathrm{Fe}_{2} \mathrm{~N}_{2} \mathrm{O}_{2}[\mathrm{M}]^{+}$638.1314, found 638.1308.

Ferrosalen (-)-8. Following the procedure for the preparation of (-)-2, (-)14 (404 mg, $1.443 \mathrm{mmol})$ and (-)-15 (82.4 mg, $0.722 \mathrm{mmol})$ in $\mathrm{MeOH}(15 \mathrm{~mL})$ were stirred at $\mathrm{rt}$ overnight. The product was purified with flash column chromatography $\left(\mathrm{SiO}_{2}\right.$, hexanes/ $\left.\mathrm{Et}_{2} \mathrm{O} / \mathrm{MeOH} 1: 1: 0.03\right)$, and (-)-8 was obtained as a red foam (302 mg, $0.473 \mathrm{mmol}, 65 \%): \mathrm{R}_{f}=0.25\left(\mathrm{SiO}_{2}\right.$, hexanes/ $\mathrm{Et}_{2} \mathrm{O} / \mathrm{MeOH}$ $1: 1: 0.03) ;[\alpha]^{21}{ }_{\mathrm{D}}=-3861^{\circ}\left(c=0.007, \mathrm{CH}_{2} \mathrm{Cl}_{2}\right) ;{ }^{1} \mathrm{H} \mathrm{NMR}\left(\mathrm{CDCl}_{3}\right) \delta 7.23(\mathrm{~d}, J=$ $12.0 \mathrm{~Hz}, 1 \mathrm{H}), 7.06(\mathrm{~d}, J=12.0 \mathrm{~Hz}, 1 \mathrm{H}), 6.20(\mathrm{~d}, J=9.6 \mathrm{~Hz}, 1 \mathrm{H}), 6.15(\mathrm{~d}, J=9.2$ Hz, 1H), $6.07(\mathrm{~d}, J=9.2 \mathrm{~Hz}, 1 \mathrm{H}), 5.98(\mathrm{~d}, J=8.8 \mathrm{~Hz}, 1 \mathrm{H}), 5.04($ br s, $1 \mathrm{H}), 5.01$ (br s, 1H), $4.60($ br s, $1 \mathrm{H}), 4.58($ br s, $1 \mathrm{H}), 4.28(\mathrm{t}, J=2.0 \mathrm{~Hz}, 1 \mathrm{H}), 4.26(\mathrm{t}, J=1.6$ $\mathrm{Hz}, 1 \mathrm{H}), 3.89(\mathrm{~s}, 5 \mathrm{H}), 3.85(\mathrm{~s}, 5 \mathrm{H}), 3.09-2.92(\mathrm{~m}, 2 \mathrm{H}), 2.24-1.20(\mathrm{~m}, 8 \mathrm{H}) ;{ }^{13} \mathrm{C}$ 
$\operatorname{NMR}\left(\mathrm{CDCl}_{3}\right) \delta 191.1,154.9,126.2,126.1,112.9,112.7,106.9,106.6,89.4,77.9$, $70.7,70.5,69.9,69.8,66.0,65.9,64.4,64.1,63.9,63.7,32.2,32.0,24.2,24.1$; HRMS (ESI) $m / z$ calcd for $[\mathrm{M}]^{+} 638.1314$, found 638.1302 .

Ferrosalen-Cu(II) complex (-)-12. A two-neck round-bottom flask was charged with (-)-2 (33.6 mg, $0.057 \mathrm{mmol})$ and the solvent mixture $\mathrm{EtOH} / \mathrm{H}_{2} \mathrm{O}(9$ : 1, $3.3 \mathrm{~mL})$. Cupric acetate $\left(11.44 \mathrm{mg}, 0.057 \mathrm{mmol}\right.$ ) was added under positive $\mathrm{N}_{2}$ pressure. After the mixture was stirred at $\mathrm{rt}$ for $2 \mathrm{~h}$, volatile components were removed under reduced pressure. The deep red mixture was suspended in EtOH (2 $\mathrm{mL}$ ) and poured onto a pad of Celite. The solid on the Celite was further washed with cold EtOH $(1 \mathrm{~mL} \times 2)$. Then, to the filter cake was added $\mathrm{CH}_{2} \mathrm{Cl}_{2}(3 \mathrm{~mL})$. The red solid was dissolved and was filtered into a clean round-bottom flask. The Celite was further washed with $\mathrm{CH}_{2} \mathrm{Cl}_{2}(3 \mathrm{~mL} \times 2)$. The combined red filtrate was evaporated under reduced pressure, giving compound (-)-12 as a red crystalline solid (28.0 mg, 75\%): $[\alpha]^{22}=-1564.7^{\circ}\left(c=0.002, \mathrm{CH}_{2} \mathrm{Cl}_{2}\right)$; HRMS (ESI) $\mathrm{m} / \mathrm{z}$ calcd for $\mathrm{C}_{32} \mathrm{H}_{30} \mathrm{CuFe}_{2} \mathrm{~N}_{2} \mathrm{O}_{2}[\mathrm{M}]^{+}$649.0302, found 649.0275. This compound is paramagnetic and was not characterized with NMR. The structure of this complex was further confirmed with single-crystal X-ray diffraction analysis. A crystal suitable for the analysis was grown by slowly diffusing pentane into a solution of (-)-12 in $\mathrm{CH}_{2} \mathrm{Cl}_{2}$ at rt. Crystal data collection and processing parameters are given in Table 1. All calculations were performed using the SHELXL-97 program suite ${ }^{86}$ 
under the GUI WinGX. ${ }^{87}$ The structures were solved by direct methods and successive interpretation of the difference Fourier maps, followed by full-matrix least-squares refinement. All non-hydrogen atoms were refined anisotropically. The contribution of the hydrogen atoms, in their calculated positions, was included in the refinement using a riding model. Upon convergence, the final Fourier difference map of the X-ray structures showed no significant peaks. All details of the structure solution and refinements are given in the Supporting Information (CIF data). As is evident in a packing diagram supplied as Supplementary material, the molecules are arranged so that the cyclopentadienyl ligands are involved in $\pi$ $\pi$ stacking with opposite sides of the salen moiety. These packing interactions may be responsible for the slight twist away from planarity of the salen ligand. Full listings of atomic coordinates, bond lengths and angles, and displacement parameters for all the structures have been deposited at the Cambridge Crystallographic Data Centre (deposition number: CCDC 816340). 


\section{Table 3.1}

Crystal Data, Data Collection, and Structure Refinement for (-)-12

\begin{tabular}{|c|c|}
\hline Empirical formula & $\mathrm{C}_{32} \mathrm{H}_{30} \mathrm{Cu} \mathrm{Fe} \mathrm{N}_{2} \mathrm{O}_{2}$ \\
\hline$M_{r}$ & 649.83 \\
\hline Crystal Syst & trigonal \\
\hline Space group & $\mathrm{P} 3{ }_{1} 2_{1}$ (No.152) \\
\hline$a, b, c / \AA$ & $11.314(3), 11.314(3), 17.897(4)$ \\
\hline$V / A^{3}$ & $1984.0(8)$ \\
\hline$\mu / m^{-1}$ & 1.913 \\
\hline$D_{\text {calcd }} / \mathrm{gcm}^{-3}$ & 1.632 \\
\hline crystal size / mm & $0.15 \times 0.25 \times 0.40$ \\
\hline$Z$ & 3 \\
\hline$T / \mathrm{K}$ & 291 \\
\hline $2 \theta_{\max } / \operatorname{deg}$ & 50 \\
\hline total, unique no. of data; $R_{\text {int }}$ & 1471,$1353 ; 0.067$ \\
\hline no. params / restraints & $177 / 0$ \\
\hline $\mathrm{R}_{1}(\mathrm{I} \geq 2 \sigma(\mathrm{I})), \mathrm{wR}_{2}, \mathrm{~S}^{\mathrm{a}}$ & $0.0554,0.1175,1.08$ \\
\hline $\begin{array}{c}w= \\
1 /\left[\sigma^{2}\left(F o^{2}\right)+(0.0384 P)^{2}+1.9441 P\right]\end{array}$ & where $\mathrm{P}=\left(\mathrm{Fo}^{2}+2 \mathrm{Fc}^{2}\right) / 3$ \\
\hline min. / max. resd. Dens / e/Ang ${ }^{3}$ & $-0.35,0.42$ \\
\hline
\end{tabular}


Ferrocenyl Ketocarboxylic Acid 17a. An oven-dried two-neck roundbottom flask was flushed with argon. $\mathrm{AlCl}_{3}(3.195 \mathrm{~g}, 23.96 \mathrm{mmol})$ and $\mathrm{CH}_{2} \mathrm{Cl}_{2}(30$ $\mathrm{mL})$ were added. Compound $\mathbf{1 6 a}{ }^{83}(5.113 \mathrm{~g}, 19.97 \mathrm{mmol})$ in $\mathrm{CH}_{2} \mathrm{Cl}_{2}(50 \mathrm{~mL})$ was then added dropwise via a cannula. The solution turned dark brown. After addition, succinic anhydride $(2.398 \mathrm{~g}, 23.96 \mathrm{mmol})$ was added under positive argon pressure. The mixture was stirred at $\mathrm{rt}$ overnight. The reaction flask was cooled with an ice bath. Ice water $(80 \mathrm{~mL})$ was added to the mixture slowly over about 5 min. The contents were transferred to a separatory funnel. The organic and aqueous phases were separated. The organic phase was washed with water $(50 \mathrm{~mL}$ $\times 3$ ), dried over anhydrous $\mathrm{Na}_{2} \mathrm{SO}_{4}$, and filtered. Solvents were removed under reduced pressure. The residue was purified with flash column chromatography $\left(\mathrm{SiO}_{2}\right.$, hexanes $\left./ \mathrm{Et}_{2} \mathrm{O} / \mathrm{CH}_{2} \mathrm{Cl}_{2} 2: 1: 1\right)$, giving $17 \mathrm{a}$ as a red solid $(5.23 \mathrm{~g}, 74 \%): \mathrm{R}_{f}$ $=0.20\left(\mathrm{SiO}_{2}\right.$, hexanes $\left./ \mathrm{Et}_{2} \mathrm{O} / \mathrm{CH}_{2} \mathrm{Cl}_{2} 2: 1: 1\right) ; \mathrm{mp} 135{ }^{\circ} \mathrm{C}(\mathrm{dec}) ;{ }^{1} \mathrm{H} \mathrm{NMR}\left(\mathrm{CDCl}_{3}\right)$ $\delta 4.24$ (br s, 1H), 3.99 (br s, 2H), 2.90 (br s, 2H), 2.61 (br s, 2H), $1.76(\mathrm{~s}, 15 \mathrm{H})$; ${ }^{13} \mathrm{C}$ NMR $\left(\mathrm{CDCl}_{3}\right) \delta 202.7,178.6,81.5,80.0,76.5,71.7,35.4,29.5,10.6$; HRMS (ESI) $m / z$ calcd for $\mathrm{C}_{19} \mathrm{H}_{24} \mathrm{FeO}_{3}[\mathrm{M}]^{+} 356.1080$, found 356.1071 .

Ferrocenyl Carboxylic Acid 18a. To a two-neck round-bottom flask containing 17a $(3.80 \mathrm{~g}, 10.67 \mathrm{mmol})$ and toluene $(100 \mathrm{~mL})$ was added $\mathrm{Zn}$ dust (20.90 g, $319.6 \mathrm{mmol})$ and $\mathrm{HgCl}_{2}$ (1.94 g, $7.143 \mathrm{mmol}$ ) sequentially under positive argon pressure. The mixture was stirred vigorously while $\mathrm{H}_{2} \mathrm{O}(100 \mathrm{~mL})$ and then 
$\mathrm{HCl}(12.1 \mathrm{M}, 100 \mathrm{~mL})$ were added via syringe. After addition, the mixture was heated to reflux for about $3 \mathrm{~h}$. TLC indicated that 17a was completely consumed. The reaction mixture was cooled to rt. Some solids were formed, which were removed by filtration. The mother liquor was transferred into a separation funnel. The aqueous phase was removed. The organic phase was washed with brine ( 80 $\mathrm{mL} \times 2$ ), dried over anhydrous $\mathrm{Na}_{2} \mathrm{SO}_{4}$, and filtered. Solvents were evaporated under reduced pressure, giving pure 18a as a red solid (3.47 g, 95\%): $\mathrm{R}_{f}=0.45$ (short $\mathrm{SiO}_{2}$ column, hexanes $/ \mathrm{Et}_{2} \mathrm{O} / \mathrm{CH}_{2} \mathrm{Cl}_{2} 2: 1: 1$ ); mp 61-64 ${ }^{\circ} \mathrm{C} ;{ }^{1} \mathrm{H}$ NMR $\left(\mathrm{CDCl}_{3}\right) \delta 3.69$ (br s, 2H), 3.59 (br s, 2H), 2.40 (t, $\left.J=7.2 \mathrm{~Hz}, 2 \mathrm{H}\right), 2.34$ (t, $J=7.2$ $\mathrm{Hz}, 2 \mathrm{H}), 1.95(\mathrm{~s}, 15 \mathrm{H}), 1.87-1.80(\mathrm{~m}, 2 \mathrm{H}) ;{ }^{13} \mathrm{C} \mathrm{NMR}\left(\mathrm{CDCl}_{3}\right) \delta 180.2,86.7,79.8$, 71.6, 70.8, 33.5, 27.0, 26.5, 10.9; HRMS (ESI) $\mathrm{m} / z$ calcd for $\mathrm{C}_{19} \mathrm{H}_{26} \mathrm{FeO}_{2}[\mathrm{M}]^{+}$ 342.1288, found 342.1276.

Racemic ferrocenocyclohexanone $( \pm)-19 a$. A two-neck round-bottom flask was charged with 18a $(3.470 \mathrm{~g}, 10.14 \mathrm{mmol})$ and $\mathrm{CCl}_{4}(100 \mathrm{~mL})$, and wrapped with aluminum foil. The solution was bubbled with argon for $10 \mathrm{~min}$. After the solution was cooled to $0{ }^{\circ} \mathrm{C}$, trifluoroacetic anhydride $(5.60 \mathrm{~mL}, 40.30$ mmol) was added via a syringe. The mixture was stirred on an ice bath and allowed to warm to rt gradually. TLC indicated that the reaction was complete in 3 h. The contents were transferred into a separatory funnel and partitioned between $10 \% \mathrm{NaOH}(120 \mathrm{~mL})$ and $\mathrm{CH}_{2} \mathrm{Cl}_{2}(80 \mathrm{~mL})$. The organic phase was washed with 
brine $(100 \mathrm{~mL} \times 2)$, dried over anhydrous $\mathrm{Na}_{2} \mathrm{SO}_{4}$, and filtered. Volatiles were removed under reduced pressure. Purification with flash column chromatography $\left(\mathrm{SiO}_{2}\right.$, hexanes/Et $\left.2 \mathrm{O} 2: 1\right)$ gave $( \pm)-19 \mathrm{a}$ as a red solid $(2.44 \mathrm{~g}, 74 \%): \mathrm{R}_{f}=0.30$ $\left(\mathrm{SiO}_{2}\right.$, hexanes/Et $\left.\mathrm{E}_{2} \mathrm{O} 1: 1\right) ; \mathrm{mp} 102{ }^{\circ} \mathrm{C} ;{ }^{1} \mathrm{H} \mathrm{NMR}\left(\mathrm{C}_{6} \mathrm{D}_{6}\right) \delta 4.28-4.26(\mathrm{~m}, 1 \mathrm{H}), 3.63$ $(\mathrm{t}, J=2.4 \mathrm{~Hz}, 1 \mathrm{H}), 3.58-3.56(\mathrm{~m}, 1 \mathrm{H}), 2.28-2.20(\mathrm{~m}, 1 \mathrm{H}), 2.17-2.09(\mathrm{~m}, 1 \mathrm{H})$, 2.04-1.77 (m, 4H), $1.56(\mathrm{~s}, 15 \mathrm{H}) ;{ }^{13} \mathrm{C}$ NMR $\left(\mathrm{C}_{6} \mathrm{D}_{6}\right) \delta 201.2,90.6,80.6,77.1,75.6$, 73.7, 69.7, 39.5, 23.9, 21.7, 10.3; HRMS (ESI) $\mathrm{m} / z$ calcd for $\mathrm{C}_{19} \mathrm{H}_{24} \mathrm{FeO}[\mathrm{M}]^{+}$ 324.1182, found 324.1172 .

Enantiopure Ferrocenocyclohexanone $(+)-19 a$. To a solution of $(+)-(S)-$ $N, S$-dimethyl-S-phenylsulfoximine $(\mathbf{2 0}, 2.80 \mathrm{~g}, 16.5 \mathrm{mmol})$ in dry THF $(40 \mathrm{~mL})$ at $0{ }^{\circ} \mathrm{C}$ was added a solution of $n$-butyllithum in hexane $(2.0 \mathrm{M}, 8.30 \mathrm{~mL})$. After it was stirred for $15 \mathrm{~min}$ at this temperature, the mixture was cooled to $-78{ }^{\circ} \mathrm{C}$. The racemic $( \pm)-19 a(2.44 \mathrm{~g}, 7.53 \mathrm{mmol})$ in dry THF $(60 \mathrm{~mL})$ was added via cannula dropwise over $10 \mathrm{~min}$. The mixture was stirred for an additional $3 \mathrm{~h}$ while being warmed to $-20{ }^{\circ} \mathrm{C}$ gradually. Saturated ammonium chloride $(50 \mathrm{~mL})$ was then added. The mixture was diluted with water $(50 \mathrm{~mL})$ and extracted with ether $(50$ $\mathrm{mL} \times 3)$. The ether phase was washed with brine $(100 \mathrm{~mL})$, dried over anhydrous $\mathrm{Na}_{2} \mathrm{SO}_{4}$, and concentrated to dryness under reduced pressure at rt. The two diastereoisomers 21xa and 21ya were not very stable; they lose their chiral auxiliary slowly even at rt. A quick separation with flash column chromatography 
$\left(\mathrm{SiO}_{2}\right.$, hexanes/ $\left.\mathrm{Et}_{2} \mathrm{O} 2: 1\right)$ gave pure $21 \mathbf{x a}$ as indicated by TLC $\left(\mathrm{R}_{f}=0.55, \mathrm{SiO}_{2}\right.$, hexanes/Et $\left.{ }_{2} \mathrm{O} 1: 1\right)$. However, 21ya was found to be contaminated with $( \pm)-19 a$. Because 21ya and ( \pm )-19a have similar $\mathrm{R}_{f}$ values $\left(\mathrm{R}_{f}=0.45, \mathrm{SiO}_{2}\right.$, hexanes/ $\mathrm{Et}_{2} \mathrm{O} 1$ : 1), attempts to separate them were not successful. The pure 21xa was dissolved in dry toluene $(30 \mathrm{~mL})$, and the solutions were heated to reflux for $12 \mathrm{~h}$. After the solution was cooled to rt, volatiles were removed. The residue was purified with flash chromatography $\left(\mathrm{SiO}_{2}\right.$, hexanes/Et $\left.2 \mathrm{O} 2: 1\right)$. Enantiopure $(+)-19 a$ was obtained as a red solid (1.11 g, 91\%): $\mathrm{R}_{f}=0.45\left(\mathrm{SiO}_{2}\right.$, hexanes/Et $\left.2 \mathrm{O} 1: 1\right) ; \mathrm{mp} 110$ ${ }^{\circ} \mathrm{C} ;[\alpha]^{23}{ }_{\mathrm{D}}=+532^{\circ}\left(c=0.018, \mathrm{CH}_{2} \mathrm{Cl}_{2}\right) ;{ }^{1} \mathrm{H}$ NMR $\left(\mathrm{C}_{6} \mathrm{D}_{6}\right) \delta 4.32($ br s, $1 \mathrm{H}), 3.63(\mathrm{t}$, $J=2.4 \mathrm{~Hz}, 1 \mathrm{H}), 3.56($ br s, $1 \mathrm{H}), 2.30-2.22(\mathrm{~m}, 1 \mathrm{H}), 2.16-2.08(\mathrm{~m}, 1 \mathrm{H}), 2.03-1.76$ $(\mathrm{m}, 4 \mathrm{H}), 1.57(\mathrm{~s}, 15 \mathrm{H}) ;{ }^{13} \mathrm{C}$ NMR $\left(\mathrm{C}_{6} \mathrm{D}_{6}\right) \delta 201.2,90.6,80.6,77.2,75.5,73.7,69.8$, 39.5, 23.9, 21.7, 10.3; HRMS (ESI) $\mathrm{m} / z$ calcd for $\mathrm{C}_{19} \mathrm{H}_{24} \mathrm{FeO}[\mathrm{M}]^{+}$324.1182, found 324.1173. The impure 21ya was also heated in toluene to give (-)-19a, which was contaminated with (+)-19a (totally $1.20 \mathrm{~g}$ ). The chiral auxiliary 20 was recovered without losing any optical purity. The combined yield of $\mathbf{2 0}$ from $\mathbf{2 1 x a}$ and $21 \mathrm{ya}$ was $89 \%(2.50 \mathrm{~g})$.

Formylated Ferrocenocyclohexanone $(+)$-22a. In a two-neck roundbottom flask was charged (+)-19a $(124.0 \mathrm{mg}, 0.380 \mathrm{mmol})$ and $\mathrm{NaH}(153.0 \mathrm{mg}$, $3.82 \mathrm{mmol})$ under nitrogen. THF $(15 \mathrm{~mL})$ and ethyl formate $(0.308 \mathrm{~mL}, 3.82$ mmol) were added via syringe sequentially. The mixture was heated to reflux for 
$3 \mathrm{~h}$. TLC indicated that the reaction was complete. After the mixture was cooled to $\mathrm{rt}$, water $(30 \mathrm{~mL})$ was added, and the contents were transferred into a separatory funnel. The mixture was extracted with ether $(15 \mathrm{~mL} \times 3)$. The combined ether extracts were washed with brine $(30 \mathrm{~mL})$, dried over anhydrous $\mathrm{Na}_{2} \mathrm{SO}_{4}$, and concentrated under reduced pressure. Purification with flash column chromatography $\left(\mathrm{SiO}_{2}\right.$, hexanes $\left./ \mathrm{Et}_{2} \mathrm{O} 4: 1\right)$ gave $(+)-22 \mathrm{a}$ as a red solid $(125.0 \mathrm{mg}$, 93\%): $\mathrm{R}_{f}=0.60\left(\mathrm{SiO}_{2}\right.$, hexanes $\left./ \mathrm{Et}_{2} \mathrm{O} 1: 1\right) ; \mathrm{mp} 130{ }^{\circ} \mathrm{C}(\mathrm{dec}) ;[\alpha]^{23}{ }_{\mathrm{D}}=+659^{\circ}(c=$ 0.018, $\left.\mathrm{CH}_{2} \mathrm{Cl}_{2}\right) ;{ }^{1} \mathrm{H}$ NMR $\left(\mathrm{C}_{6} \mathrm{D}_{6}\right) \delta 7.21(\mathrm{br} \mathrm{s}, 1 \mathrm{H}), 4.29(\mathrm{~m}, 1 \mathrm{H}), 3.72(\mathrm{t}, J=2.8 \mathrm{~Hz}$, 1H), $3.58(\mathrm{~m}, 1 \mathrm{H}), 2.33-2.23(\mathrm{~m}, 1 \mathrm{H}), 2.12-1.92(\mathrm{~m}, 4 \mathrm{H}), 1.54(\mathrm{~s}, 15 \mathrm{H}) ;{ }^{13} \mathrm{C} \mathrm{NMR}$ $\left(\mathrm{C}_{6} \mathrm{D}_{6}\right) \delta 195.4,164.6,109.2,90.4,81.2,76.4,74.2,68.9,24.6,20.9,10.3$; HRMS (ESI) $m / z$ calcd for $\mathrm{C}_{20} \mathrm{H}_{24} \mathrm{FeO}_{2}[\mathrm{M}]^{+}$352.1131, found 352.1117.

Ferrosalen (+)-9. Following the procedure for the preparation of $(-)-\mathbf{2},(+)-$ 22a $(122.0 \mathrm{mg}, 0.345 \mathrm{mmol})$ and 1,2 -ethanediamine $(11.5 \mu \mathrm{L}, 0.172 \mathrm{mmol})$ in $\mathrm{MeOH}(5 \mathrm{~mL})$ were stirred at $50{ }^{\circ} \mathrm{C}$ for $2 \mathrm{~h}$. The product was purified with flash column chromatography $\left(\mathrm{SiO}_{2}\right.$, hexanes/Et $\left.{ }_{2} \mathrm{O} / \mathrm{MeOH} 1: 1: 0.08\right)$, and (+)-9 was obtained as a red solid (101 mg, 80\%): $\mathrm{R}_{f}=0.35\left(\mathrm{SiO}_{2}\right.$, hexanes/Et $\mathrm{Et}_{2} \mathrm{O} / \mathrm{MeOH} 1: 1$ : $7.5 \%) ; \mathrm{mp} 82^{\circ} \mathrm{C}(\mathrm{dec}) ;[\alpha]^{23}{ }_{\mathrm{D}}=+120^{\circ}\left(c=0.015, \mathrm{CH}_{2} \mathrm{Cl}_{2}\right) ;{ }^{1} \mathrm{H} \mathrm{NMR}\left(\mathrm{C}_{6} \mathrm{D}_{6}\right) \delta 9.72$ (br s, 2H), $6.12(\mathrm{~s}, 1 \mathrm{H}), 6.09$ (s, 1H), $4.50($ br s, 2H), $3.70(\mathrm{t}, J=2.4 \mathrm{~Hz}, 2 \mathrm{H}), 3.57$ (br s, 2H), 2.70-2.57 (m, 2H), 2.50-2.11 (m, 10H), $1.71(\mathrm{~s}, 30 \mathrm{H}) ;{ }^{13} \mathrm{C}$ NMR $\left(\mathrm{C}_{6} \mathrm{D}_{6}\right)$ 
$\delta 192.3,148.9,102.3,89.9,80.5,79.8,74.7,72.6,69.0,49.9,28.5,22.0,10.5$;

HRMS (ESI) $m / z$ calcd for $\mathrm{C}_{42} \mathrm{H}_{52} \mathrm{Fe}_{2} \mathrm{~N}_{2} \mathrm{O}_{2}[\mathrm{M}]^{+} 728.2733$, found 728.2730 .

Ferrocene 16b. This compound was synthesized using a modified literature procedure. ${ }^{84}$ To a solution of 1-bromopentaphenylcyclopentadiene (132 mg, 0.25 mmol) in benzene $(5 \mathrm{~mL})$ was added $\mathrm{Fe}(\mathrm{CO})_{5}(59.0 \mathrm{mg}, 0.30 \mathrm{mmol})$ under nitrogen. The mixture was heated to reflux for $3 \mathrm{~h}$. After the mixture was cooled to rt, a solution of $\mathrm{CpNa}(0.263 \mathrm{~mL}$ of $2.0 \mathrm{M}$ in THF, $0.525 \mathrm{mmol})$ was added via syringe. The mixture was stirred at $\mathrm{rt}$ for $18 \mathrm{~h}$. The resulting orange mixture was filtered through Celite. The filtrate was collected, and solvents were removed under reduced pressure. The orange residue was heated to $160{ }^{\circ} \mathrm{C}$ under vacuum for $3 \mathrm{~h}$. After it was cooled to $\mathrm{rt}$, the remaining mixture was suspended in toluene and filtered through Celite. The filtrate was collected, and solvents were removed. Purification by recrystallization in hot toluene gave $\mathbf{1 6 b}$ as a red crystalline solid (115 mg, 81\%).

Ferrocenyl Ketocarboxylic Acid 17b. Following a procedure similar to that for the preparation of $\mathbf{1 7 a}$, the reaction of $\mathbf{1 6 b}(1.882 \mathrm{~g}, 3.325 \mathrm{mmol}), \mathrm{AlCl}_{3}$ (0.935 g, $7.012 \mathrm{mmol})$, and succinic anhydride $(0.332 \mathrm{~g}, 3.323 \mathrm{mmol})$ in $\mathrm{CH}_{2} \mathrm{Cl}_{2}$ at reflux temperature in $24 \mathrm{~h}$ gave $\mathbf{1 7} \mathbf{b}$ as a red foam after purification with flash column chromatography $\left(\mathrm{SiO}_{2}\right.$, hexanes/Et $\left.\mathrm{Et}_{2} \mathrm{O}: 1 ; 1.65 \mathrm{~g}, 75 \%\right): \mathrm{R}_{f}=0.15\left(\mathrm{SiO}_{2}\right.$, hexanes/Et $\left.{ }_{2} \mathrm{O} 1: 1\right) ;{ }^{1} \mathrm{H}$ NMR $\left(\mathrm{CDCl}_{3}\right) \delta$ 7.18-7.01 (m, 25H), 4.88 (br s, 2H), 4.50 
(br s, 2H), $2.80(\mathrm{t}, J=7.2 \mathrm{~Hz}, 2 \mathrm{H}), 2.39(\mathrm{t}, J=7.2 \mathrm{~Hz}, 2 \mathrm{H}) ;{ }^{13} \mathrm{C} \mathrm{NMR}\left(\mathrm{CDCl}_{3}\right) \delta$ $201.9,178.3,134.7,132.1,127.2,126.6,88.2,83.1,79.0,74.8,36.2,27.9$; HRMS (ESI) $m / z$ calcd for $\mathrm{C}_{44} \mathrm{H}_{34} \mathrm{FeO}_{3}[\mathrm{M}+\mathrm{H}]^{+}$667.1936, found 667.1948.

Ferrocenyl Carboxylic Acid 18b. Following a procedure similar to that for the preparation of $\mathbf{1 8 a}$, the reduction of $\mathbf{1 7 b}(1.65 \mathrm{~g}, 2.477 \mathrm{mmol})$ with $\mathrm{Zn}$ dust (4.860 g, $74.31 \mathrm{mmol})$ and $\mathrm{HgCl}_{2}(0.450 \mathrm{~g}, 1.657 \mathrm{mmol})$ in toluene $(20 \mathrm{~mL}), \mathrm{H}_{2} \mathrm{O}$ $(20 \mathrm{~mL})$ and $\mathrm{HCl}(12.1 \mathrm{M}, 20 \mathrm{~mL})$ at reflux temperature in $24 \mathrm{~h}$ gave $\mathbf{1 8 b}$ as a red solid after purification with flash column chromatography (short $\mathrm{SiO}_{2}$ column, hexanes/Et $2 \mathrm{O} 2: 1 ; 1.35 \mathrm{~g}, 84 \%): \mathrm{R}_{f}=0.30\left(\mathrm{SiO}_{2}\right.$, hexanes/Et $\left.2 \mathrm{O} 1: 1\right) ; \mathrm{mp} 192{ }^{\circ} \mathrm{C}$; ${ }^{1} \mathrm{H} \mathrm{NMR}\left(\mathrm{CDCl}_{3}\right) \delta$ 7.15-7.01 (m, 25H), 4.15 (br s, 2H), 4.12 (br s, 2H), 2.30-2.18 (m, 4H), 1.79-1.68 (m, 2H); ${ }^{13} \mathrm{C}$ NMR $\left(\mathrm{CDCl}_{3}\right) \delta 179.1,135.9,132.4,127.1,126.1$, 90.5, 87.6, 75.0, 74.1, 33.2, 26.7, 26.5; HRMS (ESI) $m / z$ calcd for $\mathrm{C}_{44} \mathrm{H}_{36} \mathrm{FeO}_{2}$ $[\mathrm{M}]^{+} 652.2065$, found 652.2075 . The compound may decompose slowly at $\mathrm{rt}$ and storing at $-20{ }^{\circ} \mathrm{C}$ is suggested.

Racemic Ferrocenocyclohexanone $( \pm)$-19b. Following a procedure similar to that for the preparation of $( \pm)-\mathbf{1 9 a}$, cyclization of $\mathbf{1 8 b}(424.0 \mathrm{mg}, 0.650 \mathrm{mmol})$ to give $( \pm)-19 b$ was achieved with trifluoroacetic anhydride $(1.0 \mathrm{~mL}, 7.195 \mathrm{mmol})$ in $\mathrm{CCl}_{4}(15 \mathrm{~mL})$ at $50{ }^{\circ} \mathrm{C}$ overnight. Purification with flash column chromatography $\left(\mathrm{SiO}_{2}\right.$, hexanes $\left./ \mathrm{CH}_{2} \mathrm{Cl}_{2} / \mathrm{Et}_{2} \mathrm{O} 20: 20: 1\right)$ gave the product as a red solid (375.0 mg, 91\%): $\mathrm{R}_{f}=0.30$ (hexanes $/ \mathrm{CH}_{2} \mathrm{Cl}_{2} / \mathrm{Et}_{2} \mathrm{O} 20: 20: 1$ ); mp 220 
${ }^{\circ} \mathrm{C}(\mathrm{dec}) ;{ }^{1} \mathrm{H}$ NMR $\left(\mathrm{CDCl}_{3}\right) \delta$ 7.16-6.98 (m, 25H), 4.84-4.82 (m, 1H), 4.45-4.43 (m, $1 \mathrm{H}), 4.37(\mathrm{t}, J=2.4 \mathrm{~Hz}, 1 \mathrm{H}), 2.65-2.55(\mathrm{~m}, 1 \mathrm{H}), 2.44-2.28(\mathrm{~m}, 3 \mathrm{H}), 2.02-1.94(\mathrm{~m}$, 1H), 1.77-1.64 (m, 1H); ${ }^{13} \mathrm{C} \mathrm{NMR}\left(\mathrm{CDCl}_{3}\right) \delta 203.9,134.5,132.2,127.2,126.5$, 94.4, 87.7, 78.4, 77.8, 77.2, 72.8, 39.5, 24.9, 21.8; HRMS (ESI) $\mathrm{m} / z$ calcd for $\mathrm{C}_{44} \mathrm{H}_{34} \mathrm{FeO}[\mathrm{M}]^{+}$634.1965, found 634.1959.

Enantiopure ferrocenocyclohexanone (-)-19b. Following a procedure similar to that for the resolution of $( \pm)-\mathbf{1 9 a},( \pm)-19 b(437.0 \mathrm{mg}, 0.688 \mathrm{mmol})$ was first converted to $\mathbf{2 1 x b}$ and $21 \mathbf{y b}$ using $(+)-(S)-20(349.0 \mathrm{mg}, 2.065 \mathrm{mmol})$ and $n$ butyllithum in hexane $(2.0 \mathrm{M}, 1.032 \mathrm{~mL})$ in THF. Because the two diastereoisomers $\mathbf{2 1 x b}$ and $\mathbf{2 1 y b}$ slowly lose the chiral auxiliary even at rt, they were quickly separated with flash column chromatography (short $\mathrm{SiO}_{2}$ column, hexanes $/ \mathrm{CH}_{2} \mathrm{Cl}_{2} /$ EtOAc $20: 10: 1$ ). TLC analysis indicated that $\mathbf{2 1 x b}$ was still contaminated with $( \pm)-\mathbf{1 9 b}$. Because their $\mathrm{R}_{f}$ values were very close $\left(\mathrm{R}_{f}=0.35\right.$, $\mathrm{SiO}_{2}$, hexanes/Et $t_{2} \mathrm{O} 2: 1$ ), attempts to separate them were not successful. However, the other diastereoisomer 21yb, which had an $\mathrm{R}_{f}$ value of $0.20\left(\mathrm{SiO}_{2}\right.$, hexanes $/ \mathrm{Et}_{2} \mathrm{O} 2:$ 1), was obtained in pure form. The solution of $21 \mathbf{y b}$ in dry toluene $(10 \mathrm{~mL})$ was then heated to reflux overnight. Enantiopure (-)-19b was obtained as a red solid (171 mg, $78 \%): \mathrm{R}_{f}=0.35\left(\mathrm{SiO}_{2}\right.$, hexanes $/ \mathrm{CH}_{2} \mathrm{Cl}_{2} / \mathrm{EtOAc}$ $20: 10: 1) ; \mathrm{mp} 220{ }^{\circ} \mathrm{C}(\mathrm{dec}) ;[\alpha]^{23} \mathrm{D}=-311^{\circ}\left(c=0.0095, \mathrm{CH}_{2} \mathrm{Cl}_{2}\right) ;{ }^{1} \mathrm{H}$ NMR $\left(\mathrm{CDCl}_{3}\right) \delta$ 7.17-6.96 (m, 25H), $4.83($ br s, $1 \mathrm{H}), 4.44$ (br s, 1H), 4.38 (br s, $\left.1 \mathrm{H}\right)$ 
2.66-2.55 (m, 1H), 2.45-2.28 (m, 3H), 2.02-1.93 (m, 1H), 1.79-1.64 (m, 1H); ${ }^{13} \mathrm{C}$ $\operatorname{NMR}\left(\mathrm{CDCl}_{3}\right) \delta 204.0,134.5,132.2,127.2,126.5,94.4,87.7,78.4,77.8,77.2$ 72.8, 39.5, 24.9, 21.8; HRMS (ESI) $m / z$ calcd for $\mathrm{C}_{44} \mathrm{H}_{34} \mathrm{FeO}[\mathrm{M}]^{+}$634.1965, found 634.1956 . The impure $\mathbf{2 1 x b}$ was also heated in toluene to give $(+)-\mathbf{1 9 b}$, which was contaminated with (-)-19b (total $262 \mathrm{mg}$ ). The chiral auxiliary 20 was recovered without losing any optical purity. The combined yield of $\mathbf{2 0}$ from $\mathbf{2 1 x b}$ and $21 \mathbf{y b}$ was $86 \%$ (300 $\mathrm{mg})$.

Formylated Ferrocenocyclohexanone (-)-22b. A procedure similar to that for the synthesis of (+)-22a was followed. Compound (-)-19b $171.0 \mathrm{mg}, 0.269$ $\mathrm{mmol})$, NaH (214.0 $\mathrm{mg}, 5.380 \mathrm{mmol})$, and ethyl formate $(0.434 \mathrm{~mL}, 5.380 \mathrm{mmol})$ in THF $(20 \mathrm{~mL})$ were heated to reflux overnight. After the mixture was cooled to rt, saturated $\mathrm{NH}_{4} \mathrm{Cl}(30 \mathrm{~mL})$ was added. The mixture was extracted with EtOAc $(15 \mathrm{~mL} \times 2)$. The organic phase was washed with brine $(30 \mathrm{~mL})$, dried over anhydrous $\mathrm{Na}_{2} \mathrm{SO}_{4}$, and concentrated under reduced pressure. Purification by flash column chromatography (short $\mathrm{SiO}_{2}$ column, hexanes $/ \mathrm{CH}_{2} \mathrm{Cl}_{2} / \mathrm{EtOAc} 40: 10: 1$ ) gave (-)-22b as a red solid (138.0 $\mathrm{mg}, 77 \%)$. The product may decompose slowly on silica gel. Enantiopure (-)-22b: $\mathrm{R}_{f}=0.25\left(\mathrm{SiO}_{2}\right.$, hexanes/Et $\left.2 \mathrm{O} 5: 1\right) ; \mathrm{mp} 210{ }^{\circ} \mathrm{C}$ (dec); $[\alpha]^{22}{ }_{\mathrm{D}}=-197^{\circ}\left(c=0.009, \mathrm{CH}_{2} \mathrm{Cl}_{2}\right) ;{ }^{1} \mathrm{H}$ NMR $\left(\mathrm{CDCl}_{3}\right) \delta 7.50-7.43($ br s, $1 \mathrm{H})$, 7.20-6.96 (m, 25H), $4.86(\mathrm{t}, J=2.0 \mathrm{~Hz}, 1 \mathrm{H}), 4.42($ br s, $1 \mathrm{H}), 4.41(\mathrm{br} \mathrm{s}, 1 \mathrm{H}), 2.68-$ $2.58(\mathrm{~m}, 1 \mathrm{H}), 2.44-2.24(\mathrm{~m}, 3 \mathrm{H}) ;{ }^{13} \mathrm{C} \mathrm{NMR}\left(\mathrm{CDCl}_{3}\right) \delta 194.7,165.4,134.6,132.5$, 
127.4, 126.7, 111.1, 91.4, 88.3, 78.7, 78.4, 77.7, 73.2, 25.6, 21.4; HRMS (ESI) $m / z$ calcd for $\mathrm{C}_{45} \mathrm{H}_{34} \mathrm{FeO}_{2}[\mathrm{M}]^{+}$662.1914, found 662.1904.

Ferrosalen (-)-10. Following the procedure for the preparation of (-)-2, (-)22b $(40.0 \mathrm{mg}, 0.0604 \mathrm{mmol})$ and 1,2-ethanediamine $(1.68 \mu \mathrm{L}, 0.0251 \mathrm{mmol})$ in $\mathrm{MeOH}(5 \mathrm{~mL})$ were stirred at $50{ }^{\circ} \mathrm{C}$ for $24 \mathrm{~h}$. Purification by flash column chromatography $\left(\mathrm{SiO}_{2}\right.$, hexanes/ $\left.\mathrm{Et}_{2} \mathrm{O} / \mathrm{MeOH} 1: 1: 0.02\right)$ gave (-)-10 as a red solid (23.0 mg, 68\%): $\mathrm{R}_{f}=0.10\left(\mathrm{SiO}_{2}\right.$, hexanes/Et $\left.\mathrm{Et}_{2} \mathrm{O} 1: 1\right) ; \mathrm{mp} 124-127{ }^{\circ} \mathrm{C} ;[\alpha]^{22}=-$ $69^{\circ}\left(c=0.0225, \mathrm{CH}_{2} \mathrm{Cl}_{2}\right) ;{ }^{1} \mathrm{H}$ NMR $\left(\mathrm{CDCl}_{3}\right) \delta 9.38(\mathrm{br} \mathrm{s}, 2 \mathrm{H}), 7.14-6.96(\mathrm{~m}, 50 \mathrm{H})$, $6.46(\mathrm{~s}, 1 \mathrm{H}), 6.43(\mathrm{~s}, 1 \mathrm{H}), 4.75(\mathrm{br} \mathrm{s}, 2 \mathrm{H}), 4.24(\mathrm{br} \mathrm{s}, 4 \mathrm{H}), 3.32-3.20(\mathrm{br} \mathrm{s}, 2 \mathrm{H})$ 3.14-3.00 (br s, $2 \mathrm{H}), 2.58-2.06(\mathrm{~m}, 8 \mathrm{H}) ;{ }^{13} \mathrm{C} \mathrm{NMR}\left(\mathrm{CDCl}_{3}\right) \delta 192.0,149.1,135.2$ $132.7,127.2,126.3,103.9,91.3,87.9,82.0,77.0,76.6,72.7,50.4,29.2,22.2$ HRMS (ESI) $m / z$ calcd for $\mathrm{C}_{92} \mathrm{H}_{72} \mathrm{Fe}_{2} \mathrm{~N}_{2} \mathrm{O}_{2}[\mathrm{M}]^{+}$1348.4293, found 1348.4292; calcd for $[\mathrm{M}+\mathrm{H}]^{+}$1349.4365, found 1349.4360 .

\section{Enantioselective Carbonyl-ene Reaction Catalyzed with Ferrosalen-} Co(III) Complexes. ${ }^{88}$ Ligand (-)-8 is used as an example. In a round-bottom flask containing (-)-8 (190 mg, $0.298 \mathrm{mmol})$ and $\mathrm{MeOH}(10 \mathrm{~mL})$ was added $\mathrm{Co}(\mathrm{OAc})_{2}$ • $4 \mathrm{H}_{2} \mathrm{O}(74.2 \mathrm{mg}, 0.298 \mathrm{mmol})$ in $\mathrm{MeOH}(5 \mathrm{~mL})$ via a cannula. The mixture was stirred at $\mathrm{rt}$ for $1 \mathrm{~h}$. The solvent was removed under reduced pressure on a rotary evaporator. The flask, which contained the residue, was then wrapped with aluminum foil. $\mathrm{CH}_{2} \mathrm{Cl}_{2}(15 \mathrm{~mL})$ was added via syringe, which was followed by 
addition of $\mathrm{AgSbF}_{6}$ (205 mg, $0.596 \mathrm{mmol}$ ). The mixture was stirred at $\mathrm{rt}$ overnight. The resulting black suspension was poured onto a pad of Celite, which was washed with $\mathrm{CH}_{2} \mathrm{Cl}_{2}$. The filtrate was discarded. The Celite pad was then washed with acetone. The filtrate was concentrated to dryness under reduced pressure to give the $\mathrm{Co}$ (III) complex. The compound was used directly as a catalyst for the carbonyl-ene reaction without further purification. Ethyl glyoxylate $(50 \%$ in toluene; $250.9 \mathrm{mg}, 1.23 \mathrm{mmol}$ ) was heated to reflux under nitrogen for $1 \mathrm{~h}$ to crack its dimer. After it was cooled to rt, the solution was added to a round-bottom flask containing (-)-8 -Co(III) $(19.0 \mathrm{mg}, 0.02 \mathrm{mmol})$ in dry toluene $(3 \mathrm{~mL})$. The mixture was stirred at $\mathrm{rt}$ for $10 \mathrm{~min}$. $\alpha$-Methylstyrene $(48.2 \mathrm{mg}, 0.41 \mathrm{mmol})$ was then added via syringe in one portion. The reaction was allowed to proceed at $\mathrm{rt}$, and the progress was monitored with GC-MS. After $16 \mathrm{~h}$, the mixture was passed through a pad of Celite, which was washed with $\mathrm{CH}_{2} \mathrm{Cl}_{2}(3 \mathrm{~mL} \times 3)$. Volatiles were removed under reduced pressure. The residue was purified with flash column chromatography $\left(\mathrm{SiO}_{2}\right.$, hexanes/ $\left.\mathrm{Et}_{2} \mathrm{O} 4: 1\right)$. The product $\mathbf{2 3}^{88}$ was obtained as a colorless oil (70.0 mg, 78\%). The ee was determined with chiral HPLC using the conditions described in the general experimental section. The enantiomers $S$-23 and $R-\mathbf{2 3}$ were eluted at 17.0 and 21.0 min, respectively. The ee was $29 \%$ with $R$ 23 being the major enantiomer. In addition to ligand (-)-8, all other ligands, including (-)-1, (-)-2, (+)-3, (-)-4, (+)-5, (-)-6, (+)-7, (+)-9, and (-)-10 were also 
tested for the reaction. The yields ranged from $20 \%$ to $99 \%$. The ees ranged from $0 \%$ to $10 \%$.

\section{Enantioselective Strecker Reaction Catalyzed with Ferrosalen-AI(III)}

Complexes. $^{44}$ Ligand (-)-1 is used as an example. In a round-bottom flask containing ligand (-)-1 (18.0 mg, $0.031 \mathrm{mmol})$ and dry $\mathrm{CH}_{2} \mathrm{Cl}_{2}(5 \mathrm{~mL})$ was added $\mathrm{Et}_{2} \mathrm{AlCl}(1.0 \mathrm{M}$ solution in hexanes, $27.8 \mu \mathrm{L}, 0.028 \mathrm{mmol})$ via syringe. The mixture was stirred at $\mathrm{rt}$ for $2 \mathrm{~h}$ under nitrogen. (E)- $\mathrm{N}$-Butylideneprop-2-en-1amine $(34.5 \mathrm{mg}, 0.31 \mathrm{mmol})$ was added via syringe. After the mixture was cooled to $-78{ }^{\circ} \mathrm{C}$, a solution of $\mathrm{TMSCN}(62 \mu \mathrm{L}, 0.456 \mathrm{mmol})$ in $\mathrm{CH}_{2} \mathrm{Cl}_{2}(2 \mathrm{~mL})$ was added via a cannula dropwise. The reaction mixture was warmed to rt gradually over $12 \mathrm{~h}$. Pyridine ( $2 \mathrm{~mL}$ ) was added, which was followed by benzoyl chloride $(0.5 \mathrm{~mL})$. The mixture was stirred for $1 \mathrm{~h}$. Solvent was removed under reduced pressure. The residue was purified by flash column chromatography $\left(\mathrm{SiO}_{2}\right.$, hexanes/ $\mathrm{Et}_{2} \mathrm{O} 10: 1$ to $\left.5: 1\right)$ to give pure product $\mathbf{2 4}$ as a colorless oil $(77.9 \mathrm{mg}$, $100 \%) .{ }^{44}$ The ee was determined with chiral HPLC using the conditions described in the general experimental section. The enantiomers (-)-24 and (+)-24 were eluted at 19.1 and $20.0 \mathrm{~min}$, respectively. The ee was $20 \%$ with $(+)-24$ being the major enantiomer. In addition to ligand (-)-1, all other ligands, including (-)-2, (+)-3, (-)4, $(+)-5,(-)-6,(+)-7,(-)-8,(+)-9$, and (-)-10 were also tested for the reaction. The yields were all quantitative. The ees ranged from $0 \%$ to $18 \%$. 
Enantioselective Silylcyanation of an Aldehyde. ${ }^{62}$ Ligand $(+)-3$ is used as an example. In a round-bottom flask under nitrogen was charged (+)-3 (15.2 mg, $0.0205 \mathrm{mmol})$ and $\mathrm{CH}_{2} \mathrm{Cl}_{2}(1 \mathrm{~mL}) . \mathrm{Et}_{2} \mathrm{AlCl}(20.5 \mathrm{uL}$ of $1.0 \mathrm{M}$ solution in hexanes, $0.0205 \mathrm{mmol}$ ) was added via syringe. The mixture was stirred at $\mathrm{rt}$ for $5 \mathrm{~h}$. $\mathrm{Oct}_{3} \mathrm{PO}$ (23.8 $\mathrm{mg}, 0.0616 \mathrm{mmol})$ in $\mathrm{CH}_{2} \mathrm{Cl}_{2}(1 \mathrm{~mL})$ was then added via cannula. After the mixture was cooled to $-20^{\circ} \mathrm{C}$, freshly distilled benzaldehyde $(43.6 \mathrm{mg}, 0.41 \mathrm{mmol})$ and trimethylsilylcyanide (136 $\mu \mathrm{l}, 1.025 \mathrm{mmol})$ were added via syringe sequentially. The reaction was allowed to proceed at $-20{ }^{\circ} \mathrm{C}$, monitored with GCMS, and found complete in $24 \mathrm{~h}$. Volatiles were removed under reduced pressure. The residue was suspended in ether and passed through a 1-inch pad of silica gel to remove the catalyst. The filtrate was concentrated to dryness. Purification with flash column chromatography $\left(\mathrm{SiO}_{2}\right.$, hexanes/Et $\left.{ }_{2} \mathrm{O} 10: 1\right)$ gave product $\mathbf{2 5}^{62}$ as a colorless liquid (76.0 mg, 89\%). The ee was determined with chiral HPLC using the conditions described in the general experimental section. The enantiomers $S$ 25 and $R-\mathbf{2 5}$ were eluted at 4.9 and 6.0 min, respectively. The ee was $26 \%$ with $R$ 25 being the major enantiomer. In addition to ligand (+)-3, all other ligands, including (-)-1, (-)-2, (-)-4, (+)-5, (-)-6, (+)-7, (-)-8, (+)-9, and (-)-10 were also tested for the reaction. The yields ranged from $63 \%$ to $99 \%$. The ees ranged from $0 \%$ to $26 \%$. 


\section{Acknowledgement}

Financial support from the US NSF (No. CHE-0647129), Michigan Universities Commercialization Initiative, and the MTU Chemistry Department and assistance

from Mr. Jerry L. Lutz (NMR), Mr. Shane Crist (computation), and Mr. Dean W. Seppala (electronics) are gratefully acknowledged. 


\section{Chapter 4}

\section{Applications of Chiral Ferrosalen Ligands in catalysis}

This chapter describes the applications of ferrosalen compounds (-)-1 to (-)10 (Figure 4.1) in the following catalytic reactions: enantioselective carbonyl-ene reaction, enantioselective Strecker-type reaction and enantioselective silylcyanation.
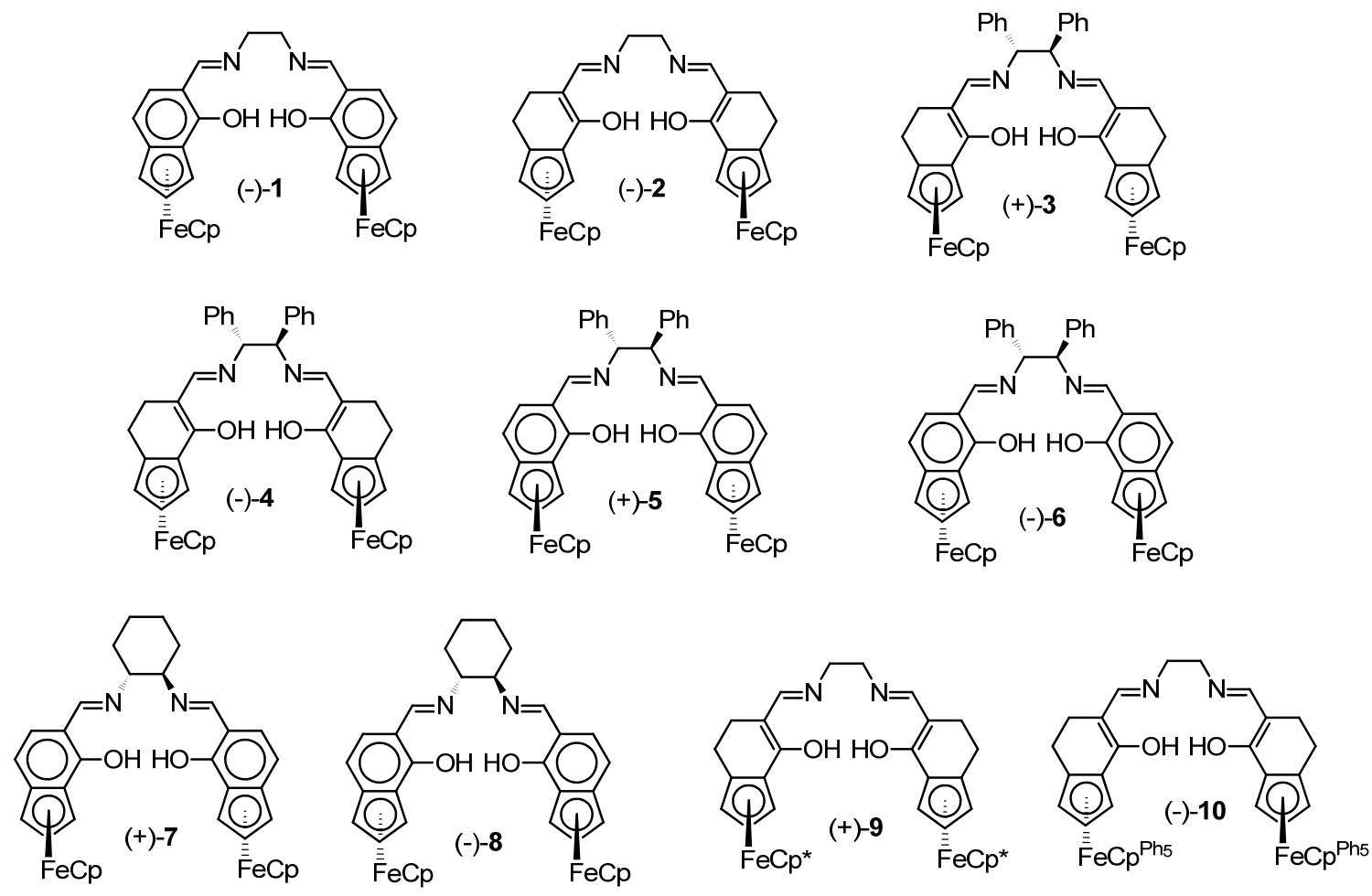

$$
\mathrm{Cp}=\mathrm{C}_{5} \mathrm{H}_{5} ; \mathrm{Cp}^{*}=\mathrm{C}_{5} \mathrm{Me}_{5} ; \mathrm{Cp}^{\mathrm{Ph} 5}=\mathrm{C}_{5} \mathrm{Ph}_{5}
$$

Figure 4.1: Ferrosalen and Ferrosalen-type ligands used in asymmetric catalysis 


\subsection{Enantioselective Carbonyl-ene reaction}

\subsubsection{Introduction}

An ene reaction can be broadly classified as an alkene (ene) component to react with a broad range of enophiles: alkenes, alkynes, allenes, carbonyls, imines, etc. In this case, a carbonyl-ene reaction refers to the reaction of an alkene with a carbonyl group. This type of reaction can be potentially used to build up a wide range of products. From the mechanism, it comes with an appealing advantage of atom efficiency: all of the atoms in the substrates end up in the product. ${ }^{89}$ The general mechanism is shown in Scheme 4.1.
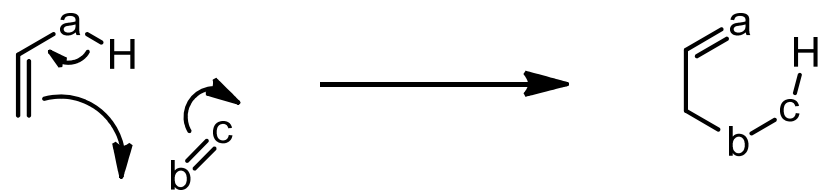

Scheme 4.1: General mechanism of an ene reaction

Theoretically, carbonyl-ene reaction can proceed without any catalysts. However, due to the high energy barrier, it often needs very high temperature to proceed. When a Lewis acid catalyst was used to activate the carbonyl group, the reaction could proceed at room temperature or even lower temperature. Enantioselective versions of this reaction started to draw attention of chemists since 1980s. The chiral element was transferred from the chiral catalyst to the substrate through the Lewis acid activation step (Scheme 4.2). 


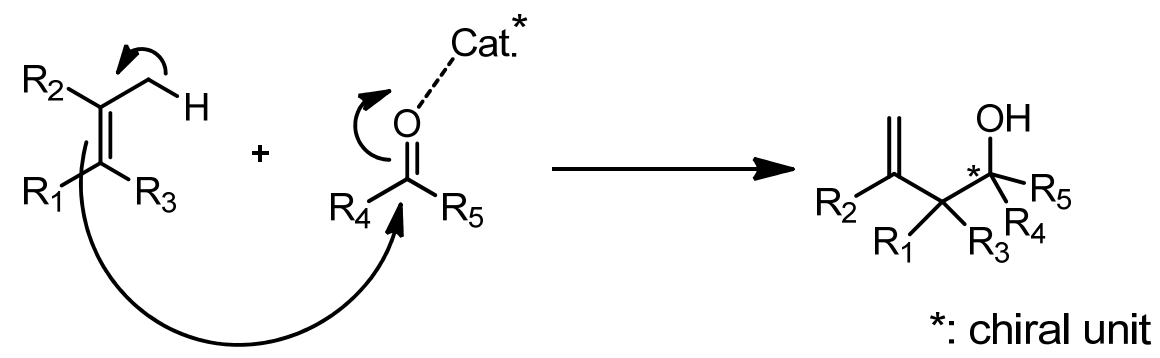

Scheme 4.2: Chirality transfer of enantioselective carbonyl-ene reaction

During the development of catalysts for enantioselective carbonyl-ene reaction, many effective ones have been discovered. For example, Ti-BINOL complexes by Nakai/Mikami, ${ }^{90-91} \mathrm{C}-2$ symmetric Cu-Box catalyst by Evans, ${ }^{92-93}$ tridentate Cr(III)-Schiff base complexes by Jacobsen, ${ }^{94}$ and also the use of C-2 symmetric metal-salen complexes (figure 4.2). ${ }^{88}$
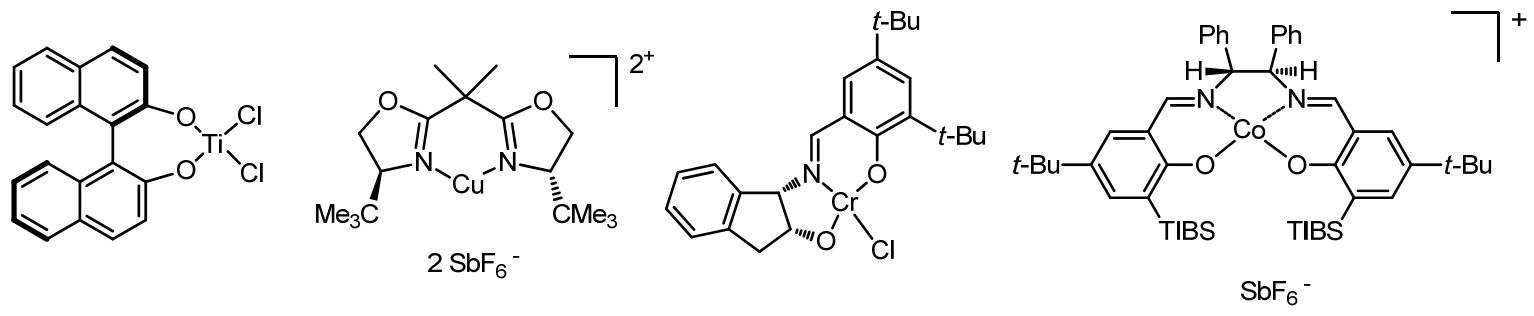

Figure 4.2: Example catalysts for enantioselective carbonyl-ene reaction

\subsubsection{Result and discussion}

For the initial studies, we examined the reaction with racemic ferrosalen ligand ( \pm )-11 and a known salen ligand $\mathbf{1 2}$ (Table 4.1). The catalysts were synthesized by the known procedure of stirring the specific salen ligand with 
$\mathrm{Co}(\mathrm{OAc})_{2} \cdot 4 \mathrm{H}_{2} \mathrm{O}$ in $\mathrm{MeOH}$ followed by hexafluoroantimonate adduct formation. The benchmark catalytic reactions were carried out in toluene at room temperature in the presence of $5 \mathrm{~mol} \%$ of catalysts and excess of ethyl glyoxylate. In entry 1 , Product $( \pm)-\mathbf{1 5}$ was formed at $100 \%$ conversion and $1 \%$ ee. This experiment established the standard protocol for our studies; In entry 2, the enantioselectivity was compared to the literature $\left(46 \%\right.$ ee) ${ }^{88}$ This result confirmed that the HPLC analysis is effective and well-functioning. These two reactions were used as benchmark reactions to the enantioselective catalysis.

\section{Table 4.1}

Benchmark carbonyl-ene reactions using $( \pm)-\mathbf{1 1}$ and $\mathbf{1 2}$

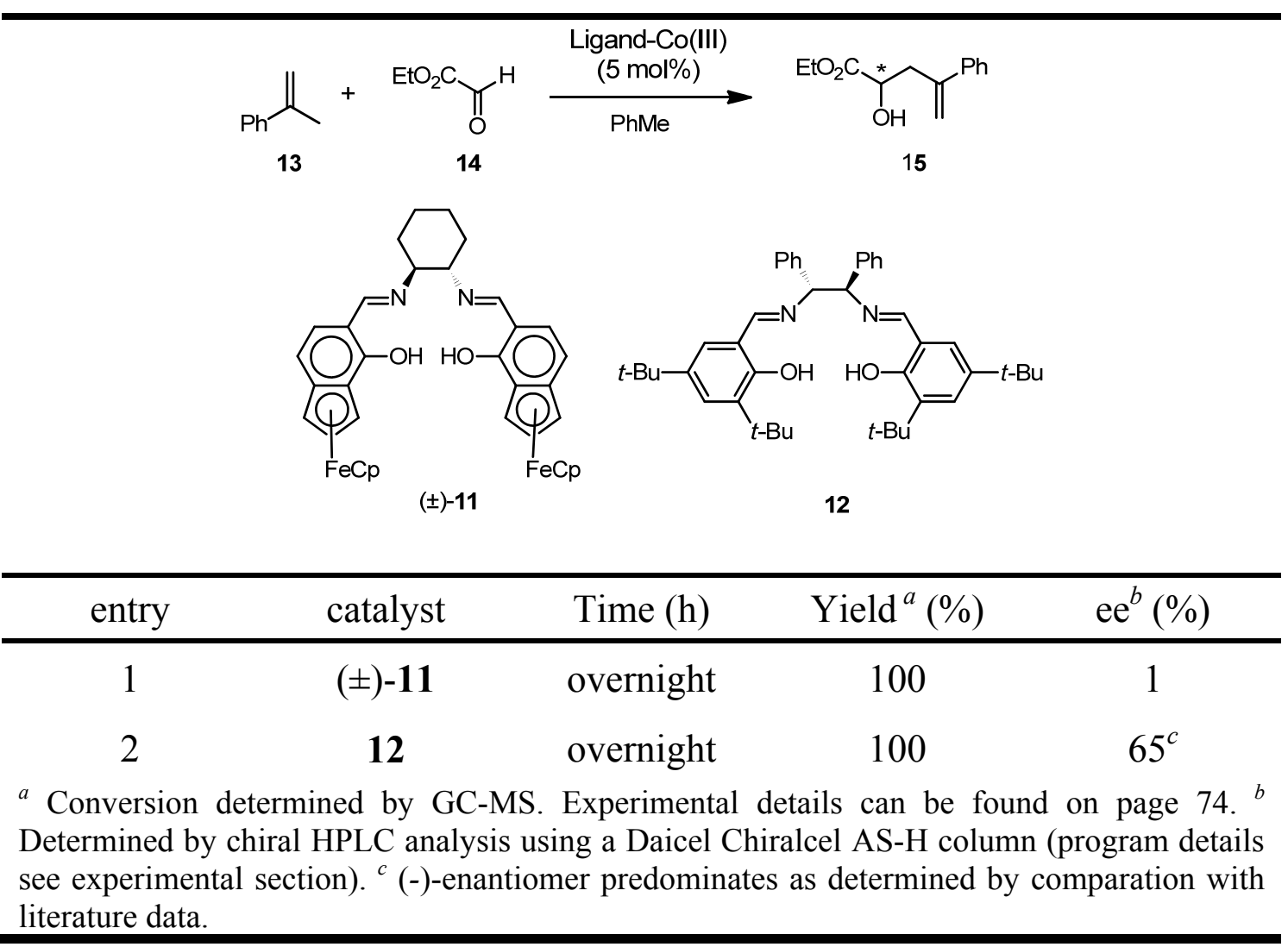


After establishing the standard conditions, enantiopure ferrosalen ligands were tested (Figure 4.1 and Table 4.2). In entry 1, the reaction was carried out in an ice bath and slowly warmed up to room temperature. Poor yield was obtained and enantioselectivity was also low. Heating up the reaction did not help with the enantioselectivity either (entry 2). The best selectivity was obtained in entry 8 using (-)-8 as ligand, which gave $29 \%$ ee with (-) isomer as the major product. Ligand (+)-7, which is a diastereoisomer of (-)-8, was also tested for the reaction. The configuration of the major enantiomer is $(+)$. We also used ligands with the bulkier $\mathrm{Cp}^{*}[(+)-9]$ and $\mathrm{Cp}^{\mathrm{Ph} 5}[(-)-\mathbf{1 0}]$ for the reaction. Unfortunately no ee was found (entry 9 and 10). The reason could be the steric bulkiness on the ligands. The active site for the substrate activation may be blocked. Besides Co, Ruferrosalen complexes were also tested as shown in entry 11 and 12 , only $10 \%$ ee was found when (+)-3-Ru (III) was used. 


\section{Table 4.2}

Ferrosalen complex catalyzed enantioselective carbonyl-ene reaction

\begin{tabular}{|c|c|c|c|c|c|}
\hline $\mathrm{Ph}$ & $\mathrm{EtO}_{2} \mathrm{C} \prod_{\mathrm{O}}^{\mathrm{H}}$ & $\begin{array}{l}\text { land-Co( } \\
\text { Phol\% })\end{array}$ & $\mathrm{EtO}_{2} \mathrm{C}$ & & \\
\hline entry & $\operatorname{ligand}^{a}$ & $\mathrm{~T}\left({ }^{\circ} \mathrm{C}\right)$ & solvent & yield $(\%)$ & $\mathrm{ee}^{b}(\%)$ \\
\hline 1 & $(-)-1$ & $0-\mathrm{rt}$ & PhMe & $20^{c}$ & 5 \\
\hline 2 & $(-)-2$ & 70 & $\mathrm{PhMe}$ & 43 & 3 \\
\hline 3 & $(+)-3$ & $\mathrm{rt}$ & PhMe & $42^{c}$ & 0 \\
\hline 4 & $(-)-4$ & $\mathrm{rt}$ & PhMe & $60^{c}$ & 0 \\
\hline 5 & $(+)-5$ & $\mathrm{rt}$ & $\mathrm{PhMe}$ & 81 & 0 \\
\hline 6 & $(-)-6$ & $r t$ & $\mathrm{PhMe}$ & 88 & 0 \\
\hline 7 & $(+)-7$ & $\mathrm{rt}$ & $\mathrm{PhMe}$ & 99 & $10(+)$ \\
\hline 8 & $(-)-8$ & $\mathrm{rt}$ & $\mathrm{PhMe}$ & 78 & $29(-)$ \\
\hline 9 & $(+)-9$ & $\mathrm{rt}$ & PhMe & 72 & 0 \\
\hline 10 & $(-)-10$ & $\mathrm{rt}$ & $\mathrm{PhMe}$ & 56 & 0 \\
\hline 11 & $(+)-3-R u(I I I)$ & $\mathrm{rt}$ & $\mathrm{CH}_{2} \mathrm{Cl}_{2}$ & $65^{c}$ & $10(-)$ \\
\hline 12 & $(-)-8-\mathrm{Ru}(\mathrm{III})^{d}$ & $\mathrm{rt}$ & $\begin{array}{l}\mathrm{PhMe} / \\
\mathrm{CH}_{2} \mathrm{Cl}_{2}\end{array}$ & 76 & 0 \\
\hline \multicolumn{6}{|c|}{$\begin{array}{l}{ }^{a} \text { Experimental details can be found on page } 74 .{ }^{b} \text { Determined by chiral HPLC analysis using a } \\
\text { Daicel Chiralcel AS-H column (program details see experimental section on page } 74 \text { ), Specific } \\
\text { configurations determined by comparison with literature data. }{ }^{c} \text { Yield determined by GC-MS. }{ }^{d} \\
10 \% \text { catalyst loading. }\end{array}$} \\
\hline
\end{tabular}




\subsection{Enantioselective Strecker-type reaction}

\subsubsection{Introduction}

The Strecker reaction is one of the most important and convenient methods for the synthesis of $\alpha$-amino acids. In the reaction, $\alpha$-aminonitriles are prepared by addition of hydrogen cyanide to an imine (Scheme 4.3), which can be hydrolyzed to give the desired amino acid. The substrates are very cheap because the imines can be readily prepared by the condensation of the corresponding aldehyde or ketone with amines.
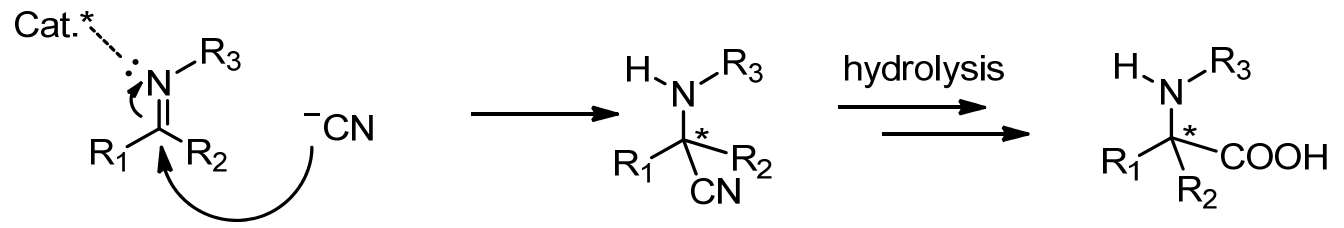

Scheme 4.3: General mechanism of enantioselective Strecker reaction

Stereoselective Strecker synthesis has been well developed due to the importance of optically active $\alpha$-amino acids in pharmaceutical industry. ${ }^{95}$ The most developed method is asymmetric induction by using imines which already bear chiral auxiliary groups. ${ }^{96-98}$ In late 1990s, the first catalytic enantioselective version of the reaction was reported. Since then many successful chiral metal catalysts have been discovered, which include aluminum, titanium, zirconium and lanthanoid complexes (Figure 4.3). 


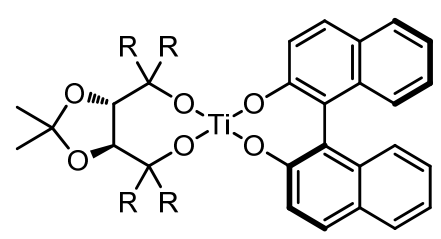

$(\mathrm{R}=\beta$-naphthyl)
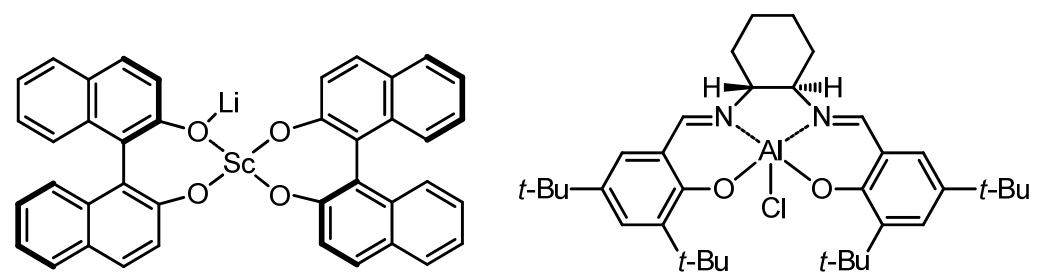

Figure 4.3: Known catalysts for enantioselective Strecker reaction

\subsubsection{Result and discussion}

We first optimized the reaction conditions using the racemic ligand $( \pm)-\mathbf{1 9}$. Aluminum was chosen to be the metal atom of the Lewis acid catalyst. As compared to other salen-metal complexes, salen- $\mathrm{AlCl}$ is the most effective catalyst in both conversion and enantioselectivity according to literature. ${ }^{44}$ The catalyst was generated in situ by stirring $( \pm)-\mathbf{1}(10 \mathrm{~mol} \%)$ and diethyl aluminum chloride ( 9 mol \%) in anhydrous $\mathrm{CH}_{2} \mathrm{Cl}_{2}$ before adding the substrates. The reaction was carried out at room temperature overnight then quenched with benzoyl chloride in pyridine to stabilize the amino group. It was found that the conversion was $100 \%$ based on the GC-MS analysis. HPLC analysis of the purified $\mathbf{1 8}$ shows the ratio of the two enantiomers is $1: 1$. This experiment provided a standard for the enantioselective version of the catalysis (Scheme 4.4). 


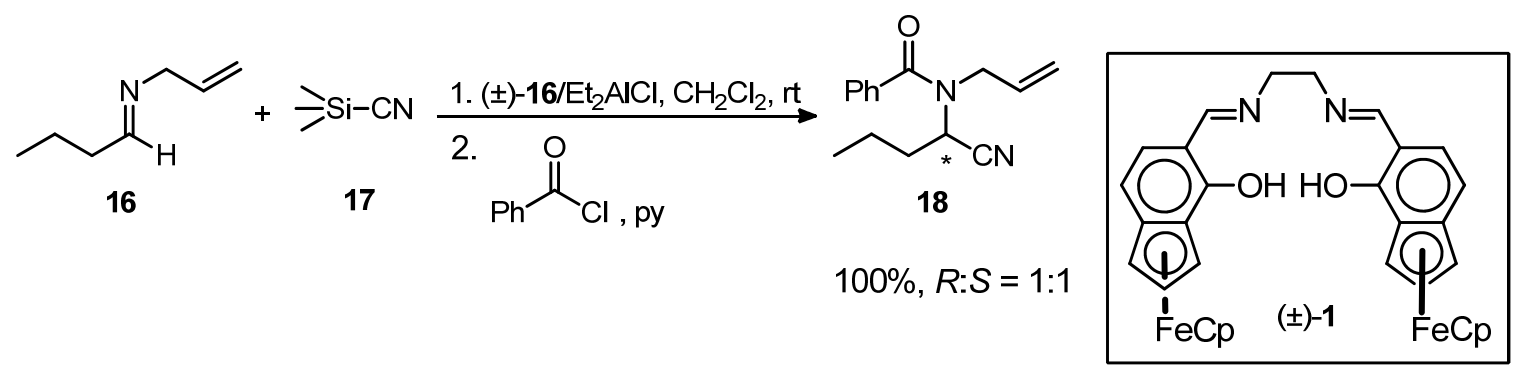

Scheme 4.4: Benchmark catalytic Strecker reaction using $( \pm)-1$

A series of ferrosalen ligands with different steric hindrance were tested for the enantioselectivities as shown in Table 4.3. Because 100\% conversion was obtained in the benchmark reaction, it is possible that background reaction is taking place in which no catalyst participated in the transformation. According to the literature, the background reaction occur rapidly at room temperature, while it is extremely slow at $-70{ }^{\circ} \mathrm{C} .{ }^{44}$ To test the effect of temperature on the selectivity of the reaction, (-)-1 was used for the reaction at different temperatures (entries 1, 2, and 3 in Table 4.3). At room temperature, 4\% ee was obtained (entry 1). When the reaction was started at $0{ }^{\circ} \mathrm{C}$ and then slowly warm up to room temperature, $8 \%$ ee was obtained (entry 2). When the reaction was carried out at $-78{ }^{\circ} \mathrm{C}$ and allowed to warm up naturally during overnight, ee was increased to $20 \%$ (entry 3 ). The result agreed with the literature ${ }^{44}$ that low temperature $\left(-78^{\circ} \mathrm{C}\right)$ should be used to maximize ee. Under low temperature conditions, (-)-2 was found to have similar selectivity to (-)-1 (entry 4, 18\% ee). In entries 11 and 12, pentamethyl and pentaphenyl substituted ligands (+)-9 and (-)-10 were tested. Interestingly, poor 
enantioselectivities was obtained. To avoid errors, which may cause low ees, these reactions were repeated. Low ees were obtained again. The reason for the low selectivities in entries 11 and 12 might be because the substituted ligands were too bulky for the catalyst to coordinate with the imine, which prevented the catalyzed reaction, and the product formed was from the competing background reaction. 


\section{Table 4.3}

Ferrosalen complex catalyzed enantioselective Strecker reaction

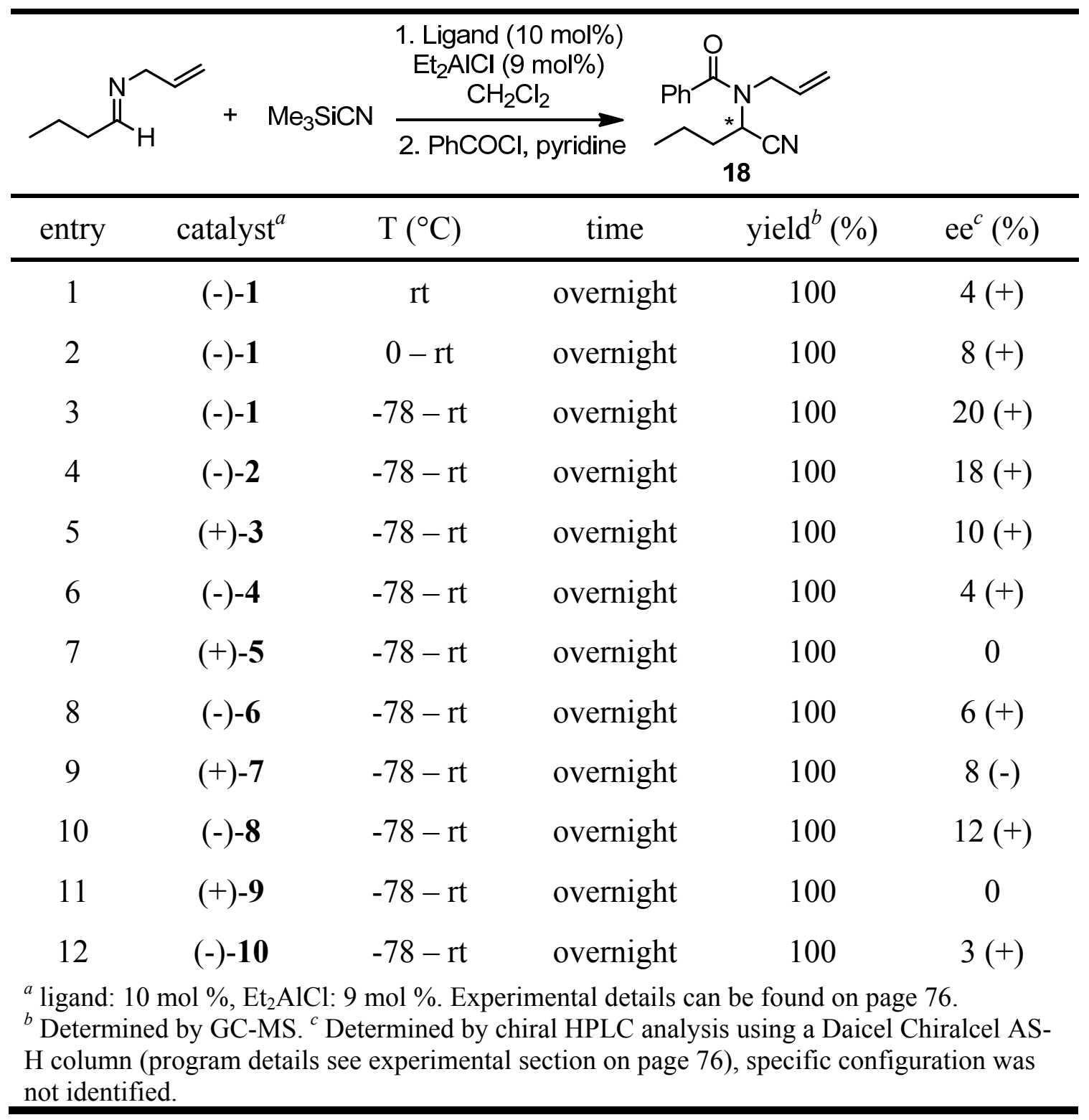




\subsection{Enantioselective silylcyanation reaction}

We also tested enantioselective silylcyanation reaction, a similar reaction to Strecker-type reaction. The reactions were carried out by reacting benzaldehyde with an excess of trimethylsilylcyanide (2.5 equiv.) using the optimized

conditions. ${ }^{99-100}$ The results are shown in Table 4.4. Compared to the Strecker-type reaction, the enantioselectivities in the silylcyanation reaction were better controlled by the chiral ligands, possibly because there was no or if there was, slower background reaction. The best enantioselectivity obtained was $26 \%$ ee, with (+)-3 as ligand. Interestingly, using (-)-4, the diastereoisomer of (+)-3, product was obtained with the same (-) configuration (entry 4). The same (-) configurations were also observed on (+)-5 and (-)-6 (entry 5 and 6). The reason might be that the enantioselectivities for these reactions were predominantly controlled by the chiral diphenylethylenediamine backbone. Pentamethyl and pentaphenyl substituted ligands (+)-9 and (-)-10 were used in entry 9 and 10 . However, very low enantioselectivities were obtained. 


\section{Table 4.4}

Ferrosalen complex catalyzed enantioselective silylcyanation reaction

\begin{tabular}{|c|c|c|c|c|c|}
\hline $\mathrm{Ph}_{\mathrm{H}}^{\mathrm{O}}$ & $\mathrm{Me}_{3} \mathrm{SiCN}$ & $\begin{array}{l}\text { Ligand }(5 \mathrm{~mol} \%) \\
\underset{\mathrm{Et}_{2} \mathrm{AlCl}(5 \mathrm{~mol} \%)}{\stackrel{\mathrm{Oct}}{3} \mathrm{PO}(15 \mathrm{~mol} \%)} \\
\underset{\mathrm{CH}_{2} \mathrm{Cl}_{2}}{\longrightarrow}\end{array}$ & $\mathrm{Ph}_{19}^{\mathrm{OSi}}$ & & \\
\hline entry & ligand & $\mathrm{T}\left({ }^{\circ} \mathrm{C}\right)$ & time $(\mathrm{h})$ & yield $^{a}(\%)$ & $\mathrm{ee}^{b}(\%)$ \\
\hline 1 & $(-)-1$ & -20 & 48 & 86 & $8(+)$ \\
\hline 2 & $(-)-2$ & -20 & 48 & 99 & $12(+)$ \\
\hline 3 & $(+)-3$ & -20 & 48 & 89 & $26(-)$ \\
\hline 4 & $(-)-4$ & -20 & 48 & 87 & $12(-)$ \\
\hline 5 & $(+)-5$ & -20 & 48 & 84 & $18(-)$ \\
\hline 6 & $(-)-6$ & -20 & 48 & 77 & $16(-)$ \\
\hline 7 & $(+)-7$ & -20 & 48 & 85 & $12(+)$ \\
\hline 8 & $(-)-8$ & -20 & 48 & 88 & $20(-)$ \\
\hline 9 & $(+)-9^{c}$ & -20 & 24 & 96 & $8(-)$ \\
\hline 10 & $(-)-10^{d}$ & -20 & 48 & 63 & 0 \\
\hline \multicolumn{6}{|c|}{$\begin{array}{l}{ }^{a} \text { Isolated yield. Experimental details can be found on page } 77 .{ }^{b} \text { Determined by chiral HPLC } \\
\text { analysis using a Daicel Chiralcel AS-H column (program details see experimental section on } \\
\text { page 77), specific configuration determined by comparing the optical rotation data with the } \\
\text { literature }{ }^{c} 1 \mathrm{~mol} \% \text { ligand, } 1 \mathrm{~mol} \% \mathrm{Et}_{2} \mathrm{AlCl}, 5 \text { mol } \% \mathrm{Oct}_{3} \mathrm{PO} .{ }^{d} 2.5 \text { mol } \% \text { ligand, } 2.5 \mathrm{~mol} \% \\
\mathrm{Et}_{2} \mathrm{AlCl}, 7.5 \mathrm{~mol} \% \mathrm{Oct}_{3} \mathrm{PO} \text {. }\end{array}$} \\
\hline
\end{tabular}




\subsection{Future directions}

For the reactions tested above, enantioselectivities were low. This low selectivity may be attributable to the reaction and the ligands. For the Strecker reaction, one possible reason for low enantioselectivity could be the background reaction, which competes with the catalyzed reaction. From the perspective of the ligand structure, one reason for the low selectivities could be the lack of steric hindrance at several open sites on our ligand framework. To solve this problem, we proposed two solutions to modify the ligand structure.

The first solution for ligand modification is to change the backbone. By constructing the salen framework with a diamine backbone that bears more bulky groups might improve enantioselectivities. Scheme 4.5 lists the finished synthesis of two noncommercial available amines. Compound 21 was obtained with $36 \%$ overall yield in two steps. Compound $\mathbf{2 2}$ was synthesized by Grignard addition to cyanogen which was prepared by a known procedure. Although a low yield was obtained (23\%), 22 was prepared on a gram scale. 

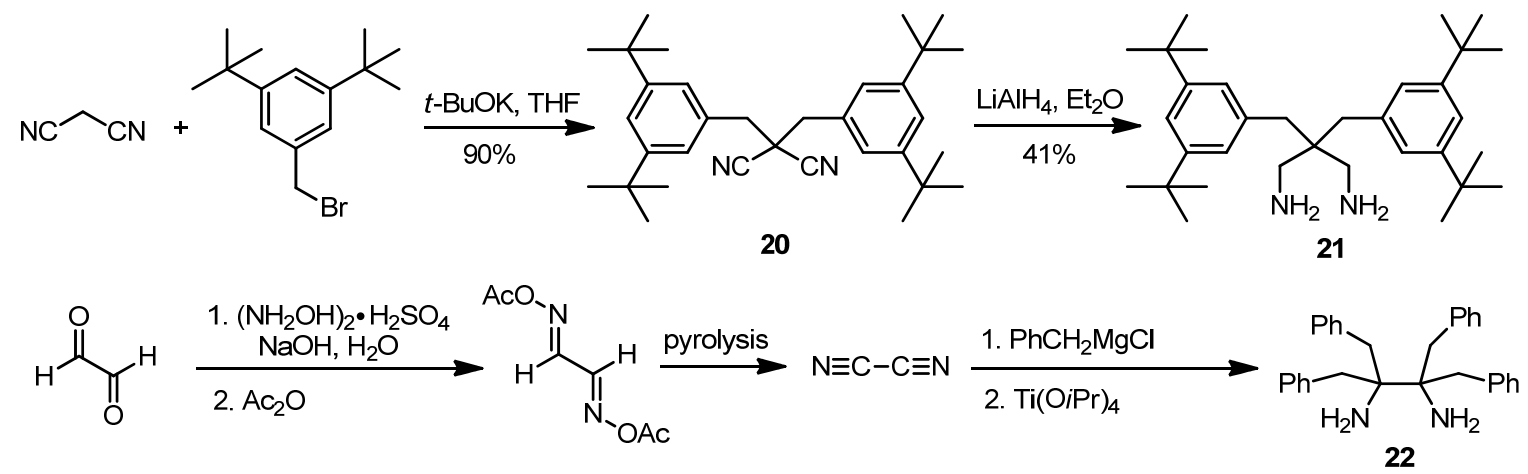

Scheme 4.5: Synthesis of steric hindered diamines 21 and 22

Another solution is to increase steric hindrance on 5, 5' positions (Figure 4.4). This is a possible solution because most successful salen ligands have bulky groups such as tert-butyl or triisobutylsilyl groups on $3,3^{\prime}$ and $5,5^{\prime}$ positions (Figure $4.4 \mathrm{a}$ ). Figure $4.4 \mathrm{~b}$ shows the catalytic mechanism of ferrosalen-metal system. In this catalytic system, the substrate activation will occur in the way that the planar chiral ferrocenyl groups will block the nucleophilic approach from the site of $3^{\prime}$ to $5^{\prime}$ positions. The approach from the site of 3 to 5 positions will be favored because of less steric hindrance. However, it is possible that the open sites at the $5,5^{\prime}$ positions could allow the approach of nucleophiles. In this case a good way to improve the ligand structure would be to insert bulky groups at the $5,5^{\prime}$ positions. 

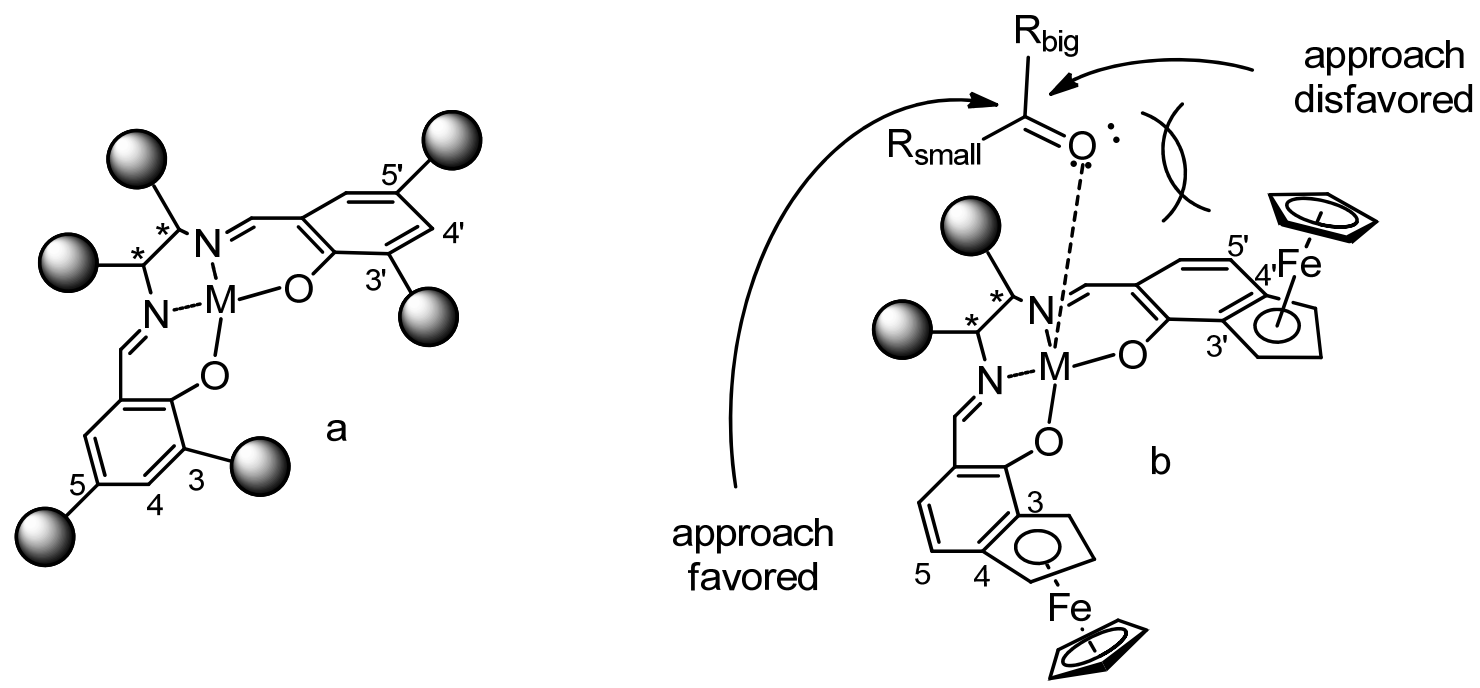

Figure 4.4: Comparison of Jacobsen's salen and ferrosalen framework

To increase the steric hindrance at the $5,5^{\prime}$ positions, a functional group needs to be inserted in the structural motif (+)-23 (Scheme 4.5). A synthetic route was designed, which could use our synthetic strategy described in Chapter 2. Starting with ester protected ferrocene derivative $\mathbf{2 7 , 2 6}$ could be readily prepared by reductive amination. We have tested this reaction, and the results are promising. The methyl ester is then hydrolyzed and the acid is cyclized. Racemic $\mathbf{2 5}$ could be obtained. Resolution of $\mathbf{2 5}$ will be achieved using the same chiral resolution method we used in Chapter 2. After formylation of $(+)-\mathbf{2 4}$ and aromatization, substituted ferrosalen motif $(+)-\mathbf{2 3}$ could be synthesized, which contains the bulky tert-amino group. 
<smiles>[R]c1cc(C=O)c(O)c2c1C=CC2=O</smiles>

$(+)-23, \mathrm{R}=\mathrm{NBn}_{2}$<smiles>[2H]c1cccc2c1C(=O)CC[C@H]2Br</smiles>

$(+)-24$

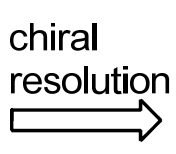

FeCp

racemic 25

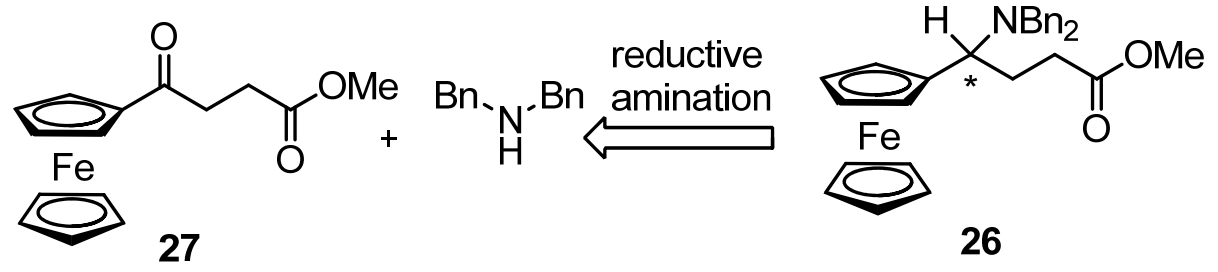

Scheme 4.5: Retro-synthetic design for the optimized ferrosalen structural motif

\subsection{Experimental section}

\section{HPLC conditions for enantioselective catalytic reactions:}

HPLC analysis of compounds $\mathbf{1 5 ,} 18$ and $\mathbf{1 9}$ were performed on a JASCO LC-2000Plus System: pump, PU-2089Plus Quaternary Gradient; detector UV2075Plus; chiral analytical column, Chiracel AS-H (5 $\mu$ m diameter, $100 \AA, 250 \times$ $4.6 \mathrm{~mm}$ ). All profiles were generated by detection of UV absorbance at $260 \mathrm{~nm}$ using the linear gradient solvent system: $1 \%$ to $10 \%$ 2-propanol in hexanes over $30 \mathrm{~min}$ at a flow rate of $1 \mathrm{~mL} / \mathrm{min}$. 


\section{Synthesis of steric hindered diamines 21 and 22:}

20: To a round bottom flask containing malononitrile $(0.116 \mathrm{~g}, 1.756 \mathrm{mmol})$, 3,5-di-t-butylbenzyl bromide $(1.089 \mathrm{~g}, 3.846 \mathrm{mmol})$ and $30 \mathrm{~mL}$ THF was added $t$ $\mathrm{BuOK}(0.432 \mathrm{~g}, 3.846 \mathrm{mmol})$ under positive $\mathrm{N}_{2}$ pressure. This mixture was heated at $50{ }^{\circ} \mathrm{C}$ overnight. The mixture was filtered through a celite pad using $\mathrm{CH}_{2} \mathrm{Cl}_{2}$, the filtrate was evaporated, and the residue was purified by flash column chromatography $\left(\mathrm{SiO}_{2}\right.$, hexanes/ $\left.\mathrm{Et}_{2} \mathrm{O} 50: 1\right)$ to give $\mathbf{2 0}$ as colorless oil $(0.740 \mathrm{~g}, 90 \%$ yield). ${ }^{1} \mathrm{H}$ NMR $\left(\mathrm{CDCl}_{3}\right) \delta 7.58(\mathrm{~s}, 2 \mathrm{H}), 7.39$ (s, 4H), 3.37 (s, 4H), 1.49 (s, 36H); ${ }^{13} \mathrm{C}$ NMR $\left(\mathrm{CDCl}_{3}\right) \delta 151.2,131.3,124.6,122.3,115.1,44.1,41.8,34.8,31.6$.

21: $\mathrm{A} \mathrm{N}_{2}$ filled round-bottom flask containing 20 (1.072g, $\left.2.280 \mathrm{mmol}\right)$ and $20 \mathrm{~mL} \mathrm{Et} \mathrm{E}_{2} \mathrm{O}$ was cooled with an ice bath. Lithium aluminumhydride $(0.260 \mathrm{~g}$, $6.830 \mathrm{mmol}$ ) was added in 3 portions under positive $\mathrm{N}_{2}$ flow. The reaction mixture was allowed to warm up to rt naturally and stirred overnight. The reaction mixture was cooled with an ice bath, $0.27 \mathrm{~mL} \mathrm{H}_{2} \mathrm{O}, 0.26 \mathrm{~mL} 15 \% \mathrm{NaOH}, 0.78 \mathrm{~mL} \mathrm{H}_{2} \mathrm{O}$ were added sequentially in $15 \mathrm{~min}$. The mixture was stirred for additional $15 \mathrm{~min}$ and was filtered through a celite pad using $\mathrm{Et}_{2} \mathrm{O}$. The filtrate was collected and the solvent was removed under reduced pressure. Purification by flash column chromatography $\left(\mathrm{SiO}_{2}\right.$, hexanes/ $\mathrm{Et}_{2} \mathrm{O} / \mathrm{Et}_{3} \mathrm{~N}$ 50:50:5) gave 21 as a light yellow oil (0.450g, 41\% yield). ${ }^{1} \mathrm{H}$ NMR $\left(\mathrm{C}_{6} \mathrm{D}_{6}\right) \delta 7.36(\mathrm{~s}, 2 \mathrm{H}), 7.25(\mathrm{~s}, 4 \mathrm{H}), 2.78(\mathrm{~s}, 4 \mathrm{H})$, 
$2.50(\mathrm{~s}, 4 \mathrm{H}), 1.28(\mathrm{~s}, 36 \mathrm{H}), 0.76(\mathrm{br} \mathrm{s}, 4 \mathrm{H}),{ }^{13} \mathrm{C} \mathrm{NMR}\left(\mathrm{C}_{6} \mathrm{D}_{6}\right) \delta 150.2,138.5,125.3$ 119.6, 45.6, 44.1, 41.1, 34.7, 31.6, 31.5.

22: Cyanogen was freshly prepared according to the literature procedure and stored under $-78^{\circ} \mathrm{C} .{ }^{101} \mathrm{~A}$ two-neck round bottom flask containing cyanogen $(1.107 \mathrm{~g}, 6.431 \mathrm{mmol})$ and $15 \mathrm{~mL} \mathrm{Et}_{2} \mathrm{O}$ was cooled down to $-78{ }^{\circ} \mathrm{C}$, benzylmagnesium chloride $(25.6 \mathrm{~mL}, 51.2 \mathrm{mmol})$ was added dropwise. The mixture was warmed up to rt in 45 min and was allowed to stir for additional 30 min. Titanium isopropoxide $(5.6 \mathrm{~mL}, 19.11 \mathrm{mmol})$ was added dropwise and the mixture was stirred at rt overnight. The mixture was cooled in an ice bath, and 100 $\mathrm{mL}$ aqueous $\mathrm{NaOH}(10 \%)$ was added dropwise. The mixture was vacuum filtered and the filtrate was partitioned between EtOAc and aqueous $\mathrm{NaOH}(10 \%)$. The organic phase was washed with brine $(80 \mathrm{~mL})$, dried over anhydrous $\mathrm{Na}_{2} \mathrm{SO}_{4}$, and filtered. The solvent was removed under reduced pressure. Purification by flash column chromatography $\left(\mathrm{SiO}_{2}\right.$, hexanes/EtOAc 5:1) gave 22 as a light yellow oil (0.622g, $23 \%$ yield). ${ }^{1} \mathrm{H}$ NMR $\left(\mathrm{CDCl}_{3}\right) \delta 7.42-7.22(\mathrm{~m}, 20 \mathrm{H}), 4.68(\mathrm{~s}, 8 \mathrm{H}), 1.78$ (br s, $4 \mathrm{H}) ;{ }^{13} \mathrm{C}$ NMR $\left(\mathrm{CDCl}_{3}\right) \delta 140.8,128.5,127.6,127.0,65.3$. 


\section{Conclusions}

The requirement of enantiopure compounds for clinical applications has led to significant progress in developing transition-metal catalyzed reactions in the past decades. Due to the fact that most catalysts consist of a metal and one or more chiral ligands, the development of chiral ligands that can offer high yields and enantioselectivity are in a high demand. Although numerous discoveries have been made in this area, most of the successful ligands are the result of hundreds of failures and extensive optimizations.

In this dissertation, we have successfully designed and synthesized a new chiral ferrosalen ligand framework. These ligands were synthesized stereoselectively using a highly effective chiral auxiliary approach. The method is inexpensive and atom-economic. More sterically hindered ligand derivatives were also synthesized with pentamethyl and pentaphenyl substituted ferrocene as the starting materials. The structure of the ligand was confirmed by X-ray crystallography study of one of the ligand-Cu(II) complex. The ligands have unique structural features, thus they may find wide applications in asymmetric catalysis.

We also explored the catalytic activities of these ferrosalen ligands in 3 asymmetric catalytic reactions: enantioselective carbonyl-ene reaction, enantioselective Strecker-type reaction and enantioselective silylcyanation. The 
catalytic reactions were carried out with good chemical yield (up to 99\%), and enantioselectivities of up to $29 \%$ for the carbonyl-ene reaction, $20 \%$ for the Strecker reaction and $26 \%$ for the silylcyanation reaction were observed. Although the enantioselectivities are far from achieving the goal as successful chiral ligands, it is encouraging that the ligands are configurationally stable and the structures can be easily optimized for better tuning the catalytic activities. 


\section{References}

1. Rouhi AM. Chiral Chemistry. Chemical \& Engineering News 2004;82(24):47-62.

2. Christmann M, Bräse S. Asymmetric synthesis : the essentials. Weinheim: Wiley-VCH; 2008. XXV-XXVI p.

3. Kotschy A, Timári G. Heterocycles from Transition Metal Catalysis : Formation and Functionalization. 2005.

4. Cahn RS, Ingold C, Prelog V. Specification of Molecular Chirality. Angewandte Chemie International Edition 1966;5(4):385-415.

5. Fu GC. Applications of Planar-Chiral Heterocycles as Ligands in Asymmetric Catalysis. Accounts of Chemical Research 2006;39:853-860.

6. Kealy TJ, Pauso PL. A New Type of Organo-Iron Compound. Nature 1951;168:1039-1040.

7. Barbaro P, Bianchini C, Giambastiani G, Parisel SL. Progress in Stereoselective Catalysis by Metal Complexes with Chiral Ferrocenyl Phosphines Coordination Chemistry Reviews 2004;248:2131-2150.

8. Dai X, Tu T, You S, Deng W, Hou XL. Asymmetric Catalysis with Chiral Ferrocene Ligands. Accounts of Chemical Research 2003;36:659-667.

9. Atkinson RCJ, Gibson VC, Long NJ. The Syntheses and Catalytic Applications of Unsymmetrical Ferrocene Ligands. Chemical Society Reviews 2004;33:313-328. 
10. Butler IR, Cullen WR, Kim TJ, Rettig SJ, Trotter J. 1,1'Bis[(Alkyl/Aryl)Phosphino]Ferrocenes - Synthesis and Metal-Complex Formation - Crystal-Structure of 3 Metal-Complexes of Fe( $\left.\eta-5-\mathrm{C}_{5} \mathrm{H}_{4} \mathrm{PPh}_{2}\right)_{2}$. Organometallics 1985;4(6):972-980.

11. Adeleke JA, Chen YW, Liu LK. Preparation and Crystal Structures of Syn$\left[(\mathrm{Mu}-\mathrm{SPh}) \mathrm{Fe}(\mathrm{Co})_{3}\right]_{2}, \quad\left(\mathrm{C}_{5} \mathrm{H}_{4} \mathrm{SPh}\right)_{2} \mathrm{Fe}, \quad\left(\mathrm{C}_{5} \mathrm{H}_{5}\right) \mathrm{Fe}\left(\mathrm{C}_{5} \mathrm{H}_{4} \mathrm{SPh}\right), \quad$ and $\left(\mathrm{C}_{5} \mathrm{H}_{4} \mathrm{SPh}\right) \mathrm{Fe}\left(\mathrm{C}_{5} \mathrm{H}_{4} \mathrm{PPh}_{2}\right)$. Organometallics 1992;11(7):2543-2550.

12. Lai L, Dong T. A Novel Method to Synthesize Unsymmetrical Disubstituted Ferrocenes. Journal of the Chemical Society, Chemical Communications 1994(20):2347-2348.

13. Dong T, Chang C. A Novel Convenient Method to Synthesize Unsymmetrical 1,1'-Disubstituted Ferrocenes Consisting of Various Phosphino, Thiolato and Pyridyl Substituents. Journal of The Chinese Chemical Society 1998;45:577-579.

14. Dong T, Ho P, Chang C. Selective Monolithiation of 1,1'Dibromoferrocene Applied to the Synthesis of New Unsymmetrical 1,1'Disubstituted Ferrocenyl Ligands. Journal of The Chinese Chemical Society 2000;47:421-424.

15. Butler IR, Davies RL. A Rapid Convenient Synthesis of Ferrocene-Based Triphos Analogue Ligands. Synthesis 1996(11):1350-1354. 
16. Marquarding D, Klusacek H, Gokel G, Hoffmann P, Ugi I. Stereoselective Syntheses. VI. Correlation of Central and Planar Chirality in Ferrocene Derivatives. Journal of the American Chemical Society 1970;92:5389-5393.

17. Hayashi T, Yamamoto K, Kumada M. Asymmetric Catalytic Hydrosilylation of Ketones Preparation of Chiral Ferrocenylphosphines as Chiral Ligands. Tetrahedron Letters 1974;15(50):4405-4408.

18. Lo MMC, Fu GC. A New Class of Planar-chiral Ligands: Synthesis of a C2-Symmetric Bisazaferrocene and its Application in the Enantioselective $\mathrm{Cu}(\mathrm{I})$-Catalyzed Cyclopropanation of Olefins. Journal of the American Chemical Society 1998;120(39):10270-10271.

19. Wurz RP, Lee EC, Ruble JC, Fu GC. Synthesis and Resolution of PlanarChiral Derivatives of 4-(Dimethylamino)pyridine. Advanced Synthesis \& Catalysis 2007;349(14-15):2345-2352.

20. Doyle MP, Hu WH, Chapman B, Marnett AB, Peterson CS, Vitale JP, Stanley SA. Enantiocontrolled Macrocycle Formation by Catalytic Intramolecular Cyclopropanation. Journal of the American Chemical Society 2000;122(24):5718-5728.

21. Rios R, Liang J, Lo MMC, Fu GC. Synthesis, Resolution and Crystallographic Characterization of a New C-2-symmetric Planar-chiral Bipyridine Ligand: Application to the Catalytic Enantioselective Cyclopropanation of Olefins. Chemical Communications 2000(5):377-378. 
22. Tanaka K, Qiao S, Tobisu M, Lo MMC, Fu GC. Enantioselective Isomerization of Allylic Alcohols Catalyzed by a Rhodium/phosphaferrocene Complex. Journal of the American Chemical Society 2000;122(40):9870-9871.

23. Tanaka K, Fu GC. A Versatile New Catalyst for the Enantioselective Isomerization of Allylic Alcohols to Aldehydes: Scope and Mechanistic Studies. Journal of Organic Chemistry 2001;66(24):8177-8186.

24. Tao B, Lo MMC, Fu GC. Planar-chiral Pyridine $N$-oxides, A New Family of Asymmetric Catalysts: Exploiting an $\eta(5)-\mathrm{C}_{5} \mathrm{Ar}_{5}$ Ligand to Achieve High Enantioselectivity. Journal of the American Chemical Society 2001;123(2):353-354.

25. Shintani R, Lo MMC, Fu GC. Synthesis and application of planar-chiral phosphaferrocene-oxazolines, a new class of P,N-ligands. Organic Letters 2000;2(23):3695-3697.

26. Shintani R, Fu GC. Copper-catalyzed Enantioselective Conjugate Addition of Diethylzinc to Acyclic Enones in the Presence of Planar-chiral Phosphaferrocene-oxazoline Ligands. Organic Letters 2002;4(21):36993702. 
27. Shintani R, Fu GC. Catalytic Enantioselective Synthesis of $\beta$-lactams: Intramolecular Kinugasa Reactions and Interception of an Intermediate in the Reaction Cascade. Angewandte Chemie International Edition 2003;42(34):4082-4085.

28. Hansen KB, Rosner T, Kubryk M, Dormer PG, Armstrong JD. Detection and Elimination of Product Inhibition from the Asymmetric Catalytic Hydrogenation of Enamines. Organic Letters 2005;7(22):4935-4938.

29. Zheng WH, Sun N, Hou XL. Highly Regio- and Enantioselective Palladium-catalyzed Allylic Alkylation and Amination of Dienyl Esters with 1,1 '-P,N-Ferrocene Ligands. Organic Letters 2005;7(23):5151-5154.

30. Yoon TP, Jacobsen EN. Privileged Chiral Catalysts. Science 2003;299(5613):1691-1693.

31. Dang TP, Kagan HB. The Asymmetric Synthesis of Hydratropic Acid and Amino-acids by Homogeneous Catalytic Hydrogenation Journal of the Chemical Society, Chemical Communications 1971(10):481-481.

32. Pfaltz A, Drury WJ. Design of Chiral Ligands for Asymmetric Catalysis: From C-2-symmetric $P, P$ - and $N, N$-ligands to Sterically and Electronically Nonsymmetrical $P, N$-ligands. Proceedings of the National Academy of Sciences of the United States of America 2004;101(16):5723-5726.

33. Cozzi PG. Metal-Salen Schiff Base Complexes in Catalysis: Practical Aspects. Chemical Society Reviews 2004;33(7):410-421. 
34. Katsuki T. Some Recent Advances in Metallosalen Chemistry. Synlett 2003(3):281-297.

35. Jacobsen EN, Zhang W, Muci AR, Ecker JR, Deng L. Highly Enantioselective Epoxidation Catalysts Derived from 1,2Diaminocyclohexane. Journal of the American Chemical Society 1991;113(18):7063-7064.

36. Jacobsen EN, Zhang W, Guler ML. Electronic Tuning of Asymmetric Catalysts. Journal of the American Chemical Society 1991;113(17):67036704.

37. Zhang W, Loebach JL, Wilson SR, Jacobsen EN. Enantioselective Epoxidation of Unfunctionalized Olefins Catalyzed by (Salen)Manganese Complexes. Journal of the American Chemical Society 1990;112(7):28012803.

38. Zhang W, Jacobsen EN. Asymmetric Olefin Epoxidation with SodiumHypochlorite Catalyzed by Easily Prepared Chiral Mn(iii) Salen Complexes. Journal of Organic Chemistry 1991;56(7):2296-2298.

39. Irie R, Noda K, Ito Y, Matsumoto N, Katsuki T. Catalytic Asymmetric Epoxidation of Unfunctionalized Olefins. Tetrahedron Letters 1990;31(50):7345-7348. 
40. Irie R, Noda K, Ito Y, Matsumoto N, Katsuki T. Catalytic Asymmetric Epoxidation of Unfunctionalized Olefins Using Chiral (Salen)Manganese(iii) Complexes. Tetrahedron: Asymmetry 1991;2(7):481-494.

41. Irie R, Noda K, Ito $\mathrm{Y}$, Katsuki T. Enantioselective Epoxidation of Unfunctionalized Olefins Using Chiral (Salen)Manganese(iii) Complexes. Tetrahedron Letters 1991;32(8):1055-1058.

42. Irie R, Ito Y, Katsuki T. Donor Ligand Effect in Asymmetric Epoxidation of Unfunctionalized Olefins with Chiral Salen Complexes. Synlett 1991(4):265-266.

43. Deng L, Jacobsen EN. A Practical, Highly Enantioselective Synthesis of the Taxol Side-Chain Via Asymmetric Catalysis. Journal of Organic Chemistry 1992;57(15):4320-4323.

44. Sigman MS, Jacobsen EN. Enantioselective Addition of Hydrogen Cyanide to Imines Catalyzed by a Chiral (salen)Al(III) Complex. Journal of the American Chemical Society 1998;120(21):5315-5316.

45. Huang Y, Iwama T, Rawal VH. Design and Development of Highly Effective Lewis Acid Catalysts for Enantioselective Diels-Alder Reactions. Journal of the American Chemical Society 2002;124(21):5950-5951. 
46. Ito YN, Katsuki T. Asymmetric Catalysis of New Generation Chiral Metallosalen Complexes. Bulletin of the Chemical Society of Japan 1999;72(4):603-619.

47. Kleij AW. Zinc-centred Salen Complexes: Versatile and Accessible Supramolecular Building Motifs. Dalton Transactions 2009(24):4635-4639.

48. Miyasaka H, Saitoh A, Abe S. Magnetic Assemblies Based on Mn(III) Salen Analogues. Coordination Chemistry Reviews 2007;251:2622-2664.

49. Gatteschi D, Sessoli R. Quantum Tunneling of Magnetization and Related Phenomena in Molecular Materials. Angewandte Chemie International Edition 2003;42(3):268-297.

50. Caneschi A, Gatteschi D, Lalioti N, Sangregorio C, Sessoli R, Venturi G, Vindigni A, Rettori A, Pini MG, Novak MA. Cobalt(II)-Nitronyl Nitroxide Chains as Molecular Magnetic Nanowires. Angewandte Chemie International Edition 2001;40(9):1760-1763.

51. Clérac R, Miyasaka H, Yamashita M, Coulon C. Evidence for Single-Chain Magnet Behavior in a MnIII-NiII Chain Designed with High Spin Magnetic Units: A Route to High Temperature Metastable Magnets. Journal of the American Chemical Society 2002;124(43):12837-12844.

52. McGarrigle EM, Gilheany DG. Chromium- and Manganese-salen Promoted Epoxidation of Alkenes. Chemical Reviews 2005;105(5):15631602. 
53. Katsuki T. Chiral Metallosalen Complexes: Structures and Catalyst Tuning for Asymmetric Epoxidation and Cyclopropanation. Advanced Synthesis \& Catalysis 2002;344(2):131-147.

54. Katsuki T. Unique Asymmetric Catalysis of cis-[$[\beta]$ Metal Complexes of Salen and its Related Schiff-baseLigands. Chemical Society Reviews 2004;33(7):437-444.

55. Kleij AW. Nonsymmetrical Salen Ligands and Their Complexes: Synthesis and Applications. European Journal of Inorganic Chemistry 2009(2):193205.

56. Venkataramanan NS, Kuppuraj G, Rajagopal S. Metal-salen Complexes as Efficient Catalysts for the Oxygenation of Heteroatom Containing Organic Compounds--Synthetic and Mechanistic Aspects. Coordination Chemistry Reviews 2005;249(11-12):1249-1268.

57. Hosoya N, Hatayama A, Irie R, Sasaki H, Katsuki T. Rational Design of Mn-Salen Epoxidation Catalysts: Preliminary Results. Tetrahedron 1994;50(15):4311-4322.

58. Sasaki H, Irie R, Hamada T, Suzuki K, Katsuki T. Rational Design of Mnsalen Catalyst (2): Highly Enantioselective Epoxidation of Conjugated cis Olefins. Tetrahedron 1994;50(41):11827-11838. 
59. Ballistreri FP, Patti A, Pedotti S, Tomaselli GA, Toscano RM. Synthesis of Novel Chiral 'Salen-type' Ferrocenyl Ligands. Tetrahedron: Asymmetry 2007;18(20):2377-2380.

60. Wölfle H, Kopacka H, Wurst K, Ongania K, Görtz H, Preishuber-Pflügl P, Bildstein B. Planar Chiral Ferrocene Salen-type 1 Ligands Featuring Additional Central and Axial Chirality. Journal of Organometallic Chemistry 2006;691(6):1197-1215.

61. Niemeyer J, Kehr G, Fröhlich R, Erker G. Salen Ligands Revisited: Synthesis and Application of a Planar Chiral "Ferro-Salen" Ligand. European Journal of Inorganic Chemistry 2010;2010(5):680-684.

62. Niemeyer J, Cloppenburg J, Fröhlich R, Kehr G, Erker G. Salen-ligands based on a planar-chiral hydroxyferrocene moiety: Synthesis, coordination chemistry and use in asymmetric silylcyanation. Journal of Organometallic Chemistry 2010;695(14):1801-1812.

63. Thimmaiah M, Luck RL, Fang S. Novel Benzoferrocenyl Chiral Ligands: Synthesis and Evaluation of Their Suitability for Asymmetric Catalysis. Journal of Organometallic Chemistry 2007;692(10):1956-1962.

64. Thimmaiah M, Luck RL, Fang S. Steric and Electronic Effects of Benzoferrocenyl Phosphine Ligands on Palladium-catalyzed Allylic Alkylation and Suzuki Coupling Reactions. The Open Organic Chemistry Journal 2008;2(1):1-9. 
65. Thimmaiah M, Zhang X, Fang S. Palladium-catalyzed Cross-coupling of Aryl Chlorides with Alkenylboronic Acids with Low E/Z Isomerization. Tetrahedron Letters 2008;49(39):5605-5607.

66. Thimmaiah M, Fang S. Efficient Palladium-catalyzed Suzuki-Miyaura Coupling of Aryl Chlorides with Arylboronic Acids using Benzoferrocenyl Phosphines as Supporting Ligands. Tetrahedron 2007;63(29):6879-6886.

67. Kuehne ME, Dai W, Li Y. New Ferrocenyl Chiral Auxiliary Substituents for Amines. Applications to Syntheses of Mossambine and Vinblastine. The Journal of Organic Chemistry 2001;66(5):1560-1566.

68. Ishizaki M, Ozaki K, Kanematsu A, Isoda T, Hoshino O. Synthetic Approaches Toward Spiro[2,3-dihydro-4H-1-benzopyran-4,1'-cyclohexan]2-one Derivatives via Radical Reactions: Total Synthesis of $( \pm$-lycoramine. The Journal of Organic Chemistry 1993;58(15):3877-3885.

69. Liotta D, Barnum C, Puleo R, Zima G, Bayer C, Kezar HS. A Simple Method for the Efficient Synthesis of Unsaturated $\beta$-Dicarbonyl Compounds. The Journal of Organic Chemistry 1981;46(14):2920-2923.

70. Suzuki T, Tanaka N, Matsumura T, Hosoya Y, Nakada M. Synthetic Studies on (-)-FR182877: Construction of the ABCD Ring System via the Intramolecular Cycloadditions Tetrahedron Letters 2007;48(37):6483-6487. 
71. Tsuji J, Minami I, Shimizu I. A Novel Palladium-catalyzed Preparative Method of $[\alpha],[\beta]-$ Unsaturated Ketones and Aldehydes from Saturated Ketones and Aldehydes via their Silyl Enol Ethers. Tetrahedron Letters 1983;24(50):5635-5638.

72. Farrugia L. ORTEP-3 for Windows - a Version of ORTEP-III With a Graphical User Interface (GUI). Journal of Applied Crystallography 1997;30(5 Part 1):565-565.

73. Zhang W, Loebach JL, Wilson SR, Jacobsen EN. Enantioselective epoxidation of unfunctionalized olefins catalyzed by salen manganese complexes. Journal of the American Chemical Society 1990;112(7):28012803.

74. Handa S, Gnanadesikan V, Matsunaga S, Shibasaki M. syn-Selective Catalytic Asymmetric Nitro-Mannich Reactions Using a Heterobimetallic $\mathrm{Cu}-\mathrm{Sm}-\mathrm{Schiff}$ Base Complex. Journal of the American Chemical Society 2007;129(16):4900-4901.

75. Sutcliffe OB, Bryce MR. Planar Chiral 2-Ferrocenyloxazolines and 1,1'Bis(oxazolinyl)ferrocenes--Syntheses and Applications in Asymmetric Catalysis. Tetrahedron: Asymmetry 2003;14(16):2297-2325.

76. Gómez Arrayás R, Adrio J, Carretero J. Recent Applications of Chiral Ferrocene Ligands in Asymmetric Catalysis. Angewandte Chemie International Edition 2006;45(46):7674-7715. 
77. Fu GC. Applications of Planar-Chiral Heterocycles as Ligands in Asymmetric Catalysis. Accounts of Chemical Research 2006;39(11):853860.

78. Mercier A, Yeo WC, Chou J, Chaudhuri PD, Bernardinelli G, Kundig EP. Synthesis of Highly Enantiomerically Enriched Planar Chiral Ruthenium Complexes via Pd-catalysed Asymmetric Hydrogenolysis. Chemical Communications 2009(35):5227-5229.

79. Kündig EP, Chaudhuri PD, House D, Bernardinelli G. Catalytic Enantioselective Hydrogenolysis of $\left[\mathrm{Cr}(\mathrm{CO})_{3}(5,8\right.$-Dibromonaphthalene)]. Angewandte Chemie International Edition 2006;45(7):1092-1095.

80. Johnson CR, Haake M, Schroeck CW. Chemistry of Sulfoxides and Related compounds. XXVI. Preparation and Synthetic Applications of (Dimethylamino)phenyloxosulfonium Methylide. Journal of the American Chemical Society 1970;92(22):6594-6598.

81. Johnson CR, Schroeck CW. Chemistry of Sulfoxides and Related Compounds. XLV. Asymmetric Syntheses using Optically Active Oxosulfonium Alkylides. Journal of the American Chemical Society 1973;95(22):7418-7423.

82. Zhang X, Luck RL, Fang S. Stereoselective Synthesis of a Chiral Ferrosalen Ligand using an Aromatization Strategy. Journal of Organometallic Chemistry;In Press, Corrected Proof. 
83. Raabe E, Koelle U. Pentamethylcyclopentadienyl-Transition Metal-PiCompounds .8. Description and Molecule Structure of Nu-5$\mathrm{C}_{5} \mathrm{Me}_{5} \mathrm{CoCl}$ (Pyridine), a Stable Cobalt(ii) Halfsandwich Compound. Journal of Organometallic Chemistry 1985;279(3):C29-C32.

84. Butler DCD, Richards CJ. Synthesis of 1'-substituted Derivatives of 1,2,3,4,5-pentaphenylferrocene. Organometallics 2002;21(24):5433-5436.

85. Kurono N, Arai K, Uemura M, Ohkuma T. $\left[\mathrm{Ru}(\text { phgly) })_{2}\right.$ (binap) $] / \mathrm{Li}_{2} \mathrm{CO}_{3}$ : A Highly Active, Robust, and Enantioselective Catalyst for the Cyanosilylation of Adehydes. Angewandte Chemie International Edition 2008;47(35):6643-6646.

86. Sheldrick GM. SHELX-97, Programs for Crystal Structure Analysis (Release 97-2). University of Gottingen, Germany 1998.

87. Farrugia L. WinGX Suite for Small-molecule Single-crystal Crystallography. Journal of Applied Crystallography 1999;32(4):837-838.

88. Hutson GE, Dave AH, Rawal VH. Highly Enantioselective Carbonyl-ene Reactions Catalyzed by a Hindered Silyl-salen-cobalt Complex. Organic Letters 2007;9(20):3869-3872.

89. Clarke ML, France MB. The Carbonyl Ene Reaction. Tetrahedron 2008;64(38):9003-9031. 
90. Mikami K, Terada M, Nakai T. Asymmetric Glyoxylate Ene Reaction Catalyzed by Chiral Titanium Complexes - a Practical Access to $\alpha$ Hydroxy Esters in High Enantiomeric Purities. Journal of the American Chemical Society 1989;111(5):1940-1941.

91. Mikami K, Terada M, Nakai T. Catalytic Asymmetric Glyoxylate Ene Reaction - a Practical Access to $\alpha$-Hydroxy Esters in High Enantiomeric Purities. Journal of the American Chemical Society 1990;112(10):39493954.

92. Evans DA, Burgey CS, Paras NA, Vojkovsky T, Tregay SW. C-2Symmetric Copper(II) Complexes as Chiral Lewis Acids. Enantioselective Catalysis of the Glyoxylate-ene Reaction. Journal of the American Chemical Society 1998;120(23):5824-5825.

93. Evans DA, Tregay SW, Burgey CS, Paras NA, Vojkovsky T. C-2Symmetric Copper(II) Complexes as Chiral Lewis acids. Catalytic Enantioselective Carbonyl-ene Reactions with Glyoxylate and Pyruvate Esters. Journal of the American Chemical Society 2000;122(33):7936-7943.

94. Ruck RT, Jacobsen EN. Asymmetric Catalysis of Hetero-ene Reactions with Tridentate Schiff Base Chromium(III) Complexes. Journal of the American Chemical Society 2002;124(12):2882-2883.

95. Groger H. Catalytic Enantioselective Strecker Reactions and Analogous Syntheses. Chemical Reviews 2003;103(8):2795-2827. 
96. Williams RM. Synthesis of Optically Active $\alpha$-Amino Acids. 1989:Chapter 5.

97. Williams RM, Hendrix JA. Asymmetric-Synthesis of Arylglycines. Chemical Reviews 1992;92(5):889-917.

98. Duthaler RO. Recent Developments in the Stereoselective Synthesis of $\alpha-$ Amino-Acids. Tetrahedron 1994;50(6):1539-1650.

99. Niemeyer J, Cloppenburg J, Frohlich R, Kehr G, Erker G. Salen-ligands Based on a Planar-chiral Hydroxyferrocene Moiety: Synthesis, Coordination Chemistry and Use in Asymmetric Silylcyanation. Journal of Organometallic Chemistry 2010;695(14):1801-1812.

100. Niemeyer J, Kehr G, Frohlich R, Erker G. Salen Ligands Revisited: Synthesis and Application of a Planar Chiral "Ferro-Salen" Ligand. European Journal of Inorganic Chemistry 2010(5):680-684.

101. Park DJ, Stern AG, Willer RL. A Convenient Laboratory Preparation of Cyanogen. Synthetic Communications 1990;20(18):2901-2906. 


\title{
Appendix A
}

\section{Supporting Information for Chapter 2}

\section{Stereoselective Synthesis of a Chiral Ferrosalen Ligand Using an Aromatization Strategy}

\author{
Xiang Zhang, Rudy L. Luck, Shiyue Fang
}

\section{Supplemental Information}

Compound numbers correspond to the numbers in the article: Xiang Zhang, Rudy L. Luck, Shiyue Fang. Journal of Organometallic Chemistry, 2010, in press. The article is in Chapter 2 of the dissertation. 


\section{A.1 General Experimental}

All reactions were performed in oven-dried glassware under a nitrogen atmosphere using standard Schlenk techniques. Reagents and solvents available from commercial sources were used as received unless otherwise noted. THF was distilled from $\mathrm{Na}$ /benzophenone ketyl. $\mathrm{MeOH}$ was distilled over $\mathrm{CaH}_{2}$. Thin layer chromatography (TLC) was performed using plates with silica gel 60F-254 over glass support, $0.25 \mu \mathrm{m}$ thickness. Flash column chromatography was performed using silica gel with particle size of $32-63 \mu \mathrm{m} .{ }^{1} \mathrm{H}$ and ${ }^{13} \mathrm{C}$ NMR spectra were measured at $400 \mathrm{MHz}$ and $100 \mathrm{MHz}$, respectively; chemical shifts $(\delta)$ were reported in reference to solvent peaks (residue $\mathrm{CHCl}_{3}$ at $\delta 7.24$ ppm for ${ }^{1} \mathrm{H}$ and $\mathrm{CDCl}_{3}$ at $\delta 77.00$ ppm for ${ }^{13} \mathrm{C}$ ). 


\section{A.2 ${ }^{1} \mathrm{H}$ and ${ }^{13} \mathrm{C}$ NMR spectra of new compounds}

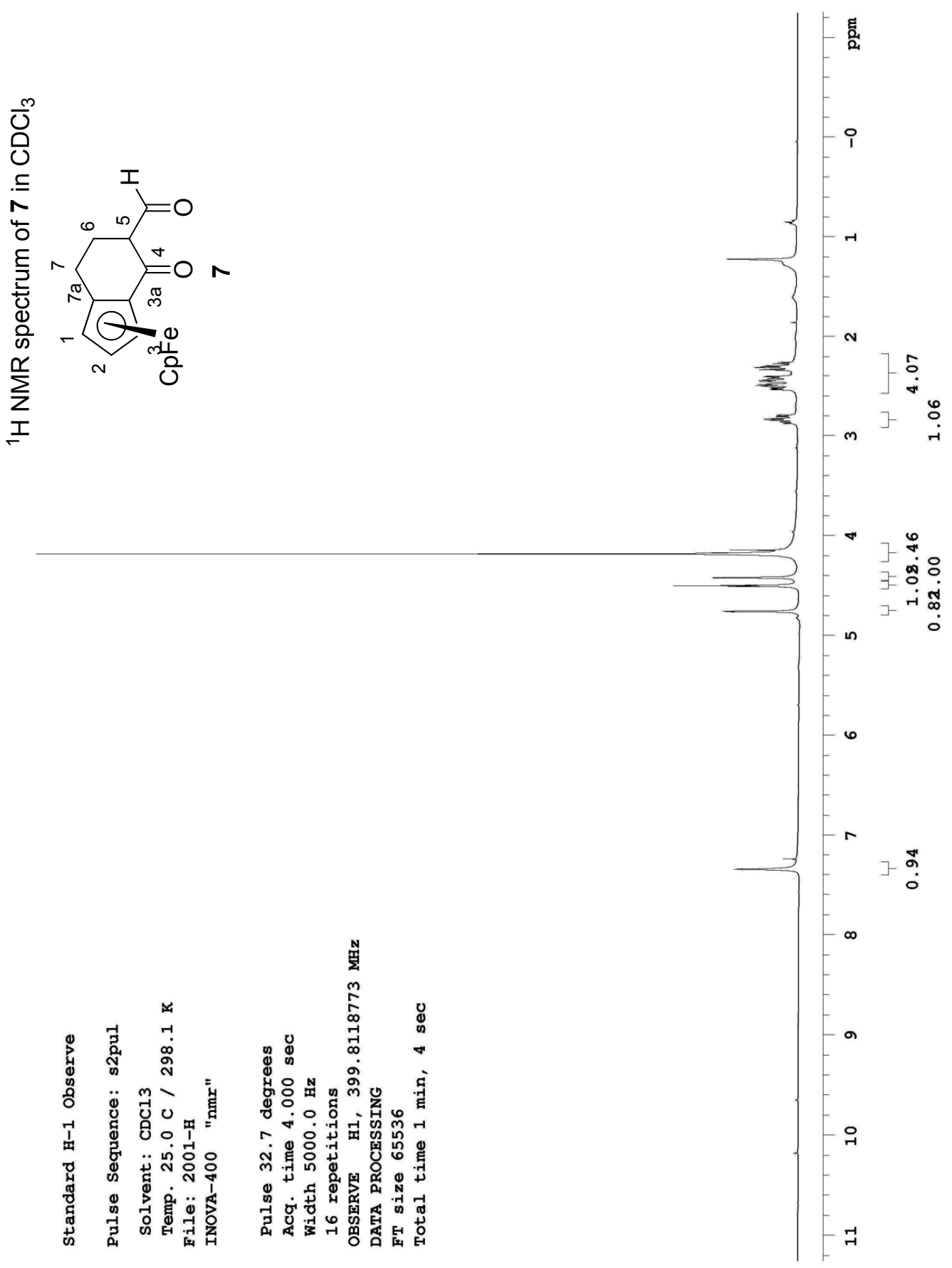

Figure A.1: ${ }^{1} \mathrm{H}$ NMR spectrum of 7 


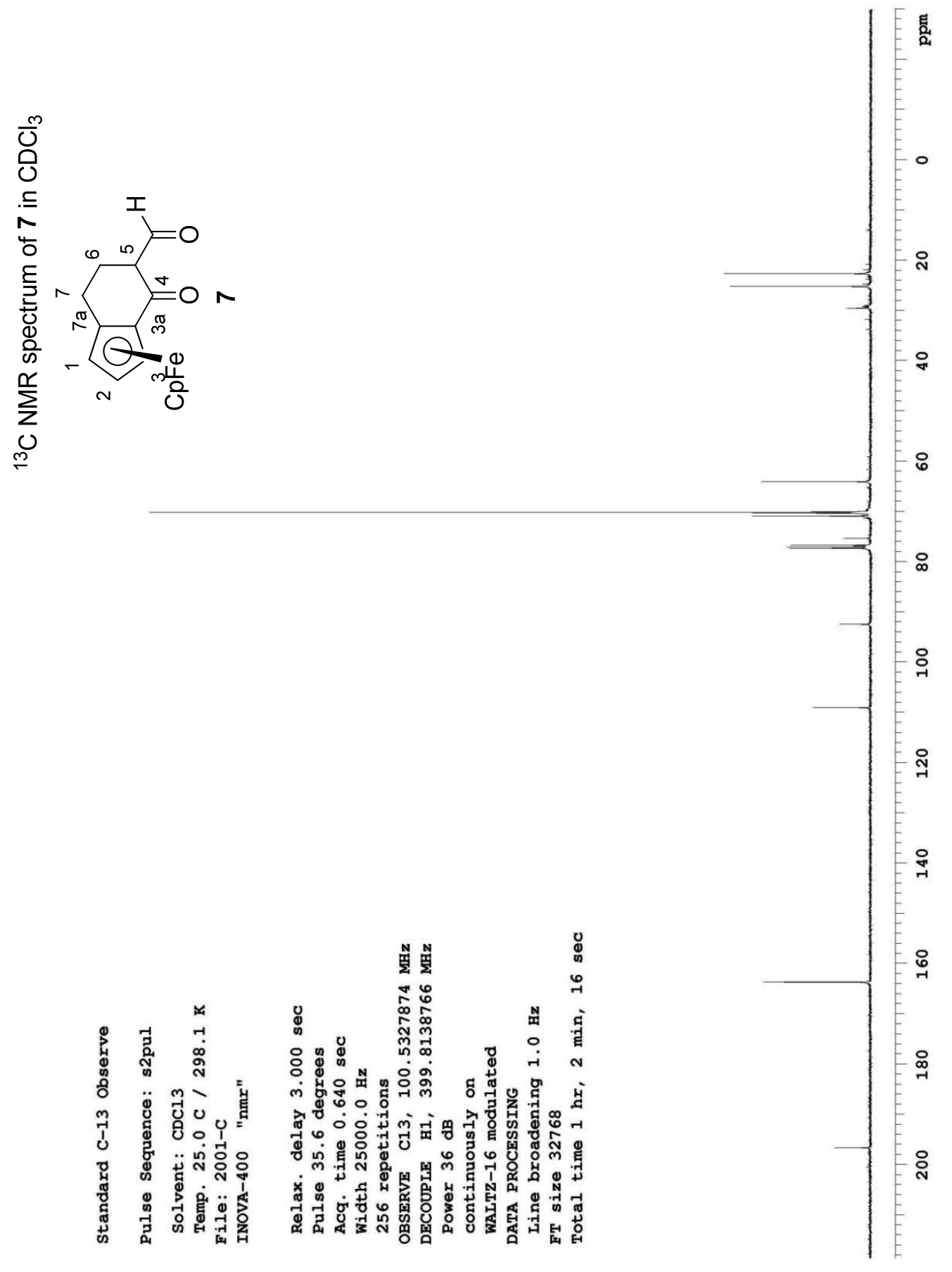

Figure A.2: ${ }^{13} \mathrm{C}$ NMR spectrum of 7 


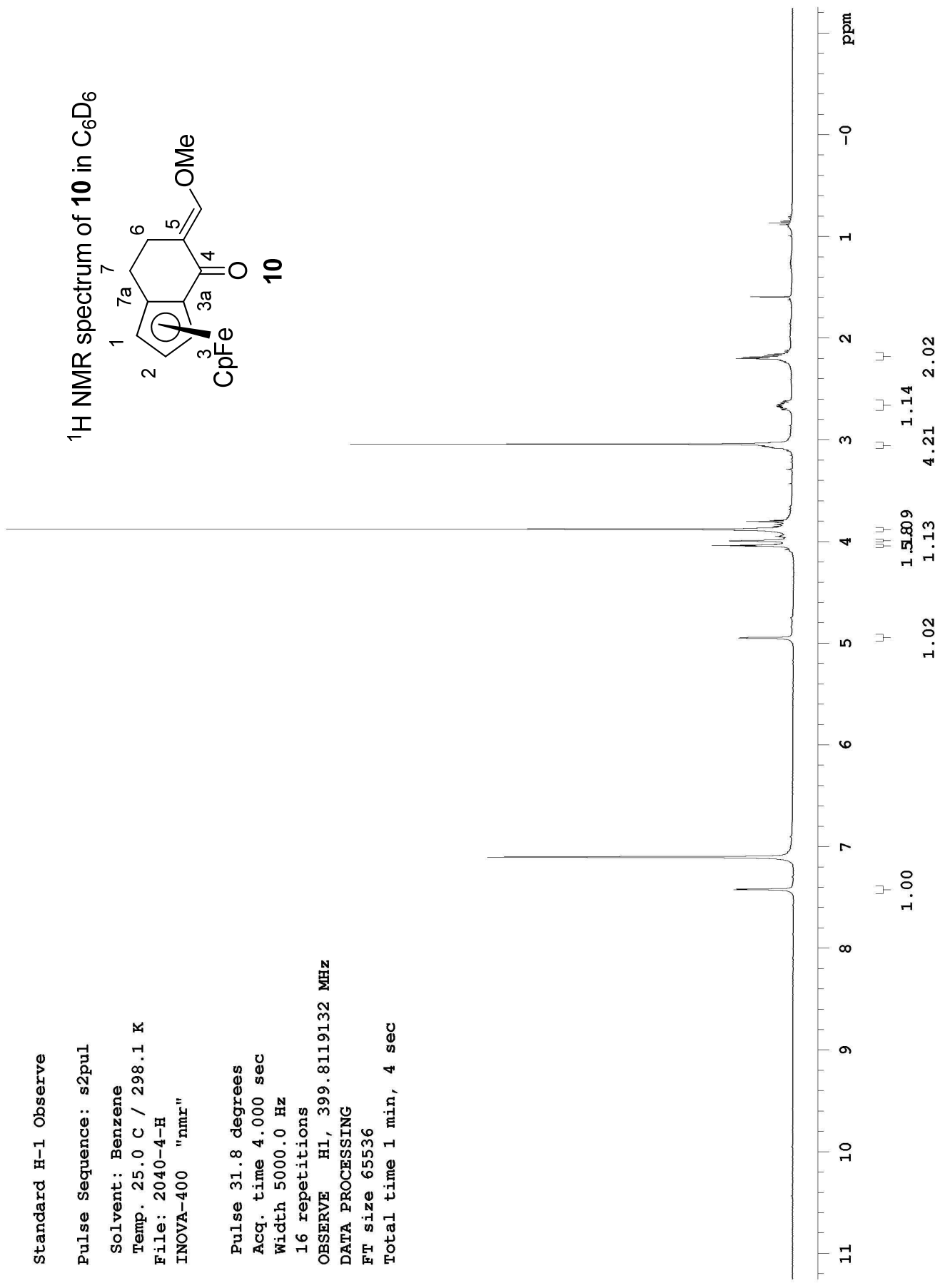

Figure A.3: ${ }^{1} \mathrm{H}$ NMR spectrum of $\mathbf{1 0}$ 


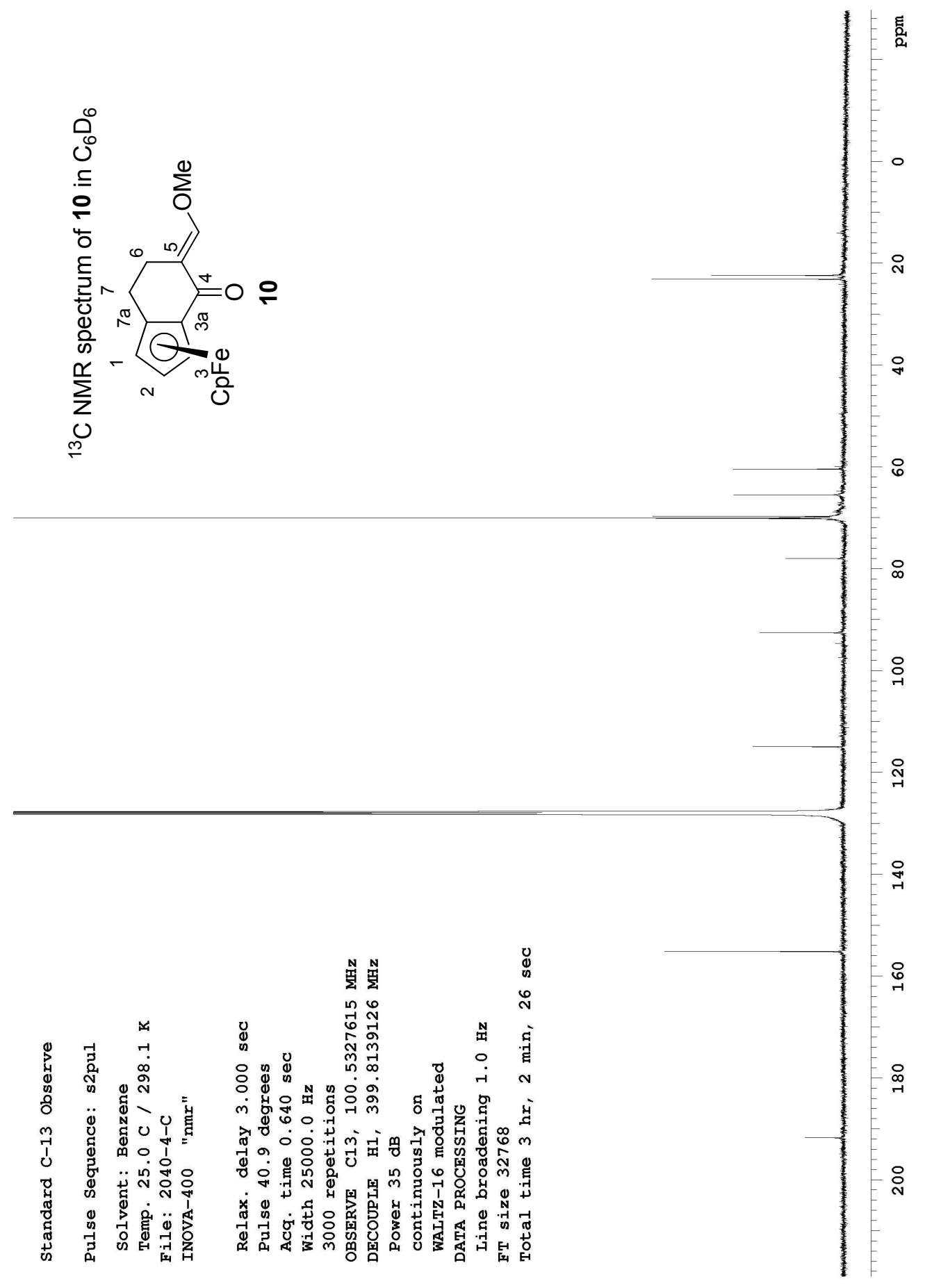

Figure A.4: ${ }^{13} \mathrm{C}$ NMR spectrum of $\mathbf{1 0}$ 

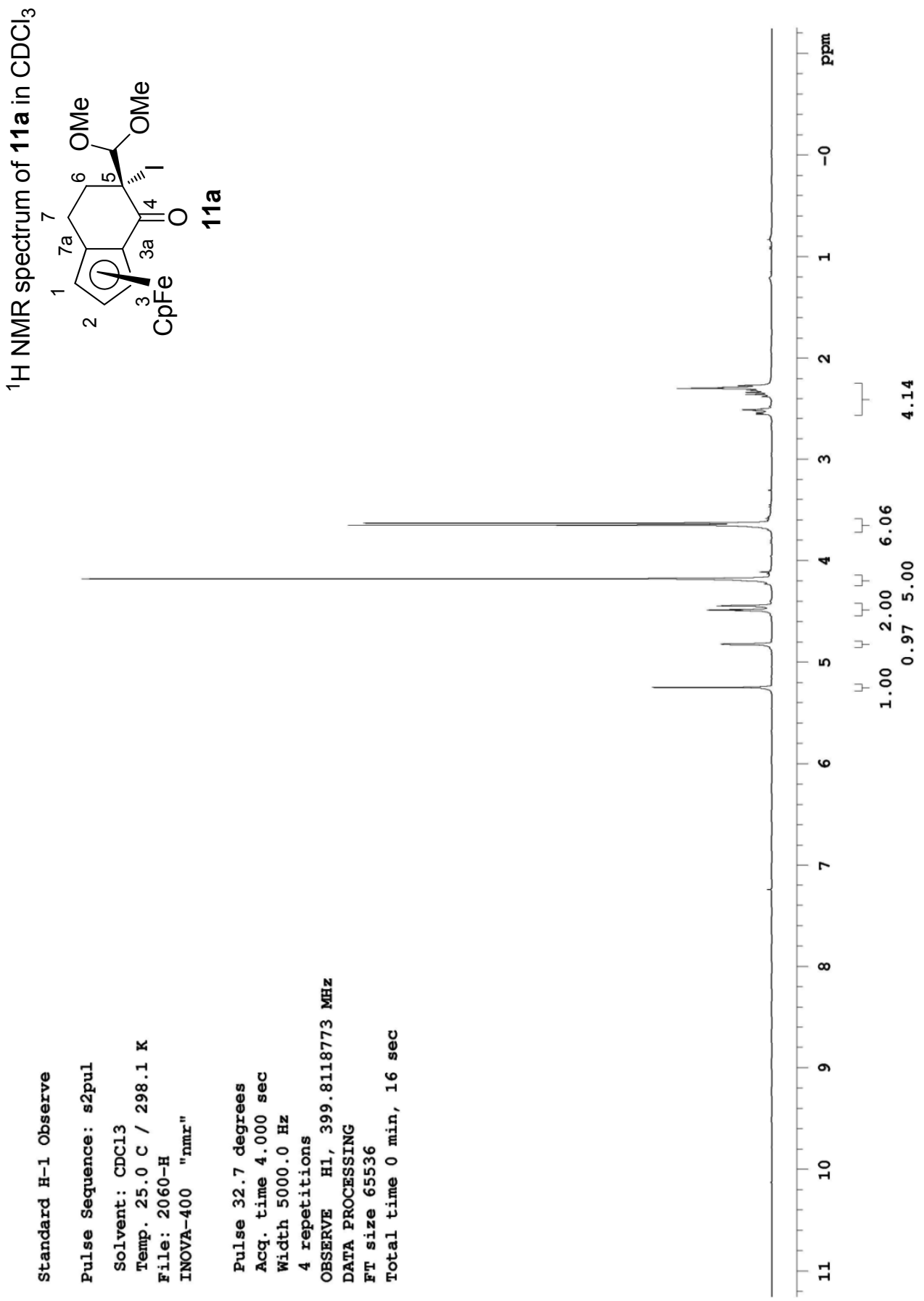

Figure A.5: ${ }^{1} \mathrm{H}$ NMR spectrum of 11a 

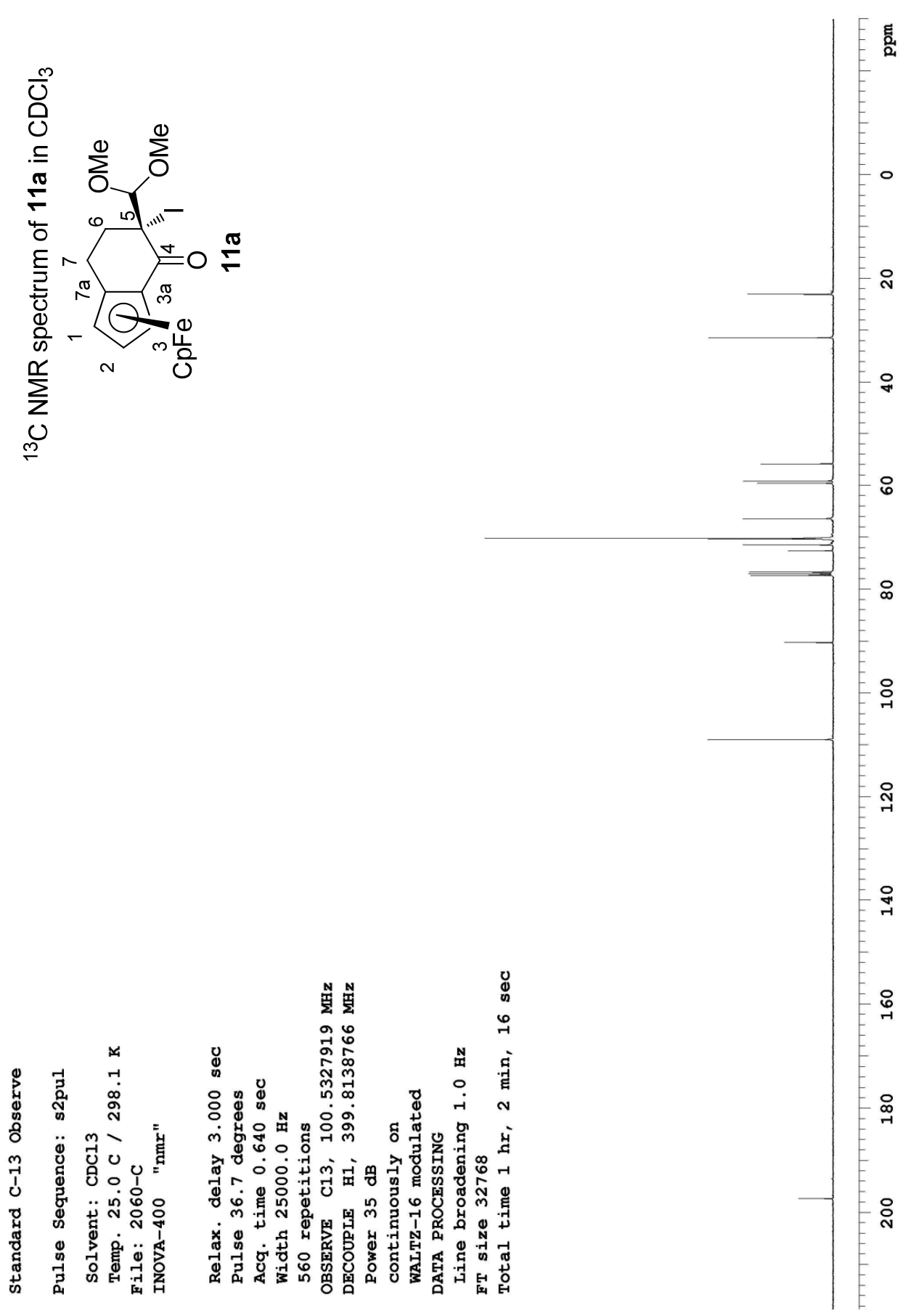

Figure A.6: ${ }^{13} \mathrm{C}$ NMR spectrum of 11a 


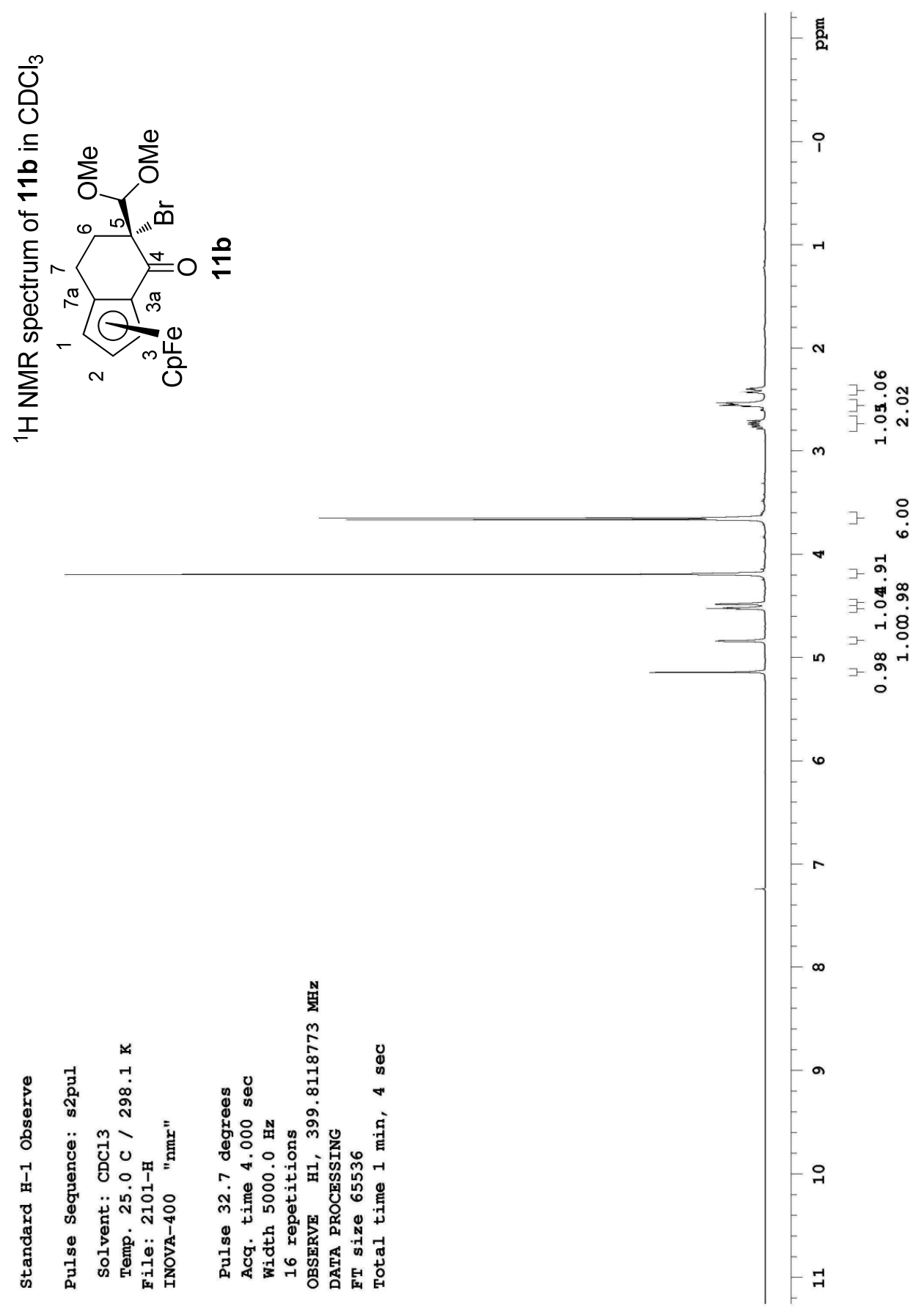

Figure A.7: ${ }^{1} \mathrm{H}$ NMR spectrum of $\mathbf{1 1 b}$ 


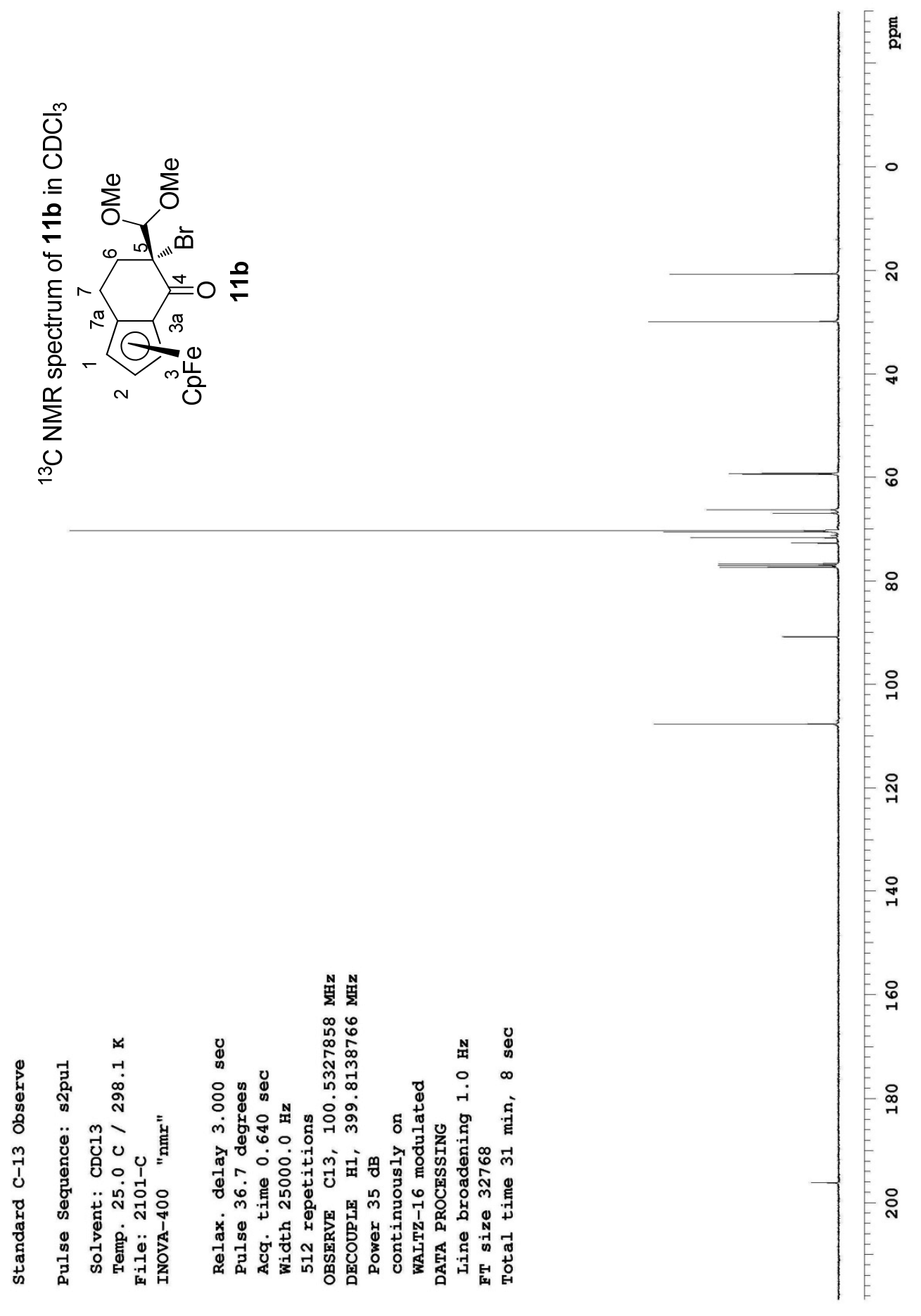

Figure A.8: ${ }^{13} \mathrm{C}$ NMR spectrum of $\mathbf{1 1 b}$ 


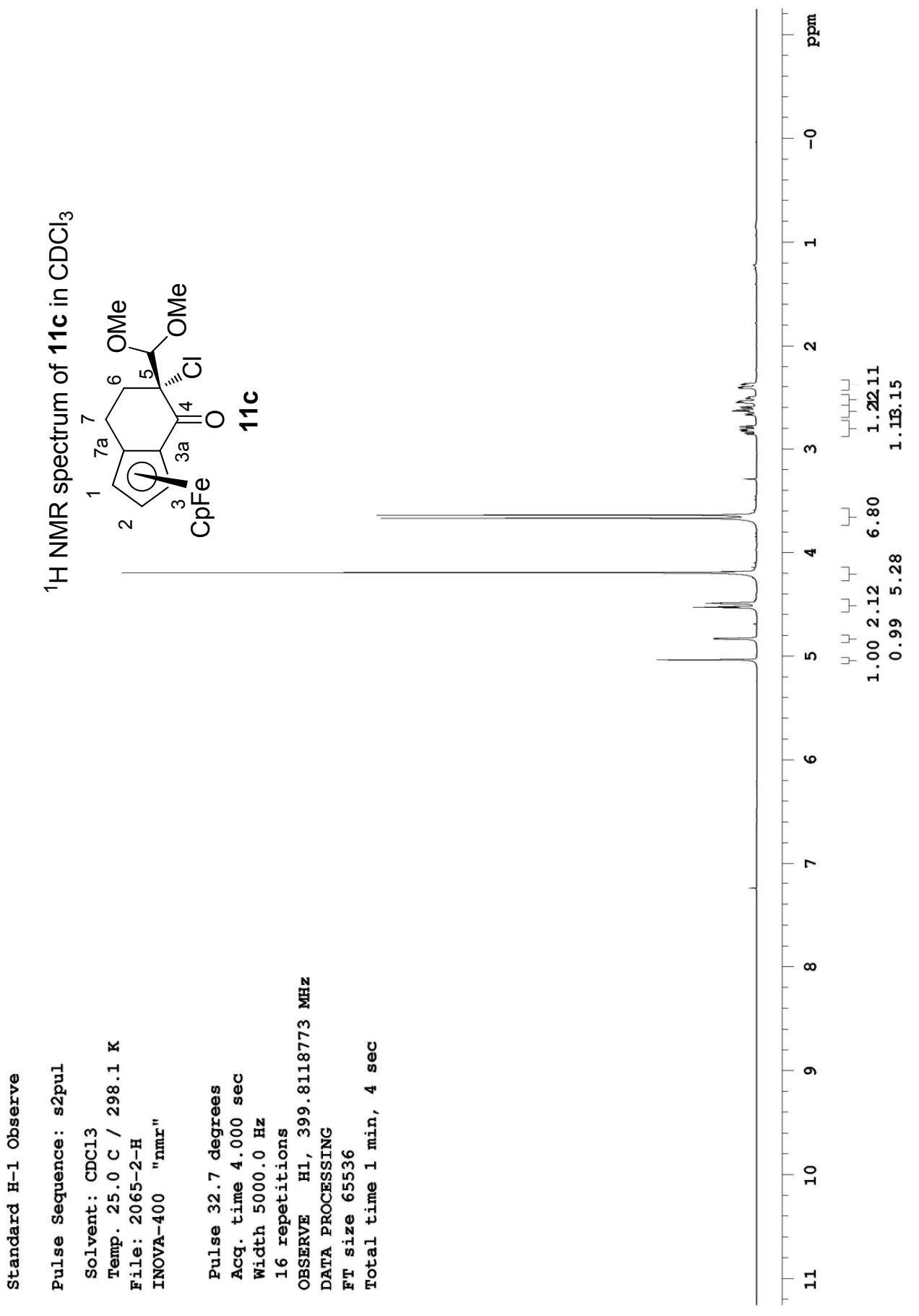

Figure A.9: ${ }^{1} \mathrm{H}$ NMR spectrum of 11c 


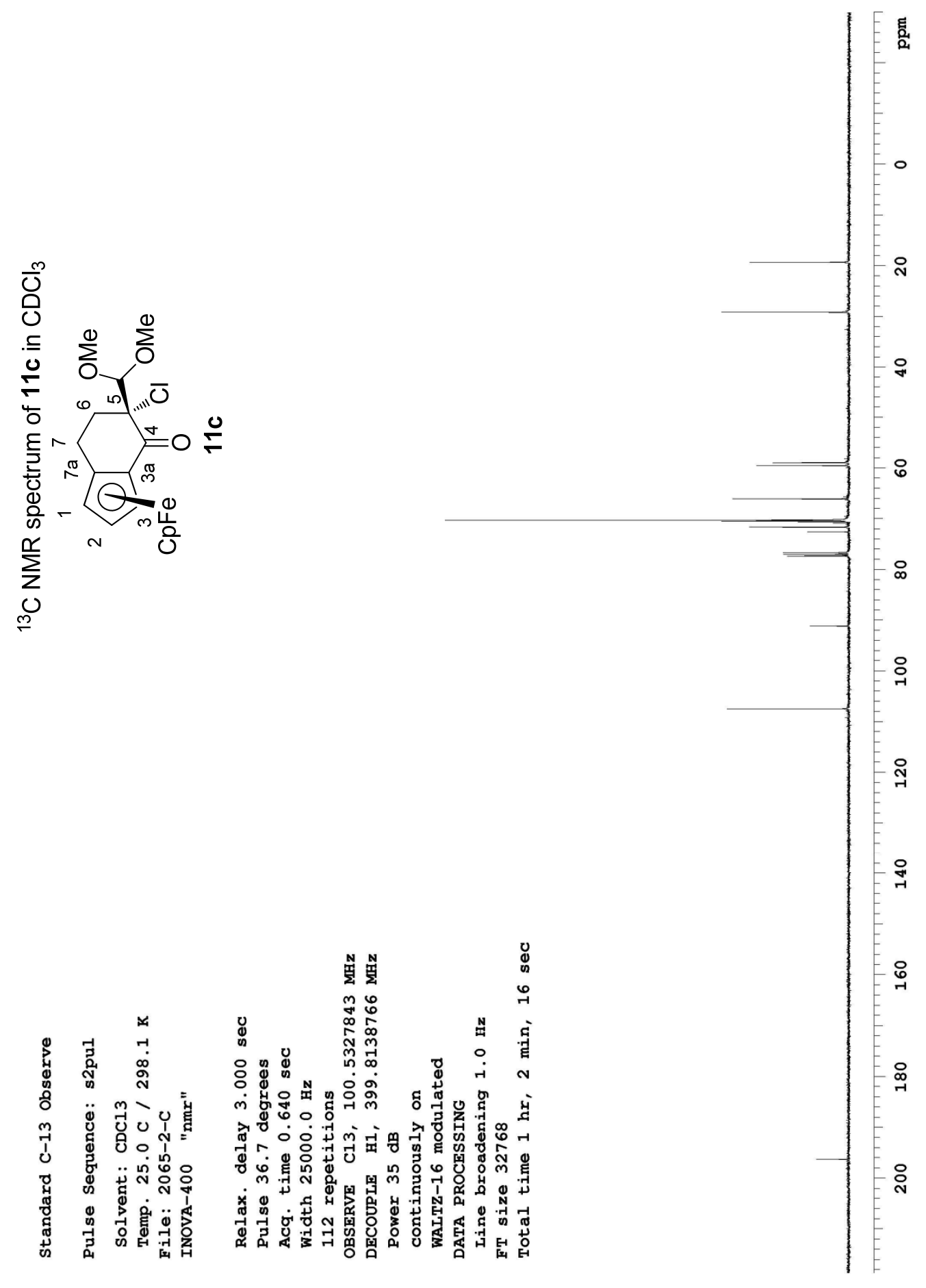

Figure A.10: ${ }^{13} \mathrm{C}$ NMR spectrum of 11c 


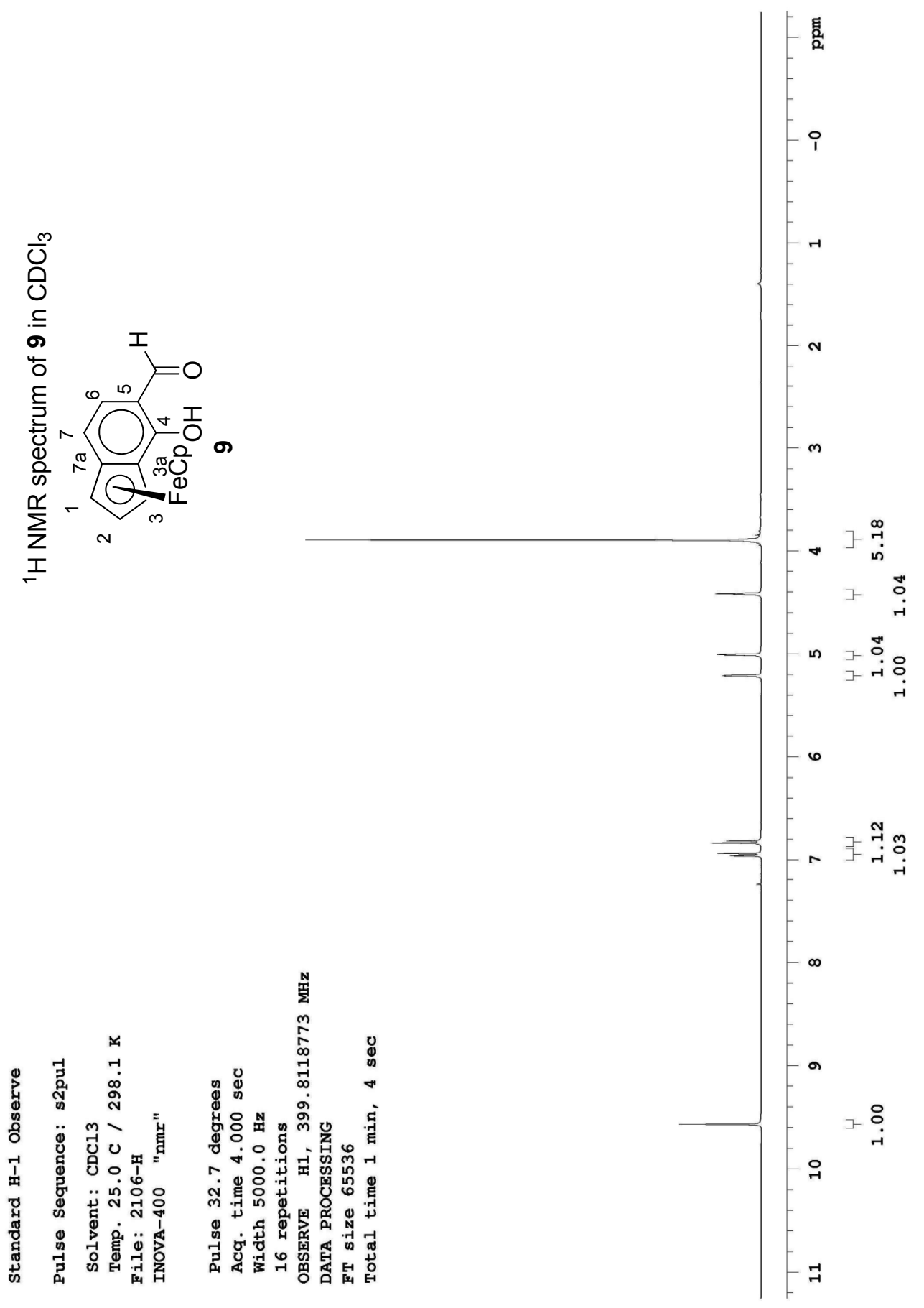

Figure A.11: ${ }^{1} \mathrm{H}$ NMR spectrum of 9 


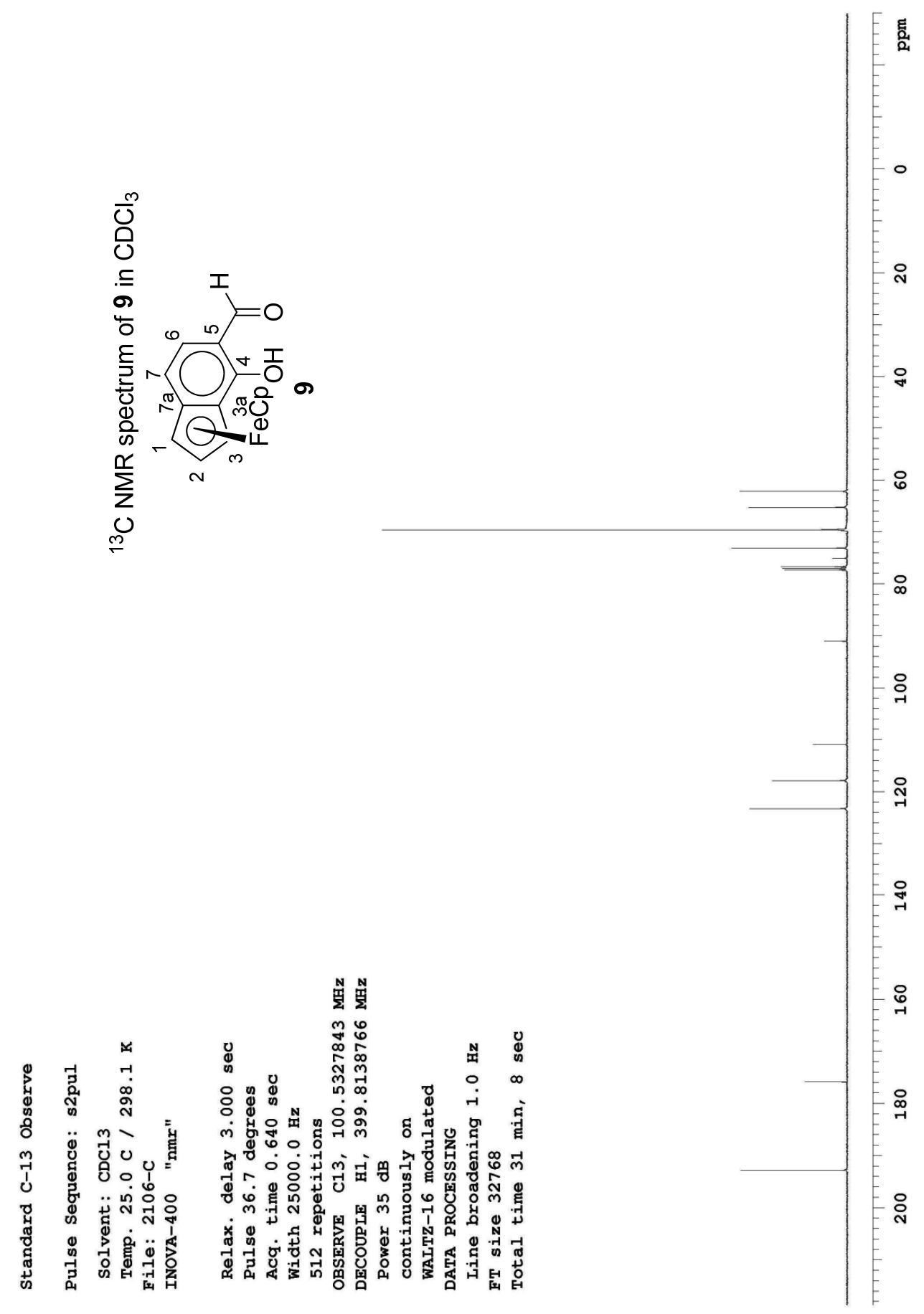

Figure A.12: ${ }^{13} \mathrm{C}$ NMR spectrum of 9 


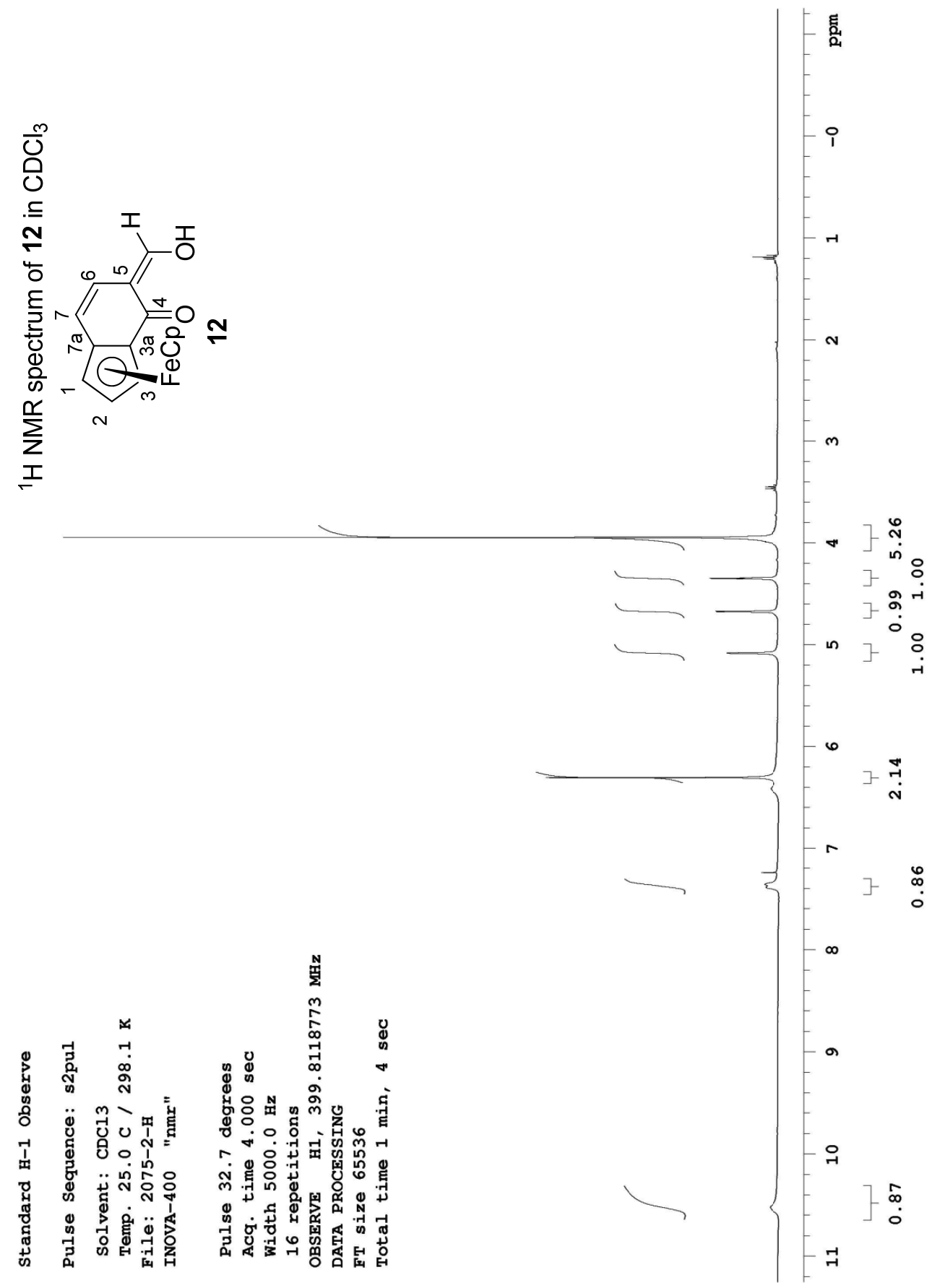

Figure A.13: ${ }^{1} \mathrm{H}$ NMR spectrum of $\mathbf{1 2}$ 


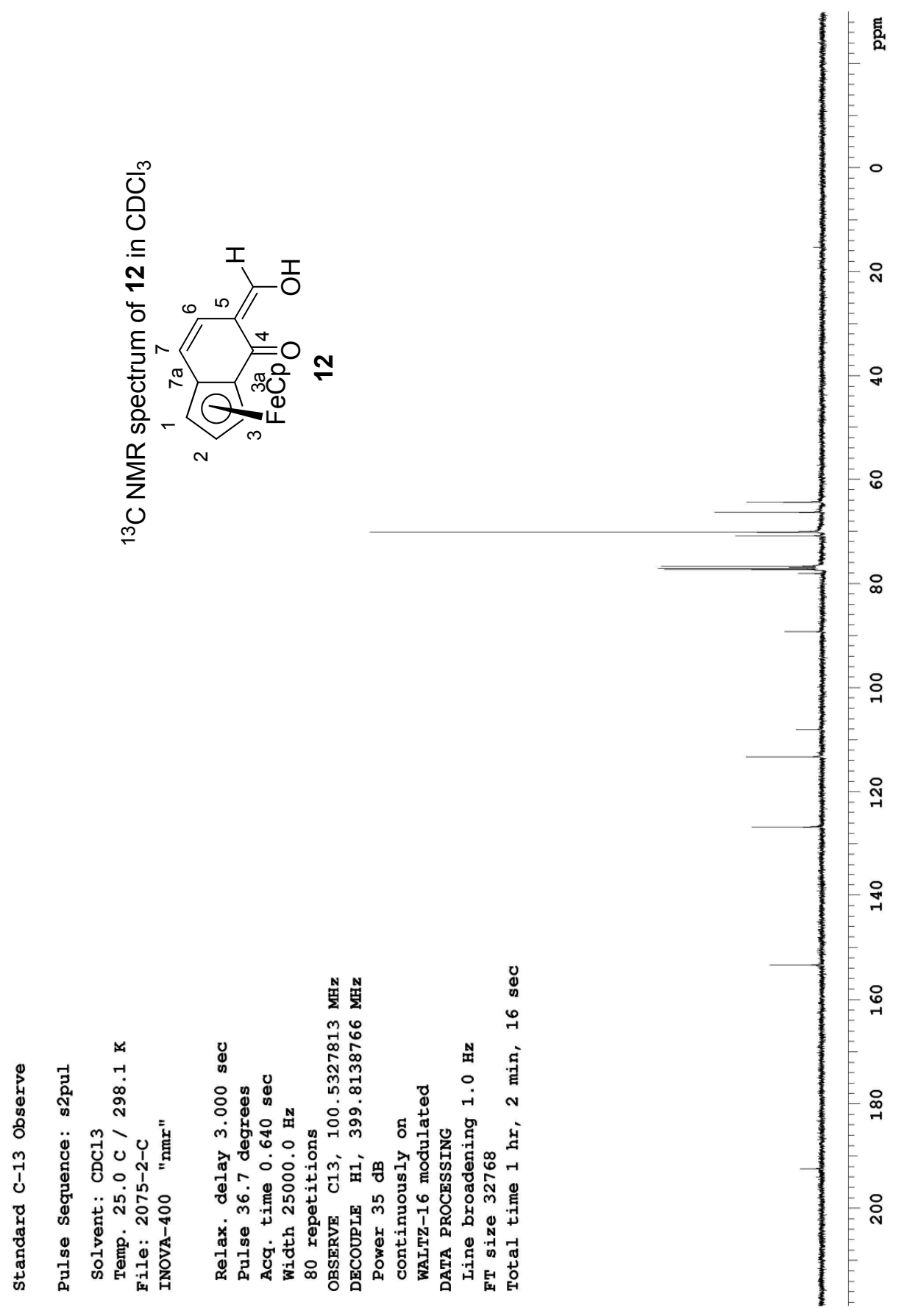

Figure A.14: ${ }^{13} \mathrm{C}$ NMR spectrum of 12 


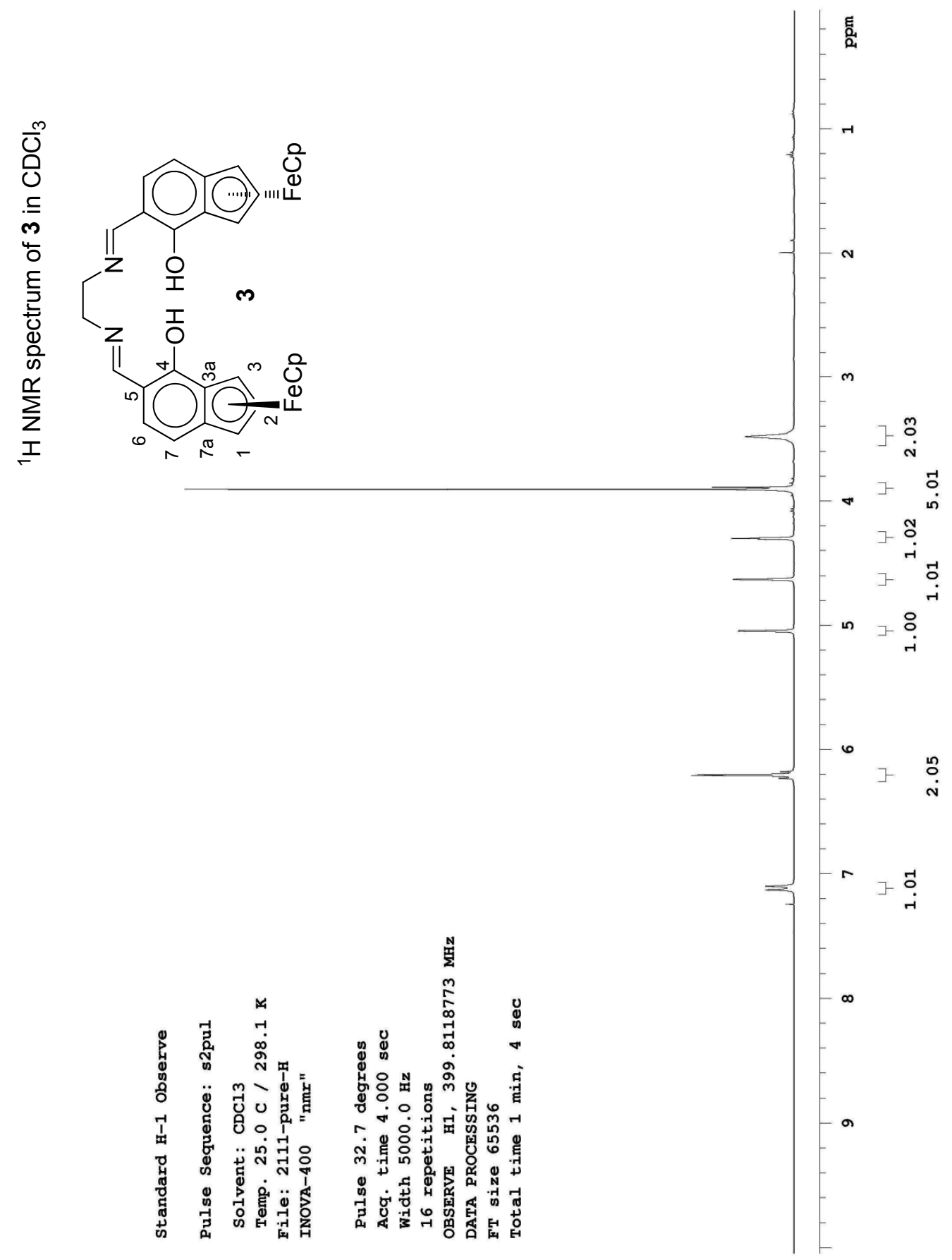

Figure A.15: ${ }^{1} \mathrm{H}$ NMR spectrum of 3 


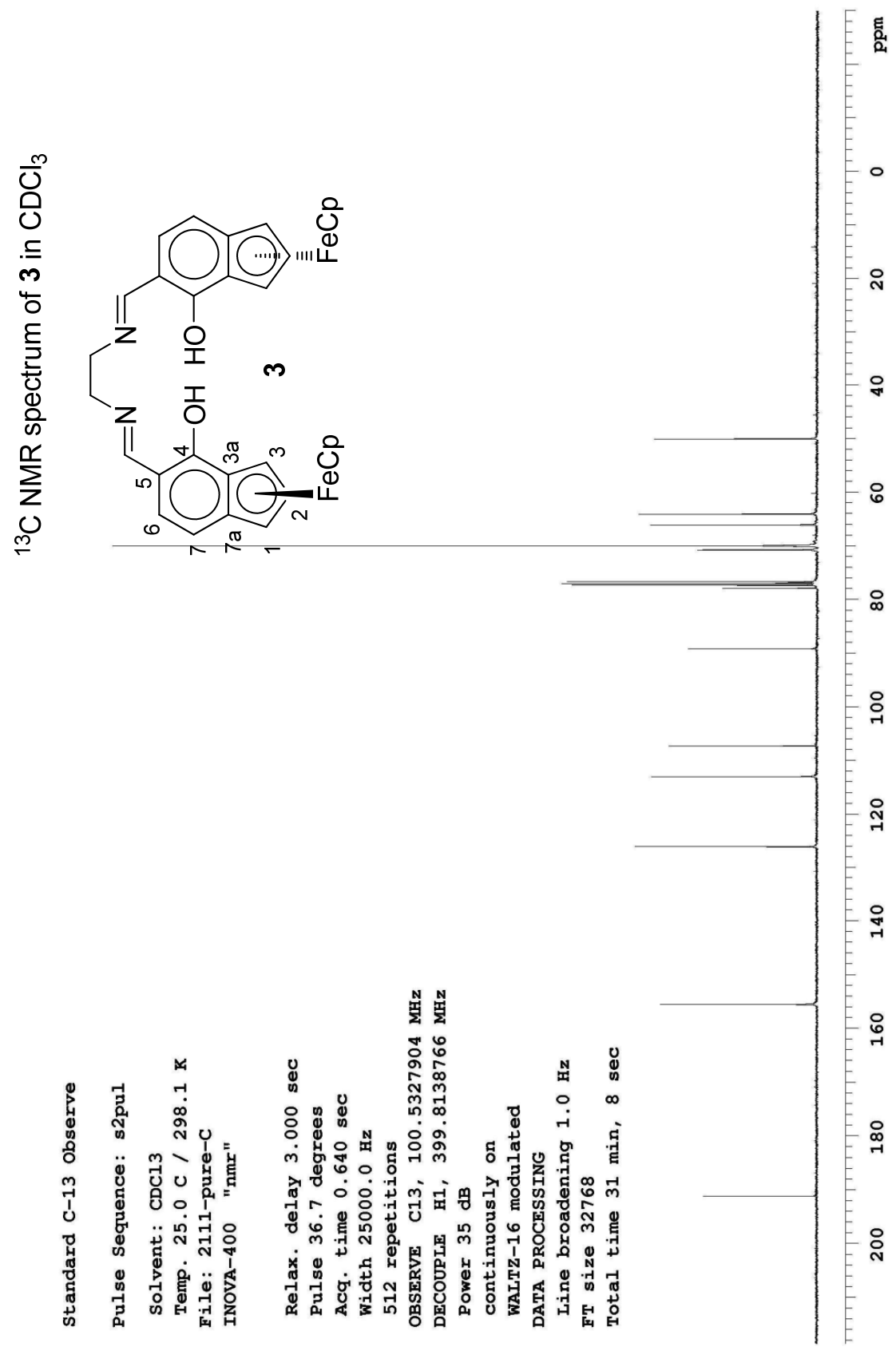

Figure A.16: ${ }^{13} \mathrm{C}$ NMR spectrum of $\mathbf{3}$ 


\section{A.3 X-ray crystal structure of compound 12}

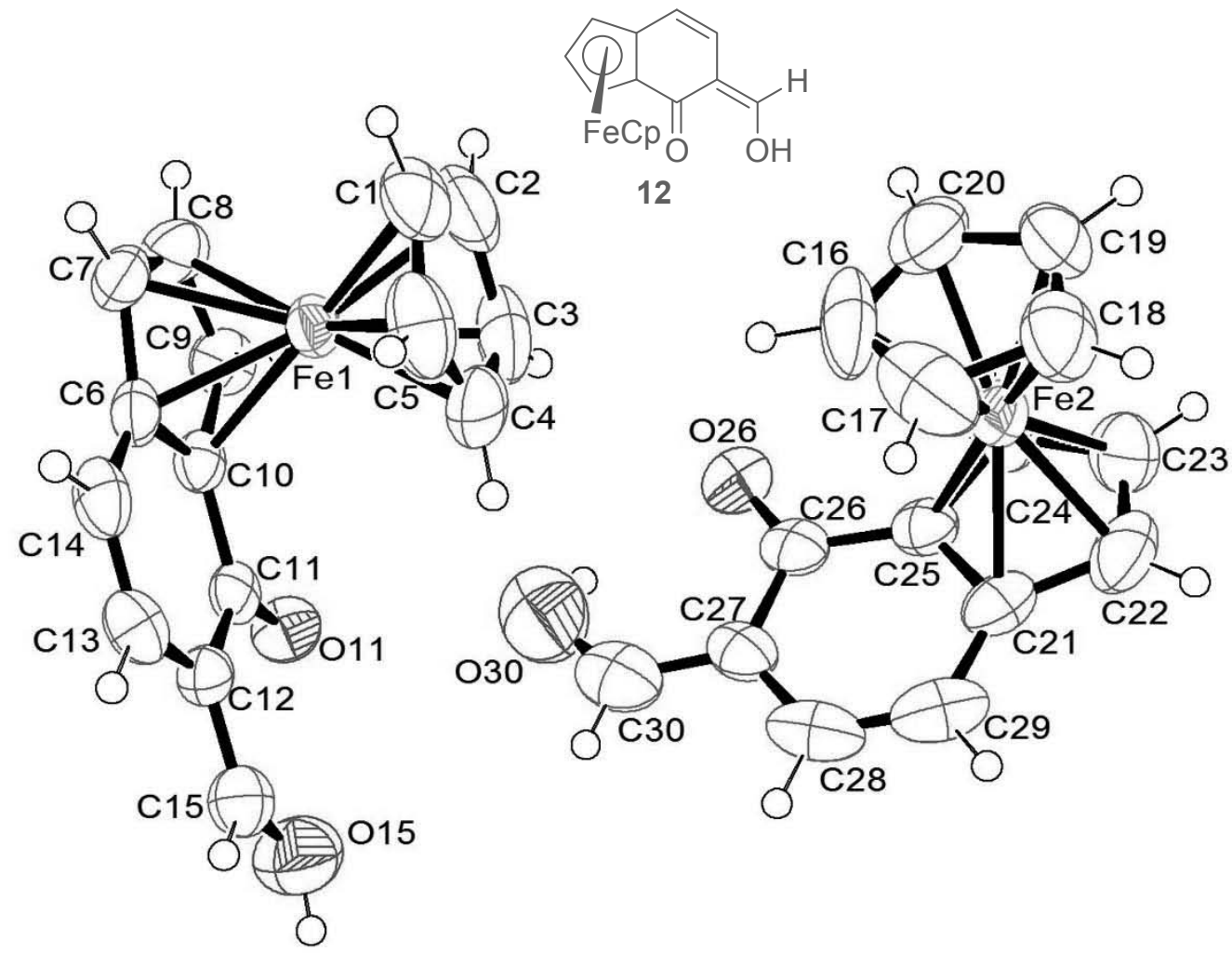

Figure A.17: X-ray crystal structure of compound 12 


\section{A.4 Low Resolution MS of Ferrosalen-Cu(II) Complex 13}

Wang/Fang \#2 ZX3081 (9145)
QT_060809_021 $16(0.317) \mathrm{Cm}(15: 24)$

100
MSU RTSF Mass Spectrometry Core

$$
\begin{aligned}
17^{+} \\
645.0
\end{aligned}
$$

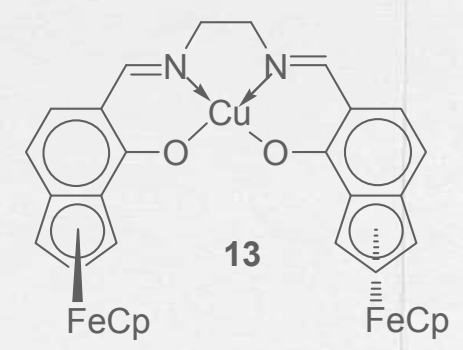

647.0

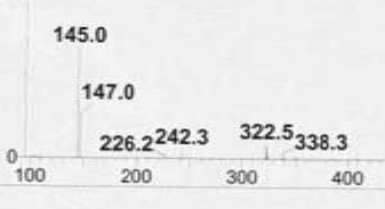

$\begin{array}{lll}497.1 & 541.0 & 643.0648 .0\end{array}$
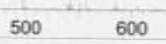

$711.1759 .2846 .0 \quad 894.1$

\begin{tabular}{crrr}
900 & \multicolumn{1}{c}{1064.1} & 1168.0 \\
9000 & 1100 & 1200 & $\mathrm{~m} / \mathrm{z}$
\end{tabular}

Figure A.18: Low Resolution MS of Ferrosalen-Cu(II) Complex 13 


\title{
Appendix B
}

\section{Supporting Information for Chapter 3}

\section{Ferrosalen and Ferrosalen-type Ligands: Structural Modulation and Applications in Asymmetric Catalysis}

\author{
Xiang Zhang, Rudy L. Luck, Shiyue Fang
}

\section{Supplemental Information}

(Compound numbers correspond to the numbers in the article: Zhang, Xiang; Luck, Rudy; Fang, Shiyue. Organometallics, 2011, accepted for publication. This article is in Chapter 3 of the dissertation.) 
B. $1{ }^{1} \mathrm{H}$ and ${ }^{13} \mathrm{C}$ NMR spectra of new compounds
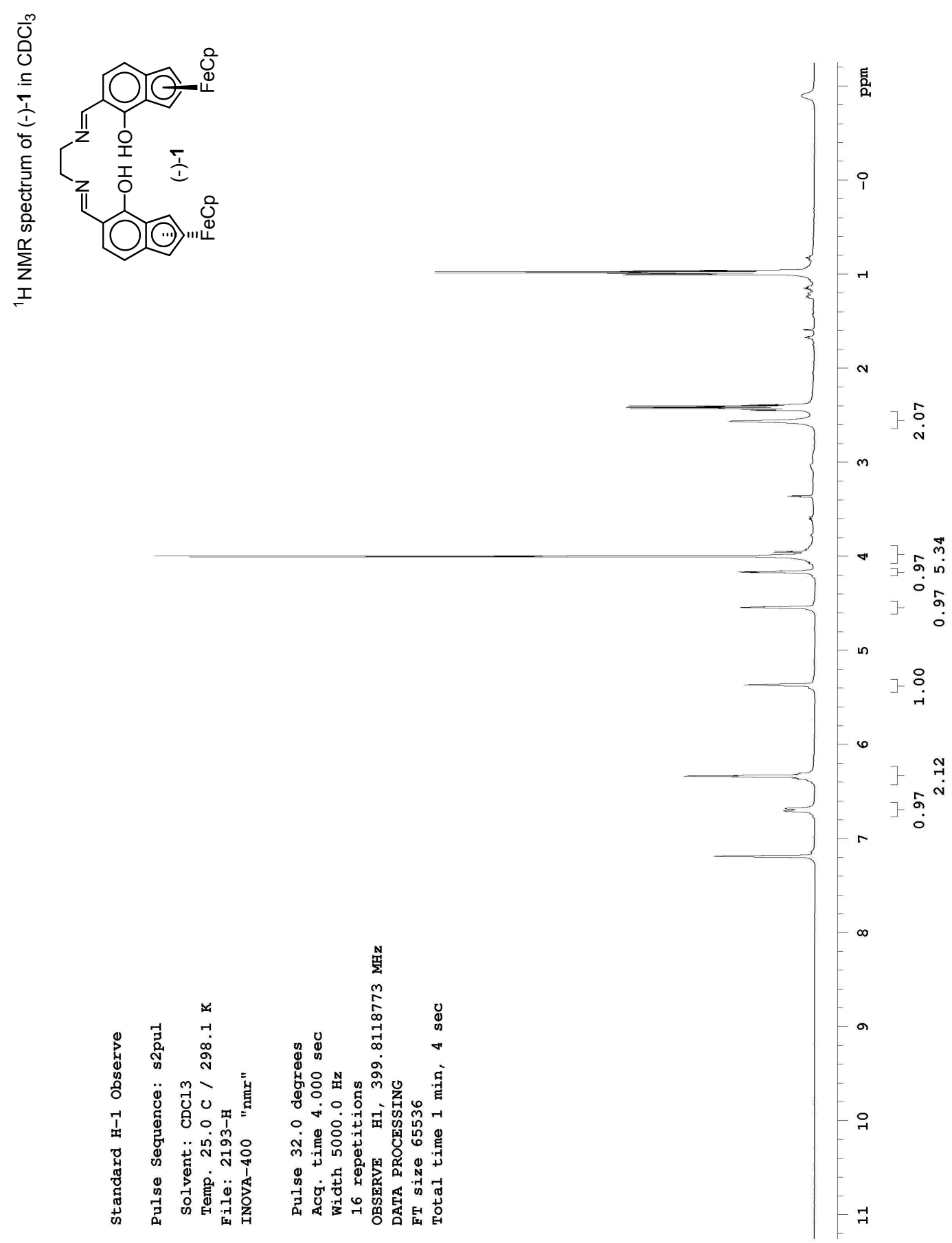

Figure B.1: ${ }^{1} \mathrm{H}$ NMR spectrum of (-)-1 

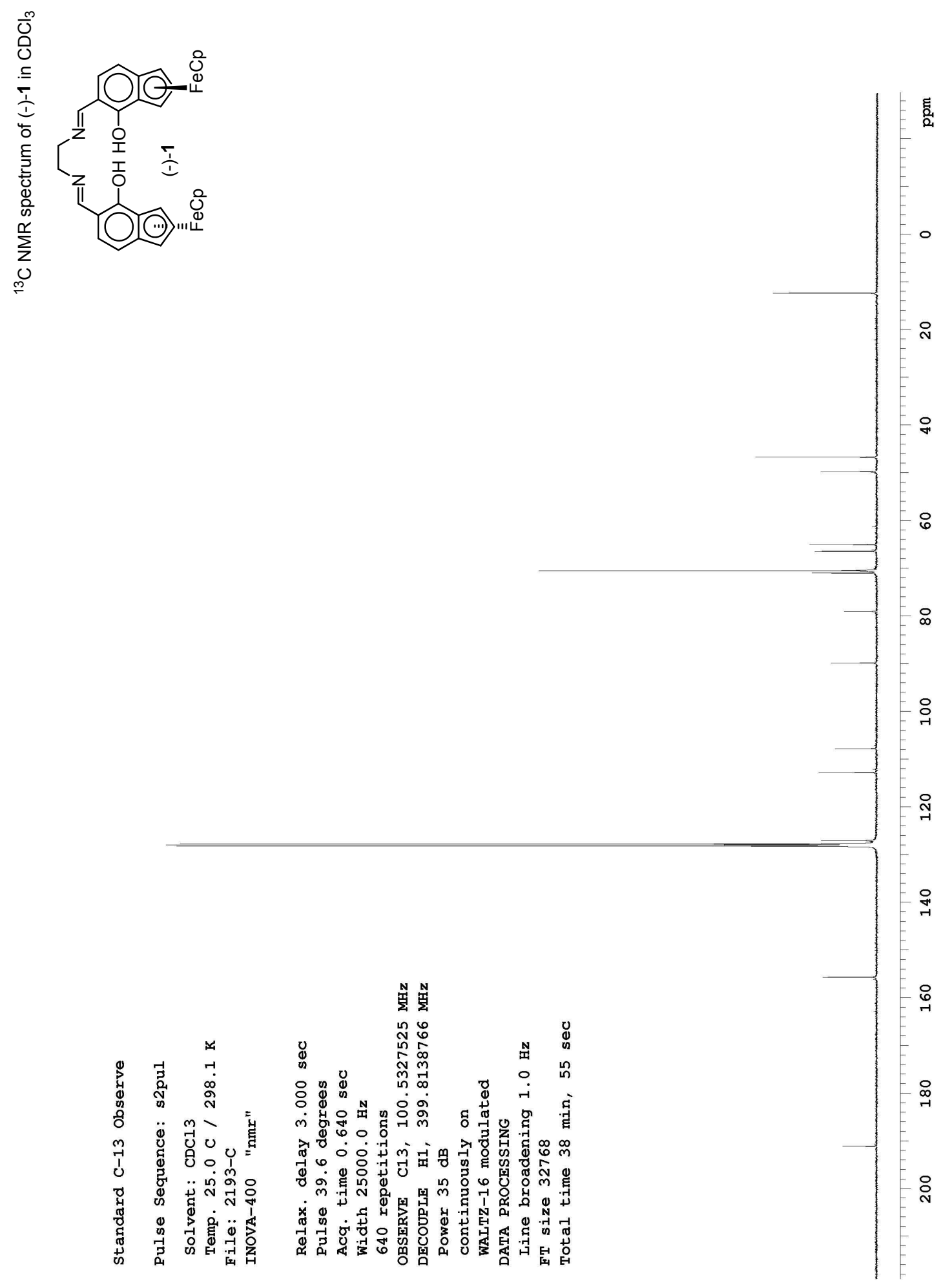

Figure B.2: ${ }^{13} \mathrm{C}$ NMR spectrum of (-)-1 

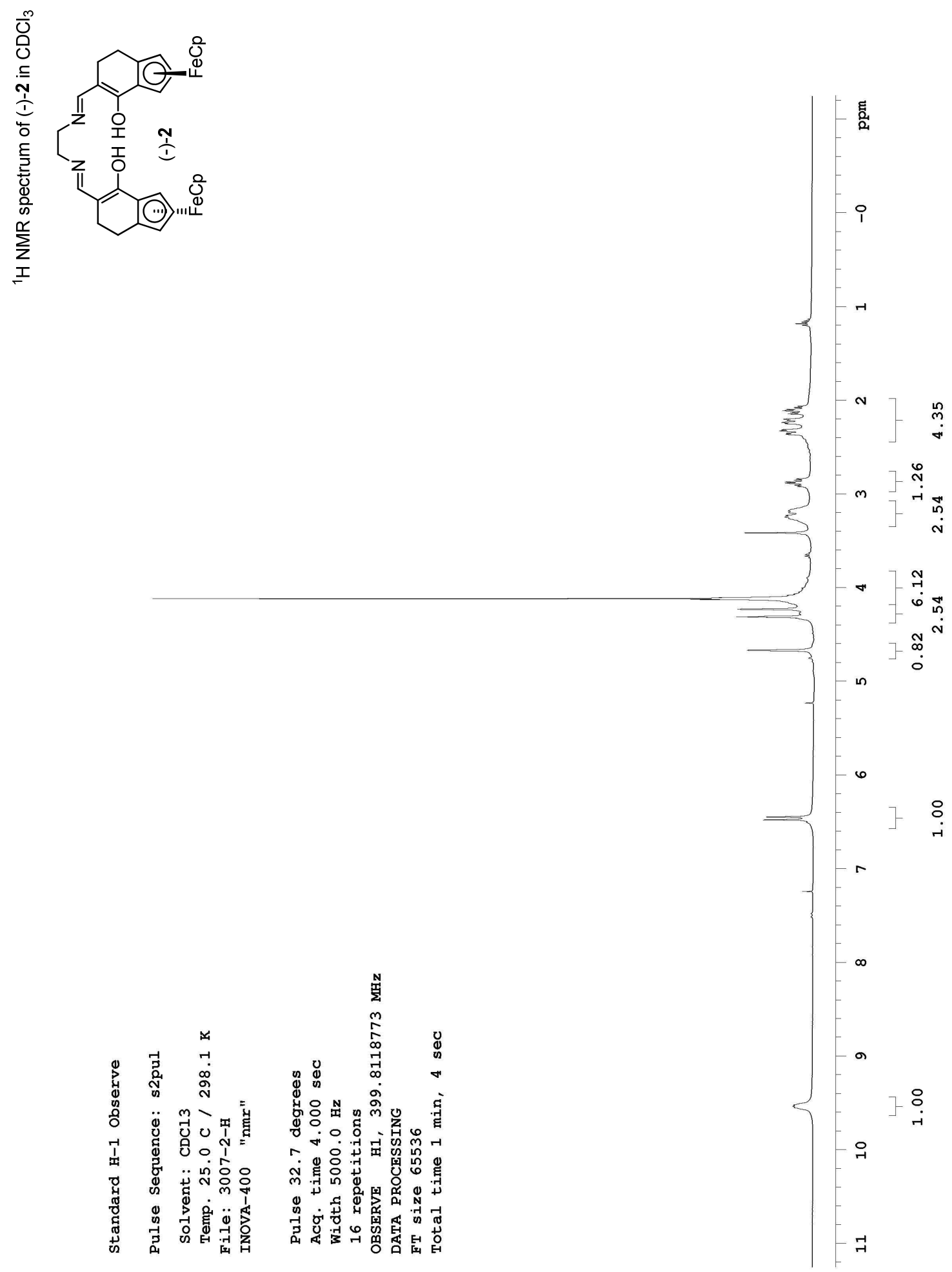

Figure B.3: ${ }^{1} \mathrm{H}$ NMR spectrum of (-)-2 

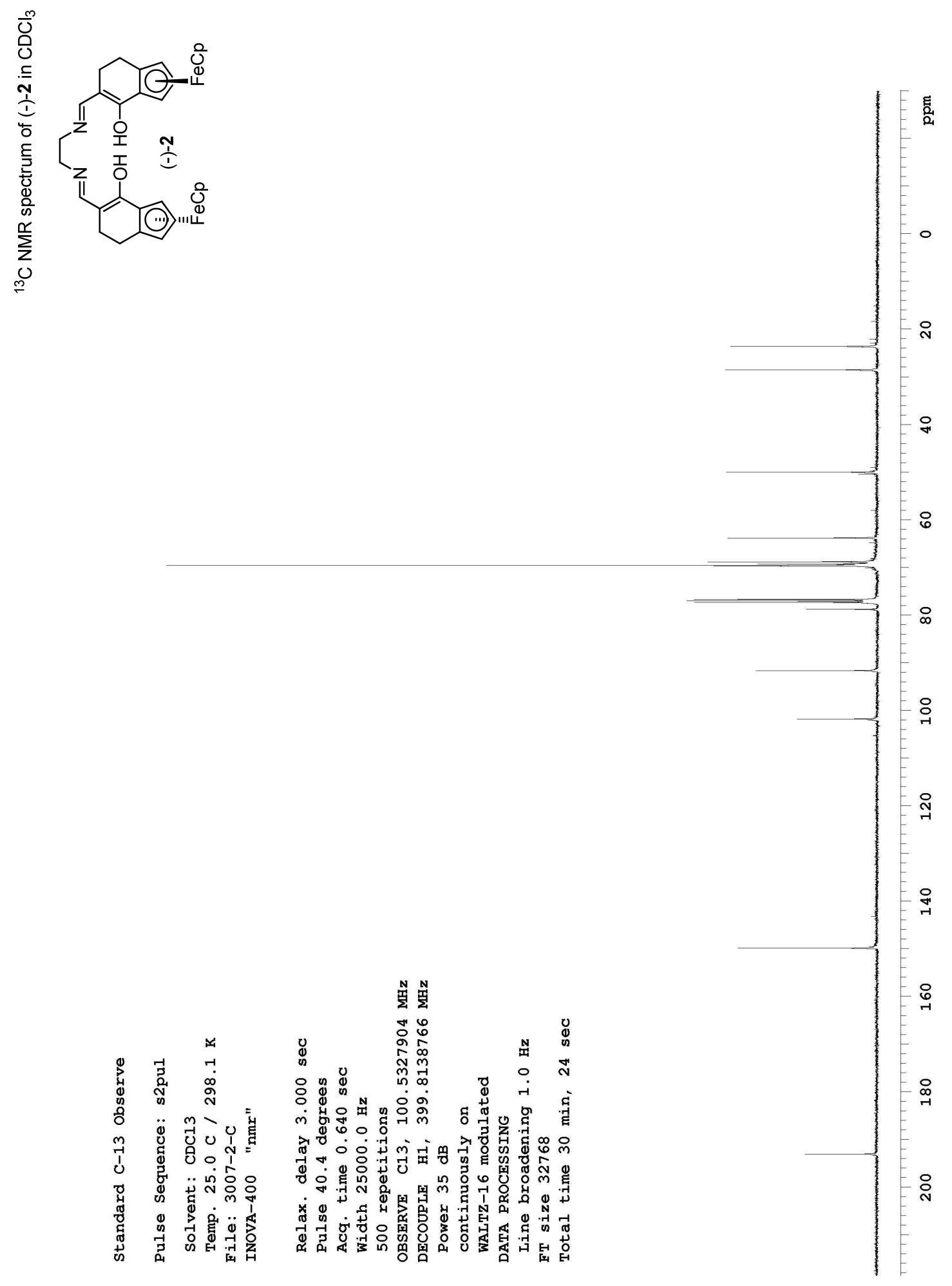

Figure B.4: ${ }^{13} \mathrm{C}$ NMR spectrum of (-)-2 

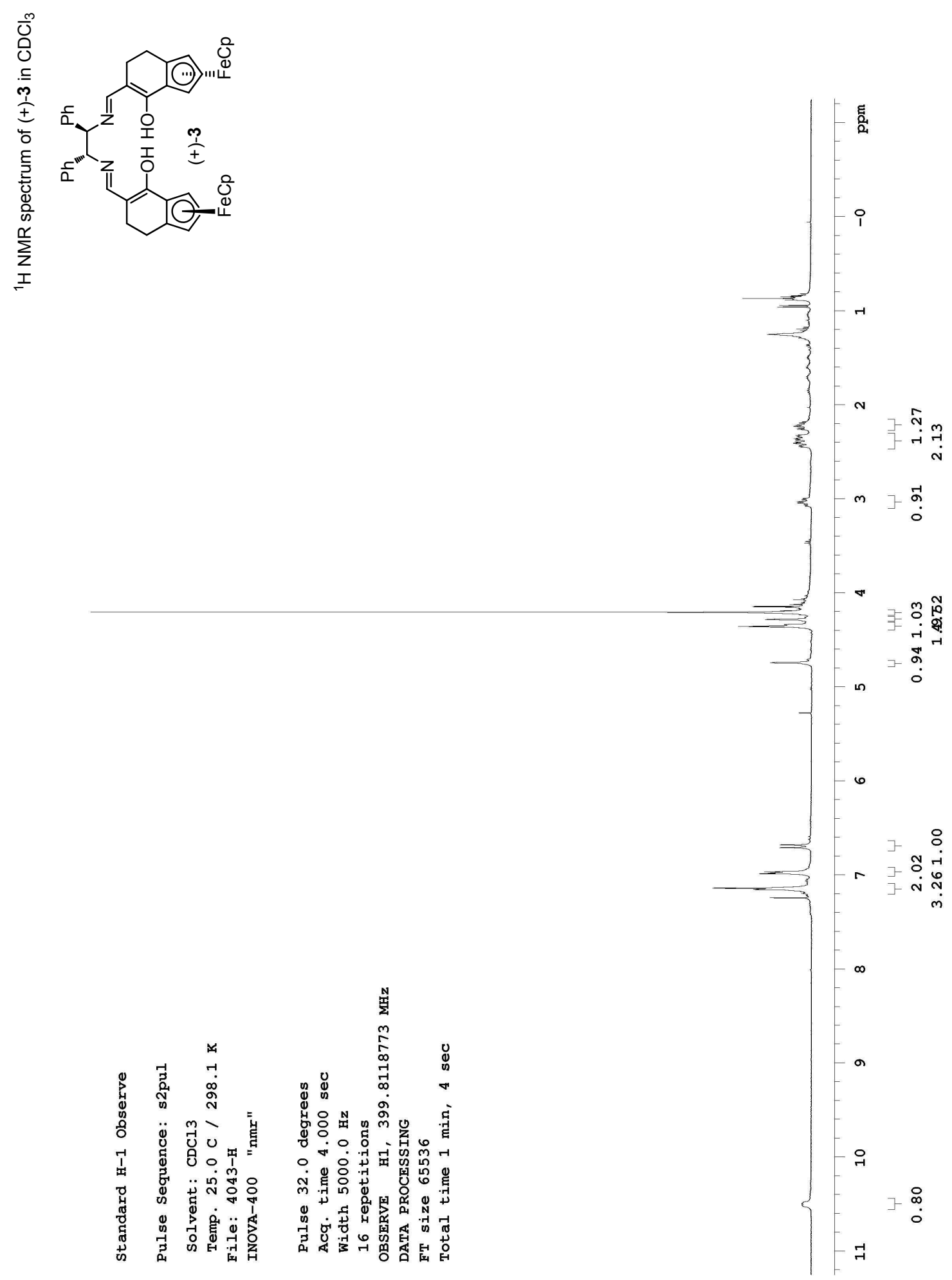

Figure B.5: ${ }^{1} \mathrm{H}$ NMR spectrum of (+)-3 

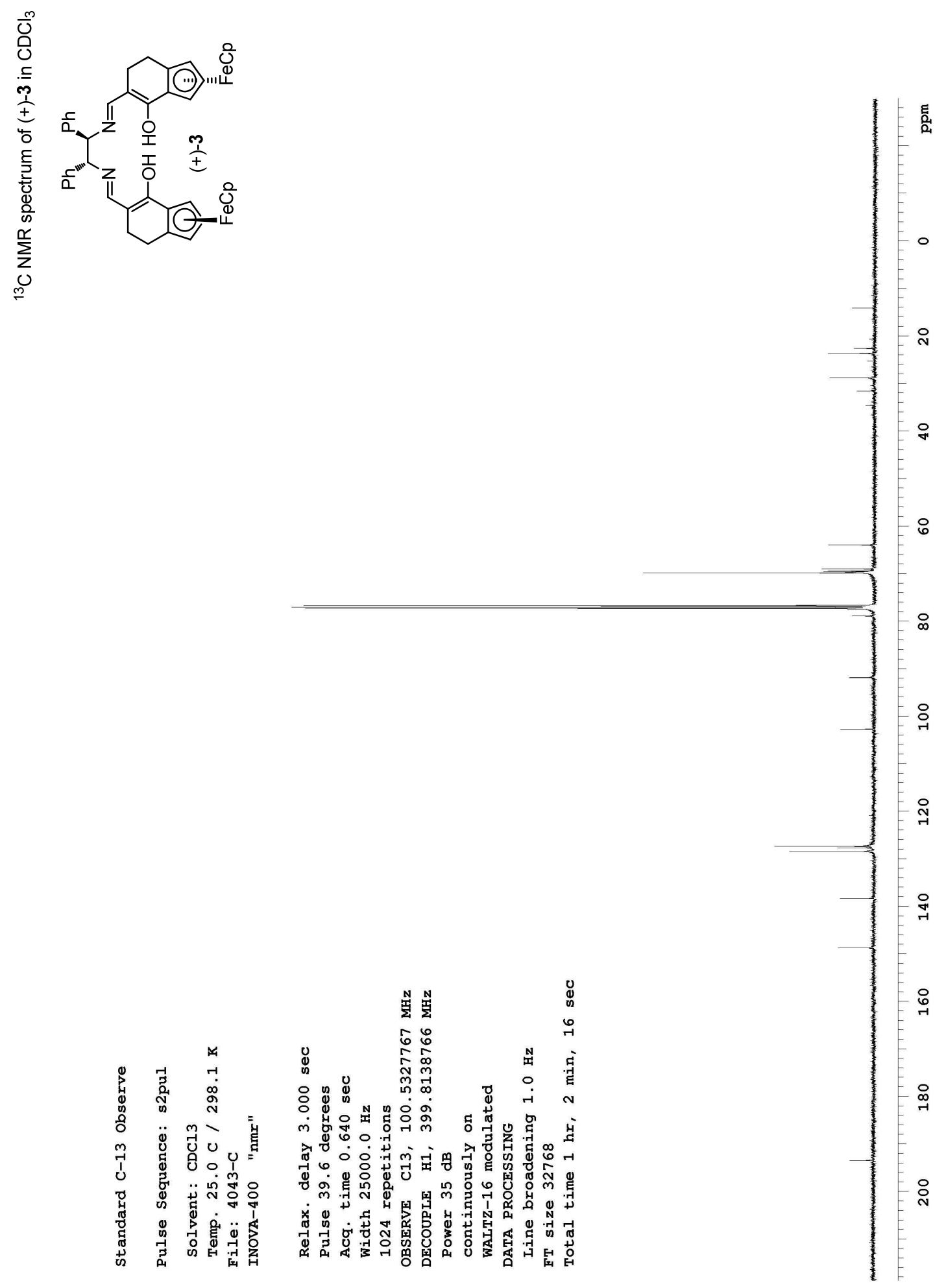

Figure B.6: ${ }^{13} \mathrm{C}$ NMR spectrum of $(+)-3$ 

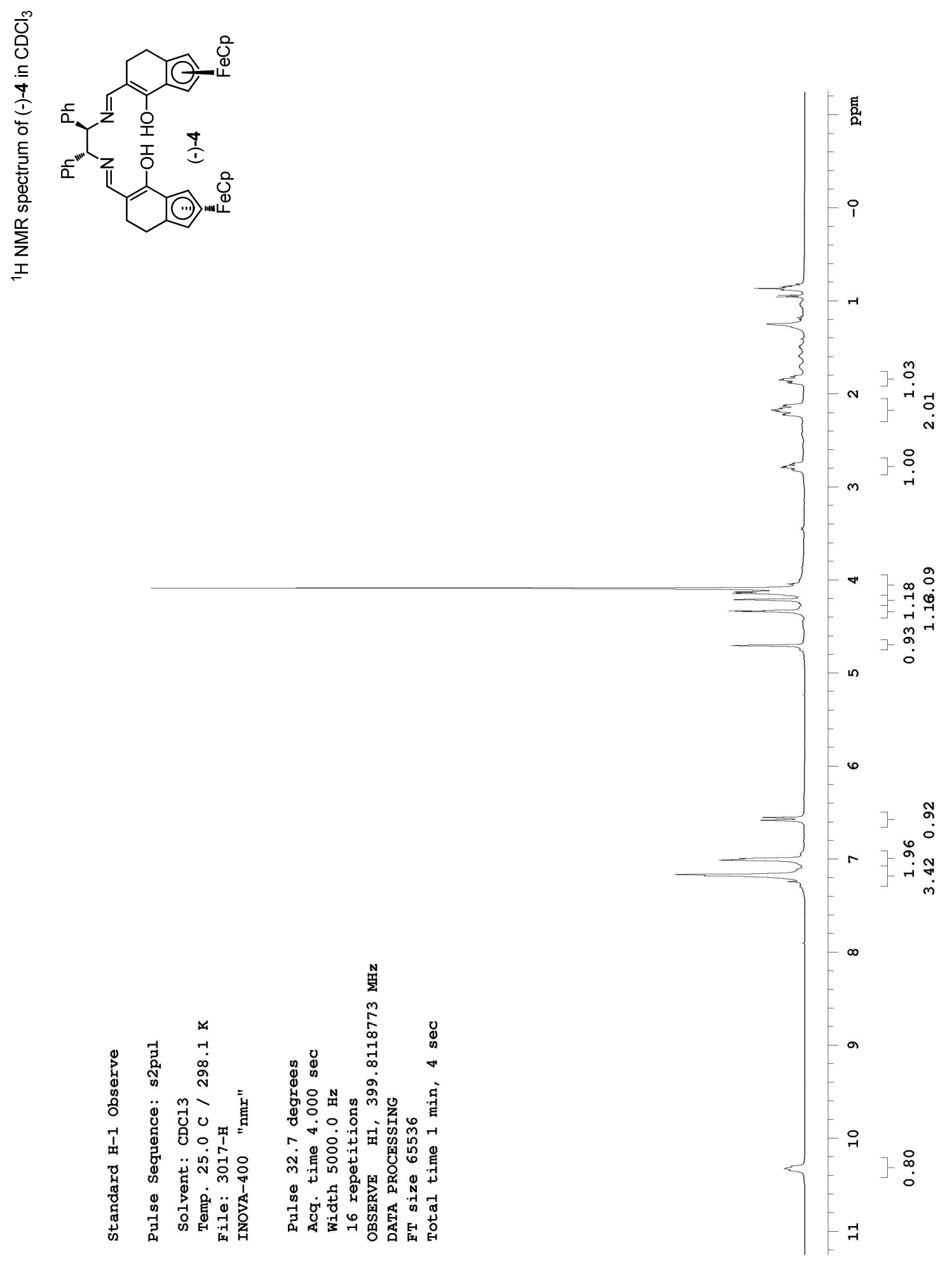

Figure B.7: ${ }^{1} \mathrm{H}$ NMR spectrum of (-)-4 

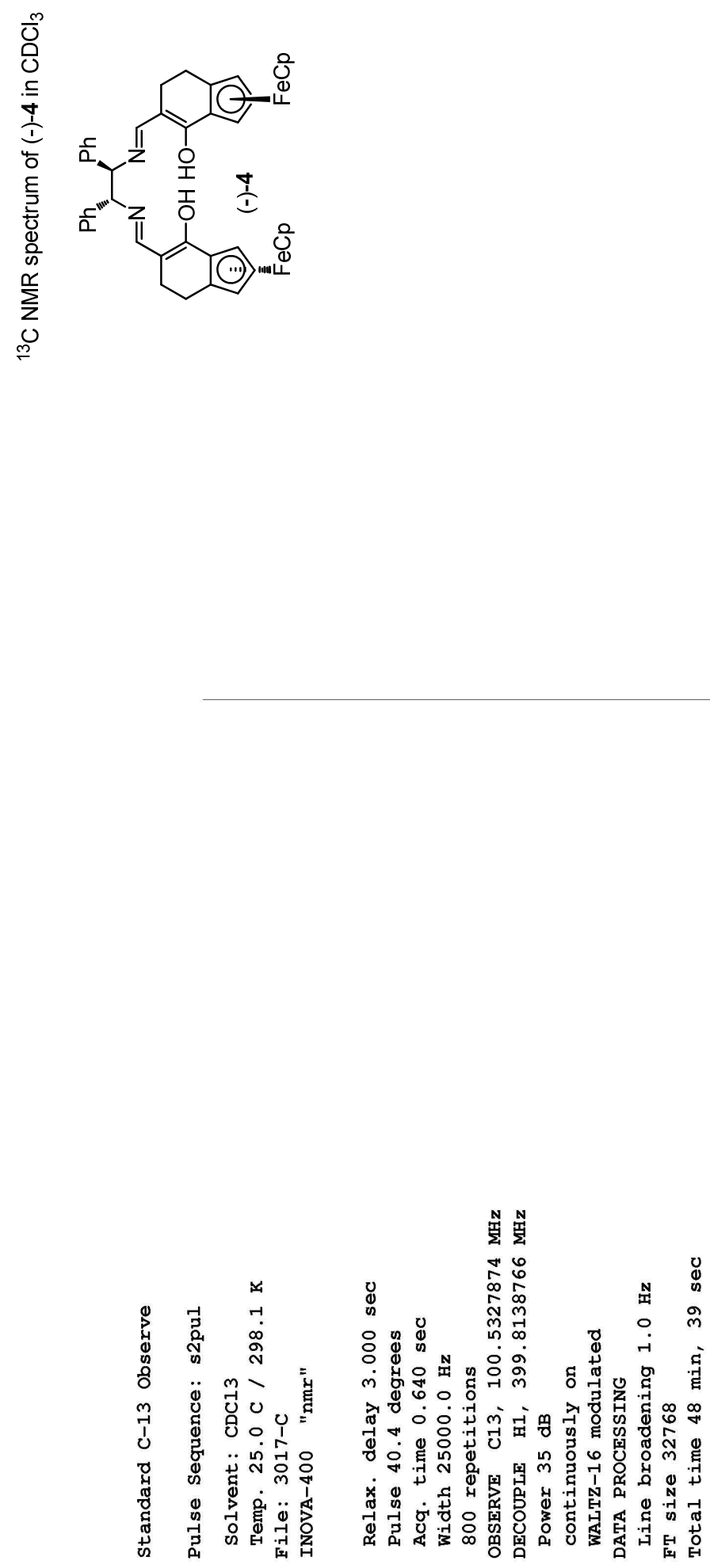

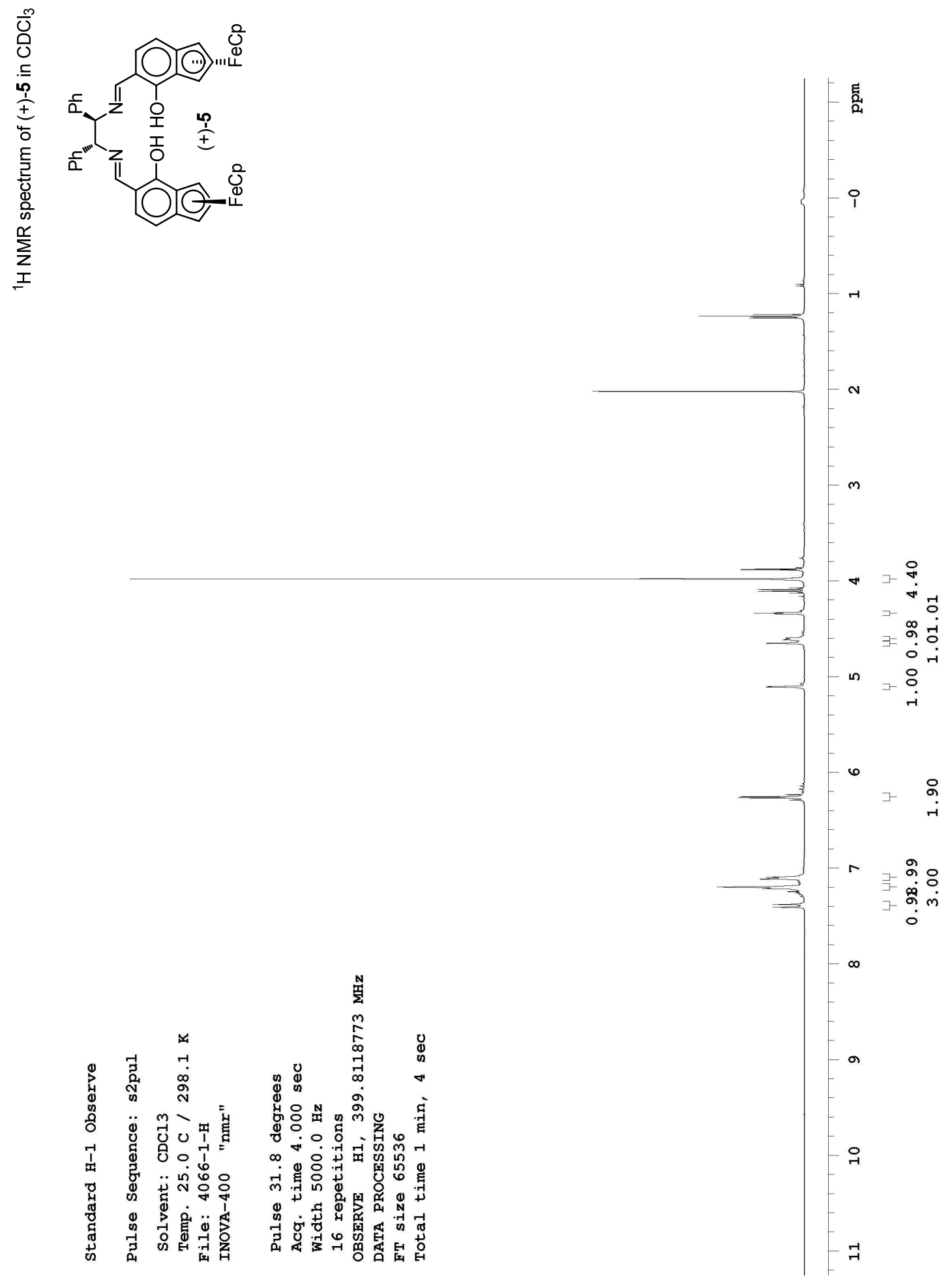

Figure B.9: ${ }^{1} \mathrm{H}$ NMR spectrum of $(+)-5$ 

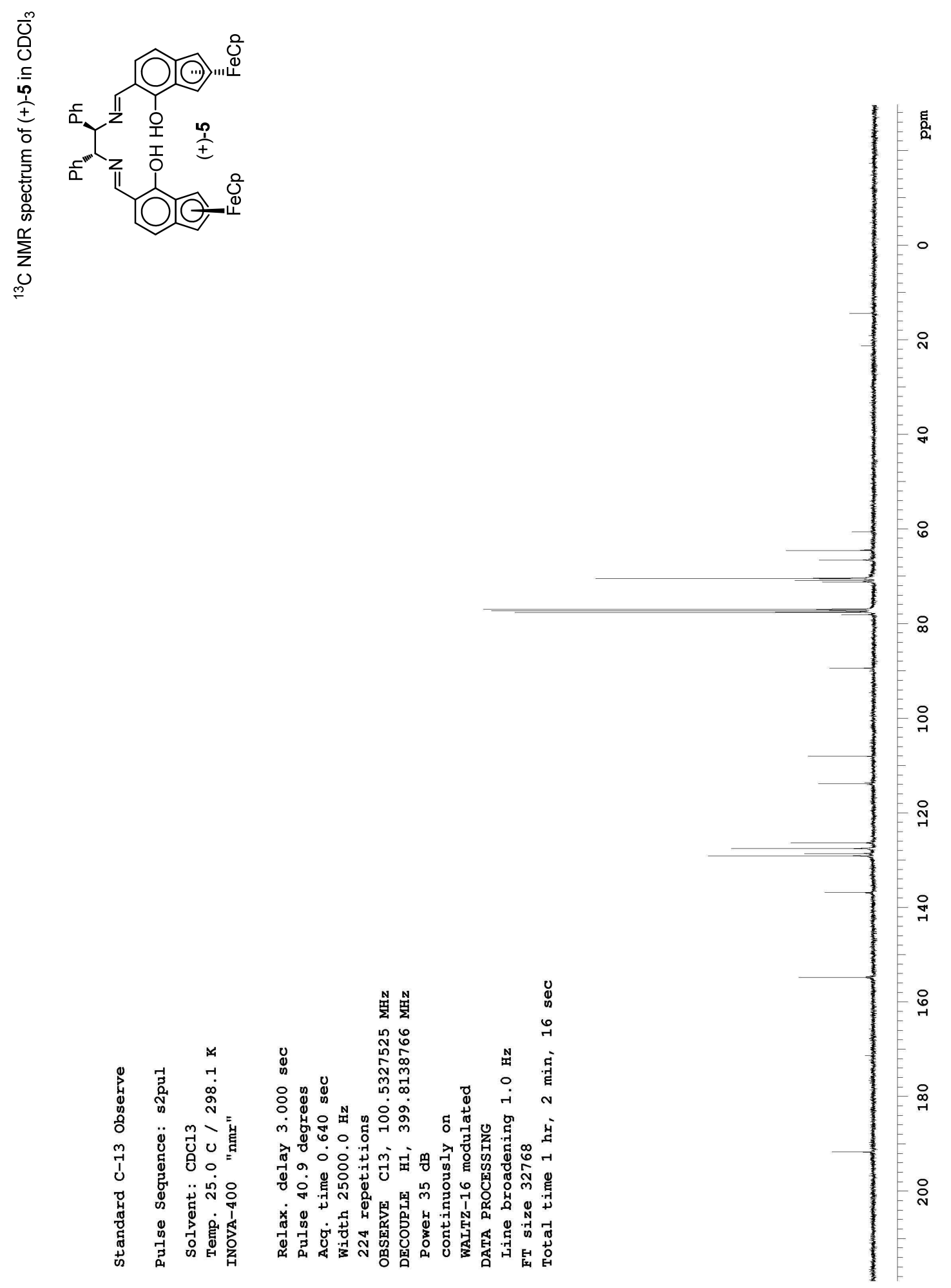

Figure B.10: ${ }^{13} \mathrm{C}$ NMR spectrum of $(+)-5$ 

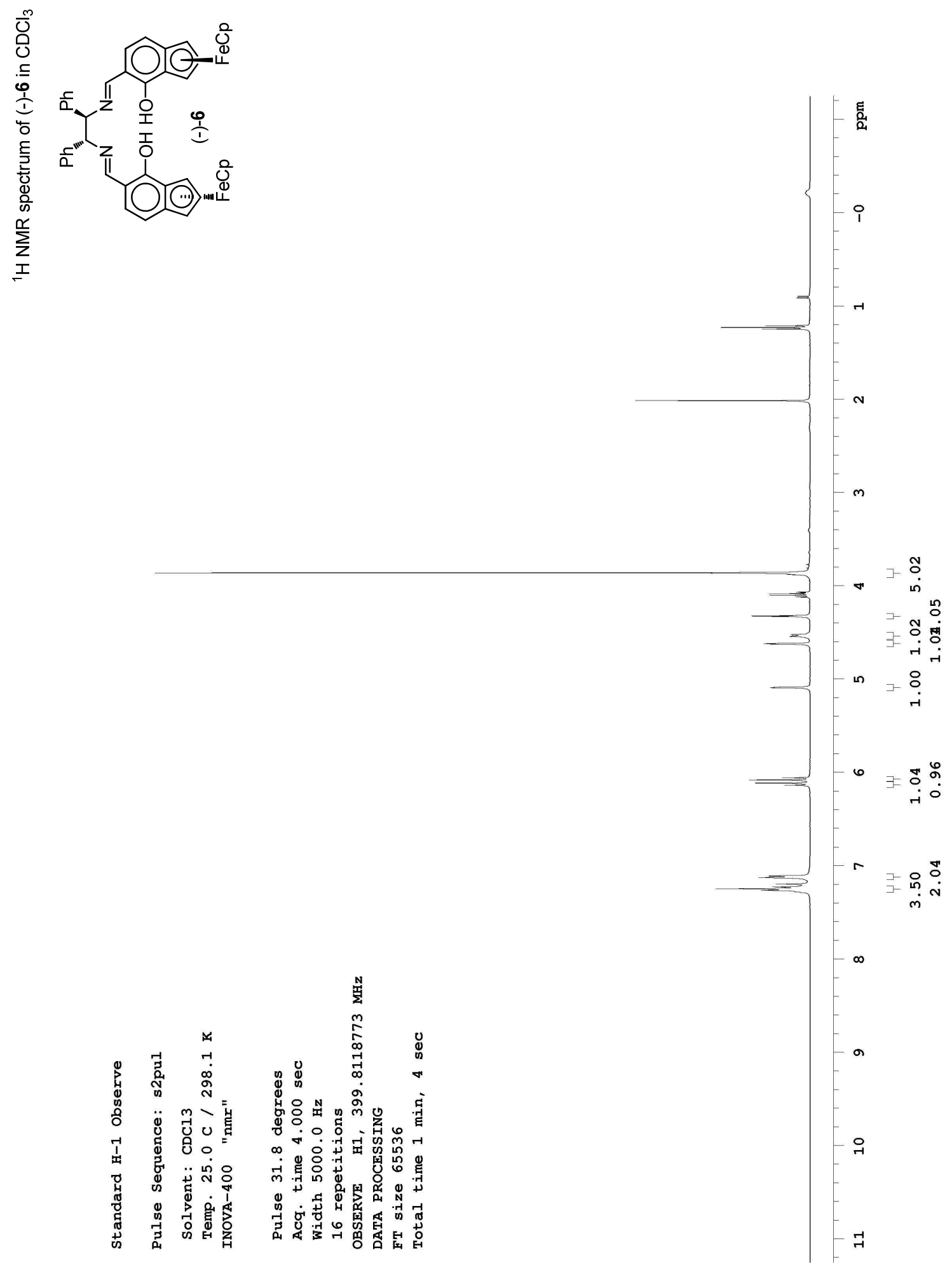

Figure B.11: ${ }^{1} \mathrm{H}$ NMR spectrum of (-)-6 

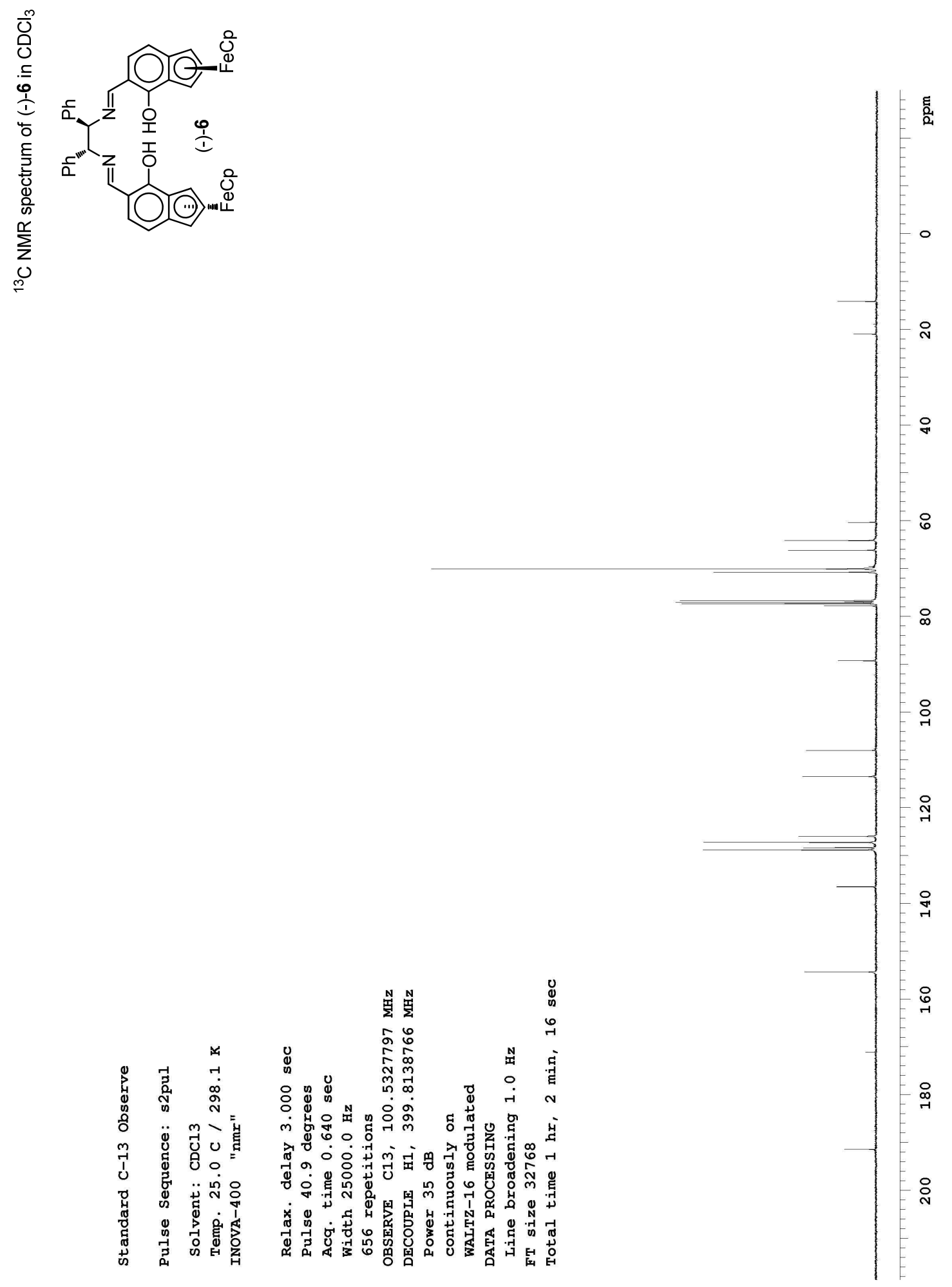

Figure B.12: ${ }^{13} \mathrm{C}$ NMR spectrum of (-)-6 

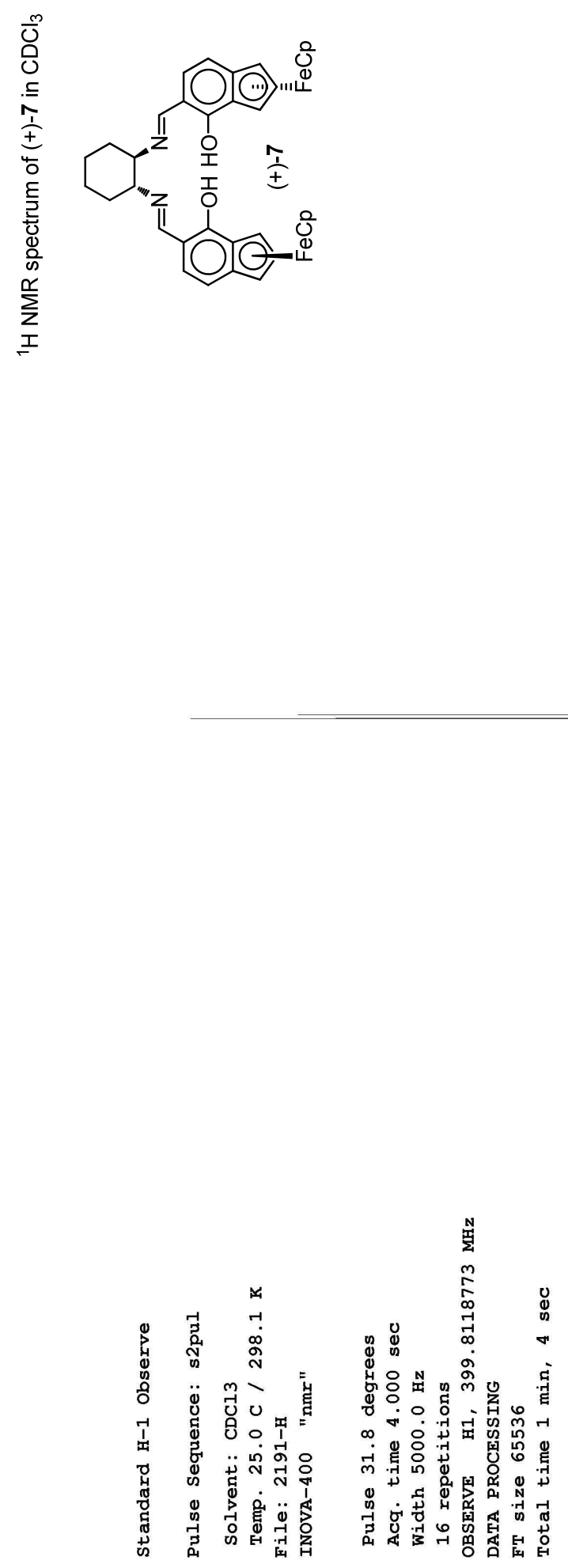

Figure B.13: ${ }^{1} \mathrm{H}$ NMR spectrum of (+)-7 

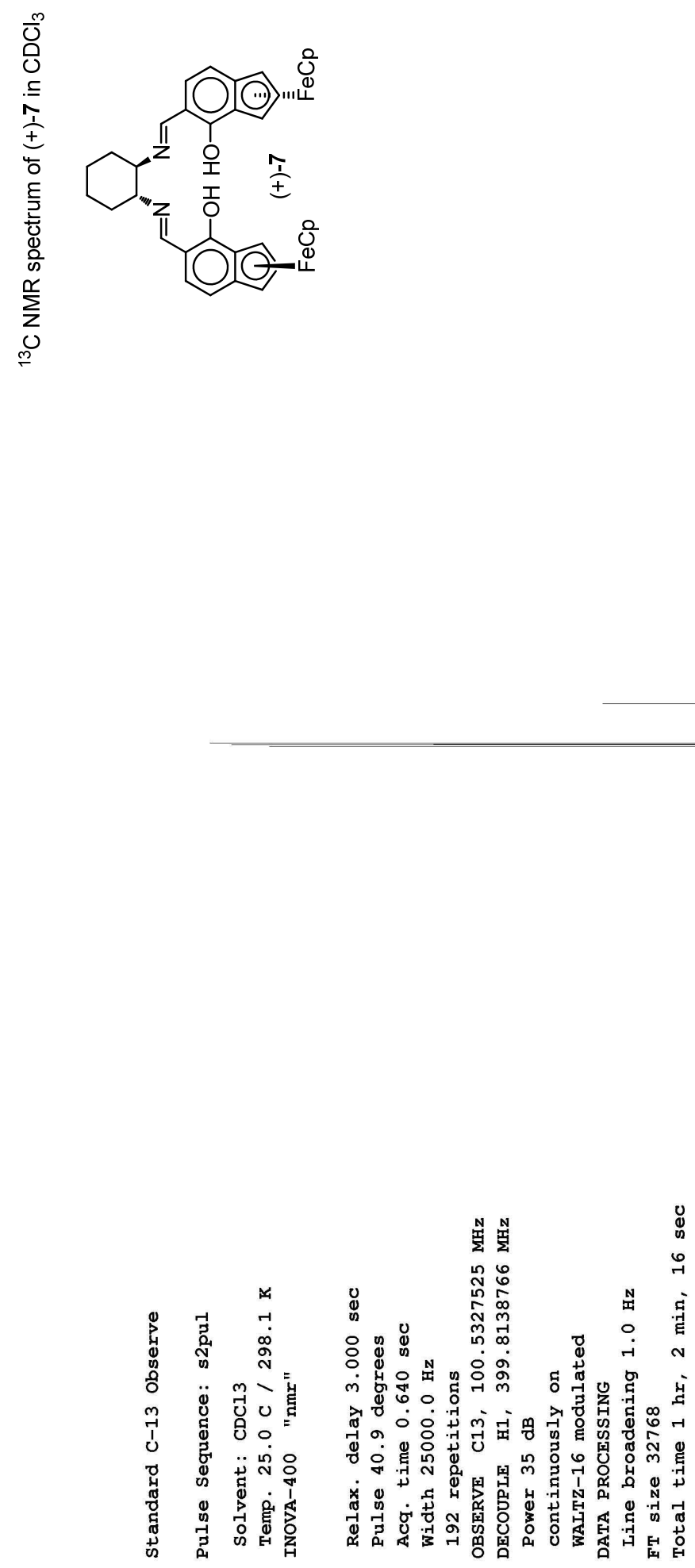

Figure B.14: ${ }^{13} \mathrm{C}$ NMR spectrum of $(+)-7$ 

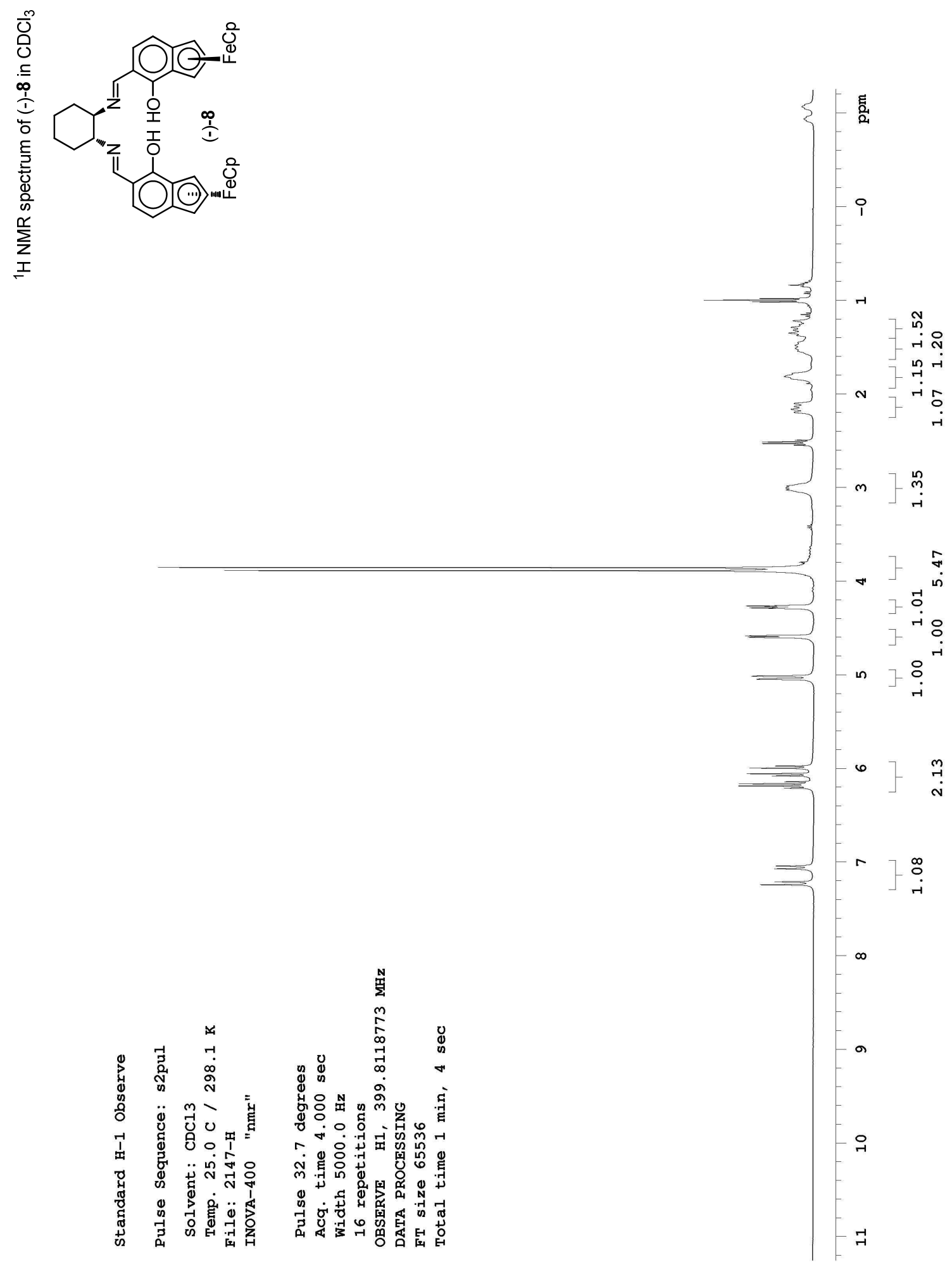

Figure B.15: ${ }^{1} \mathrm{H}$ NMR spectrum of (-)-8 

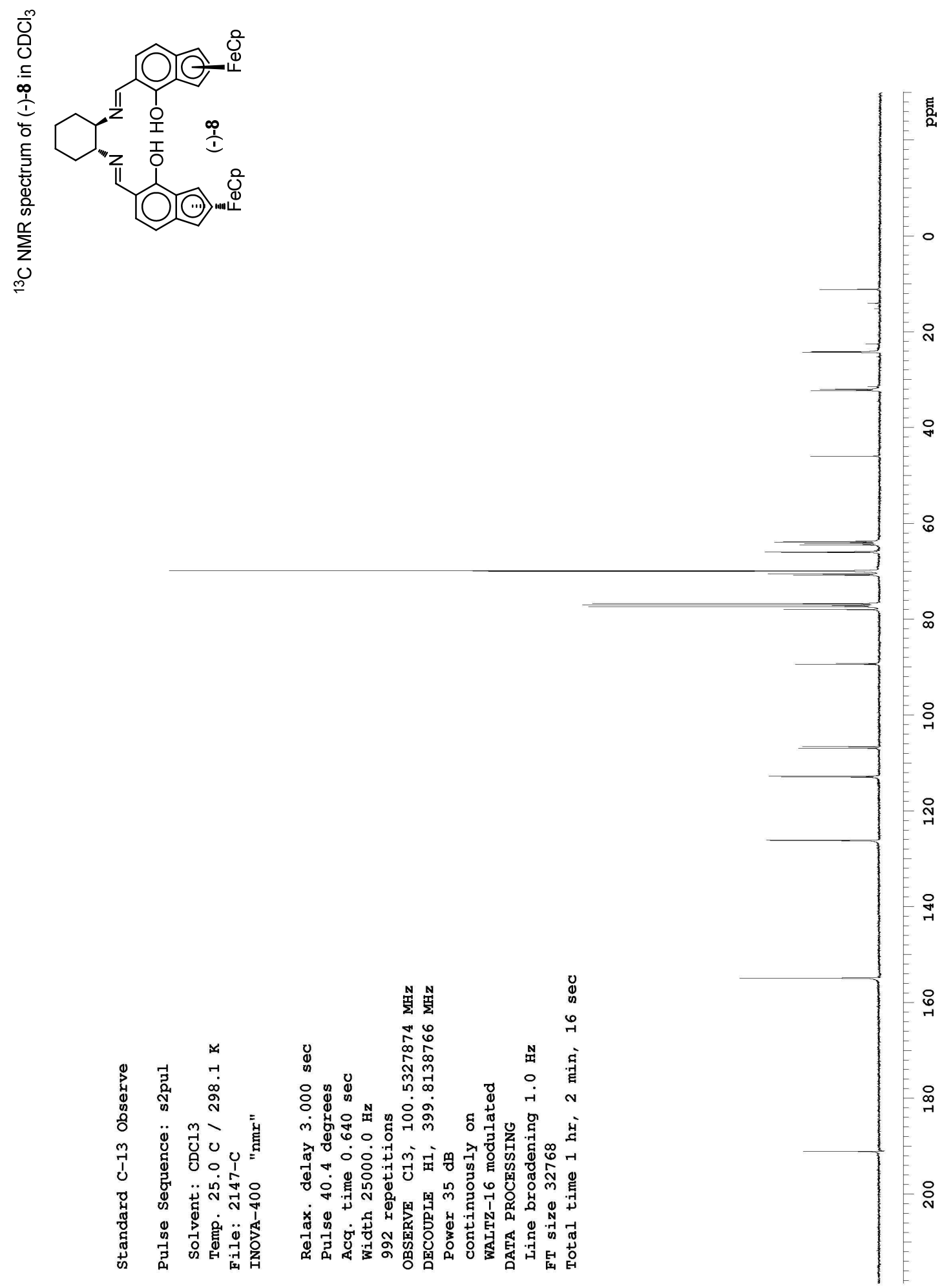

Figure B.16: ${ }^{13} \mathrm{C}$ NMR spectrum of (-)-8 

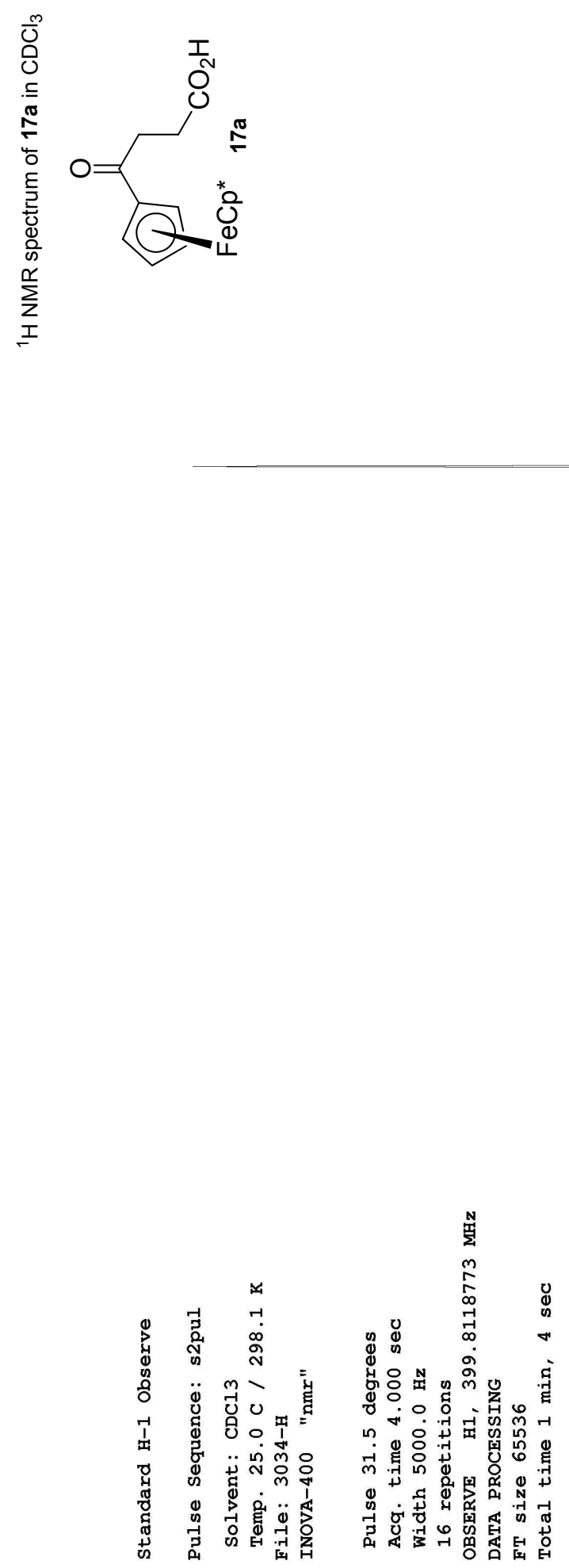

ᄀ各

Figure B.17: ${ }^{1} \mathrm{H}$ NMR spectrum of $\mathbf{1 7 a}$ 

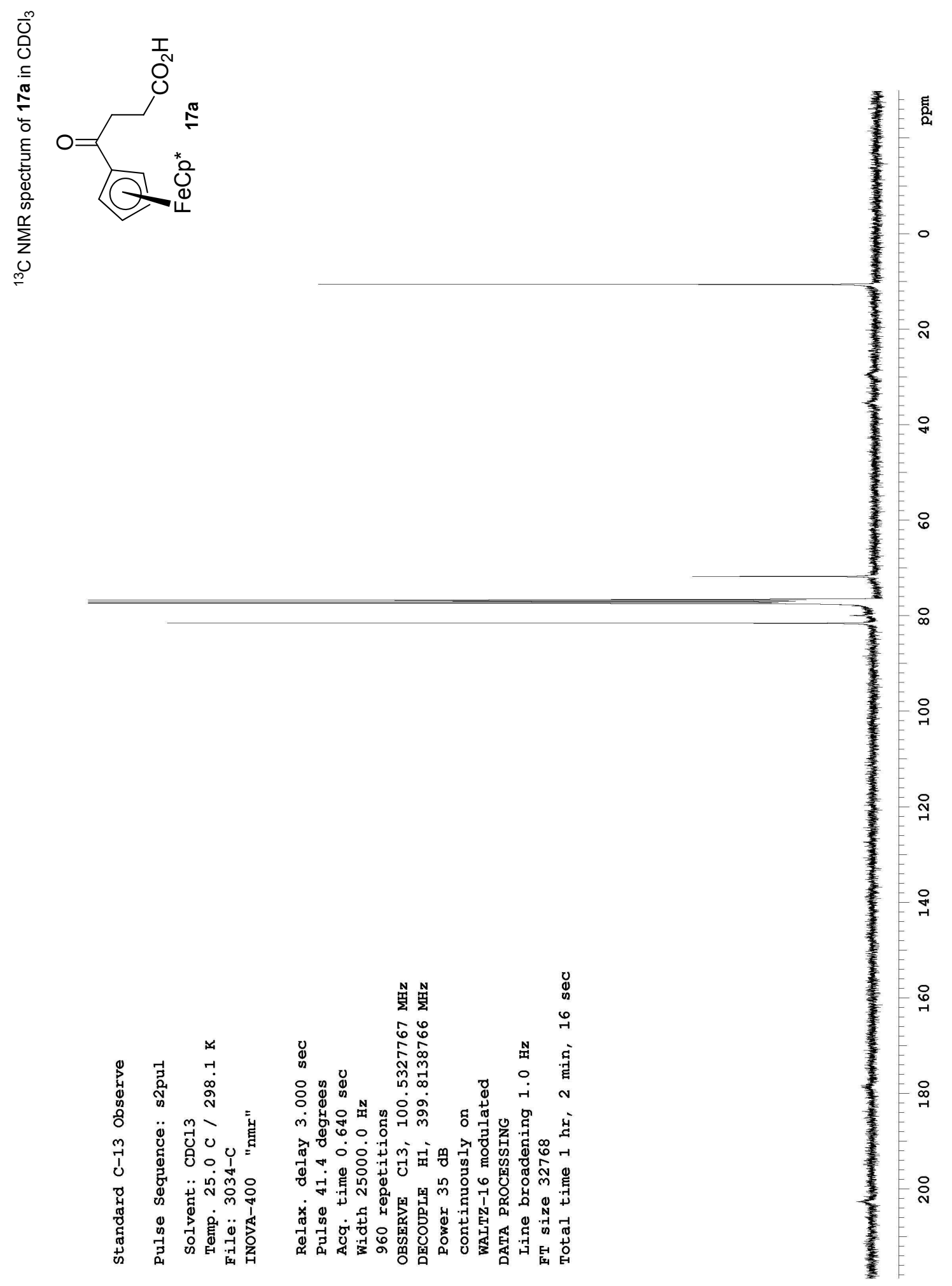

Figure B.18: ${ }^{13} \mathrm{C}$ NMR spectrum of $\mathbf{1 7 a}$ 


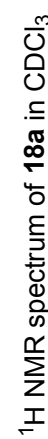
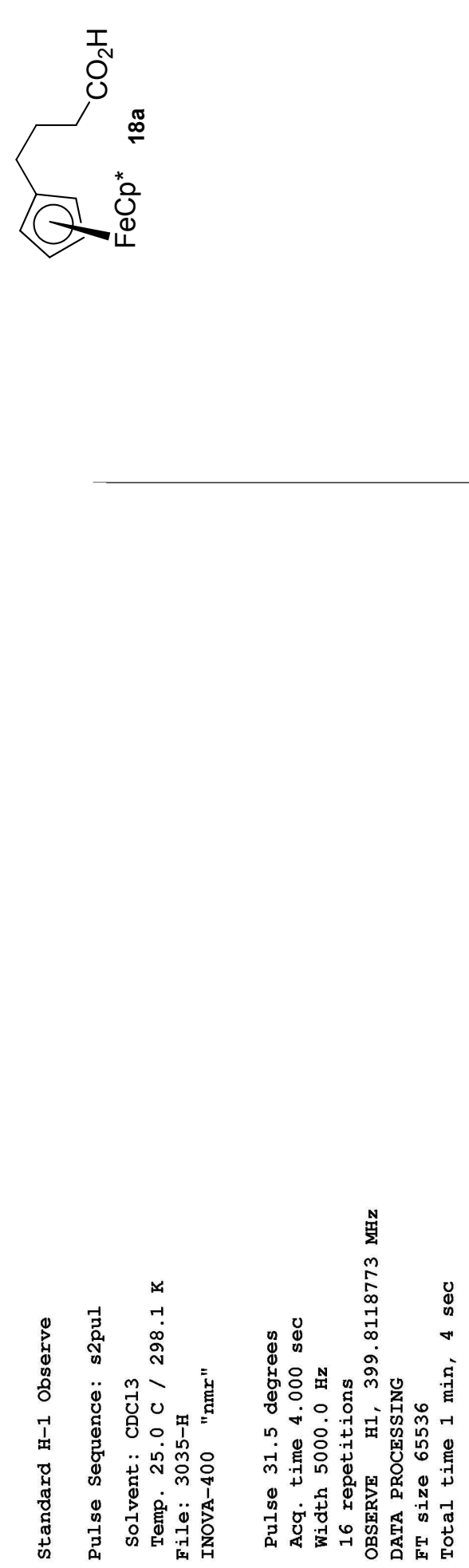

$\infty$

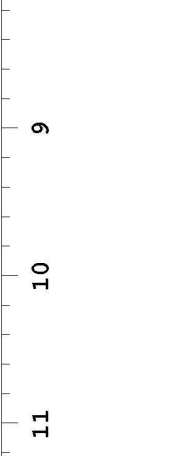

Figure B.19: ${ }^{1} \mathrm{H}$ NMR spectrum of $\mathbf{1 8 a}$ 


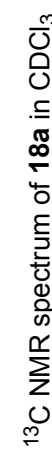
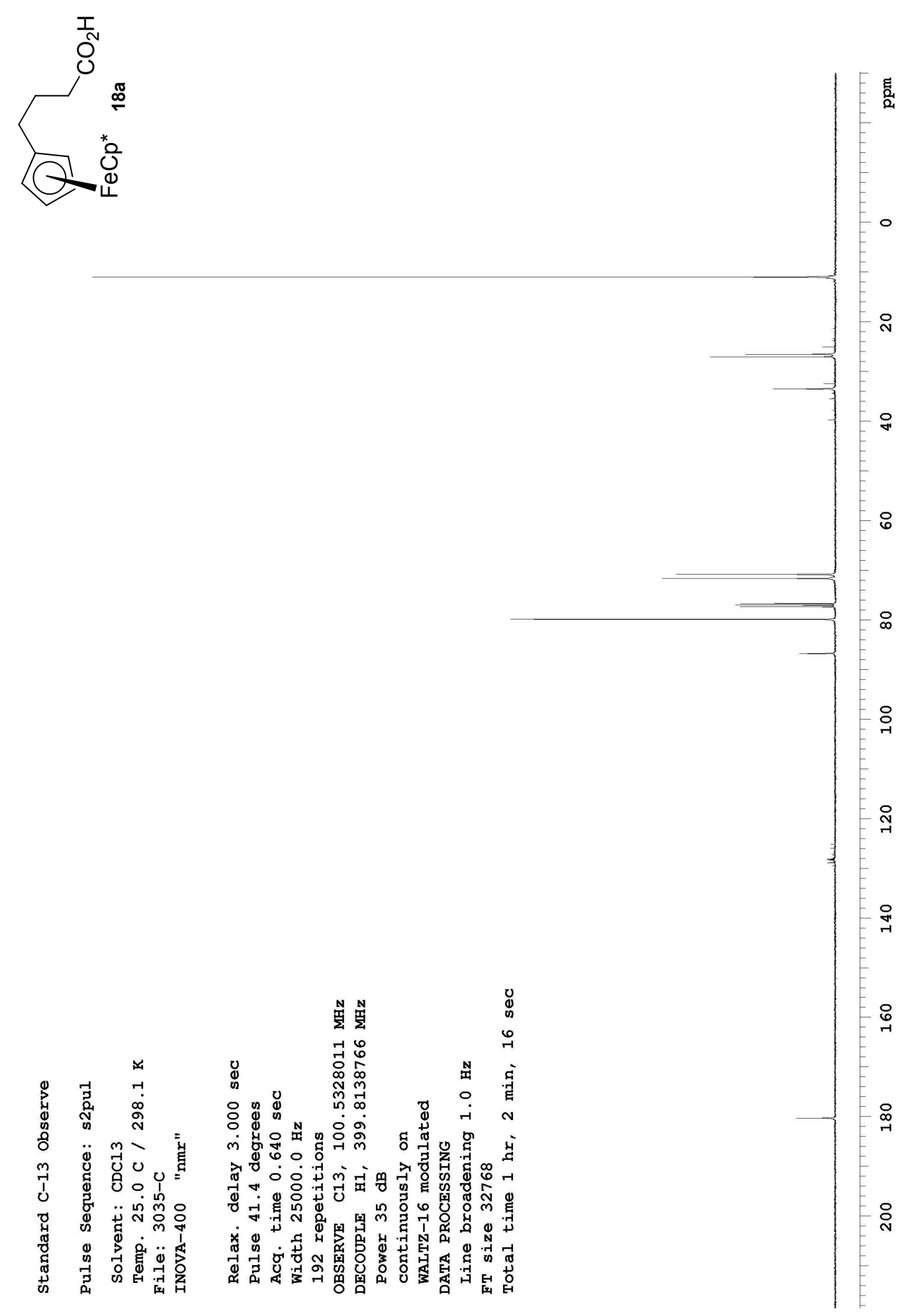

Figure B.20: ${ }^{13} \mathrm{C}$ NMR spectrum of $\mathbf{1 8 a}$ 

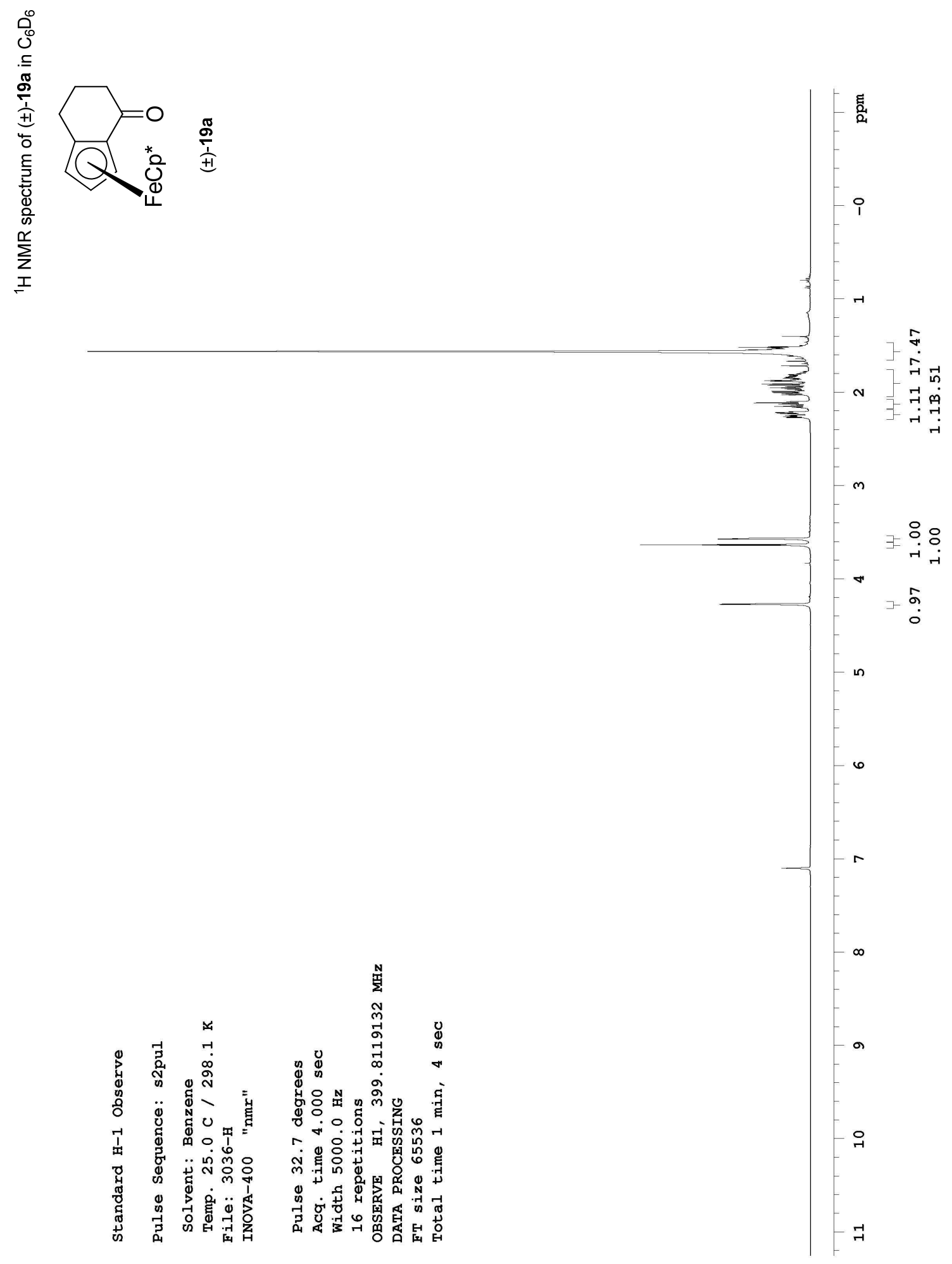

Figure B.21: ${ }^{1} \mathrm{H}$ NMR spectrum of $( \pm)-\mathbf{1 9 a}$ 


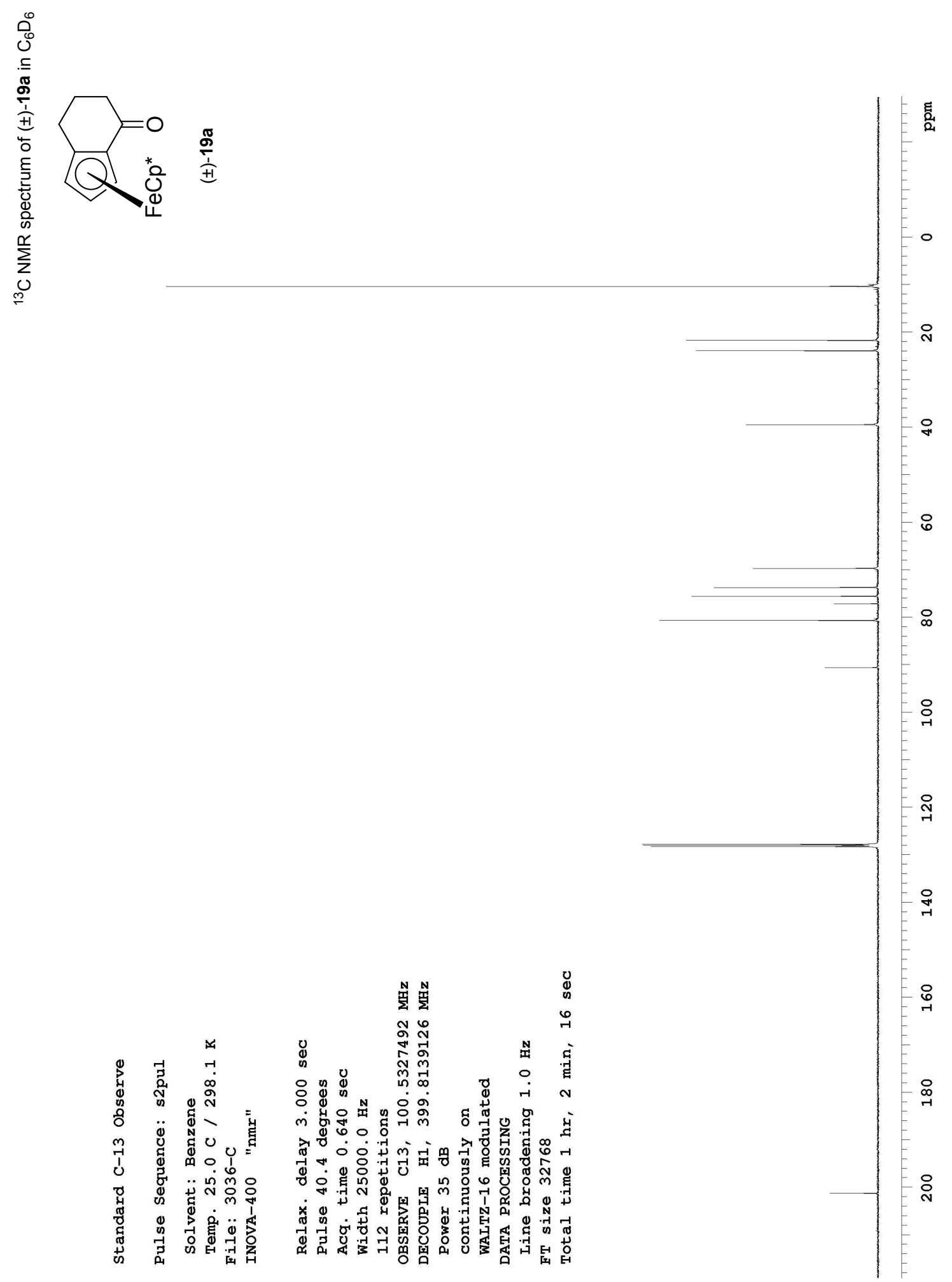

Figure B.22: ${ }^{13} \mathrm{C}$ NMR spectrum of $( \pm)-19 a$ 


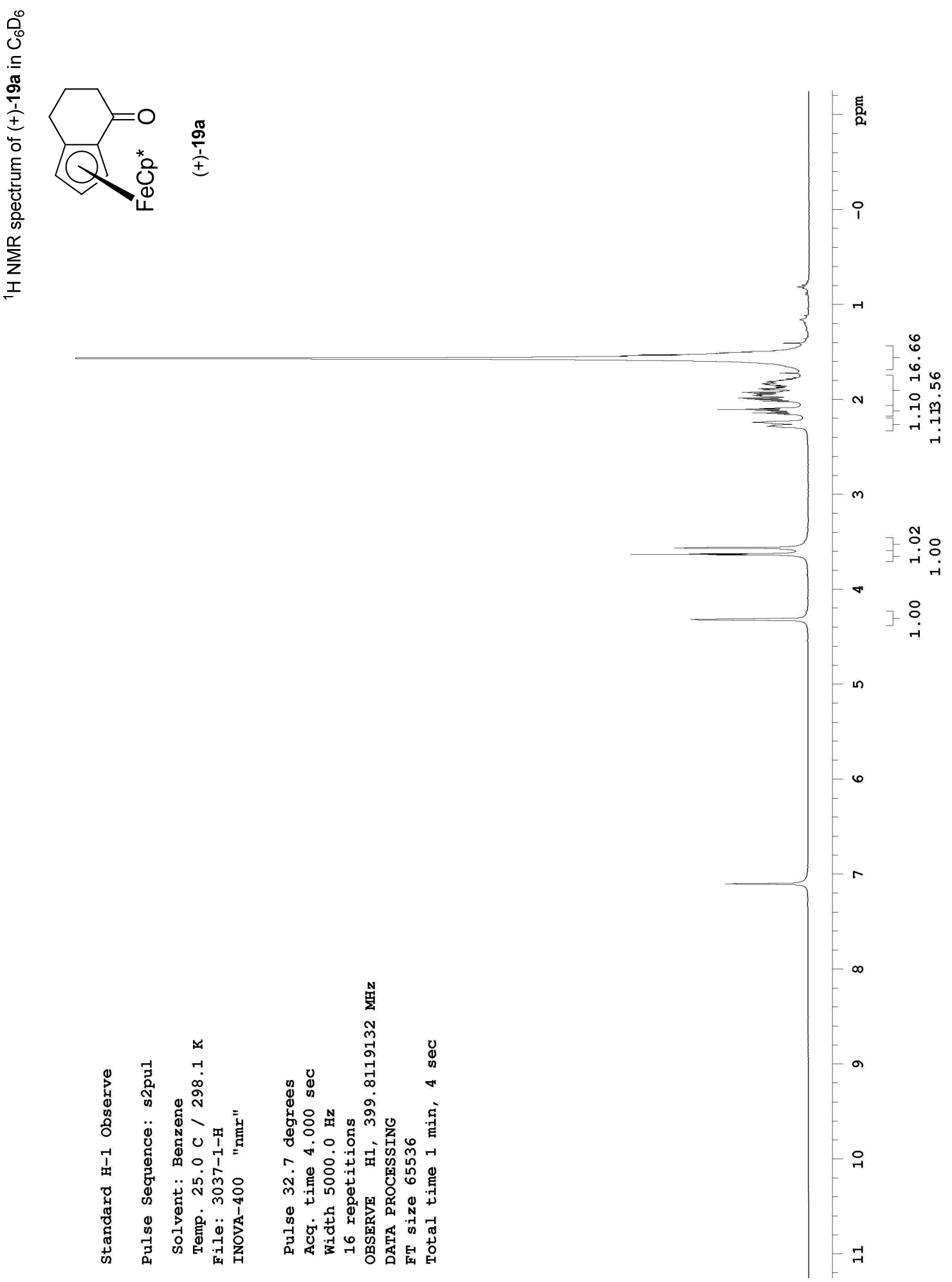

Figure B.23: ${ }^{1} \mathrm{H}$ NMR spectrum of (+)-19a 


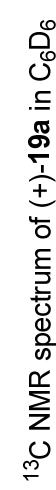

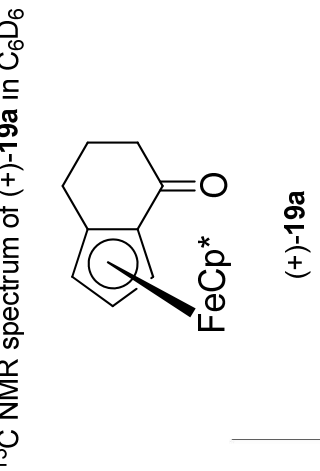

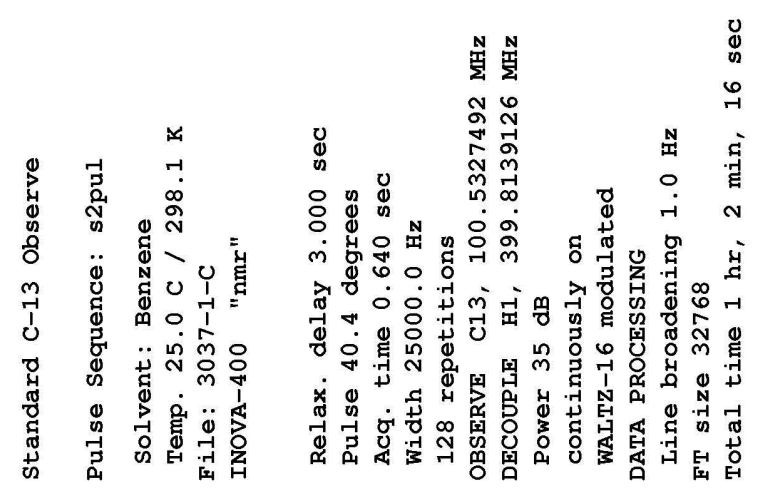

Figure B.24: ${ }^{13} \mathrm{C}$ NMR spectrum of $(+)-19 a$ 


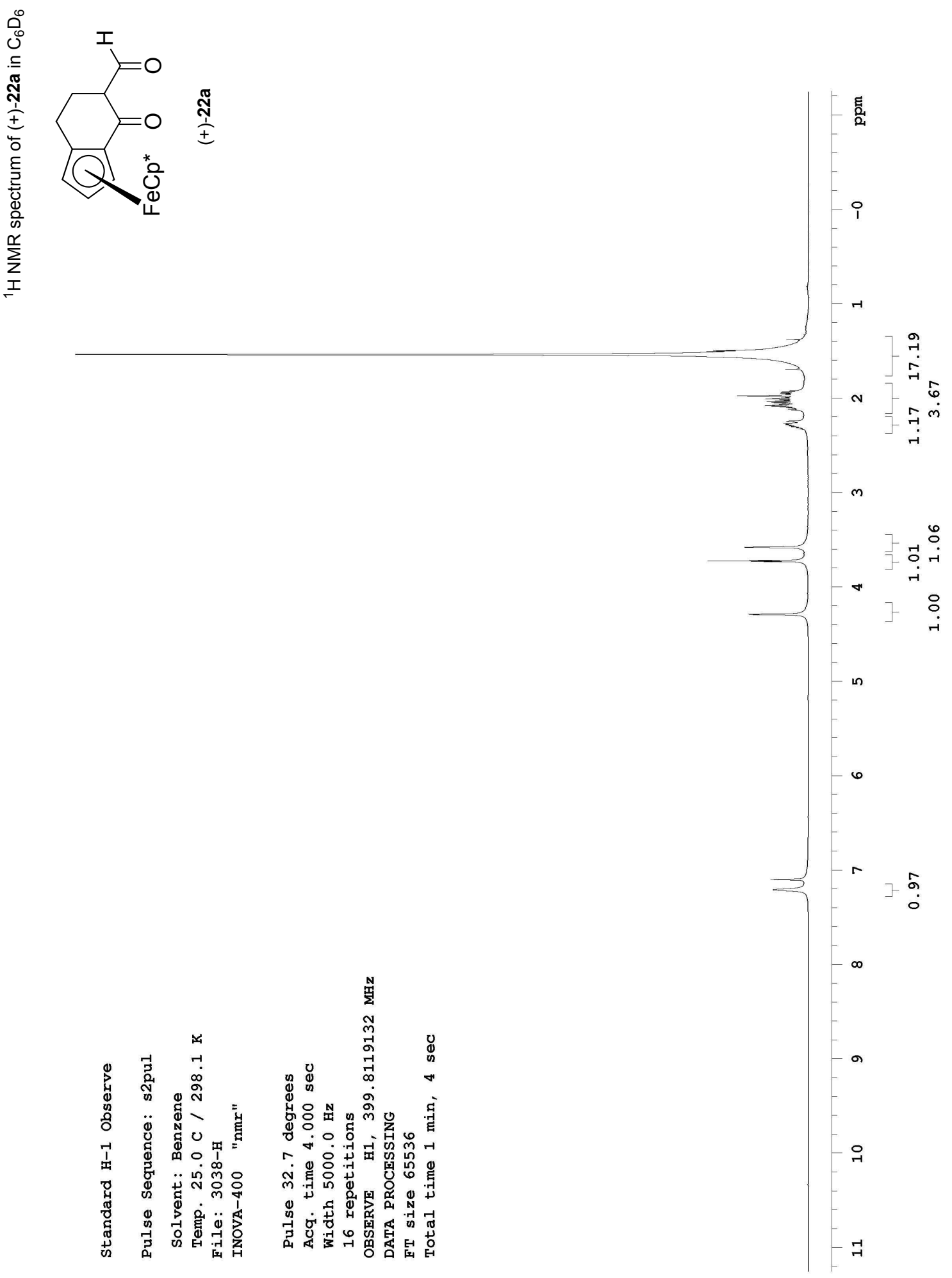

Figure B.25: ${ }^{1} \mathrm{H}$ NMR spectrum of (+)-22a 


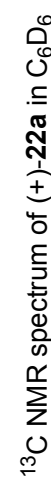
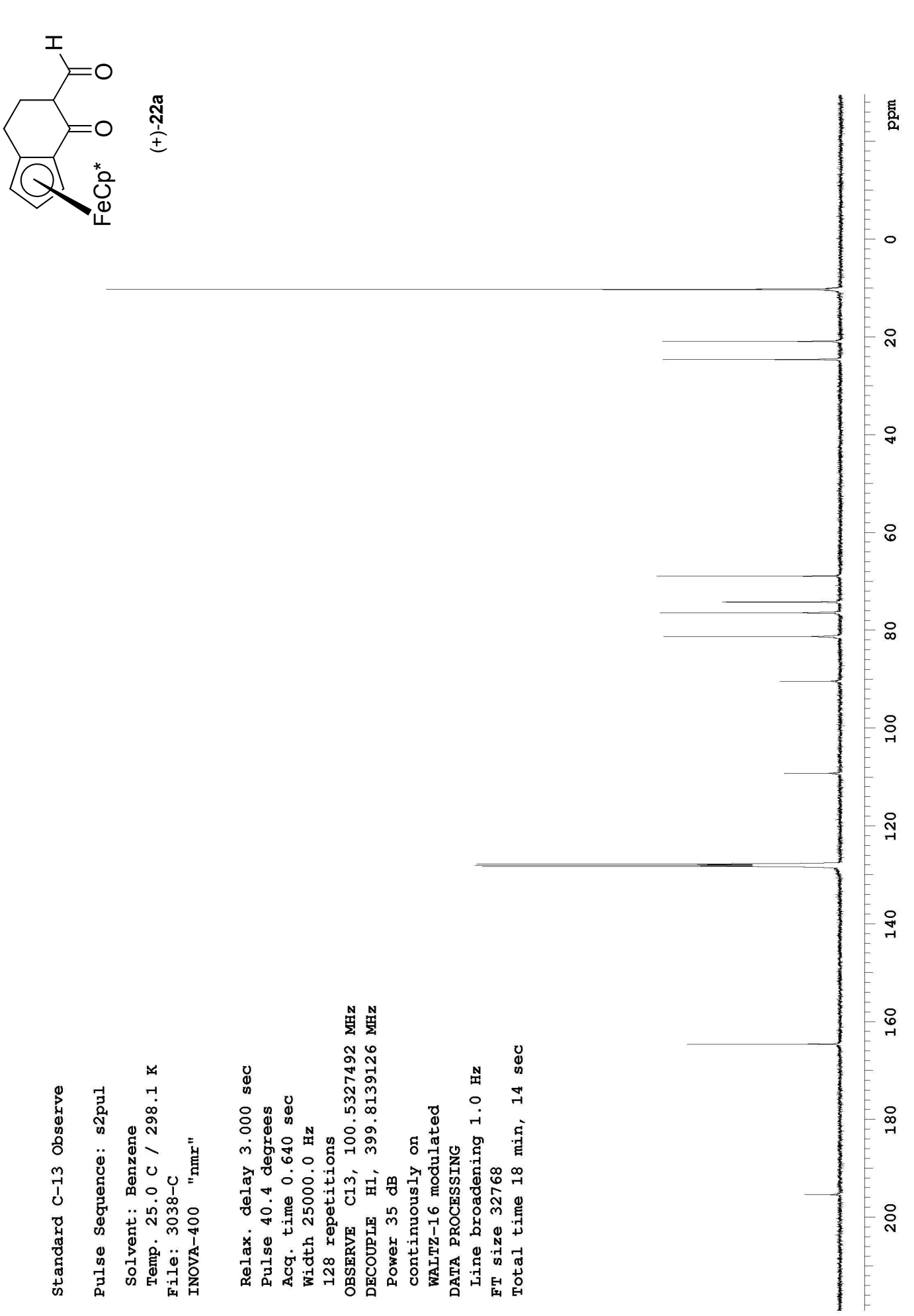

Figure B.26: ${ }^{13} \mathrm{C}$ NMR spectrum of $(+)-22 a$ 

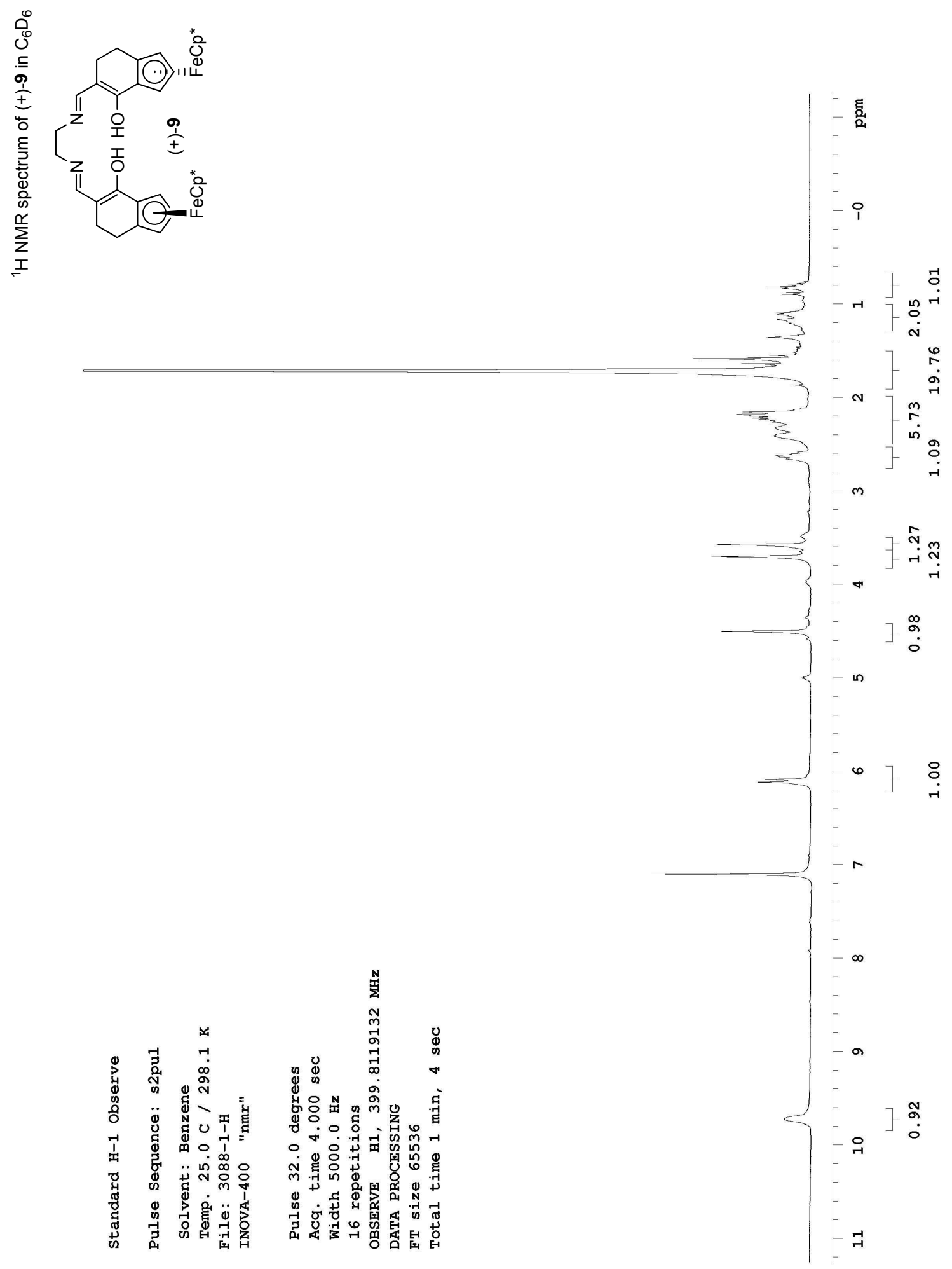

Figure B.27: ${ }^{1} \mathrm{H}$ NMR spectrum of (+)-9 

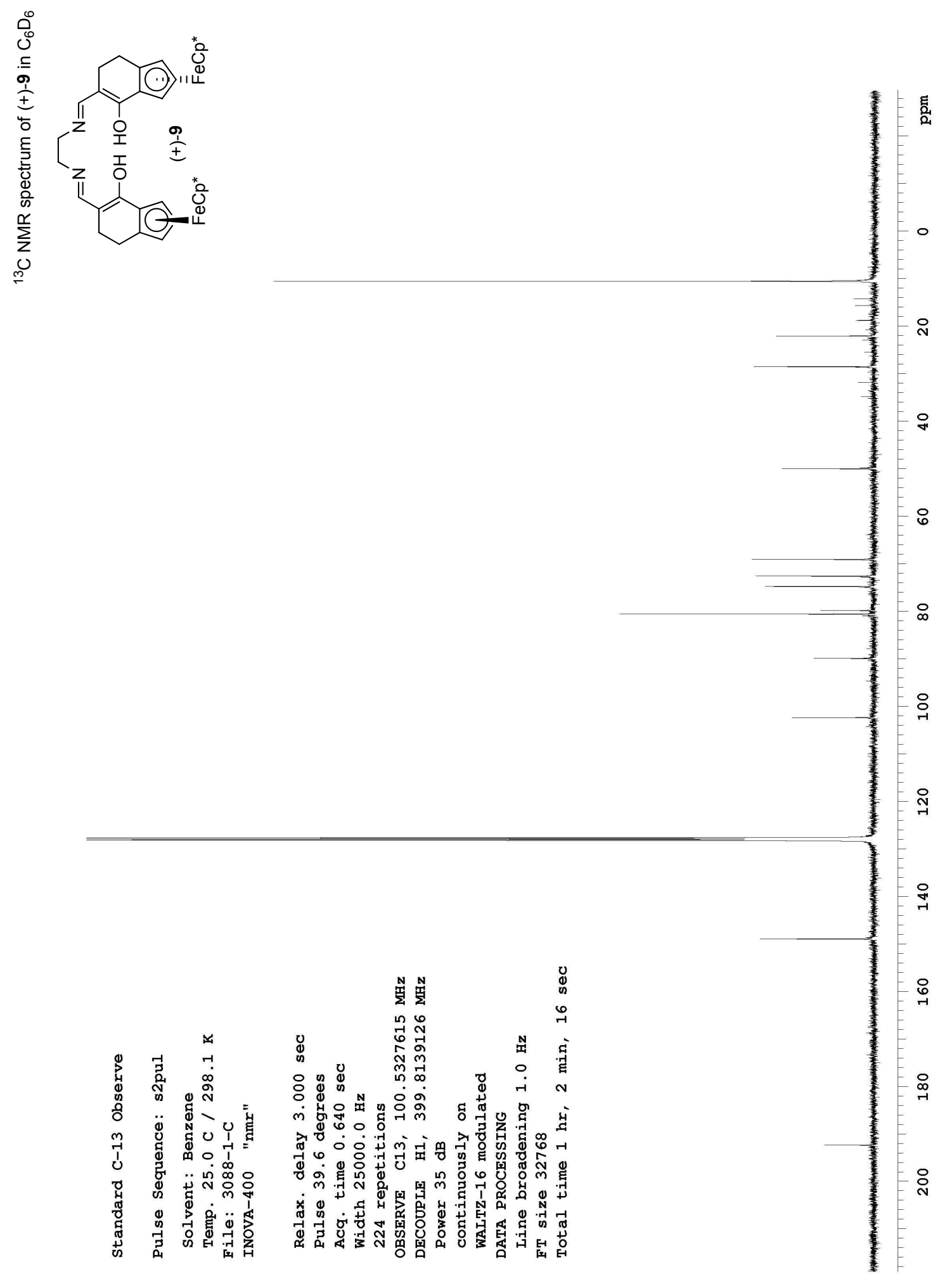

Figure B.28: ${ }^{13} \mathrm{C}$ NMR spectrum of $(+)-9$ 


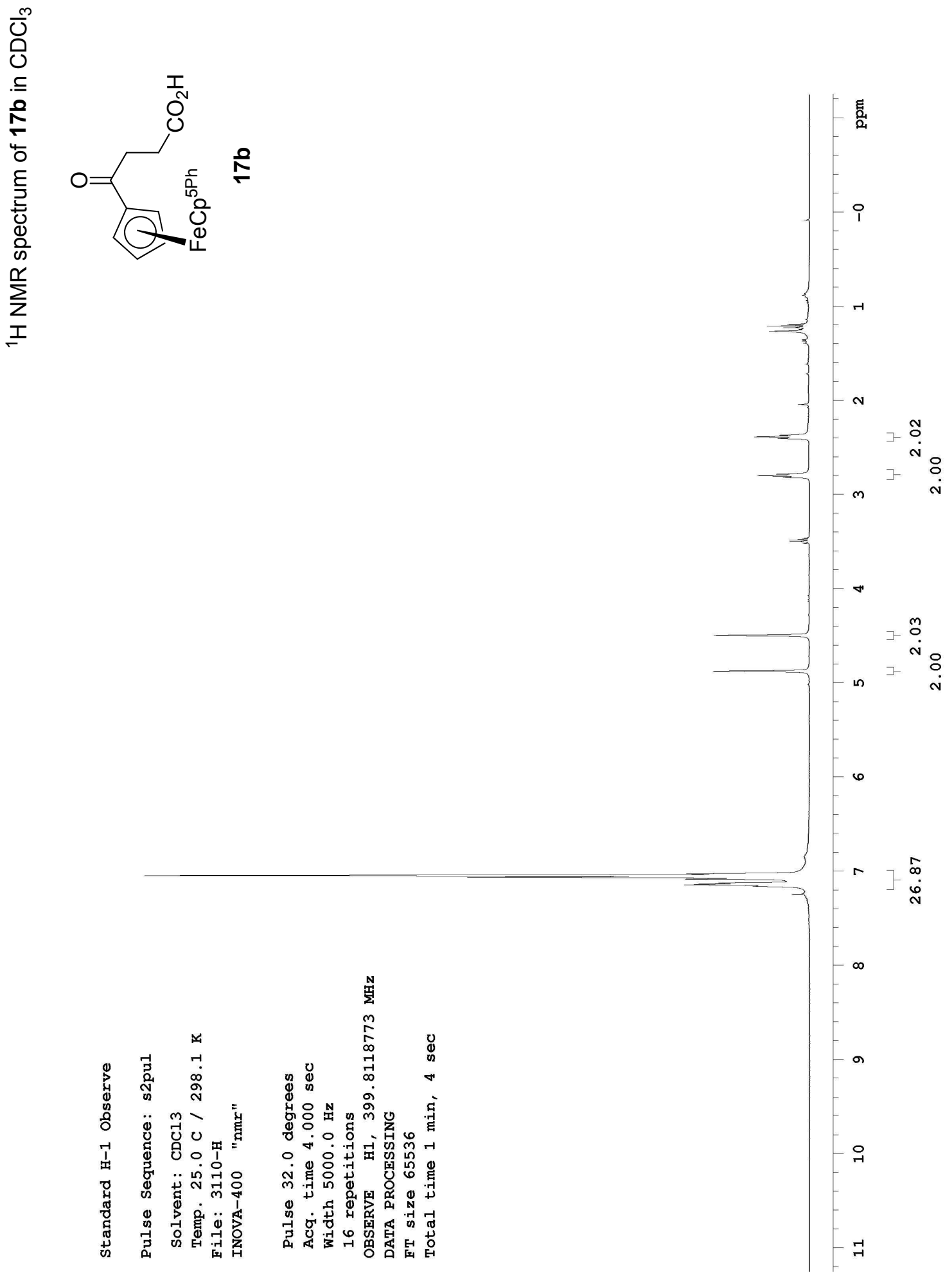

Figure B.29: ${ }^{1} \mathrm{H}$ NMR spectrum of $\mathbf{1 7 b}$ 

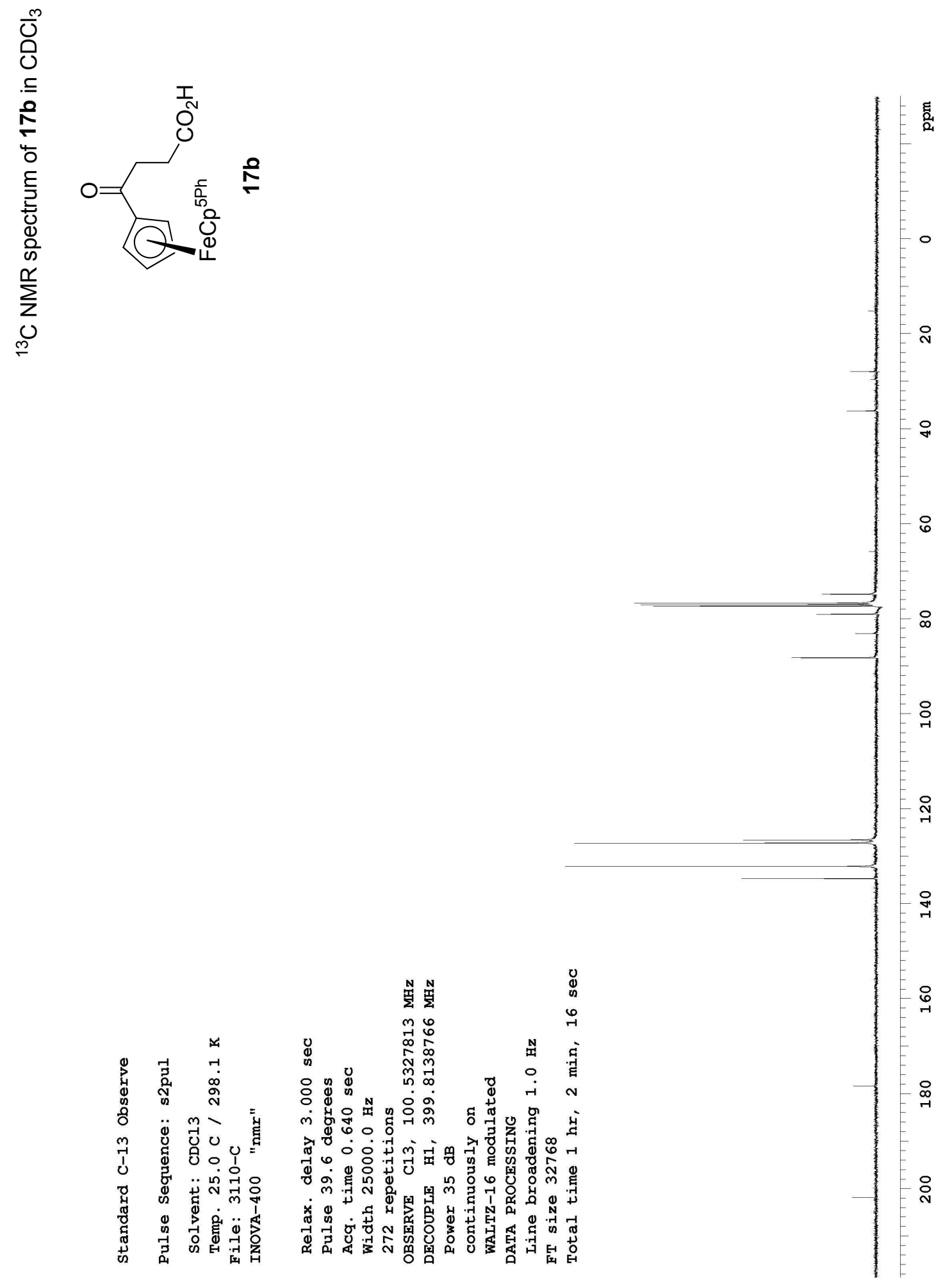

Figure B.30: ${ }^{13} \mathrm{C}$ NMR spectrum of $\mathbf{1 7 b}$ 


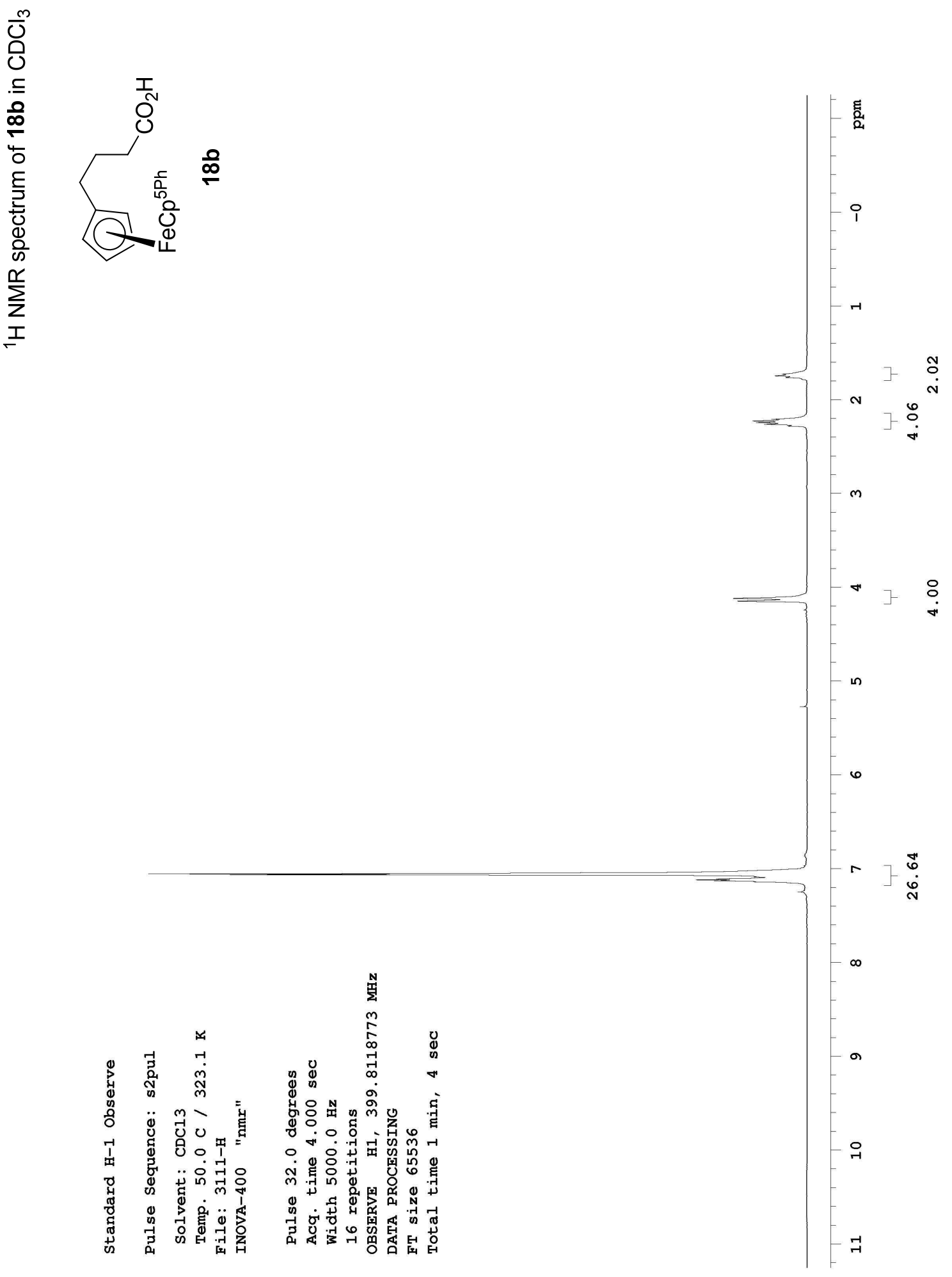

Figure B.31: ${ }^{1} \mathrm{H}$ NMR spectrum of $\mathbf{1 8 b}$ 


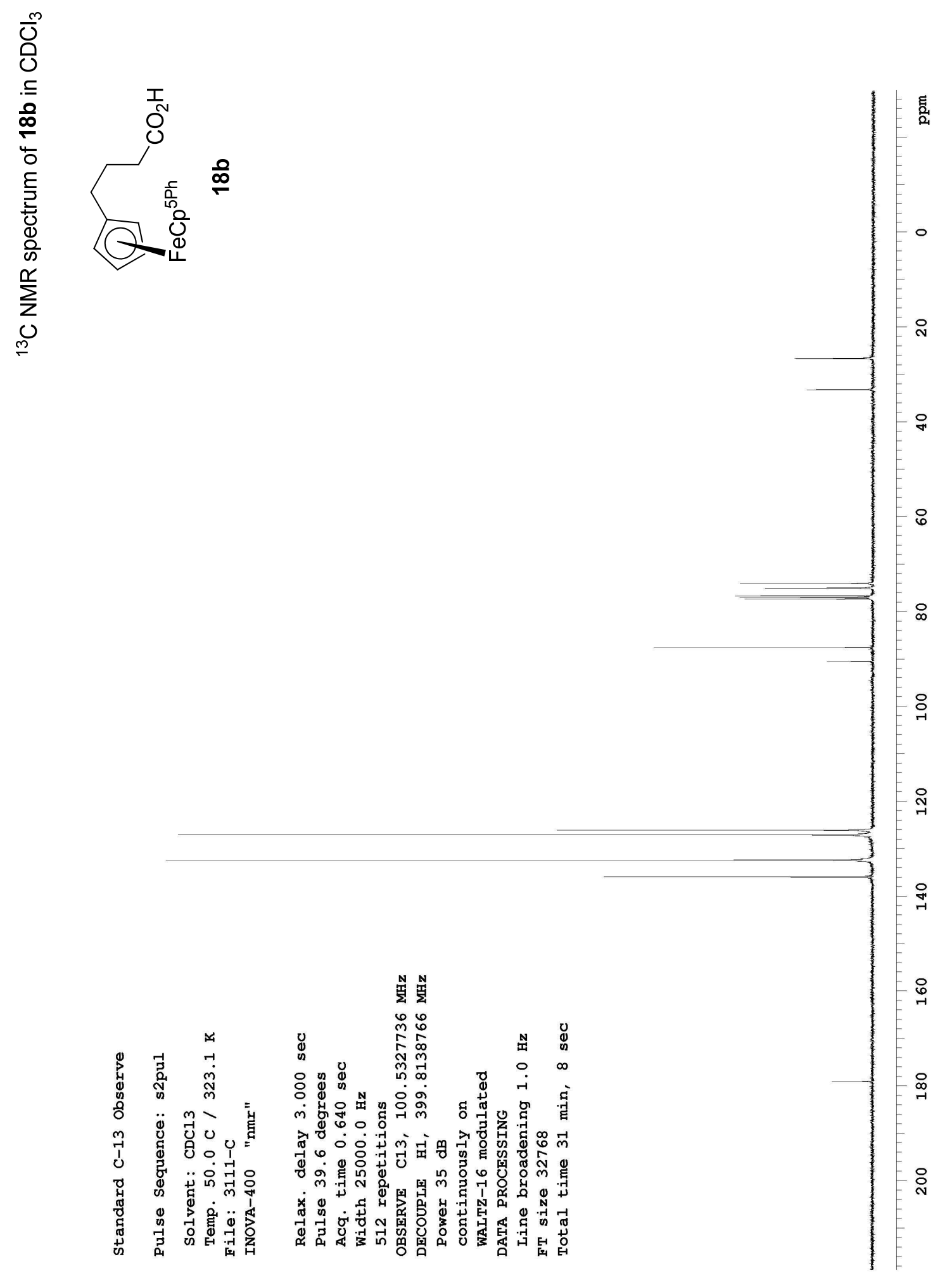

Figure B.32: ${ }^{13} \mathrm{C}$ NMR spectrum of $\mathbf{1 8 b}$ 

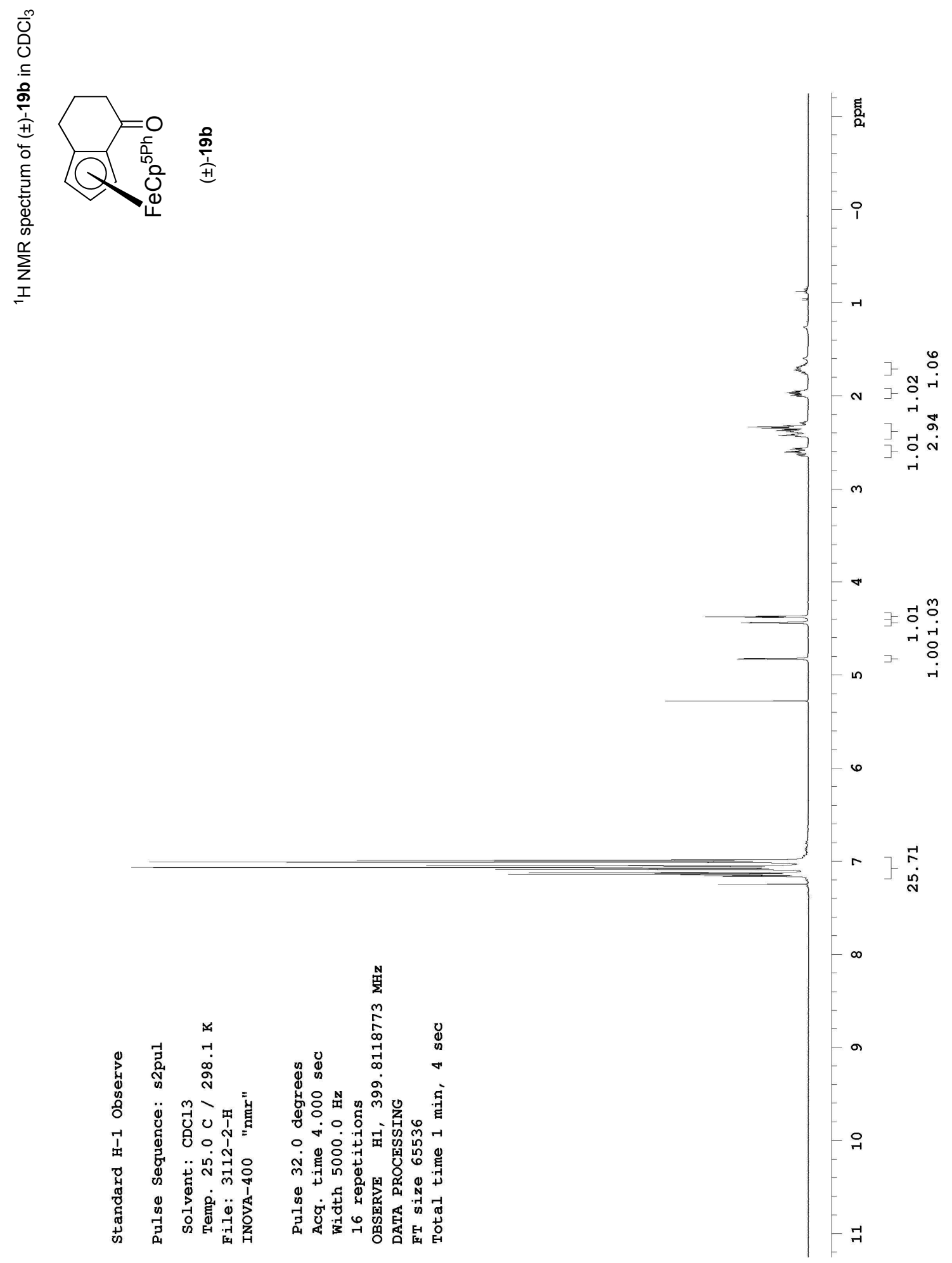

Figure B.33: ${ }^{1} \mathrm{H}$ NMR spectrum of $( \pm)-19 b$ 

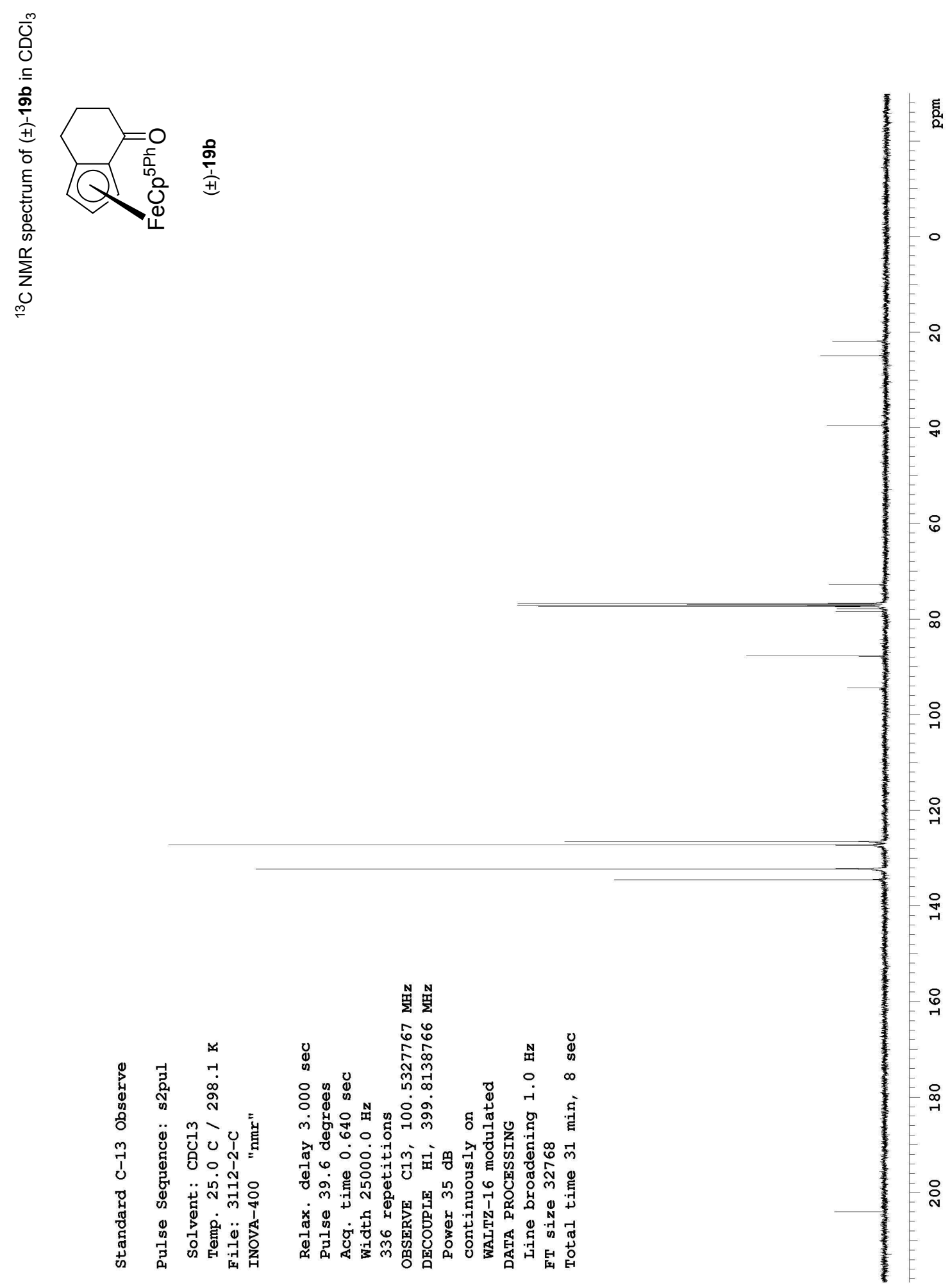

Figure B.34: ${ }^{13} \mathrm{C}$ NMR spectrum of $( \pm)-19 b$ 

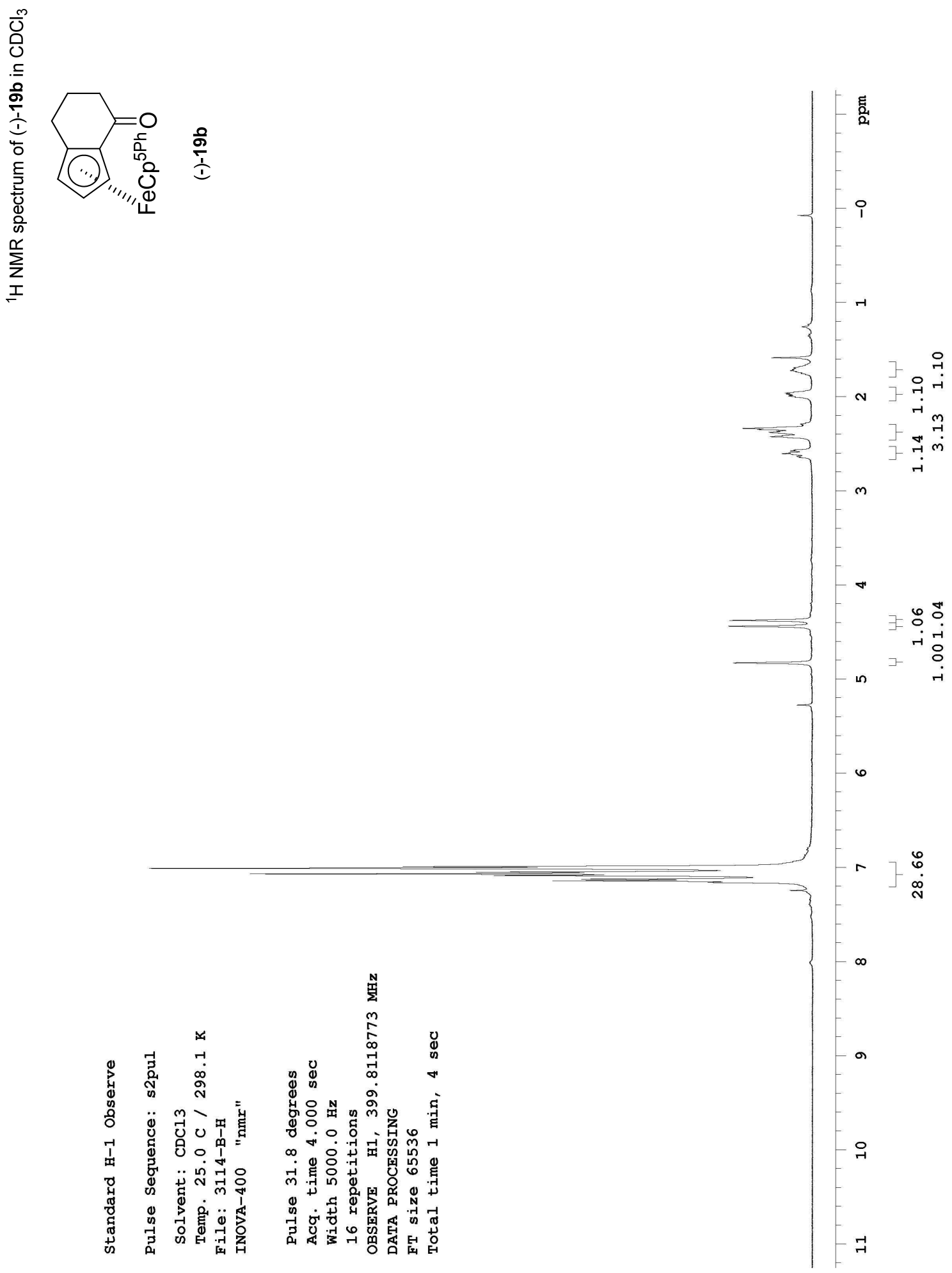

Figure B.35: ${ }^{1} \mathrm{H}$ NMR spectrum of (-)-19b 

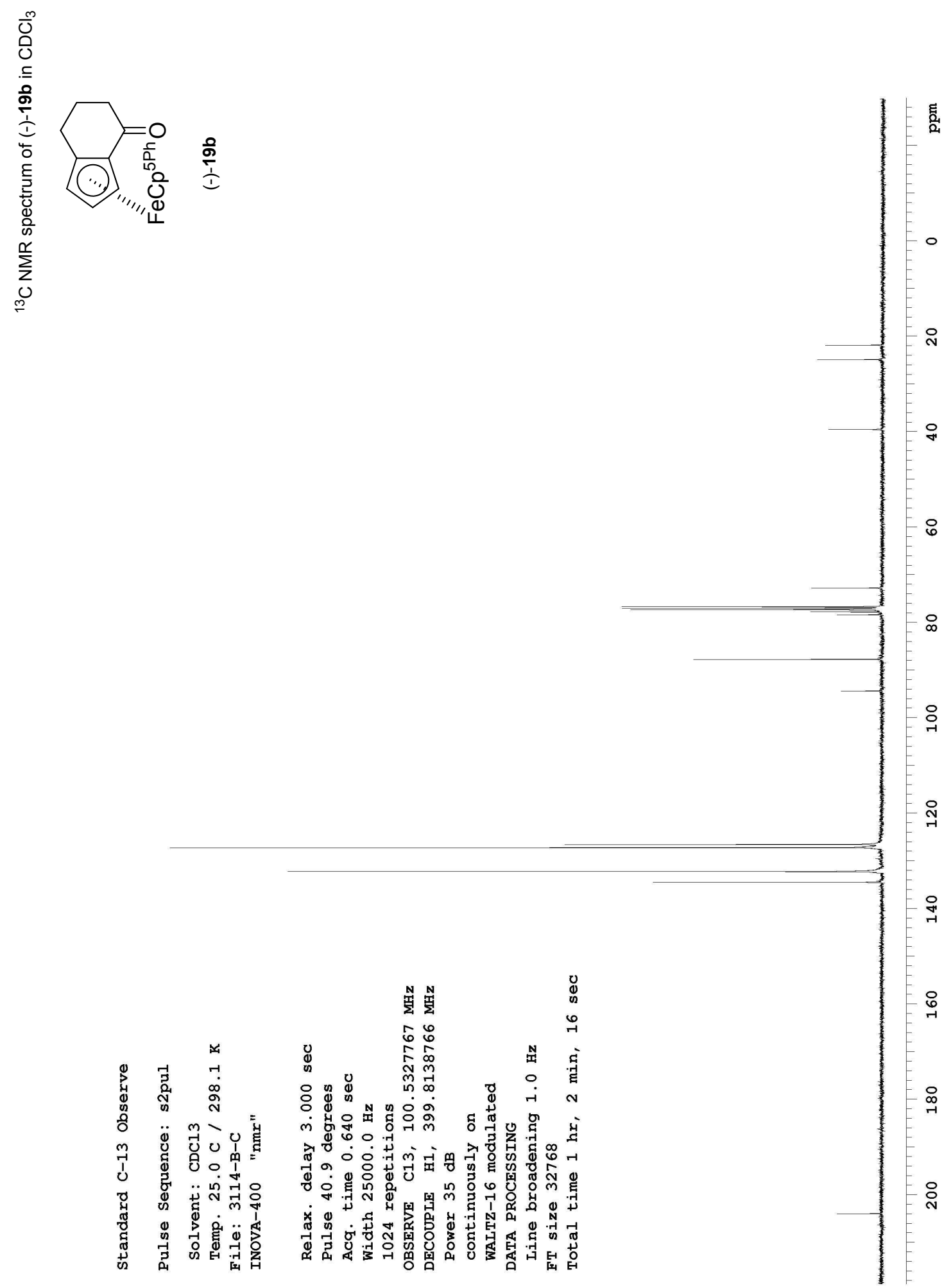

Figure B.36: ${ }^{13} \mathrm{C}$ NMR spectrum of (-)-19b 

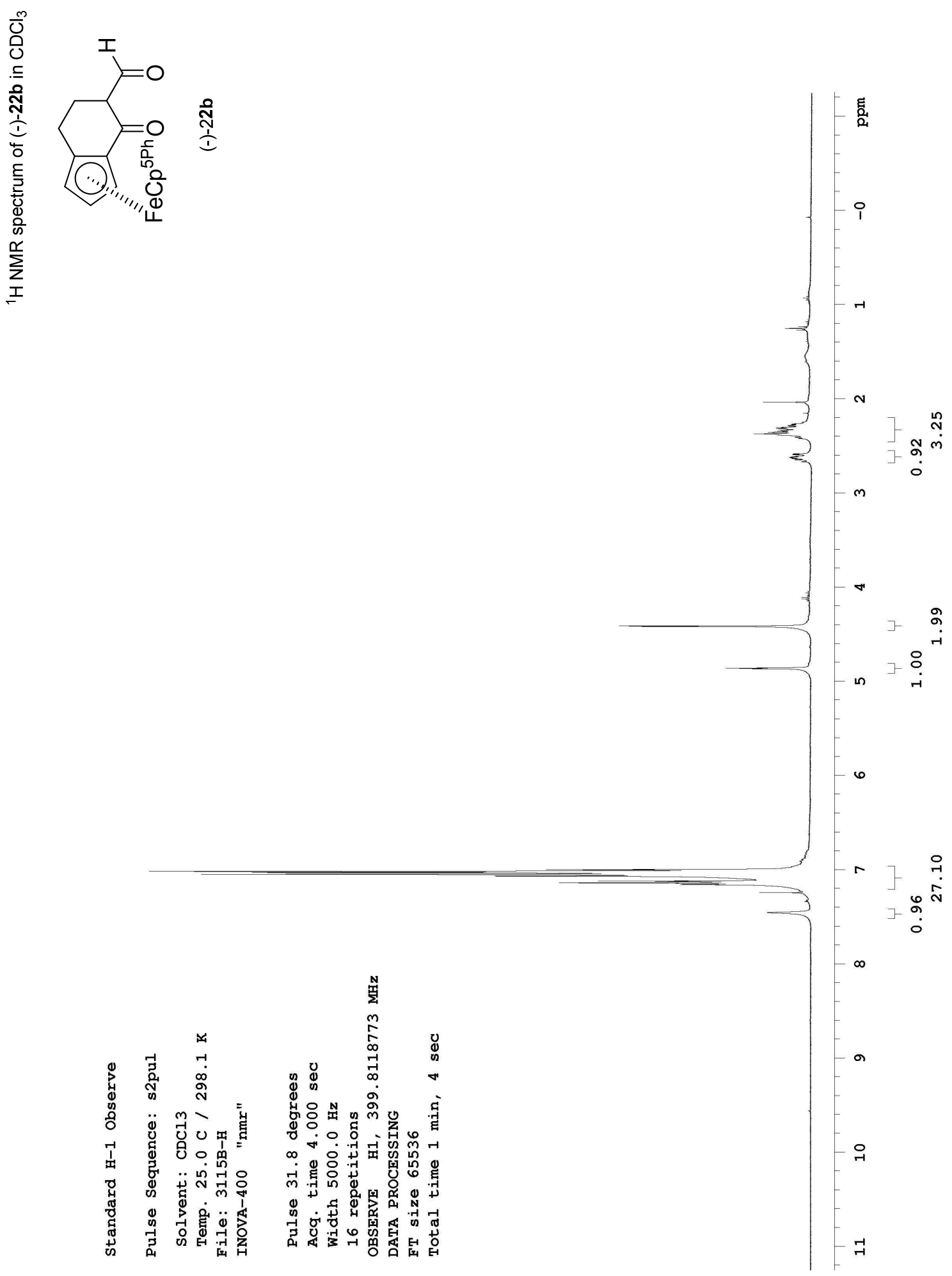

Figure B.37: ${ }^{1} \mathrm{H}$ NMR spectrum of (-)-22b 

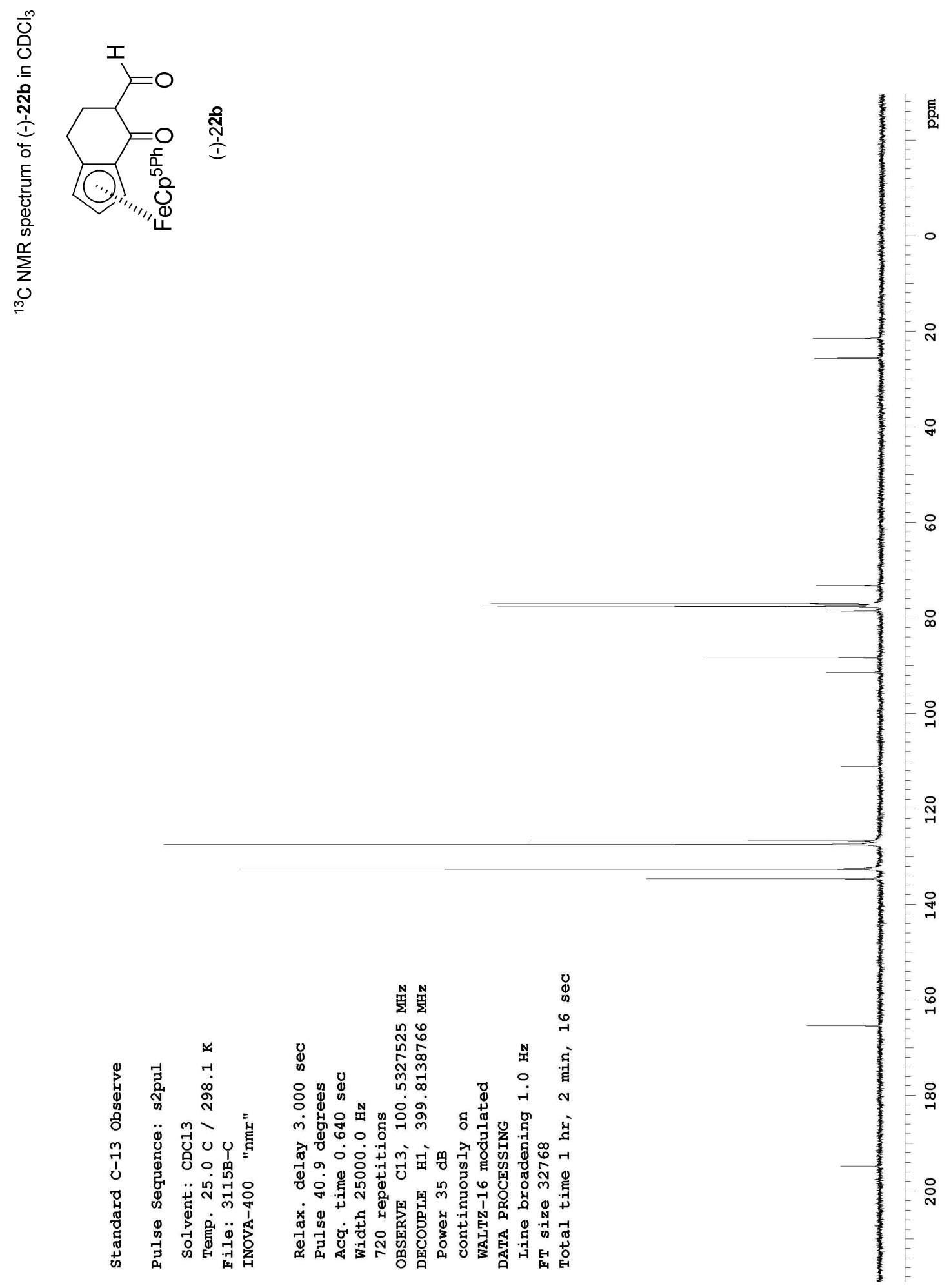

Figure B.38: ${ }^{13} \mathrm{C}$ NMR spectrum of (-)-22b 

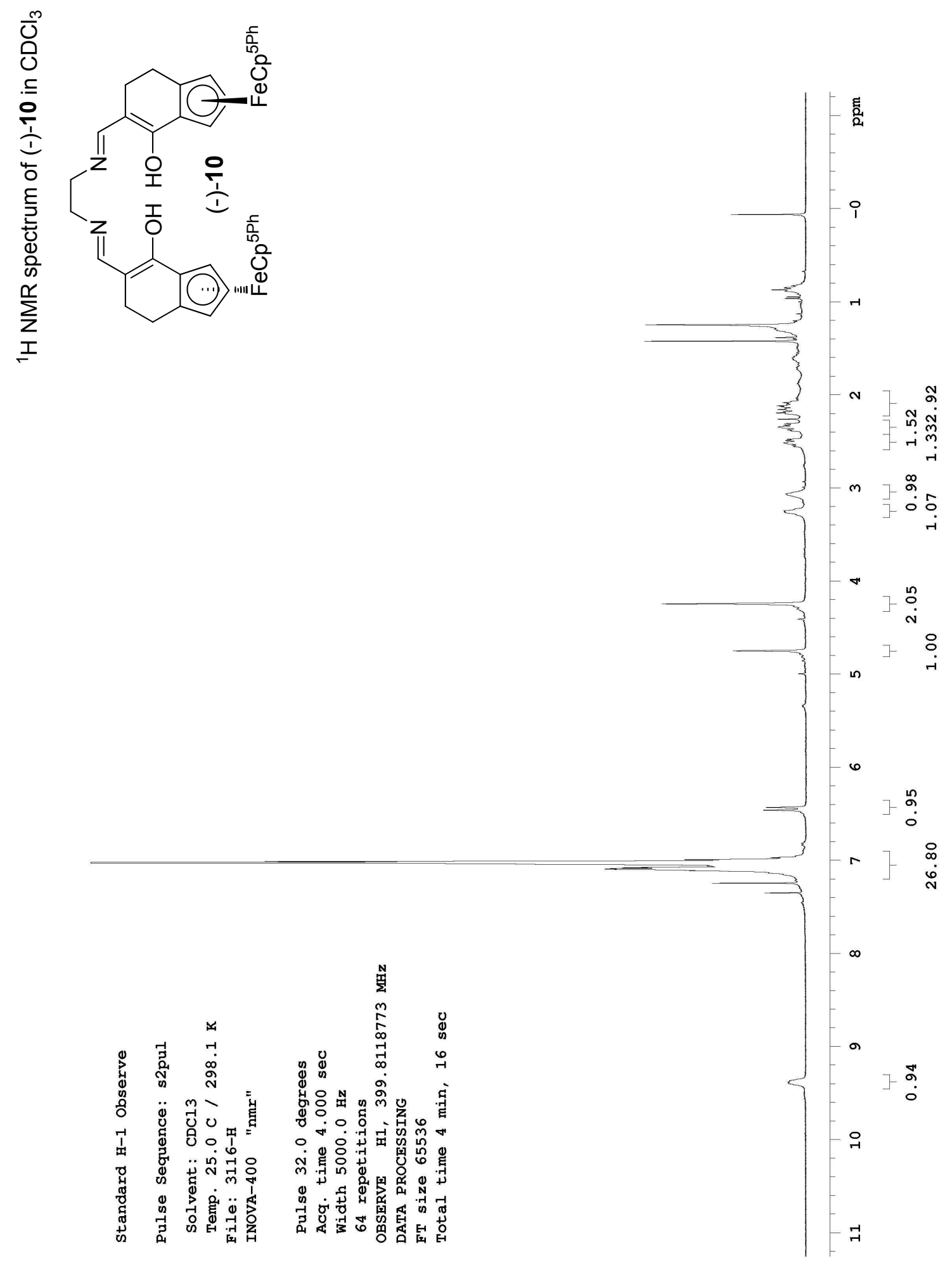

Figure B.39: ${ }^{1} \mathrm{H}$ NMR spectrum of (-)-10 

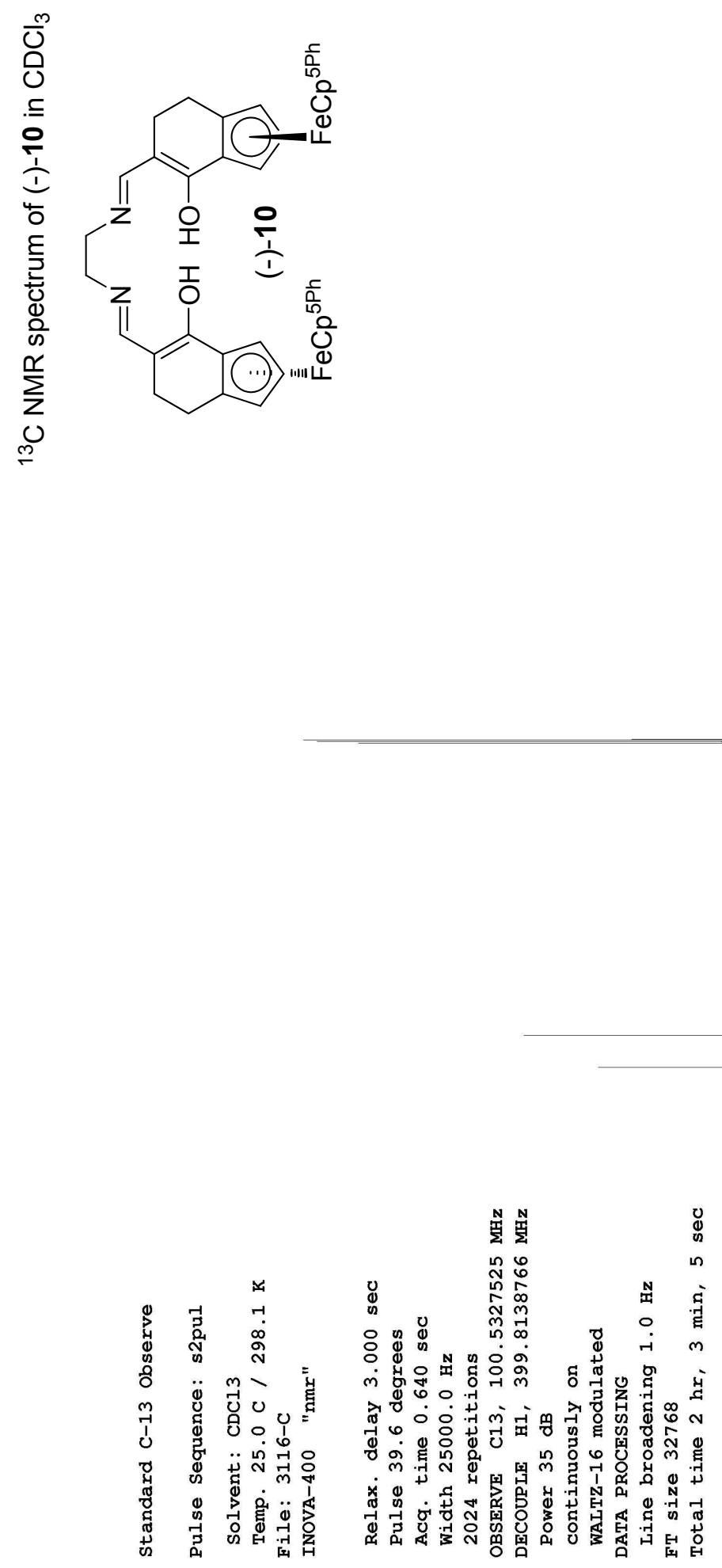

Figure B.40: ${ }^{13} \mathrm{C}$ NMR spectrum of (-)-10 


\section{B.2 High resolution MS spectra of new compounds}

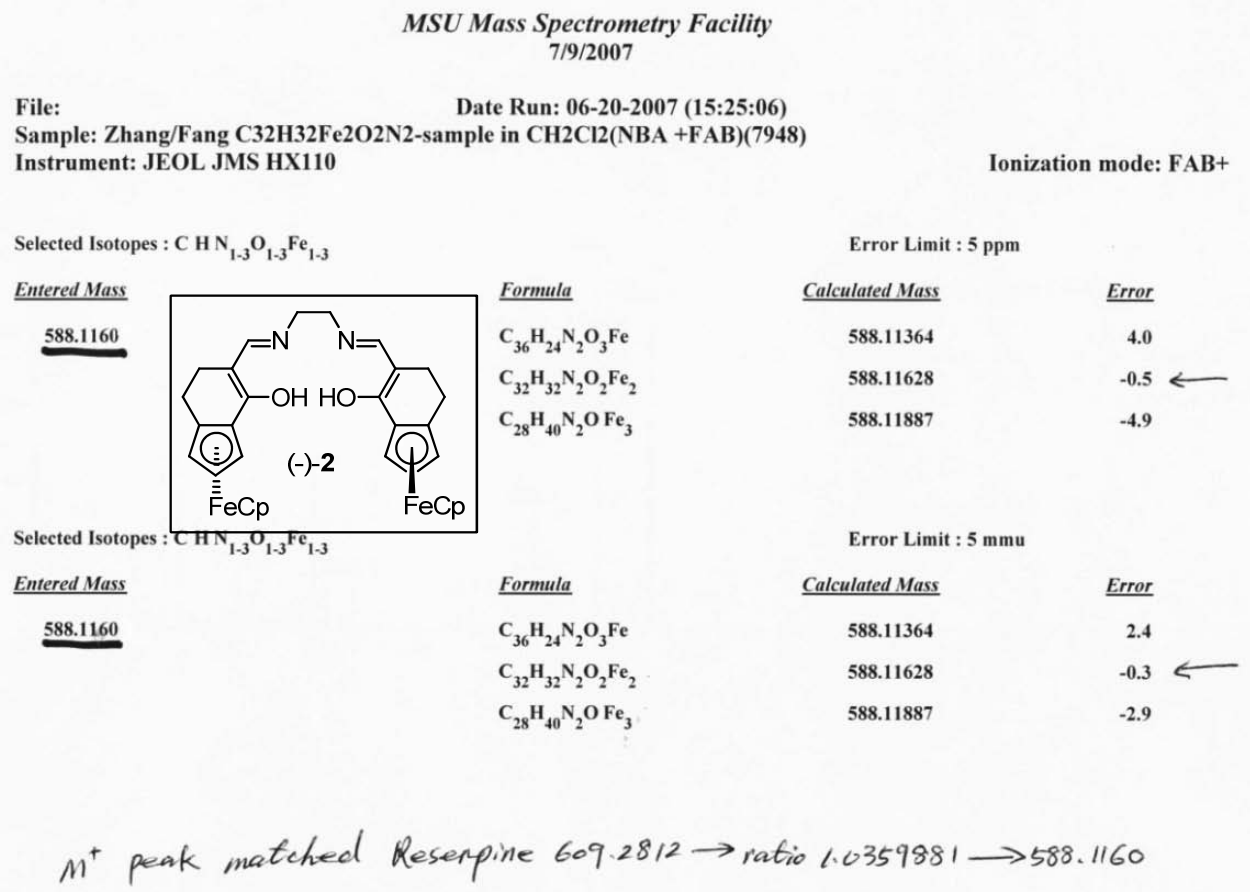

Figure B.41: High resolution MS for (-)-2

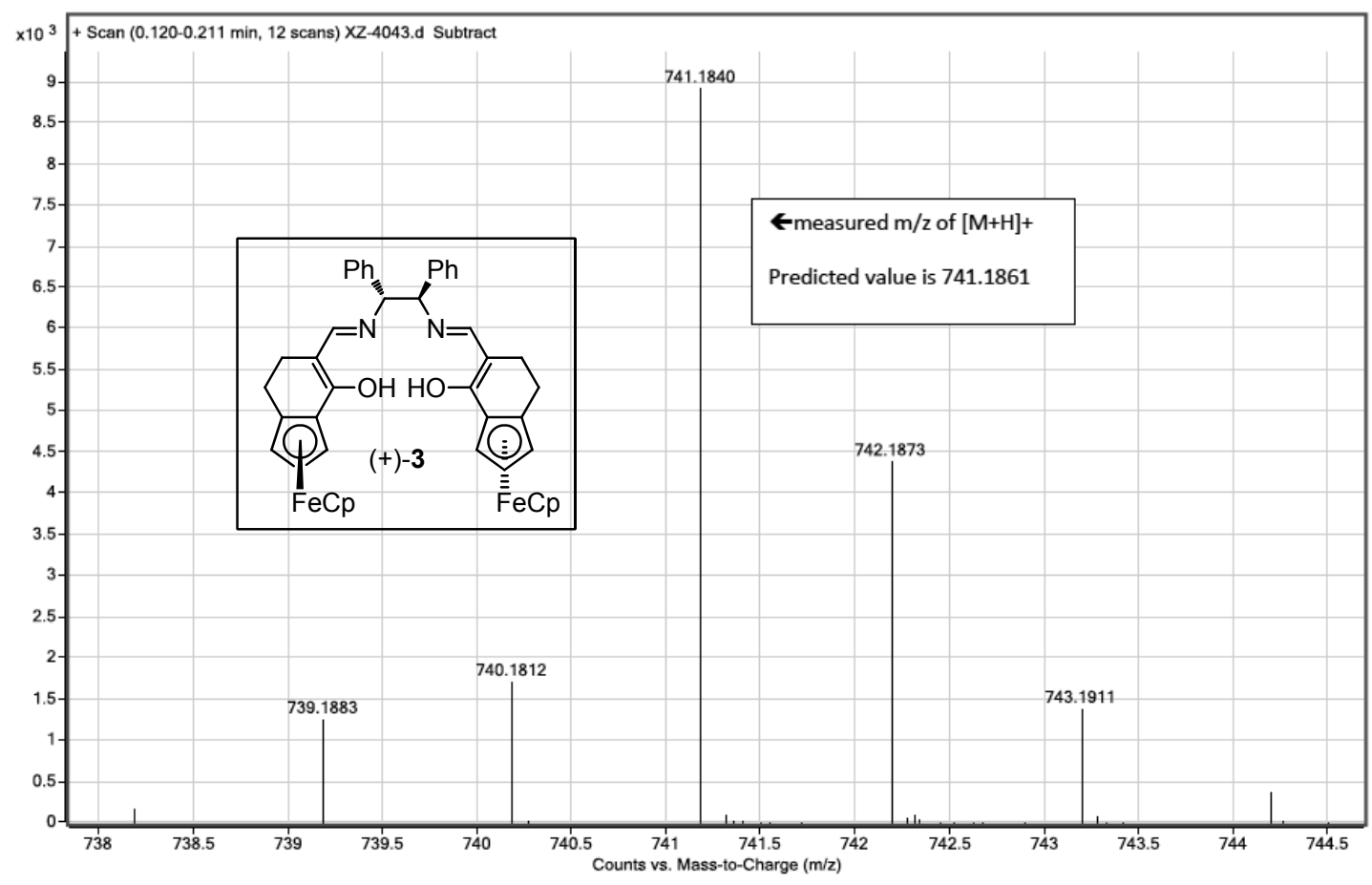

Figure B.42: High resolution MS for (+)-3 


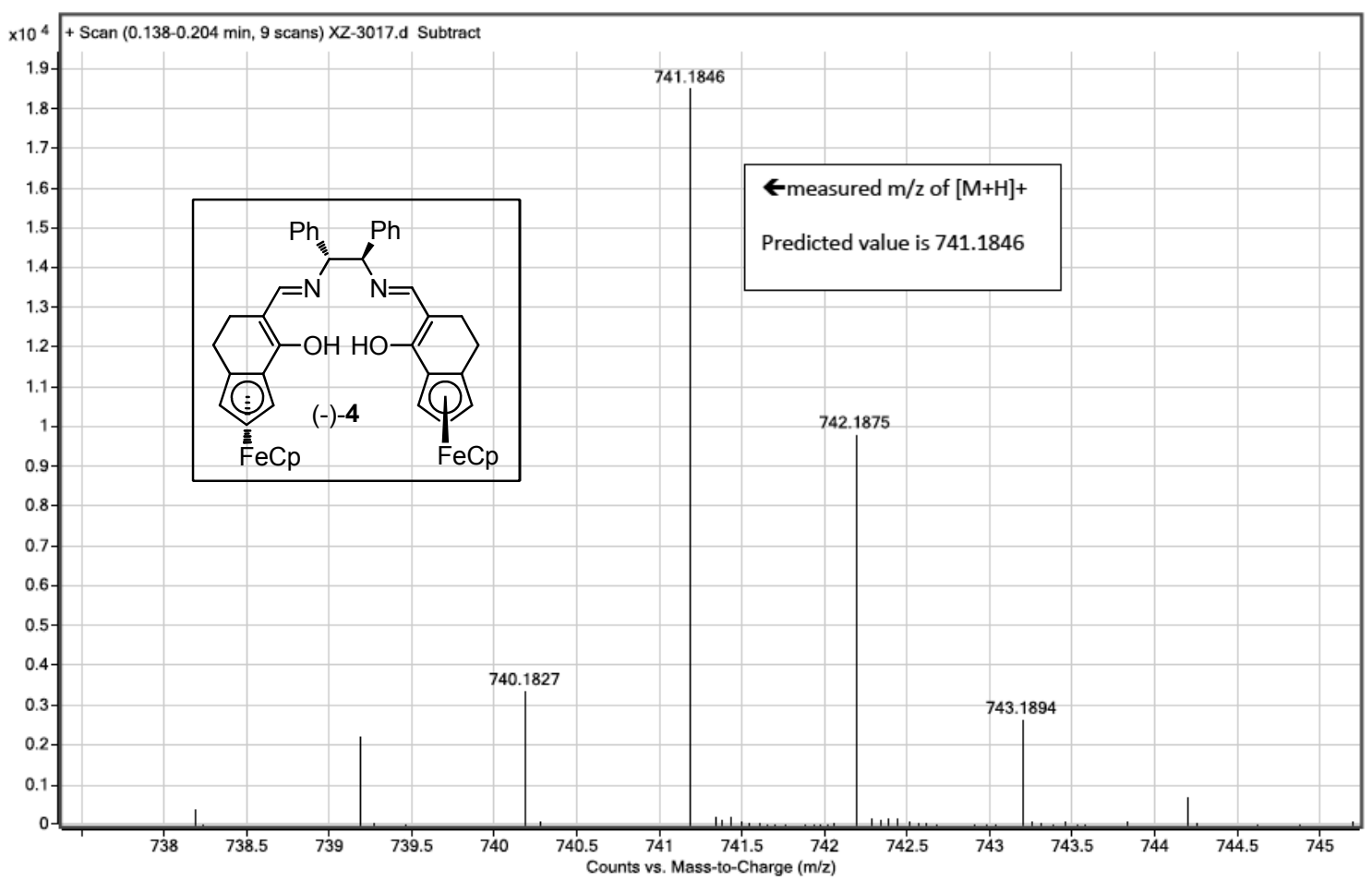

Figure B.43: High resolution MS for (-)-4

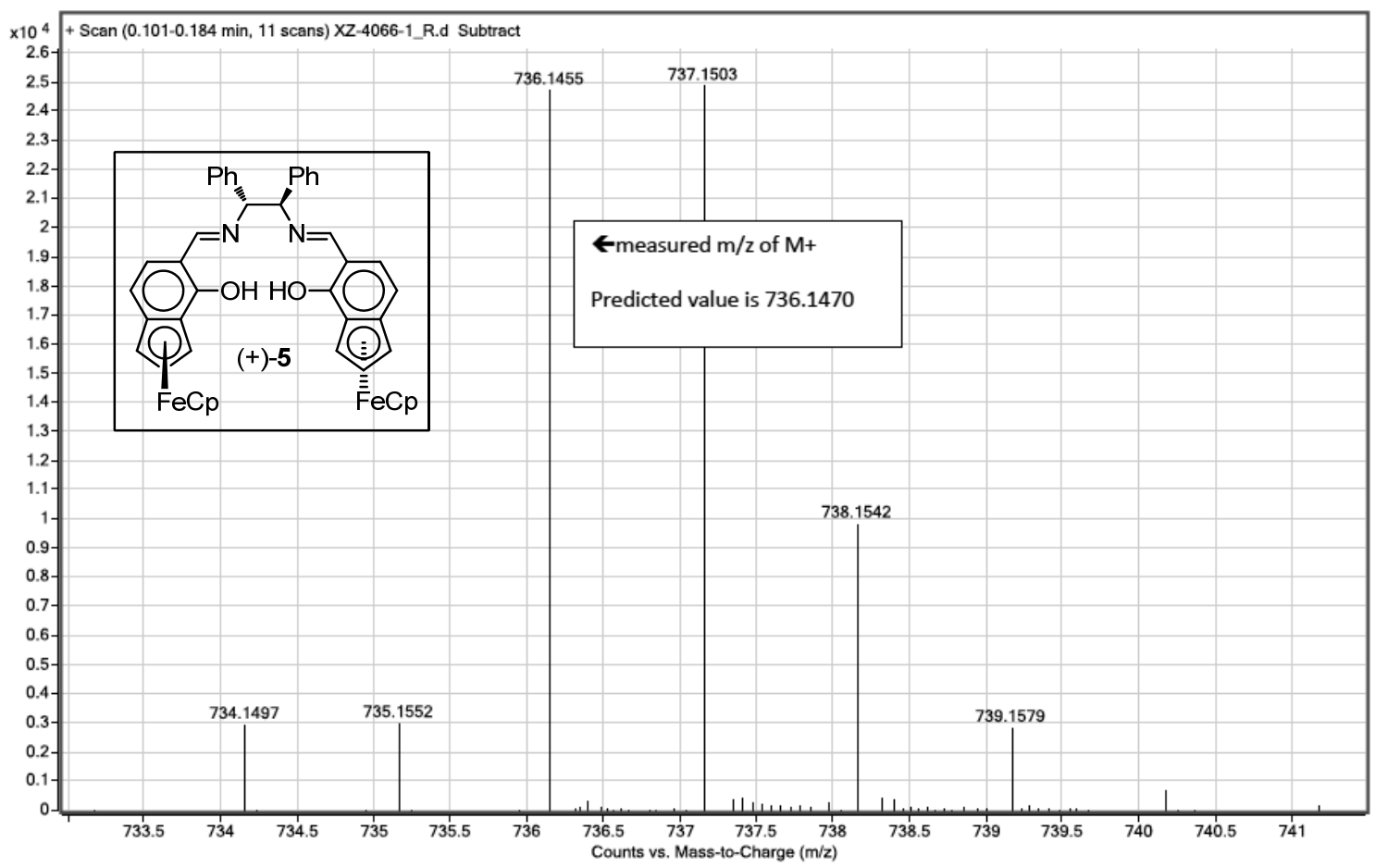

Figure B.44: High resolution MS for (+)-5 


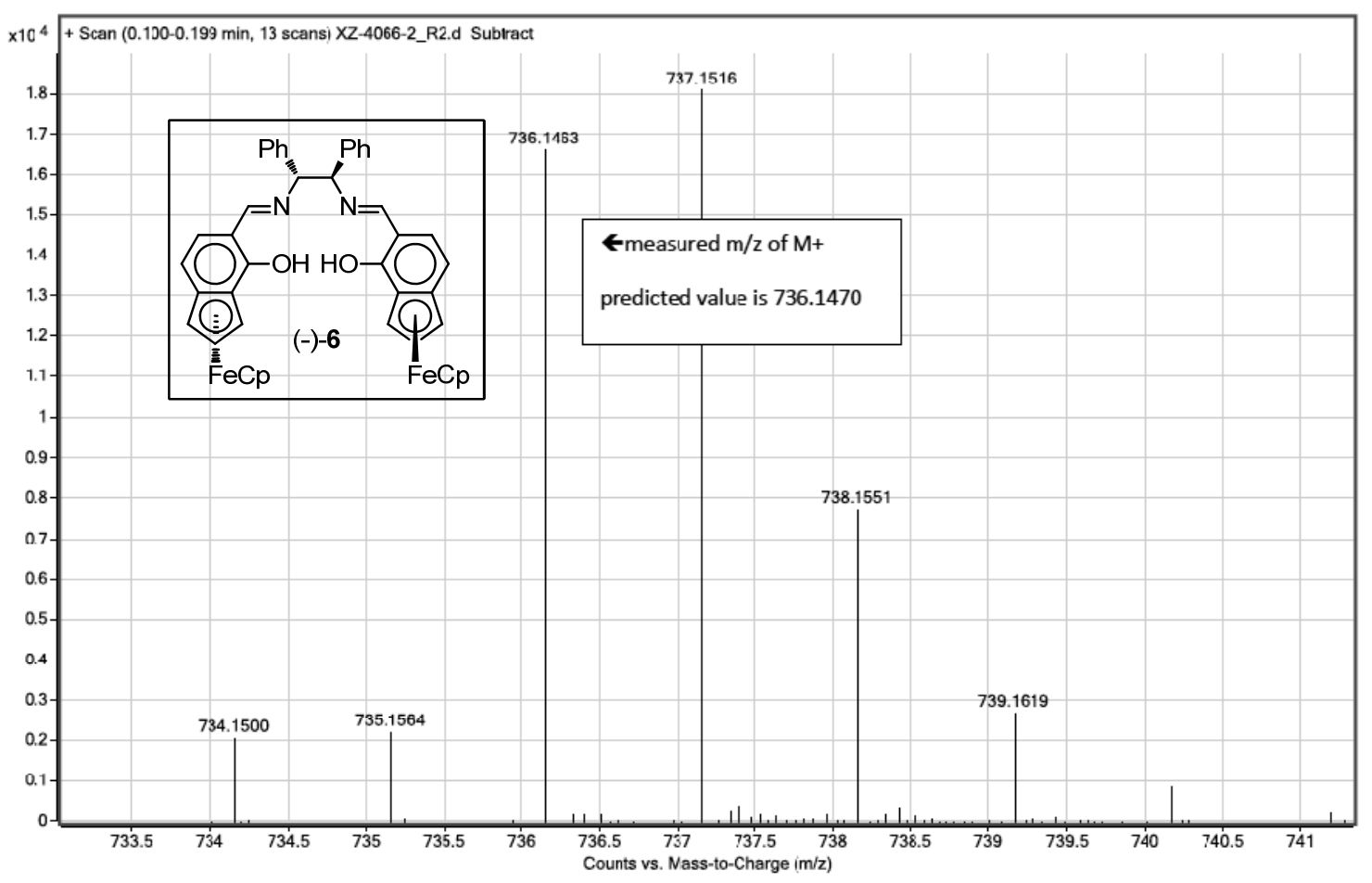

Figure B.45: High resolution MS for (-)-6

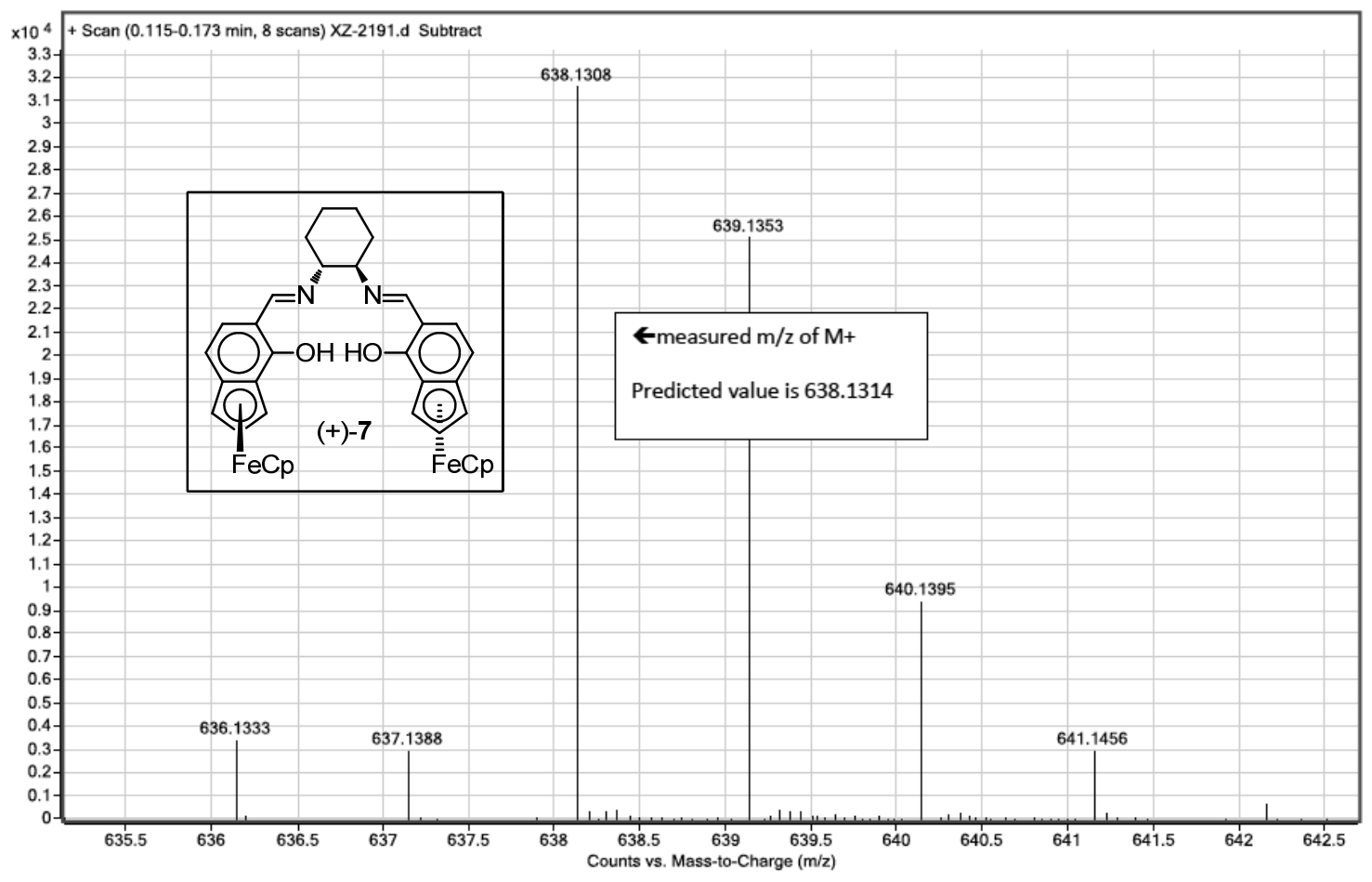

Figure B.46: High resolution MS for (+)-7 


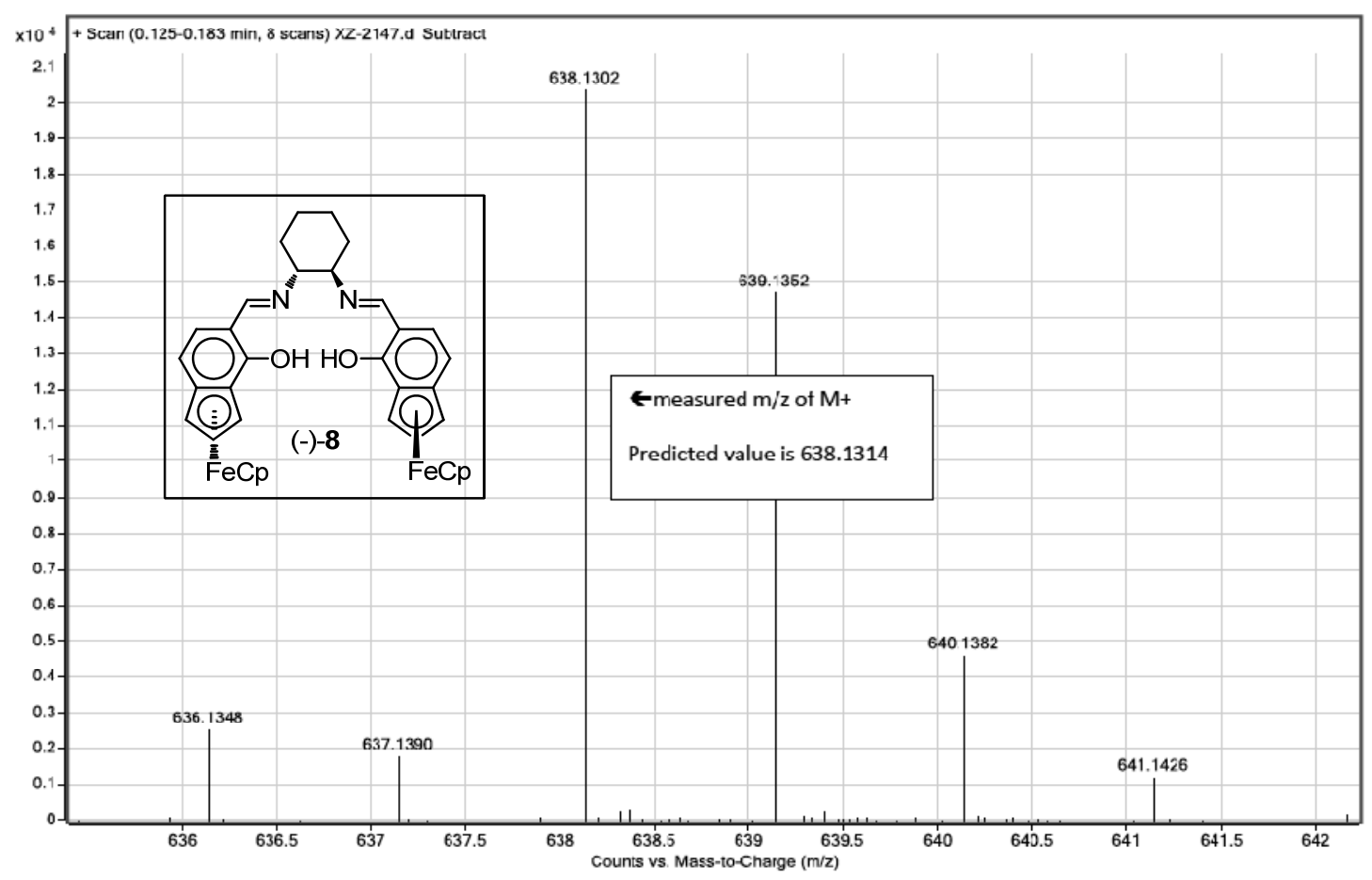

Figure B.47: High resolution MS for (-)-8

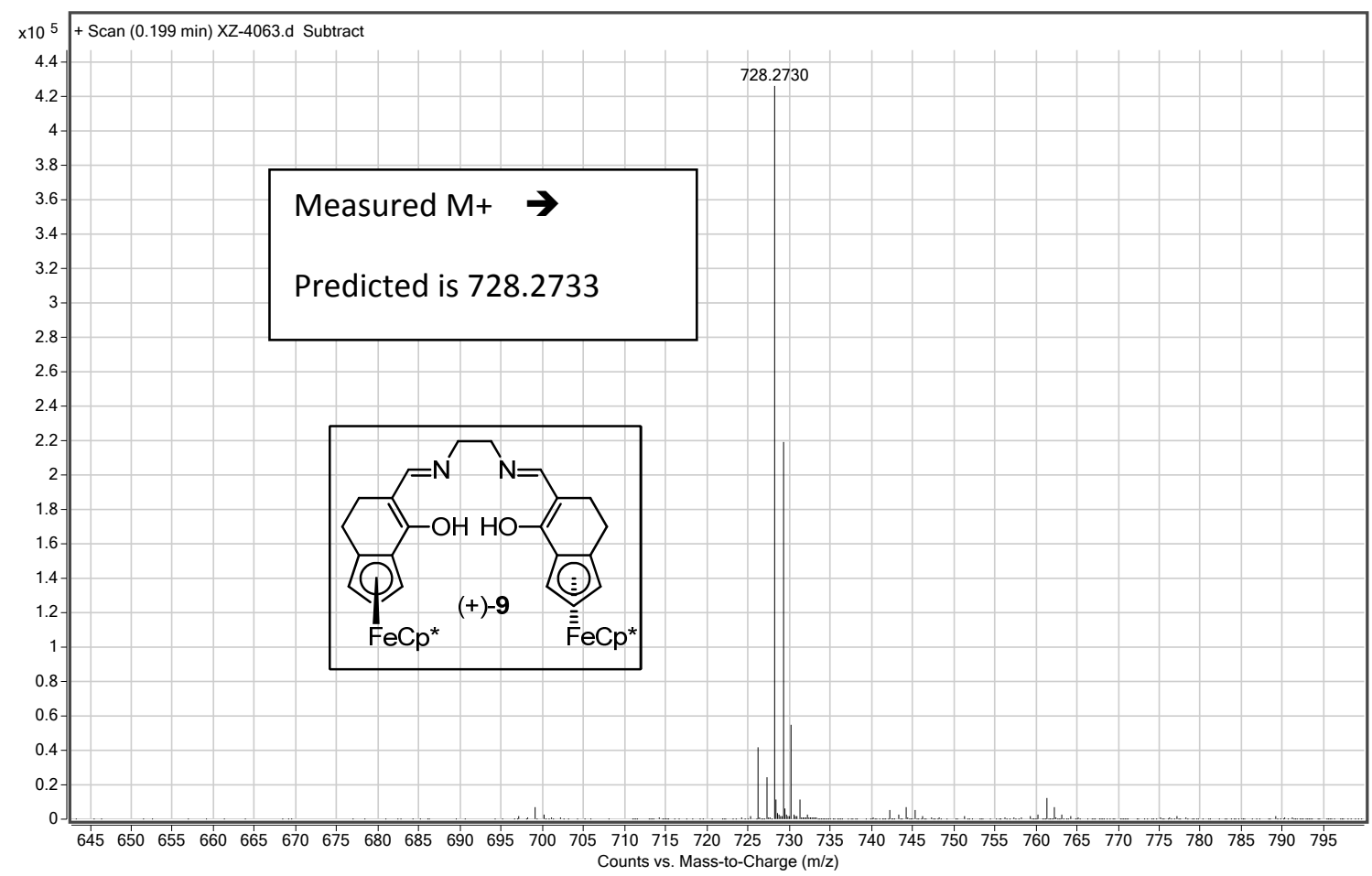

Figure B.48: High resolution MS for (+)-9 


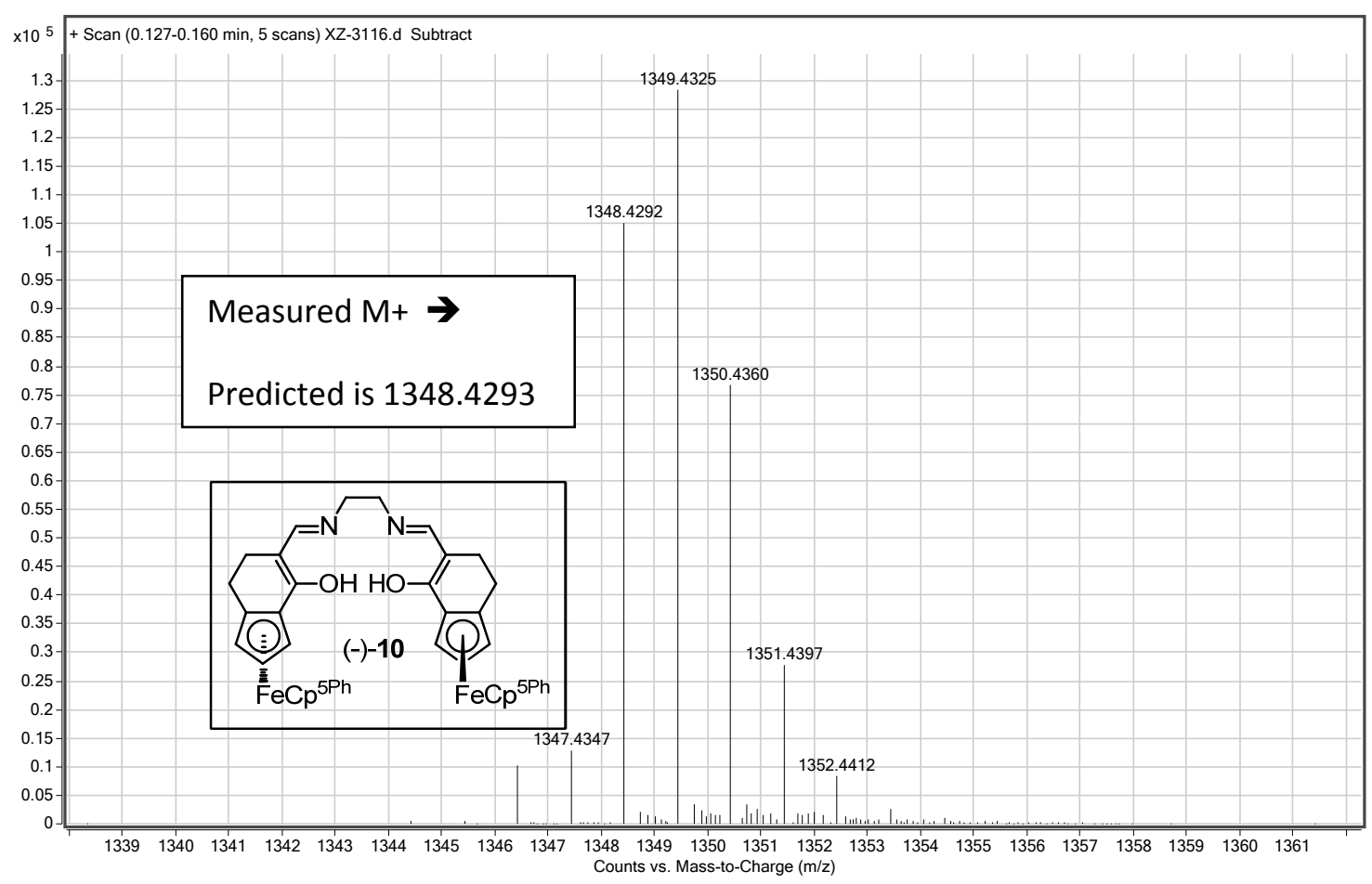

Figure B.49: High resolution MS for (-)-10

\section{Elemental Composition Report}

Page 1

Single Mass Analysis

Tolerance $=5.0$ PPM / DBE: $\min =-1.5, \max =100.0$

Isotope cluster parameters: Separation $=1.0$ Abundance $=1.0 \%$

Monoisotopic Mass, Odd and Even Electron lons

64 formula(e) evaluated with 1 results within limits (all results (up to 1000) for each mass

Zhang/Fang \#2 3070-2 (Reprepared)
QT_061209_018 $22(0.589) \mathrm{Cm}(22: 23)$

MSU RTSF Mass Spectrometry Core

100

100
0
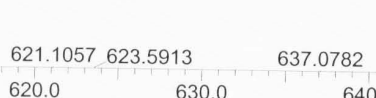

649.0275

$620.0 \quad 630.0$

637.0782

647.0277

651.0329

Minimum:

Maximum:

640.0

650.0

53.0399

Mass

$200.0 \quad 5.0$

$-1.5$

649.0275

Calc. Mass

$\mathrm{mDa}$

PPM

DBE

Score

Formula

649.0302

$-2.7$

$-4.2$

$19.0 \quad 1$

C32 H30 N2 O2 Fe2 Cu

Figure B.50: High resolution MS for (-)-12 


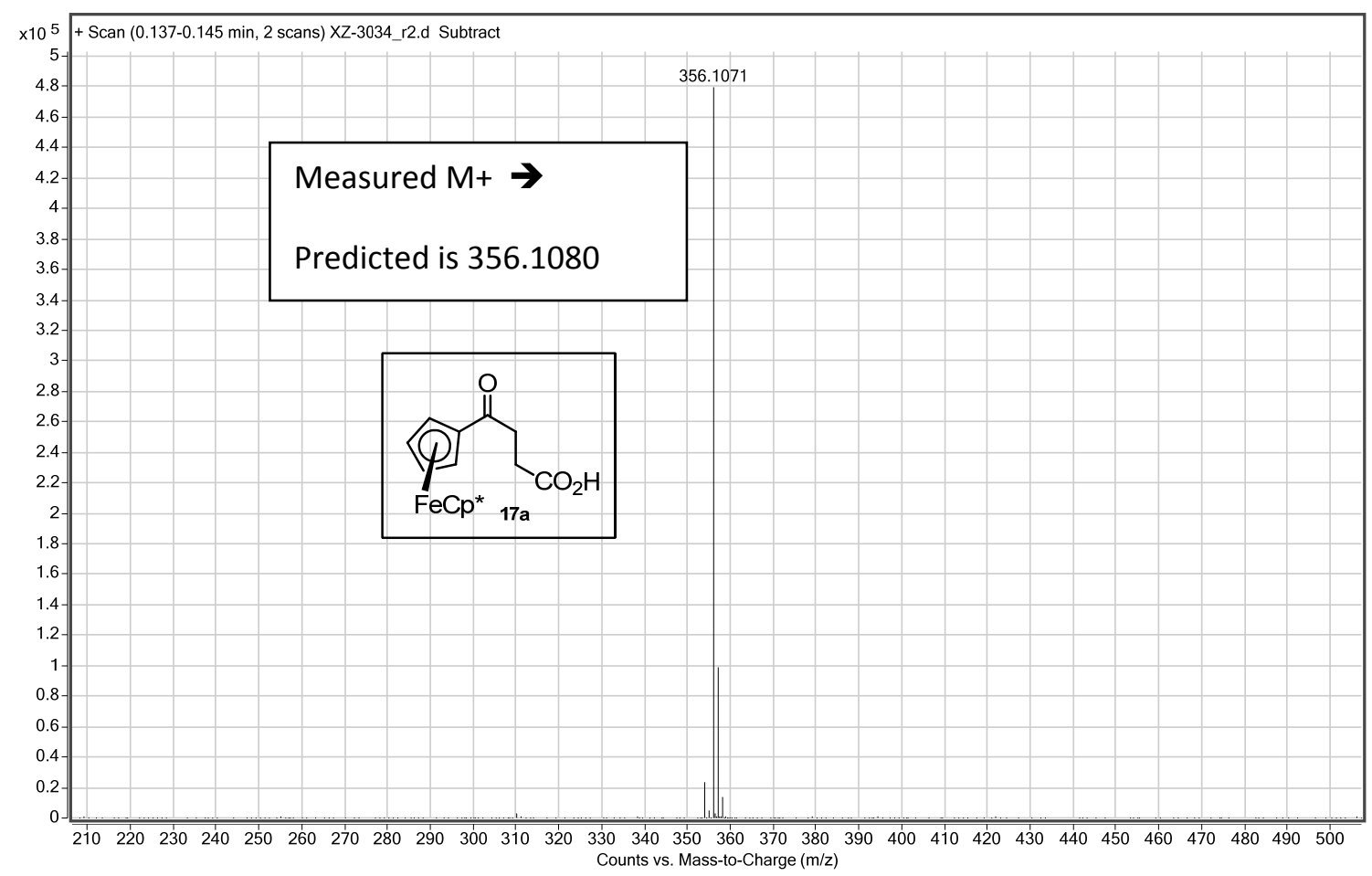

Figure B.51: High resolution MS for 17a

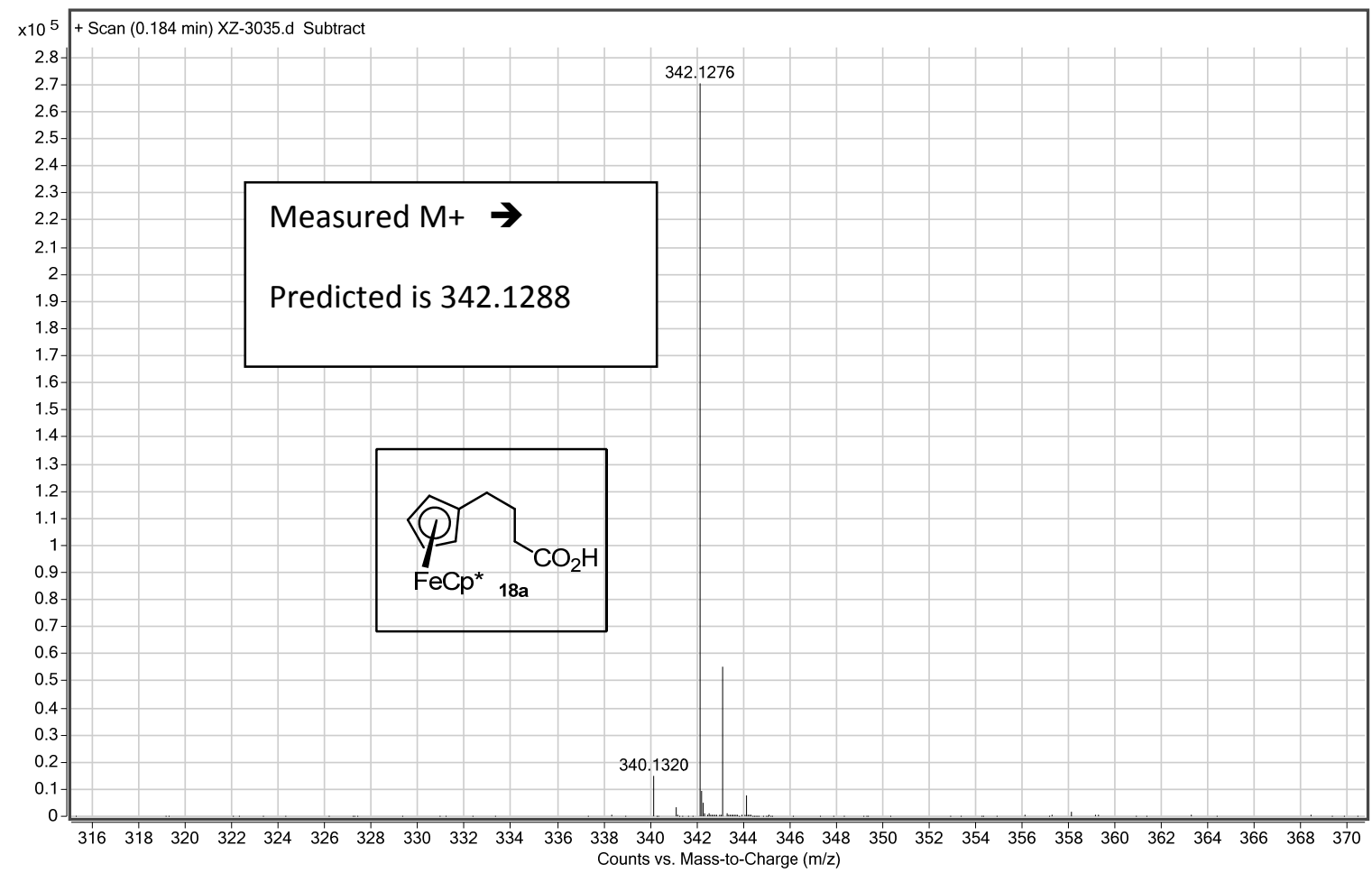

Figure B.52: High resolution MS for 18a 


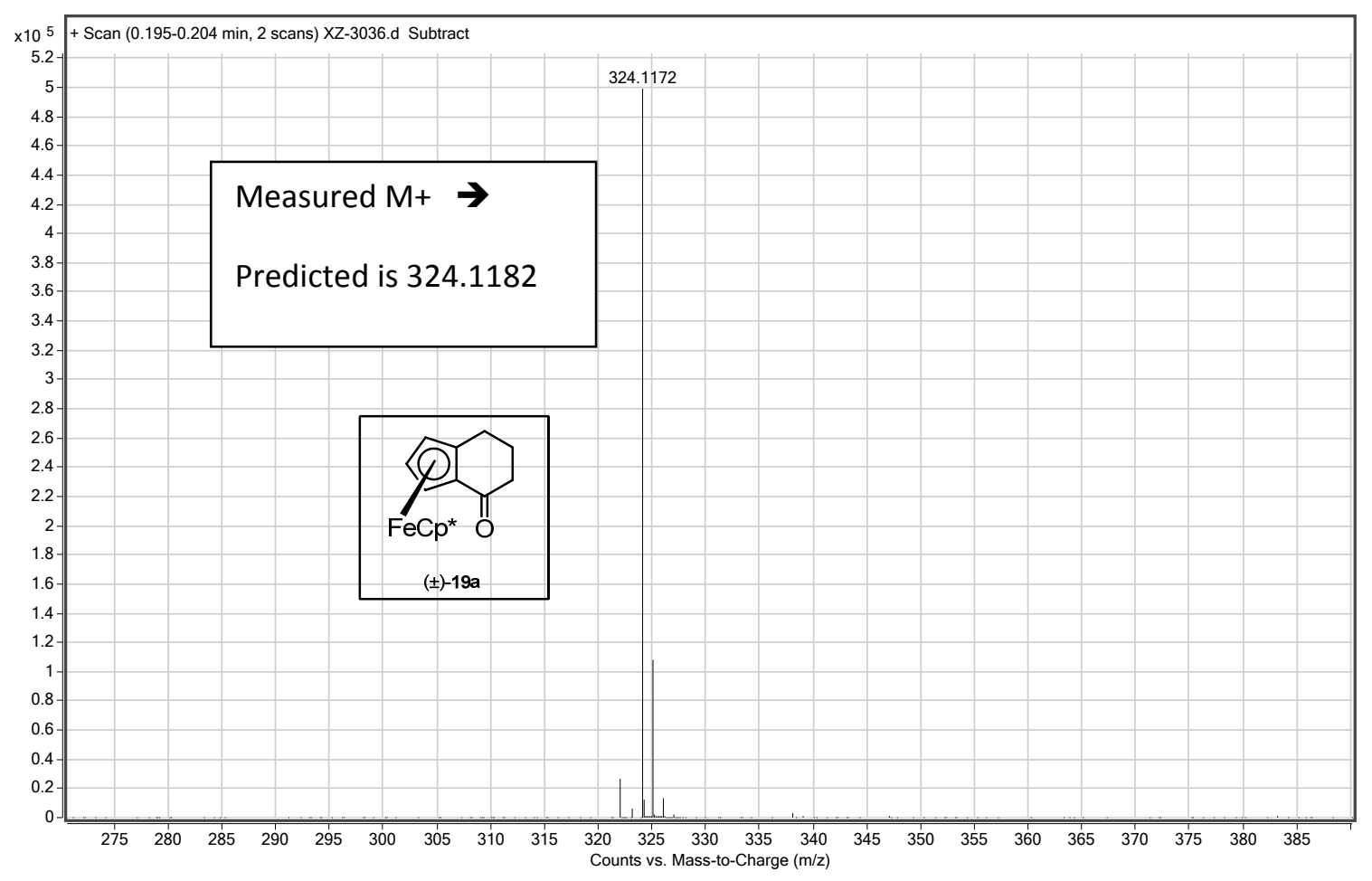

Figure B.53: High resolution MS for ( \pm )-19a

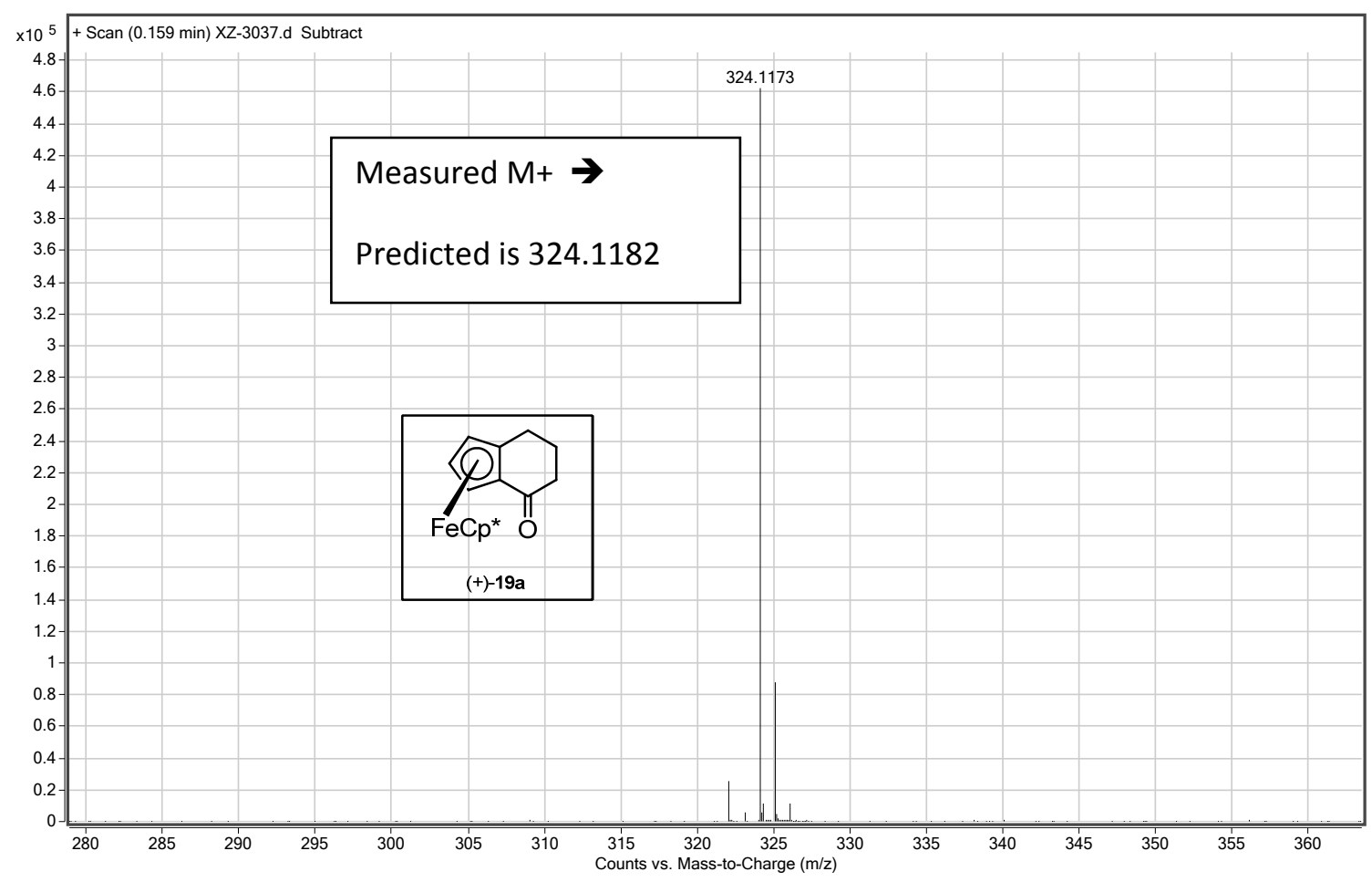

Figure B.54: High resolution MS for (+)-19a 


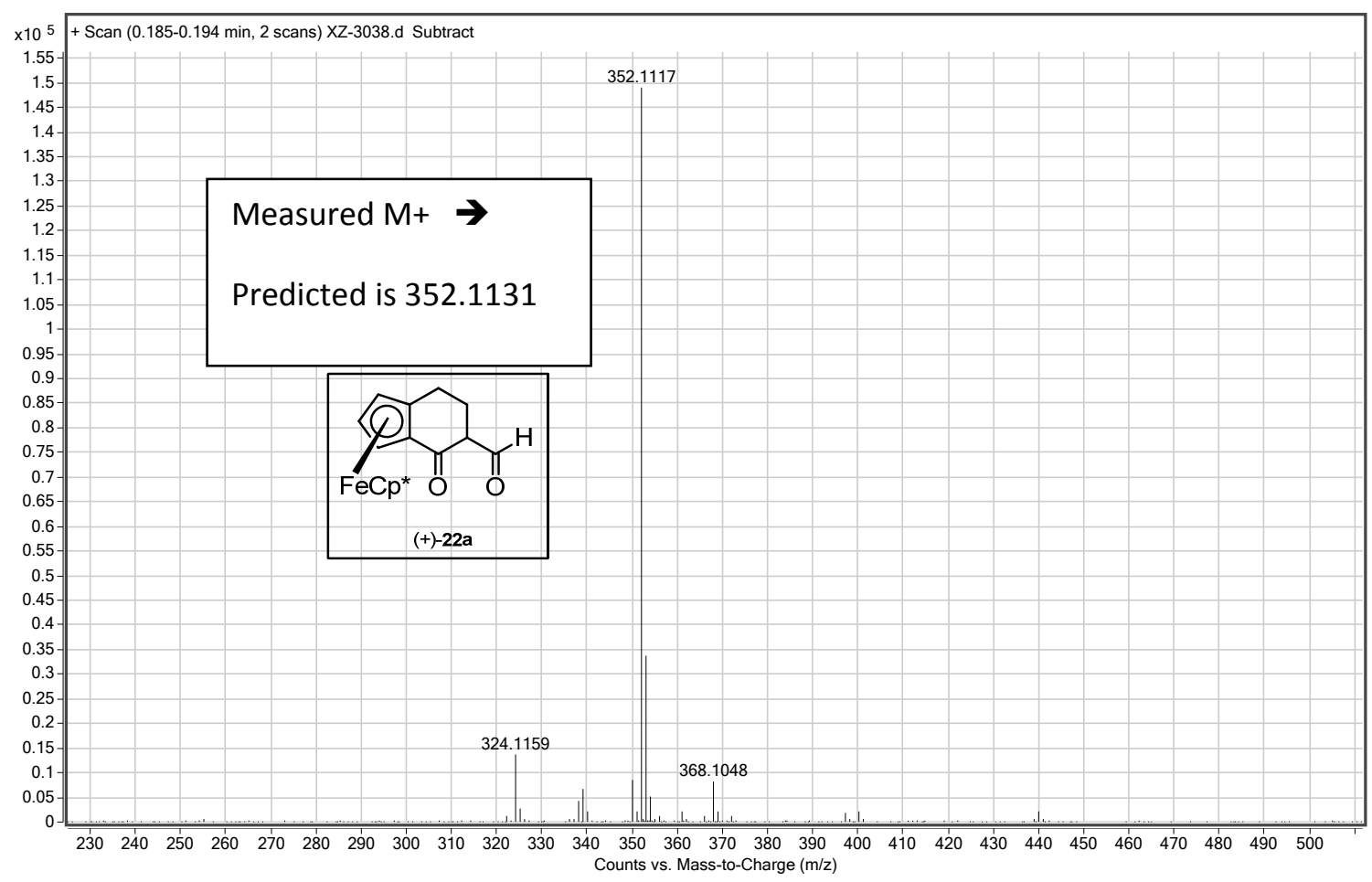

Figure B.55: High resolution MS for (+)-22a

\section{Elemental Composition Report}

\section{Single Mass Analysis}

Tolerance $=100.0$ PPM / DBE: $\min =-1.5, \max =100.0$

Isotope cluster parameters: Separation $=1.0$ Abundance $=1.0 \%$

Monoisotopic Mass, Odd and Even Electron lons

18 formula(e) evaluated with 1 results within limits (all results (up to 1000) for each mass)

MSU RTSF Mass Spectrometry Core

Zhang/Fang \#1 ID3110 (9774) HR

QT_032310_008 31 (0.828) Cm (29:31)

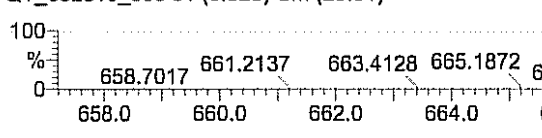

$$
667.1948
$$

668.1973669 .1940

$6.1653{ }_{670.6487673 .2146}^{674.1951} 677.5144 \quad 678.4656 \quad 680.4983$

Minimum:

Maximum:

$200.0 \quad 100.0 \quad-1.5$

Mass

Calc. Mass

mDa $\quad$ PPM

$\mathrm{DBE}$

27.

1.2

1.9
Page 1

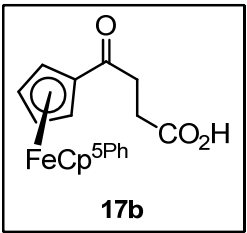

23-Mar-2010 1: TOF MS ES+
$667.1948 \quad 667.1936$ 672.0 674.0

1.2

Figure B.56: High resolution MS for 17b 
Single Mass Analysis

Tolerance $=100.0$ PPM / DBE: $\min =-1.5, \max =100.0$

Isotope cluster parameters: Separation $=1.0$ Abundance $=1.0 \%$

Monoisotopic Mass, Odd and Even Electron lons

15 formula(e) evaluated with 1 results within limits (ail results (up to 1000) for each mass)

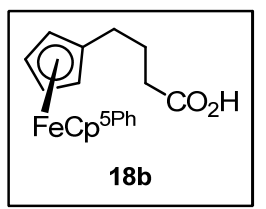

MSU RTSF Mass Spectrometry Core

Zhang/Fang \#2 ID3111 $(9774) \mathrm{HR}$
QT_032310_009 $28(0.748) \mathrm{Cm}(26: 29)$

100 - $10.2075 \quad 653.2177$

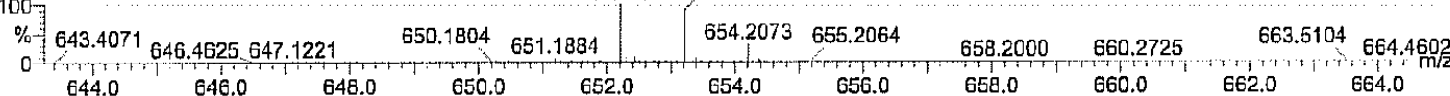

Minimum :

Maximum:

$\begin{array}{lll}200.0 \quad 100.0 \quad & -1.5 \\ 100.0\end{array}$

Mass Calc. Mass mDa PEM DEE Score Formula

$\begin{array}{llllllllll}652.2075 & 652.2065 & 1.0 & 1.6 & 27.0 & 1 & \text { C4 } & \text { H36 } & 02 & \text { Fe }\end{array}$

\section{Figure B.57: High resolution MS for $\mathbf{1 8 b}$}

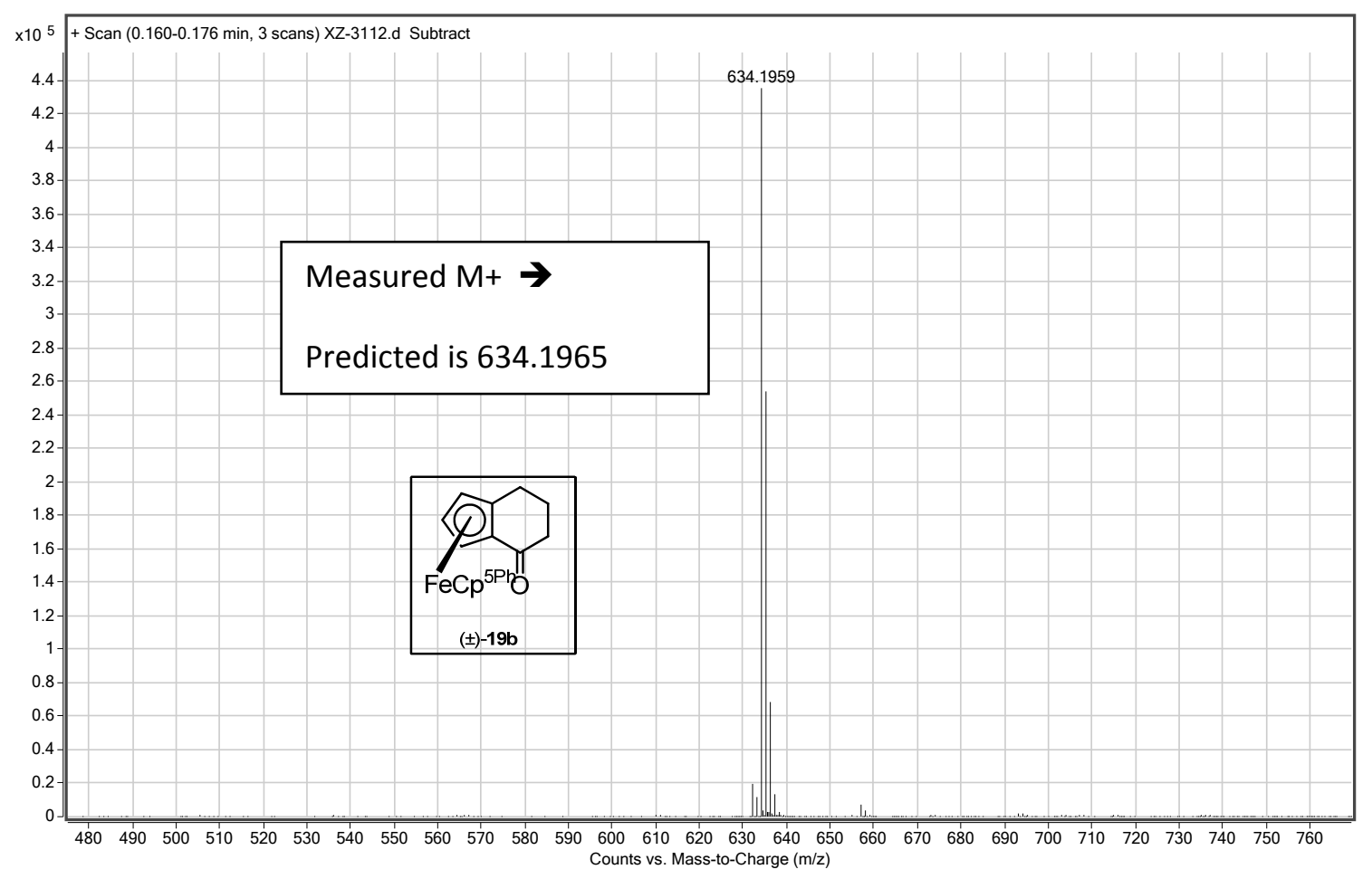

Figure B.58: High resolution MS for $( \pm)-19 b$ 


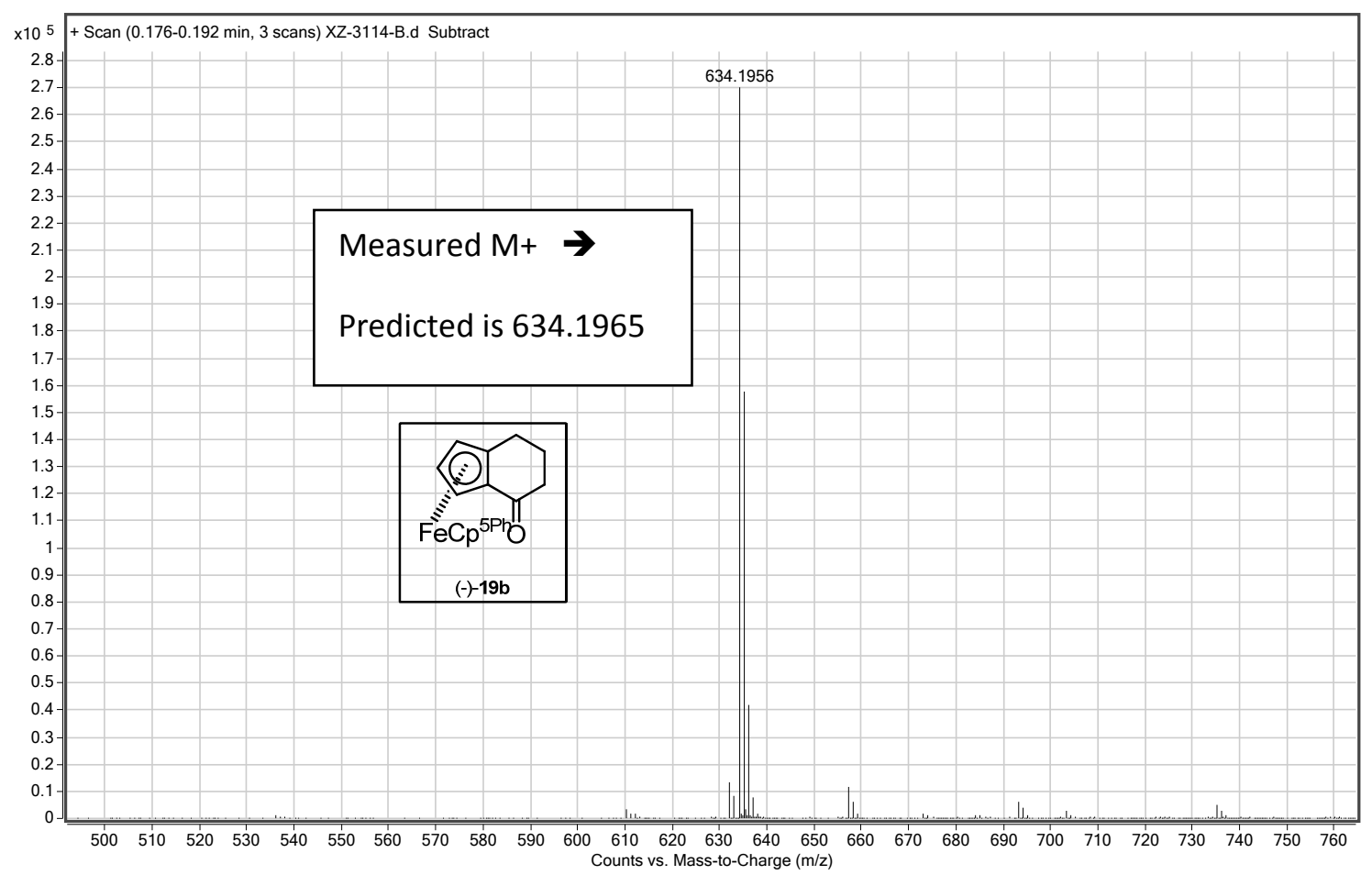

Figure B.59: High resolution MS for (-)-19b

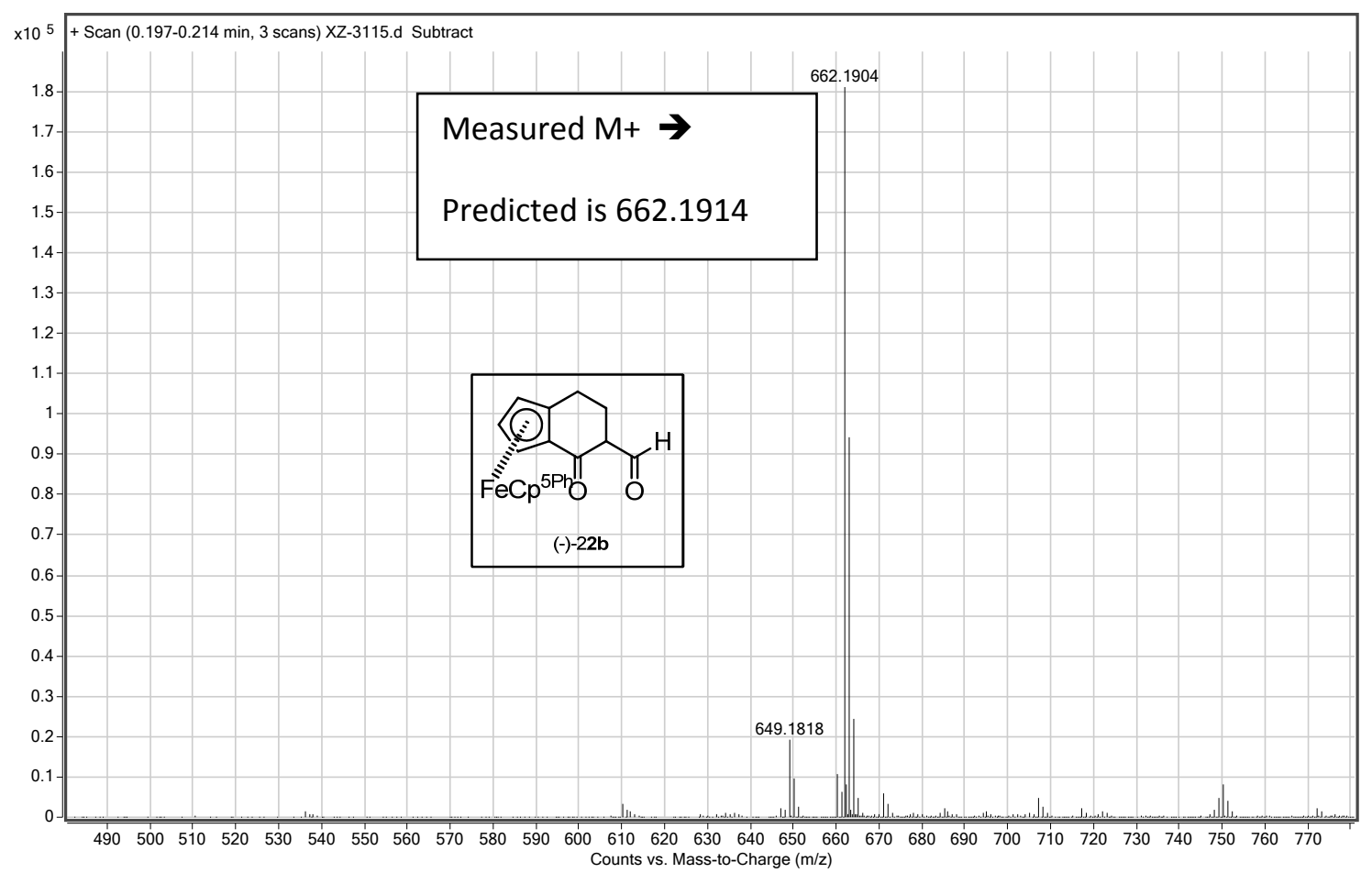

Figure B.60: High resolution MS for (-)-22b 


\section{B.3 Crystal packing of 12}

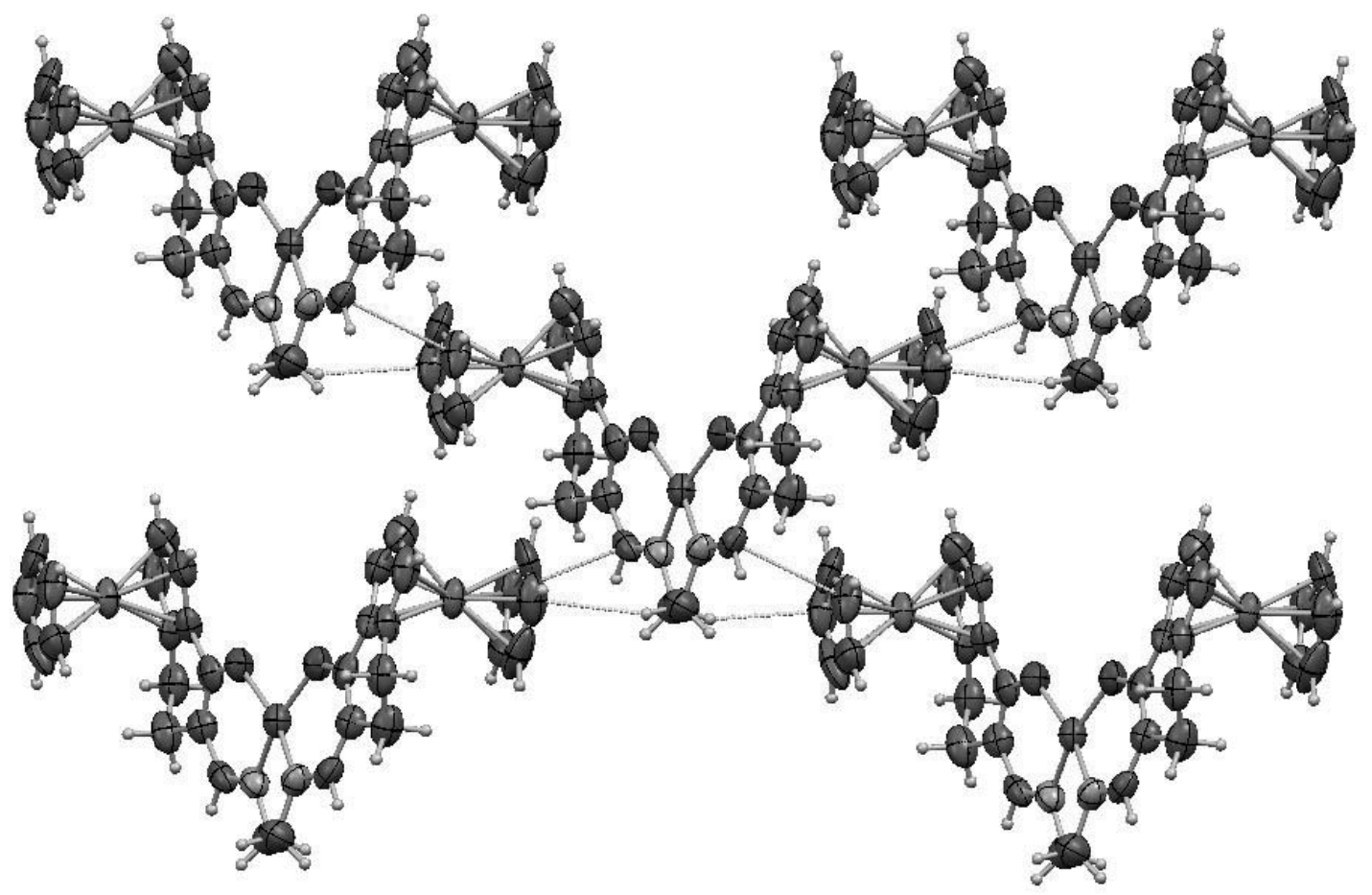

Figure B.61: Crystal packing of $\mathbf{1 2}$ 


\section{Appendix C}

\section{Supporting Information for Chapter 4}

\section{Applications of Chiral Ferrosalen Ligands in catalysis}

(Compound numbers correspond to the numbers in Chapter 4 of the dissertation.) 


\section{C.1 Chiral HPLC profiles}

Carbonyl-ene Reaction: Chiral HPLC profiles of 15:

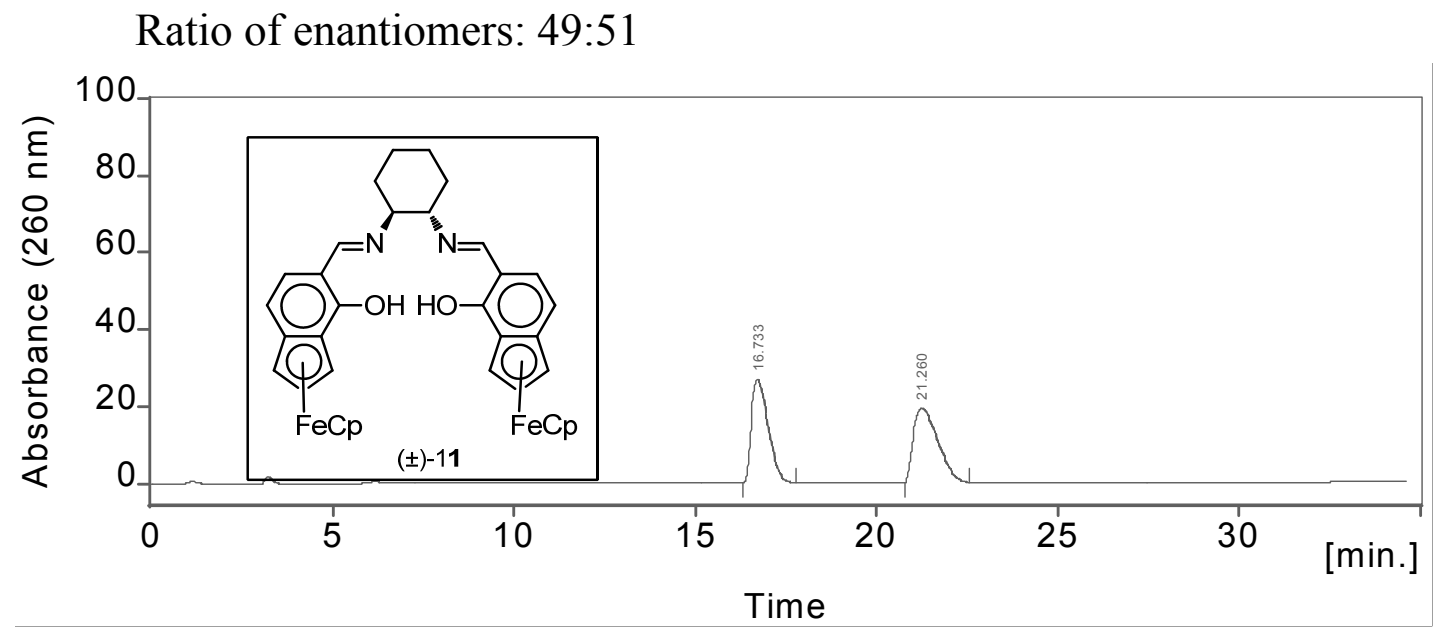

Figure C.1: HPLC profile for $\mathbf{1 5}$ using $( \pm)-11-\mathrm{Co}(\mathrm{III})$ as the catalyst

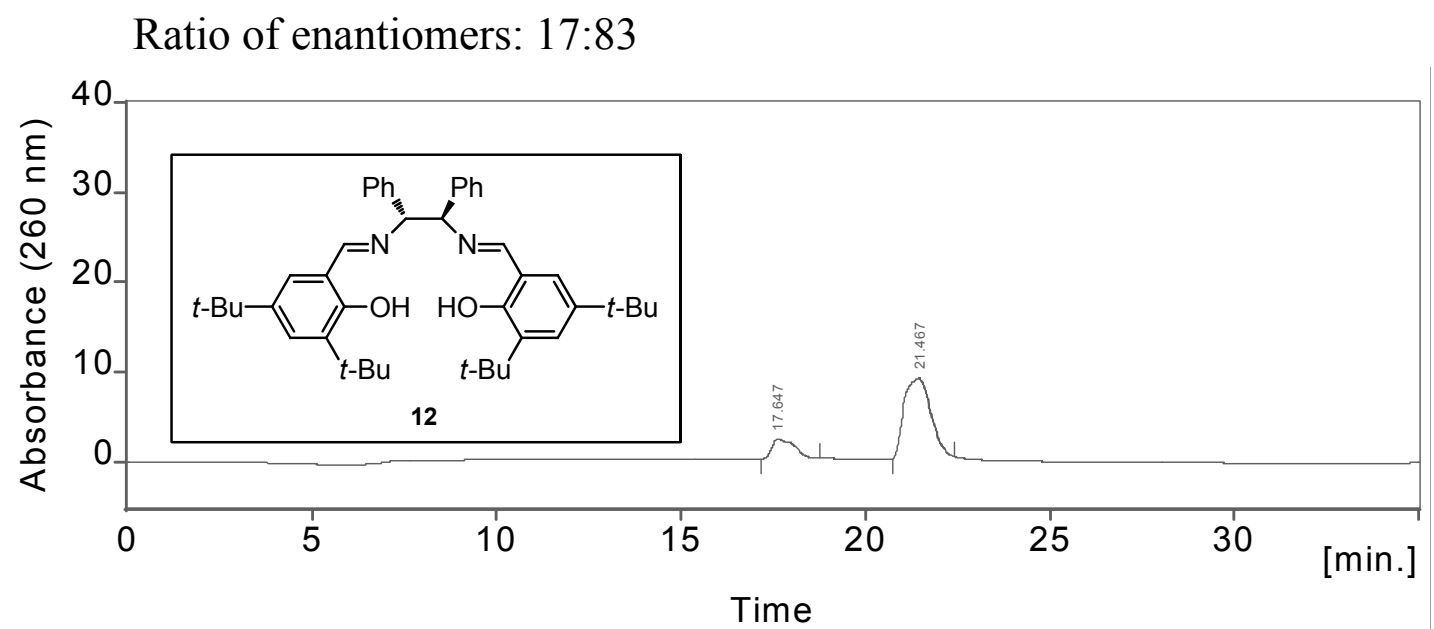

Figure C.2: HPLC profile for $\mathbf{1 5}$ using 12-Co(III) as the catalyst 


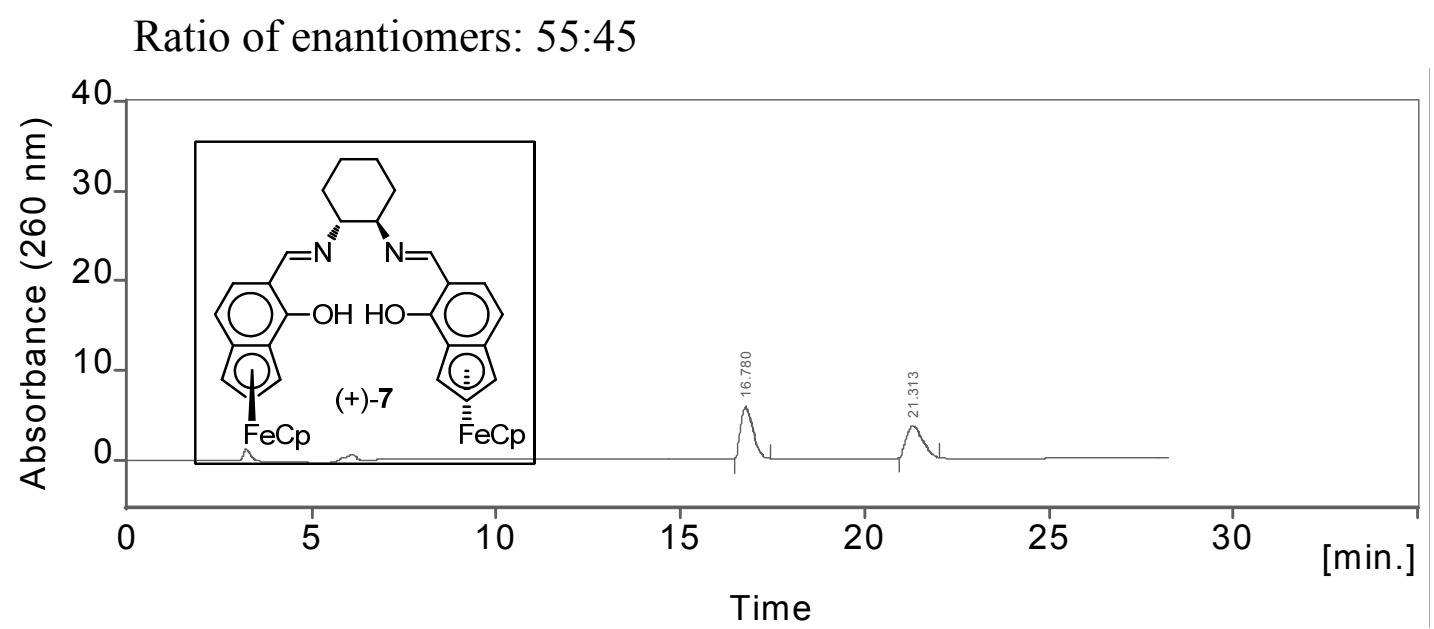

Figure C.3: HPLC profile for 15 using (+)-7-Co(III) as the catalyst

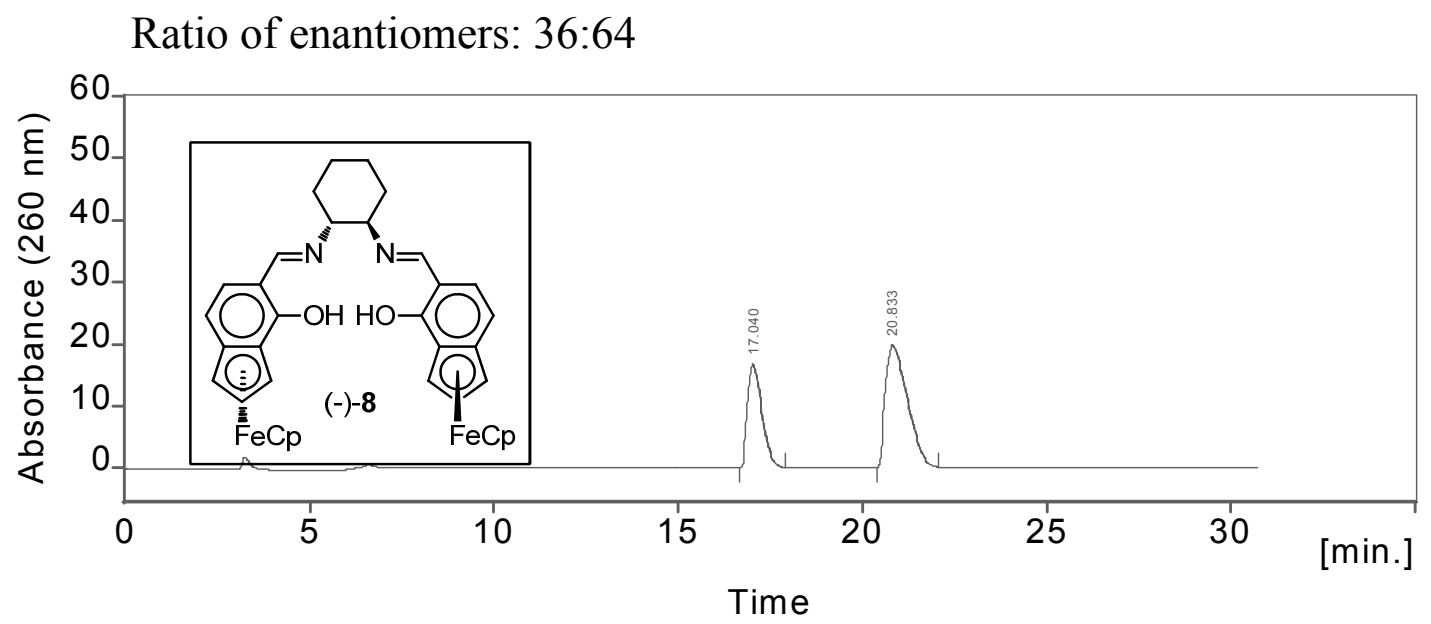

Figure C.4: HPLC profile for 15 using (-)-8-Co(III) as the catalyst 
Strecker-type Reaction: Chiral HPLC profiles of 18

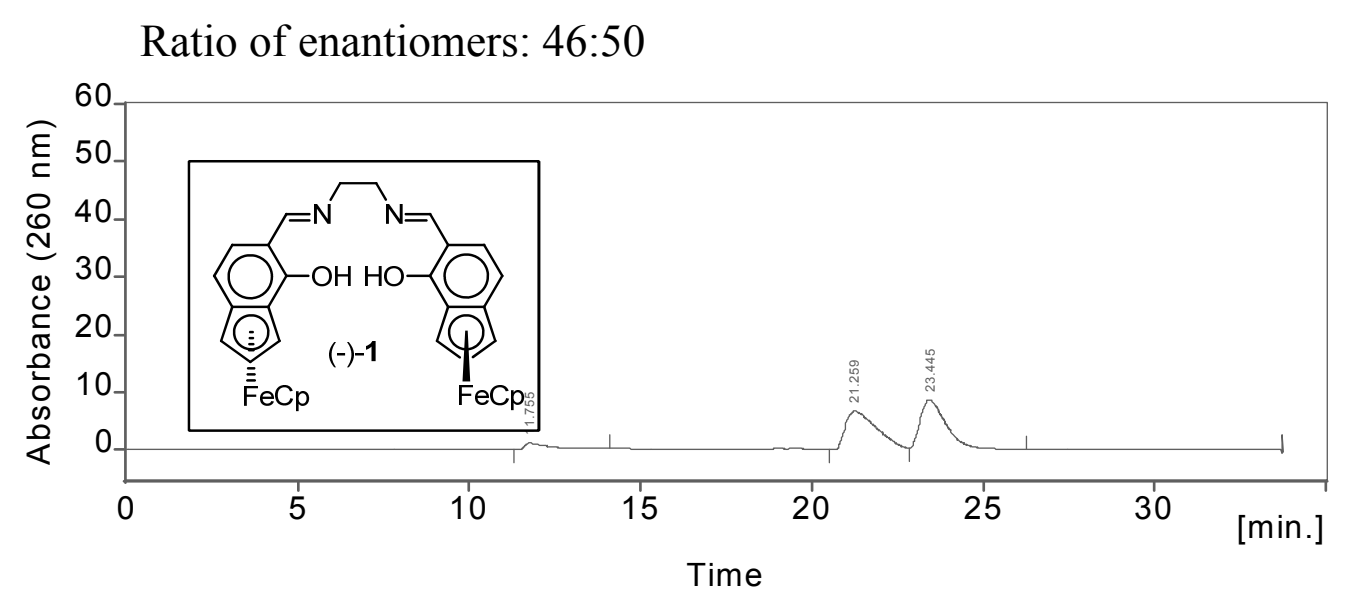

Figure C.5: HPLC profile for $\mathbf{1 8}$ using (-)-1-AlCl as the catalyst (rt)

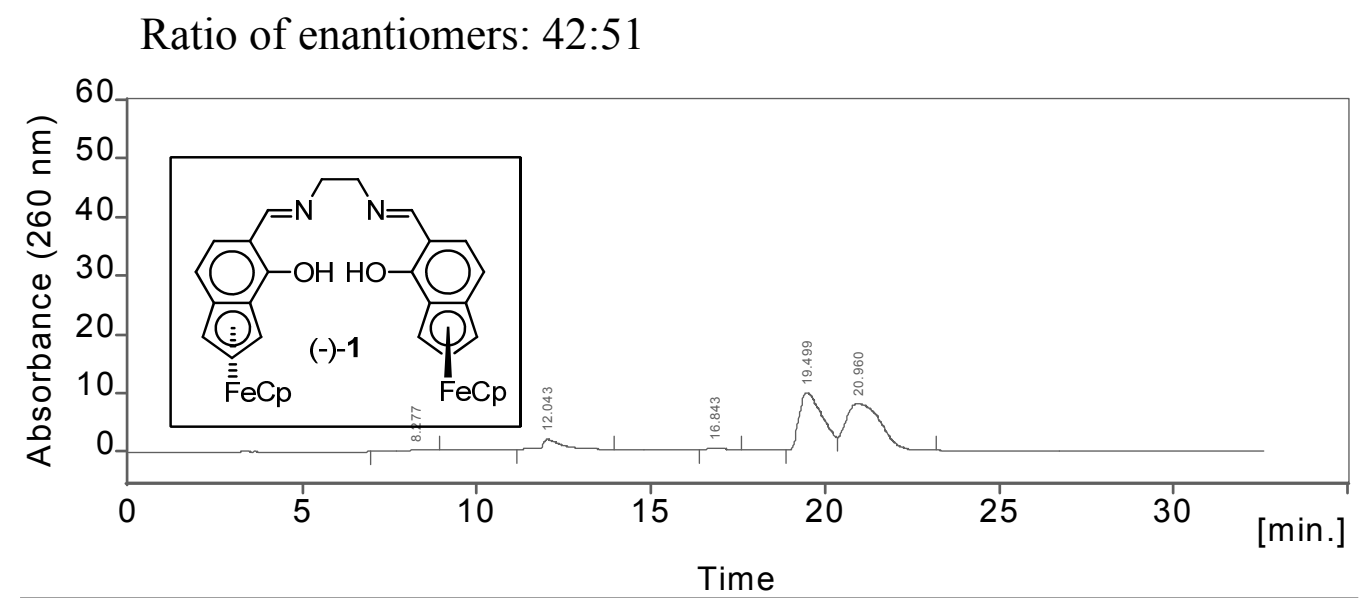

Figure C.6: $\mathrm{HPLC}$ profile for $\mathbf{1 8}$ using (-)-1- $\mathrm{AlCl}$ as the catalyst $\left(0^{\circ} \mathrm{C}-\mathrm{rt}\right)$ 
Ratio of enantiomers: 39:61

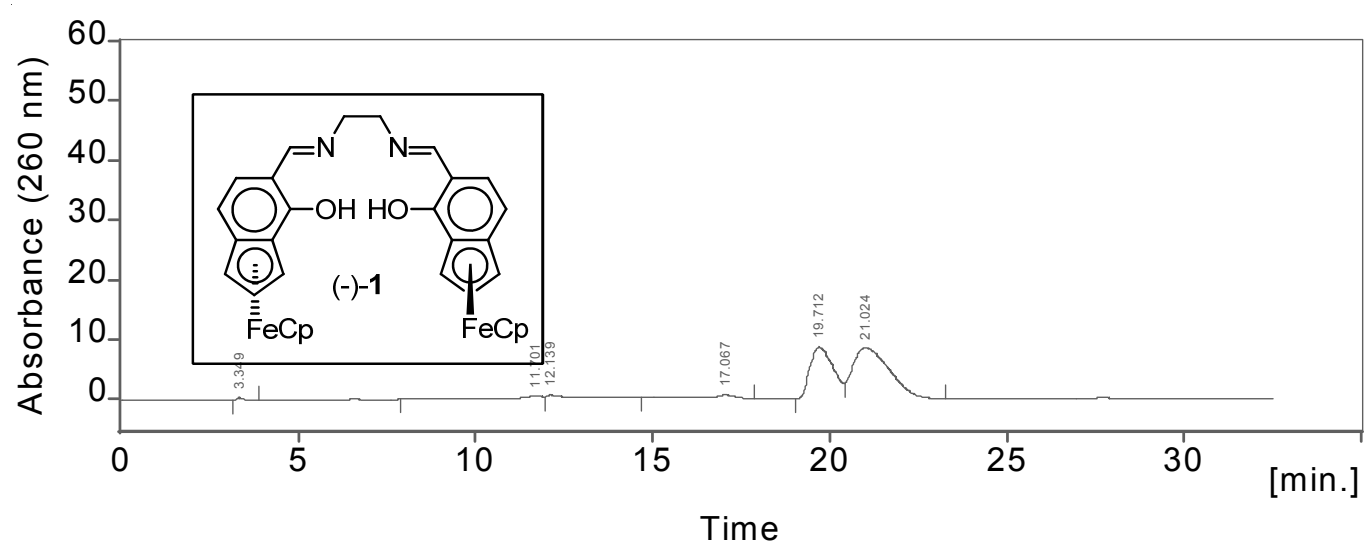

Figure C.7: HPLC profile for 18 using (-)-1- $\mathrm{AlCl}$ as the catalyst $\left(-78{ }^{\circ} \mathrm{C}-\mathrm{rt}\right)$

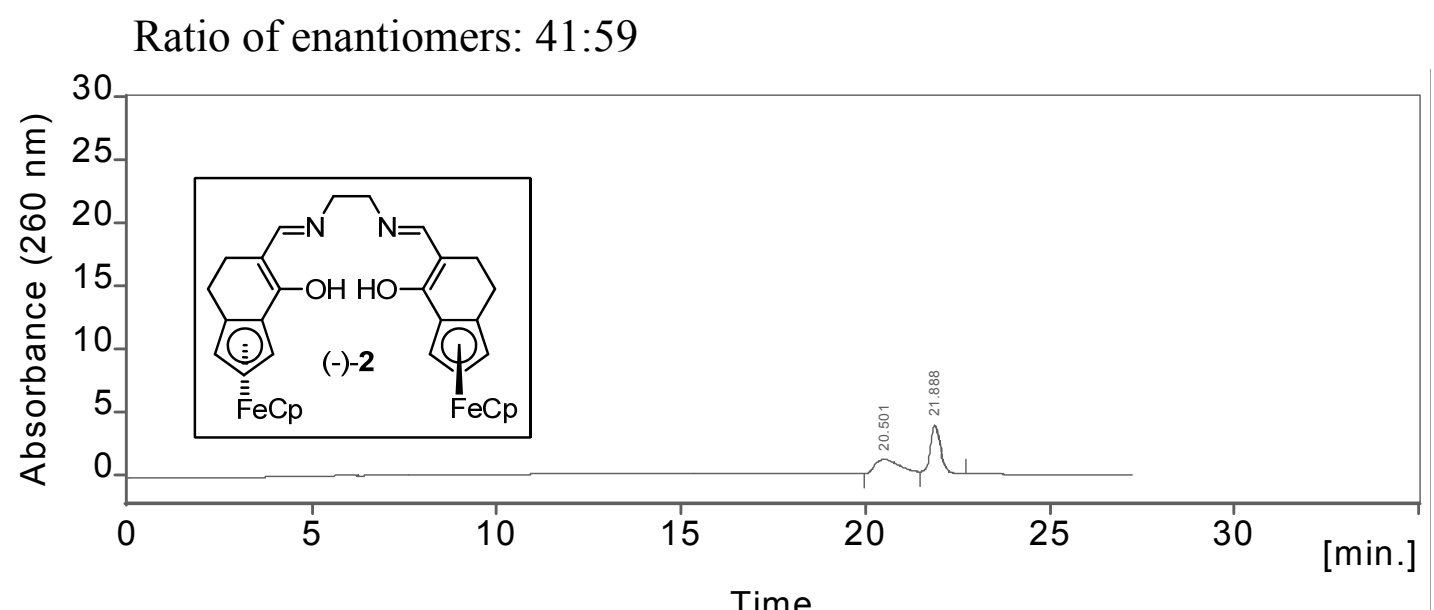

Figure C.8: HPLC profile for $\mathbf{1 8}$ using (-)-2-AlCl as the catalyst

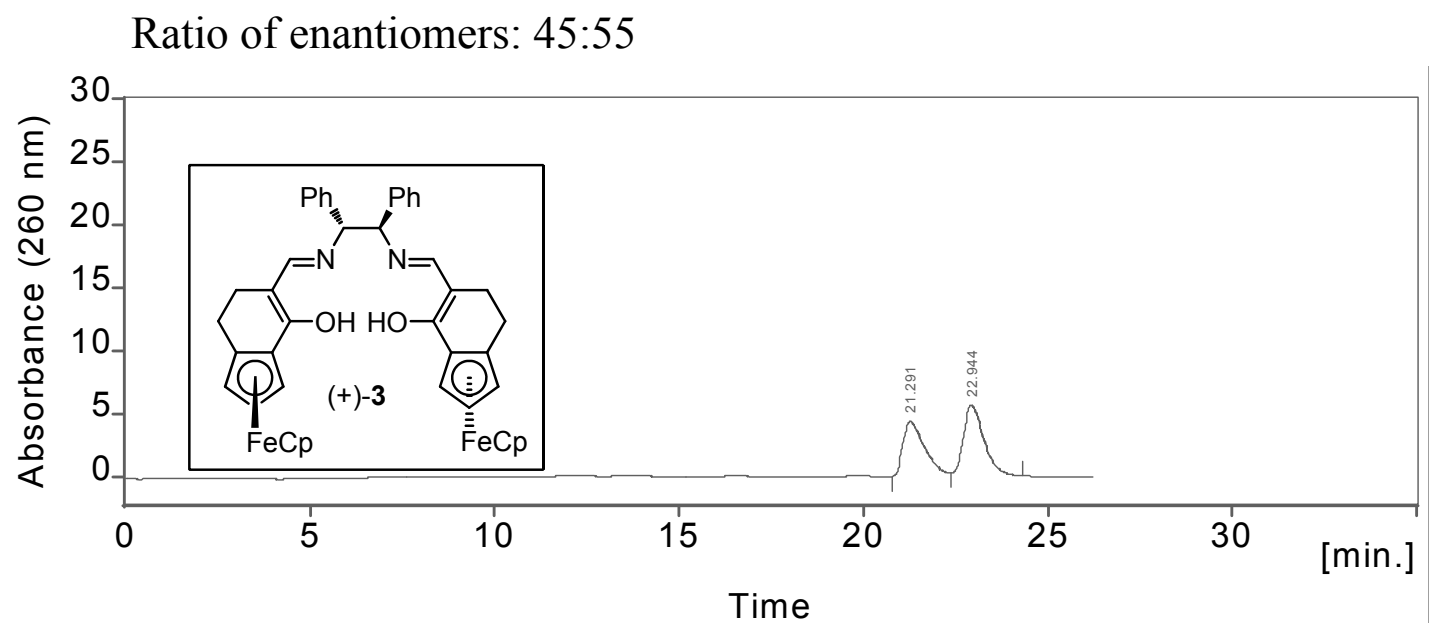

Figure C.9: HPLC profile for $\mathbf{1 8}$ using (+)-3-AlCl as the catalyst 


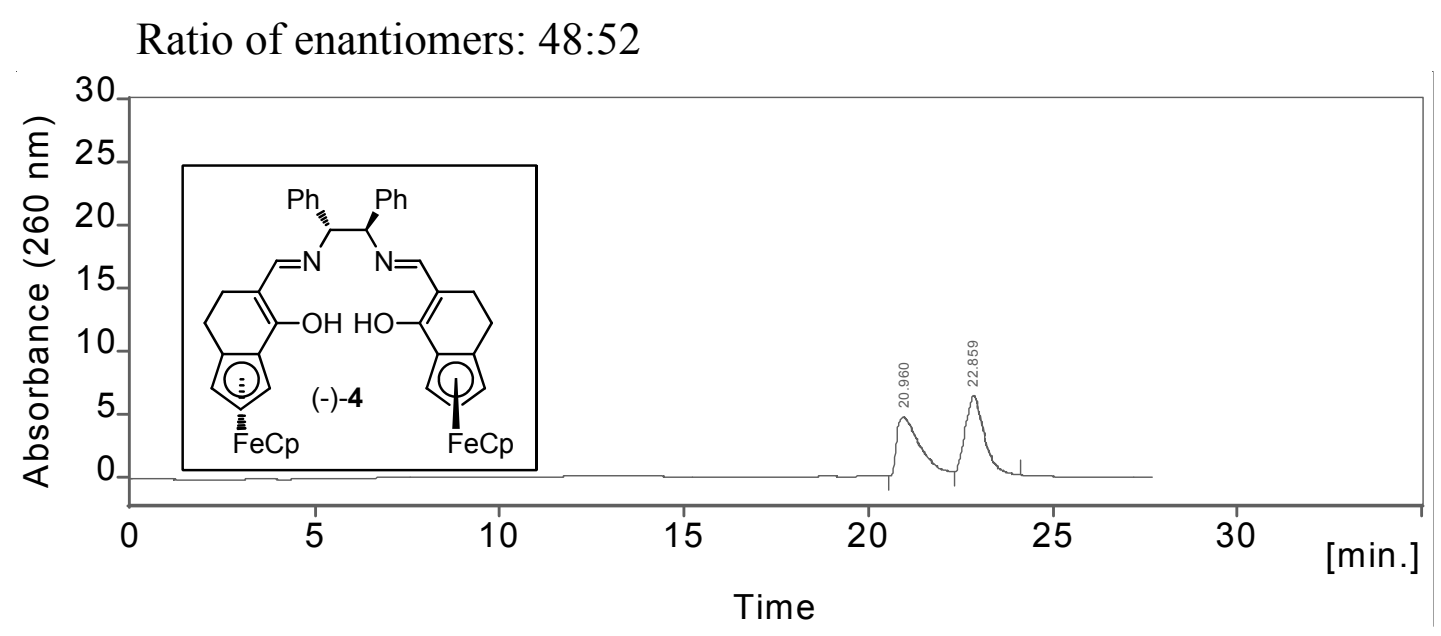

Figure C.10: HPLC profile for $\mathbf{1 8}$ using (-)-4-AlCl as the catalyst

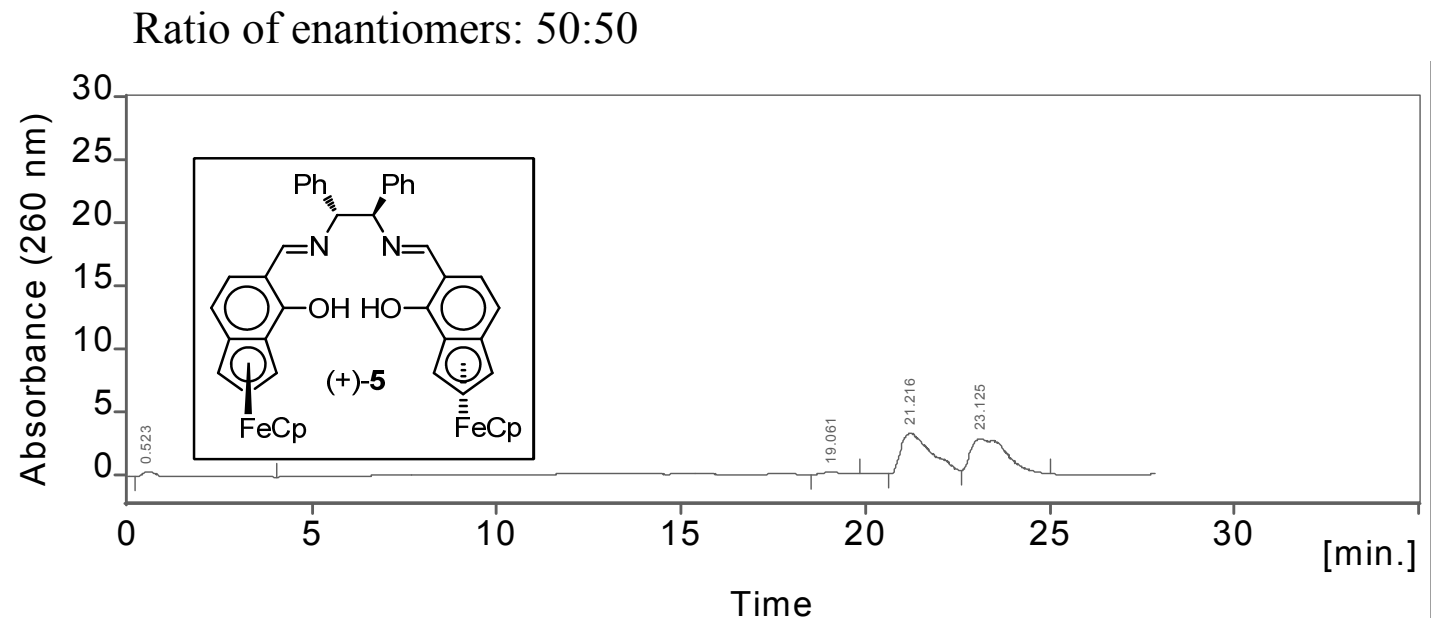

Figure C.11: HPLC profile for $\mathbf{1 8}$ using $(+)-5-\mathrm{AlCl}$ as the catalyst

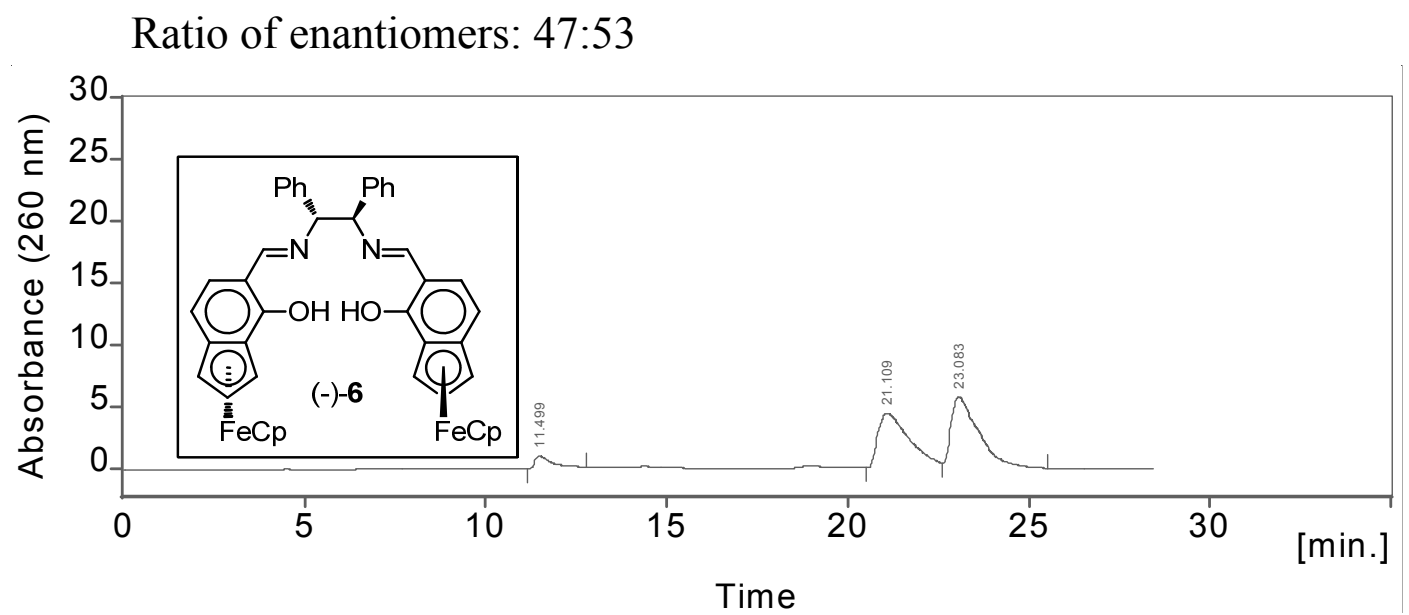

Figure C.12: HPLC profile for 18 using (-)-6- $\mathrm{AlCl}$ as the catalyst 


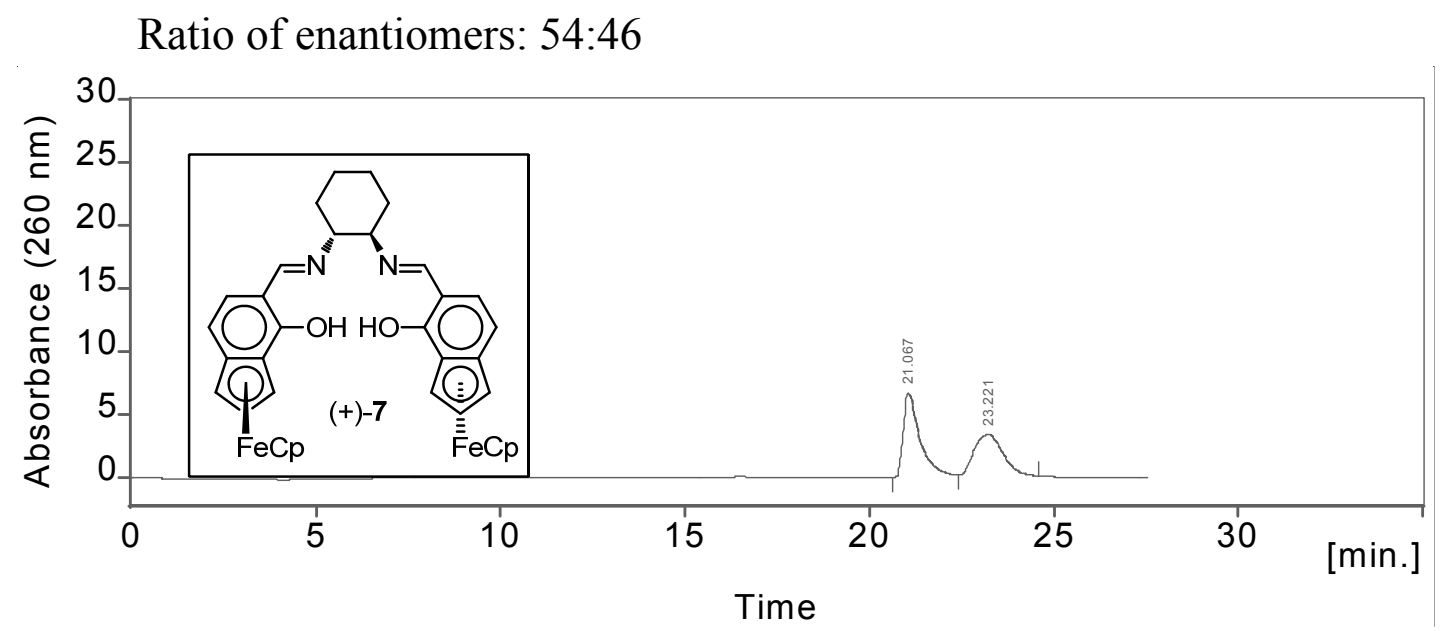

Figure C.13: HPLC profile for 18 using $(+)-7-\mathrm{AlCl}$ as the catalyst

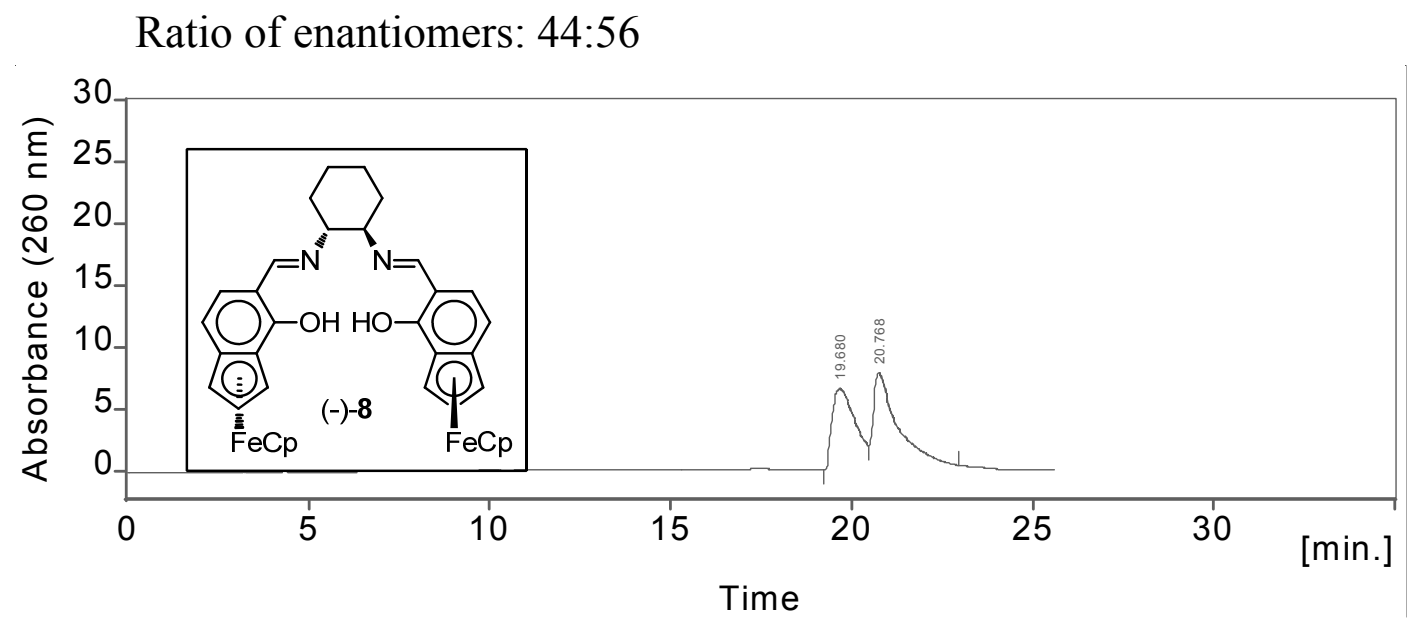

Figure C.14: HPLC profile for $\mathbf{1 8}$ using (-)-8- $\mathrm{AlCl}$ as the catalyst

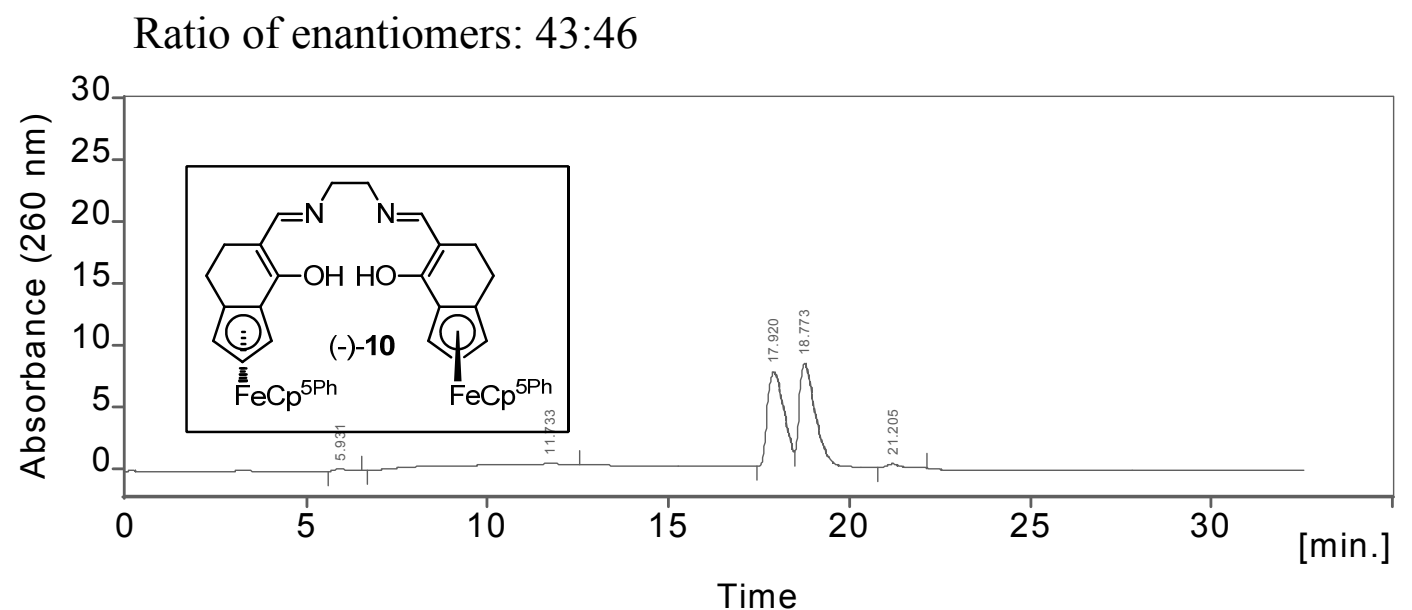

Figure C.15: HPLC profile for $\mathbf{1 8}$ using (-)-10-AlCl as the catalyst 
Silylcyanation Reaction: Chiral HPLC profiles of 19

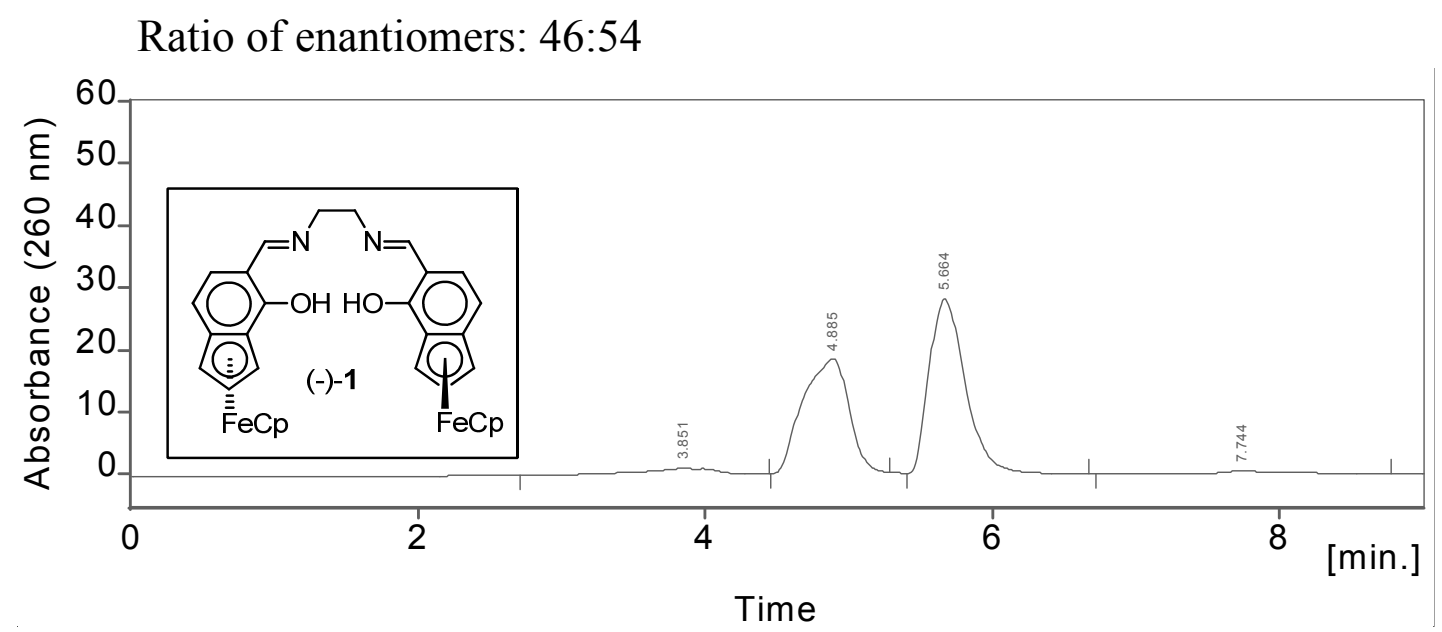

Figure C.16: HPLC profile for 19 using (-)-1- $\mathrm{AlCl}$ as the catalyst

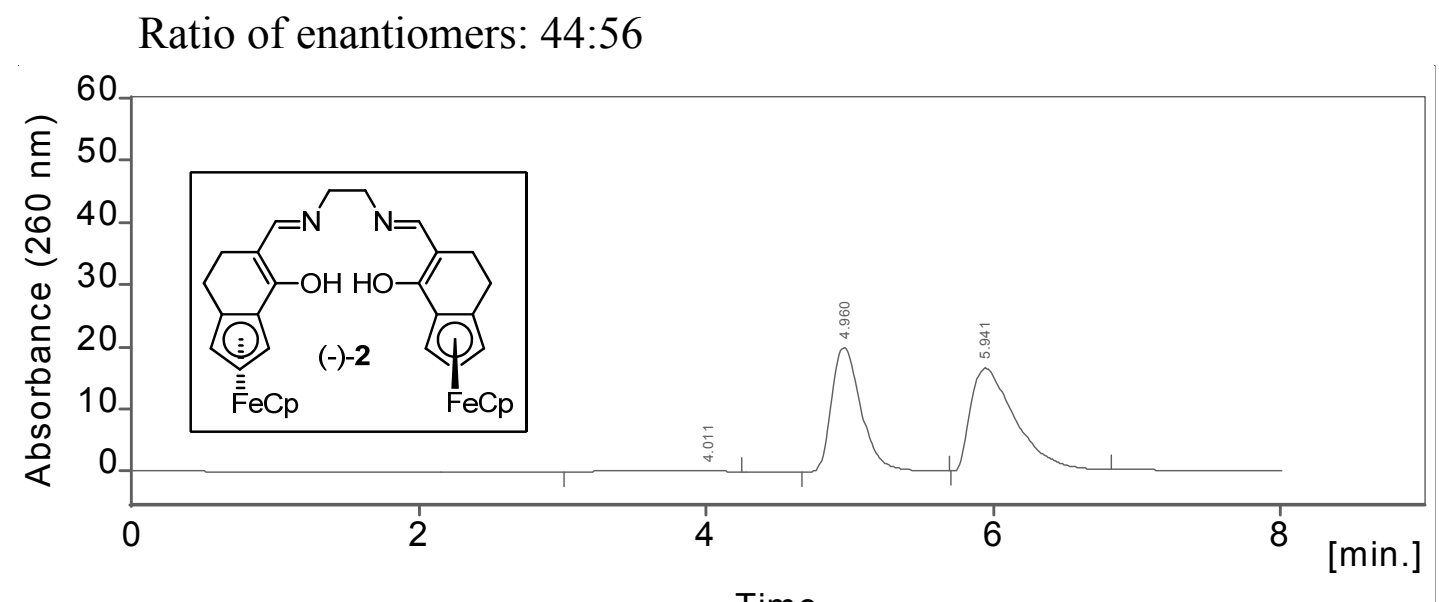

Figure C.17: HPLC profile for 19 using (-)-2- $\mathrm{AlCl}$ as the catalyst 


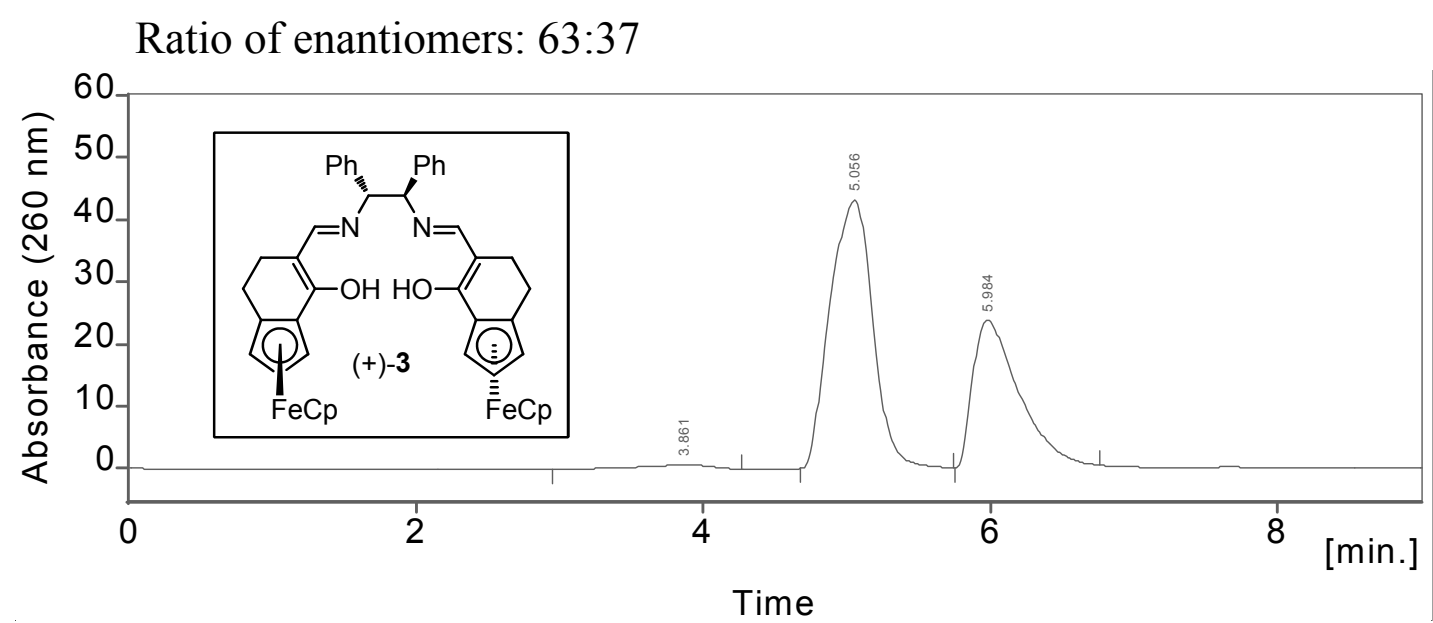

Figure C.18: HPLC profile for 19 using $(+)-3-\mathrm{AlCl}$ as the catalyst

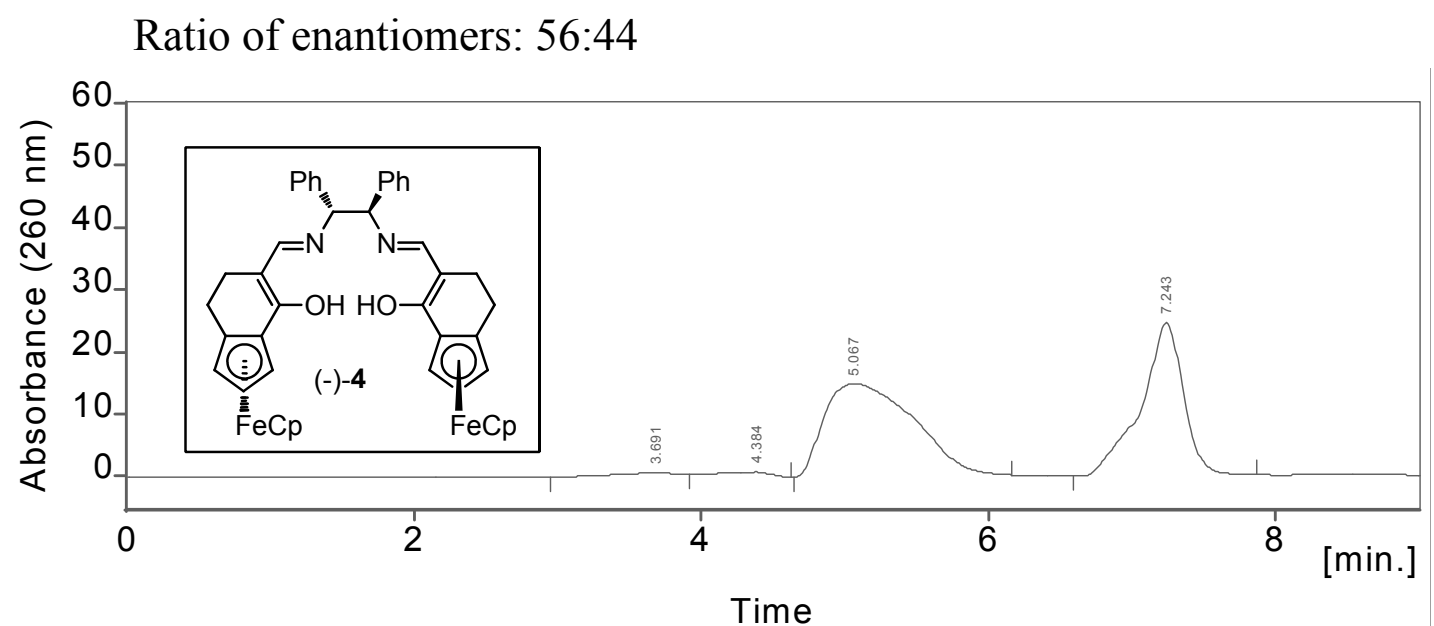

Figure C.19: HPLC profile for 19 using (-)-4-AlCl as the catalyst

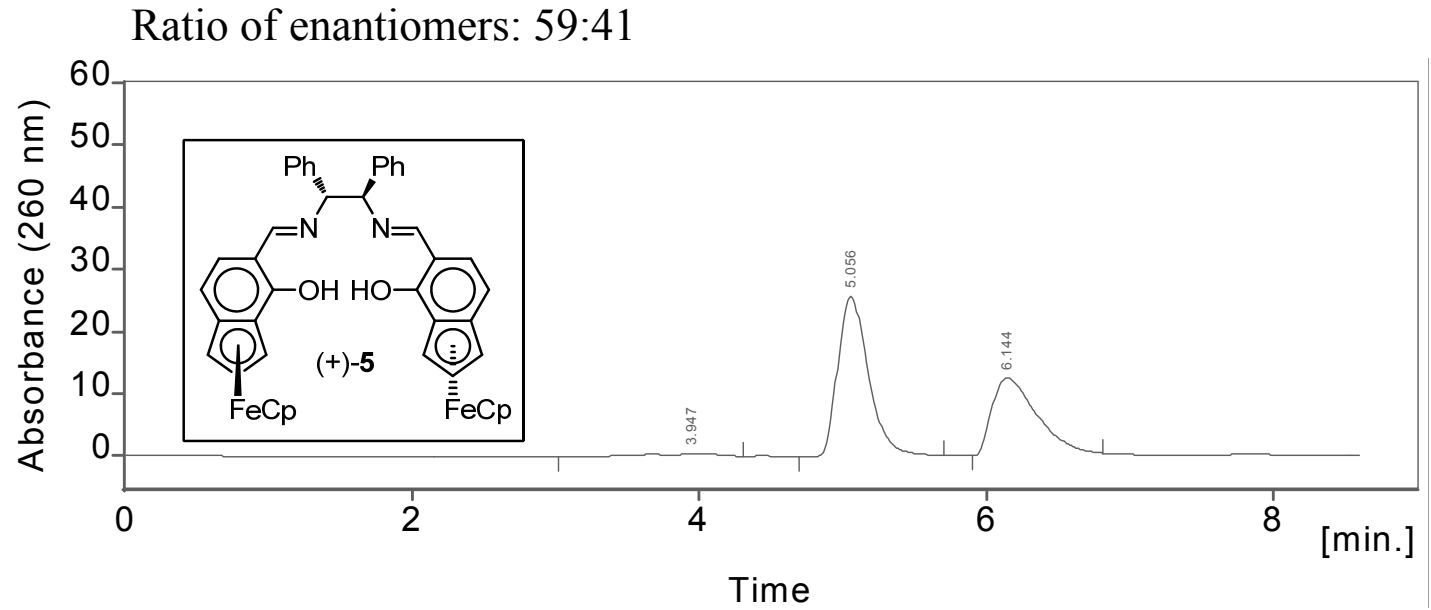

Figure C.20: $\mathrm{HPLC}$ profile for $\mathbf{1 9}$ using $(+)-\mathbf{5}-\mathrm{AlCl}$ as the catalyst 


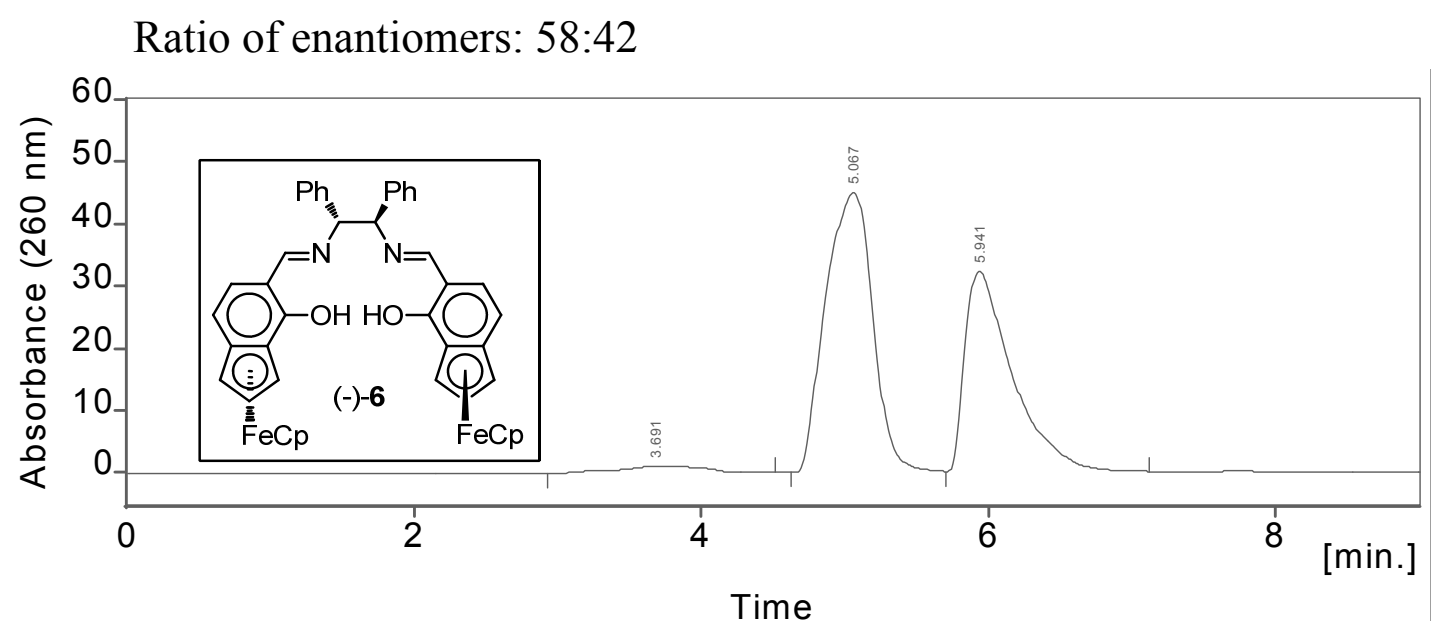

Figure C.21: HPLC profile for 19 using (-)-6- $\mathrm{AlCl}$ as the catalyst

Ratio of enantiomers: $44: 56$

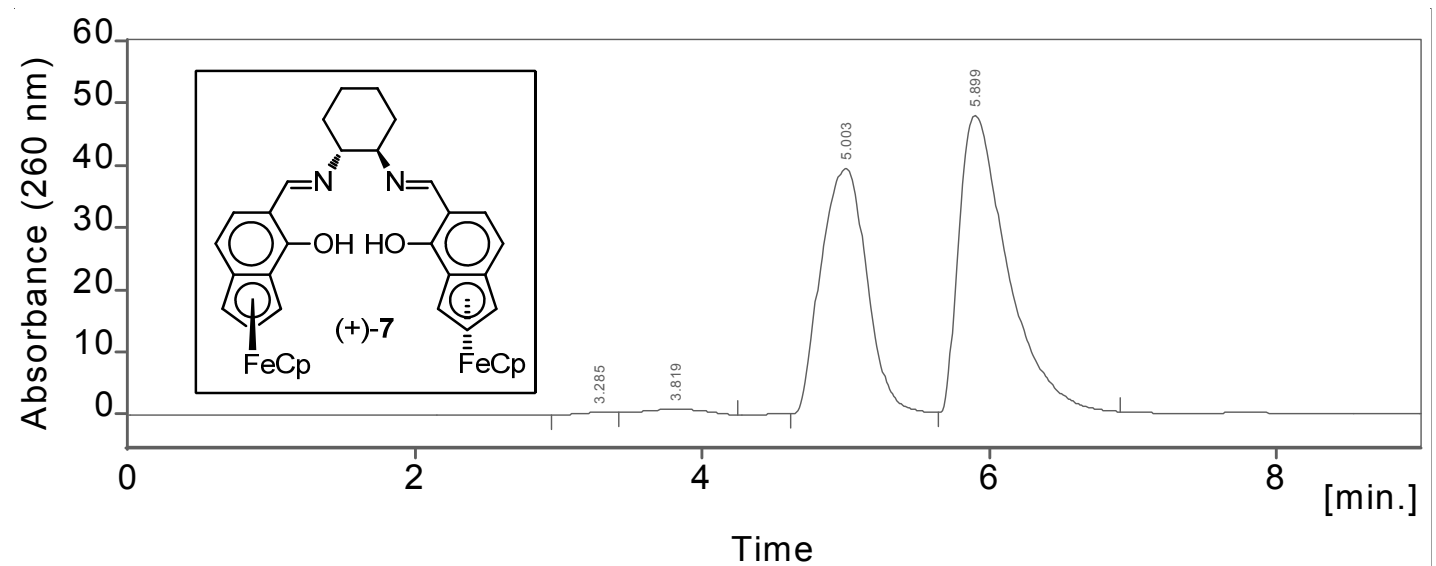

Figure C.22: HPLC profile for 19 using $(+)-7-\mathrm{AlCl}$ as the catalyst

Ratio of enantiomers: 60:40

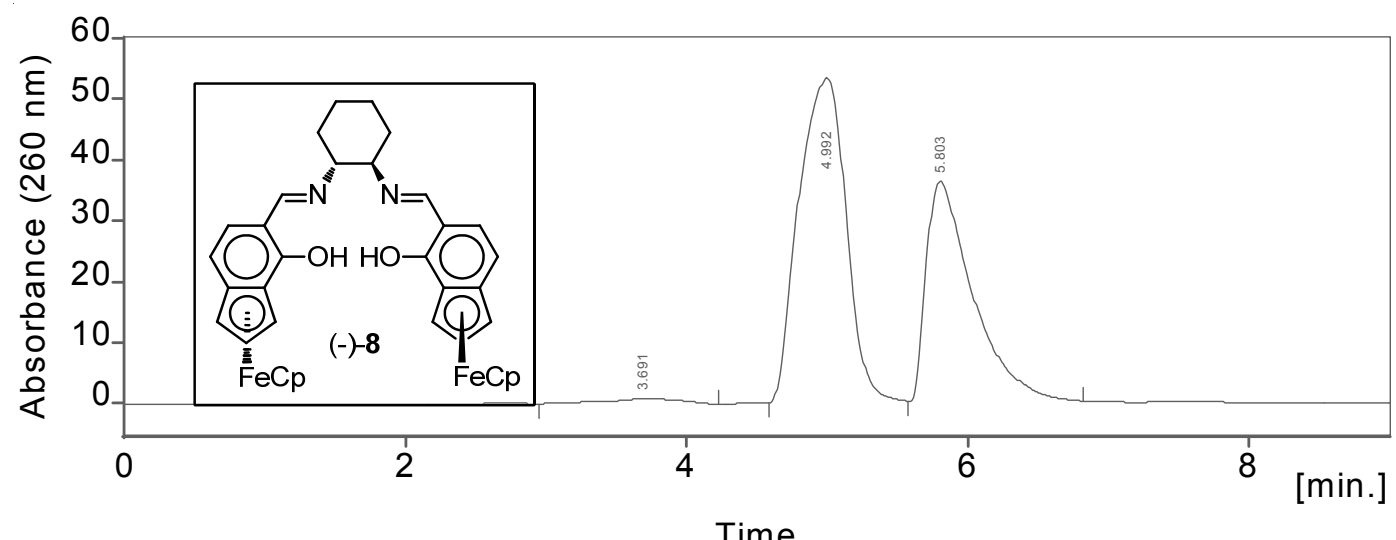

Figure C.23: HPLC profile for 19 using (-)-8- $\mathrm{AlCl}$ as the catalyst 


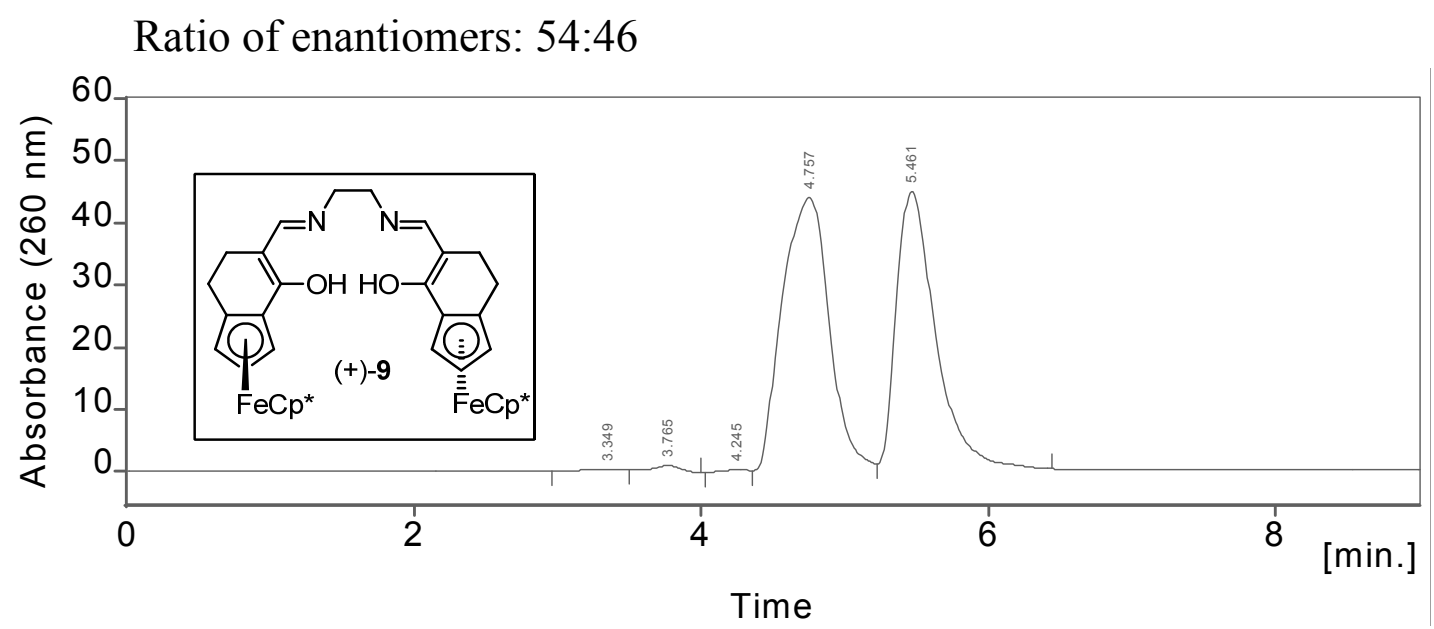

Figure C.24: HPLC profile for 19 using (+)-9-AlCl as the catalyst:

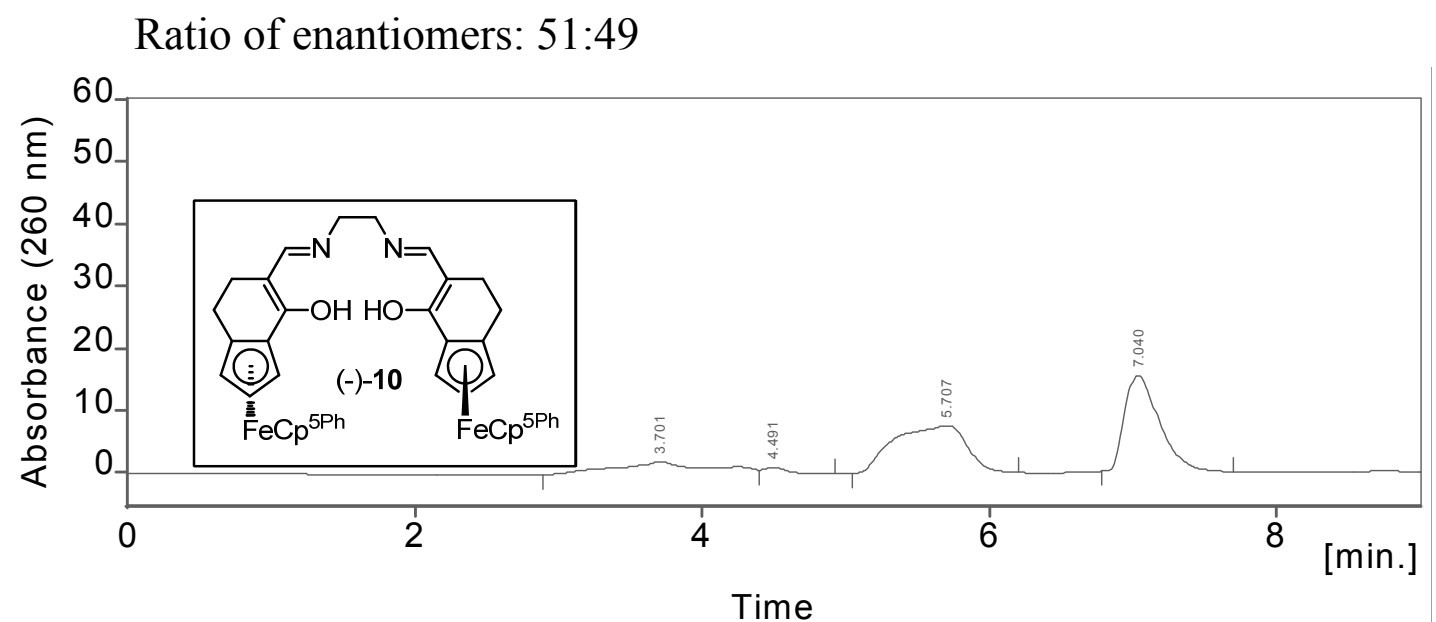

Figure C.25: HPLC profile for $\mathbf{1 9}$ using (-)-10-AlCl as the catalyst: 


\section{C. $2{ }^{1} \mathrm{H}$ and ${ }^{13} \mathrm{C}$ NMR spectra of new compounds}
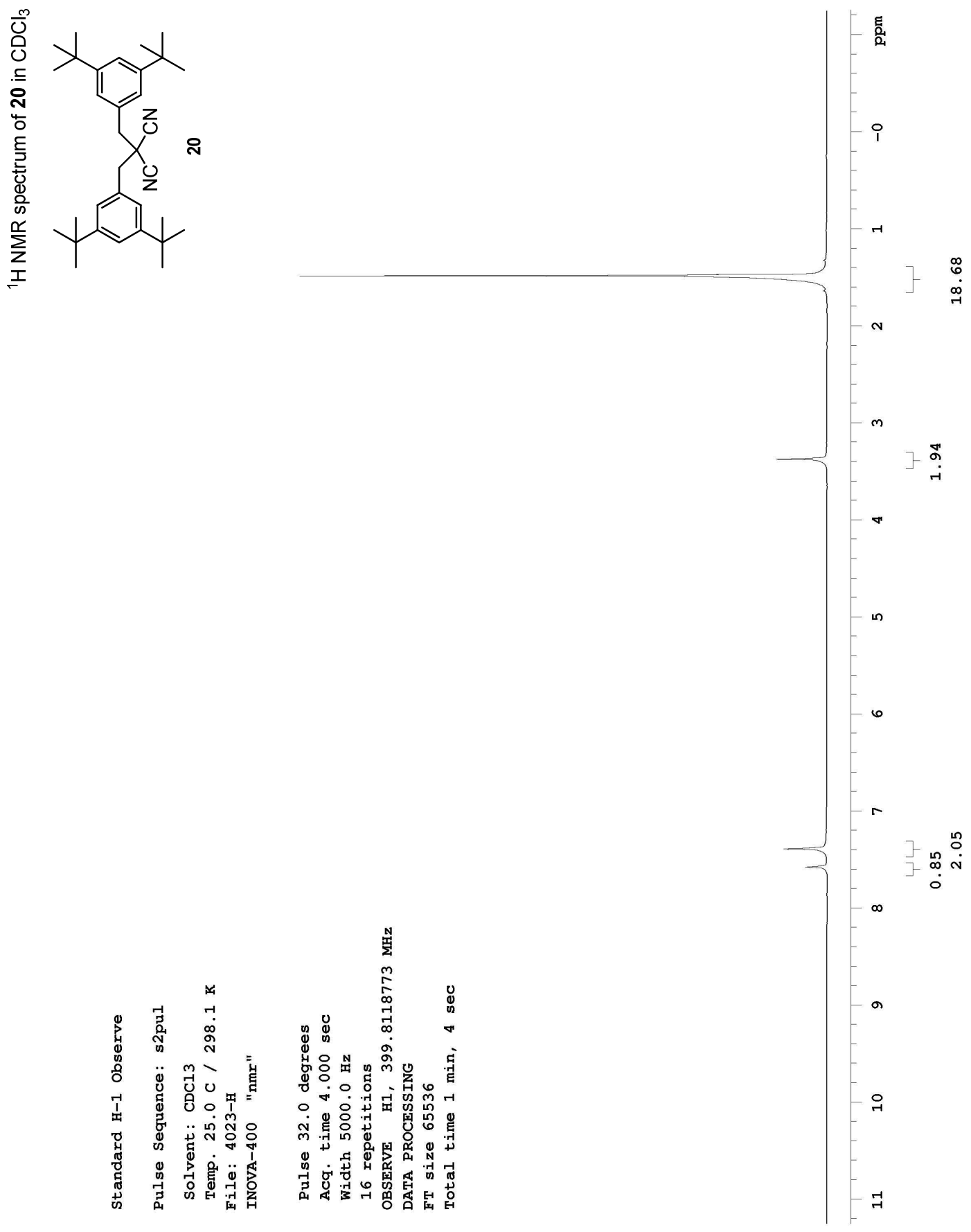

Figure C.26: ${ }^{1} \mathrm{H}$ NMR spectrum of $\mathbf{2 0}$ 

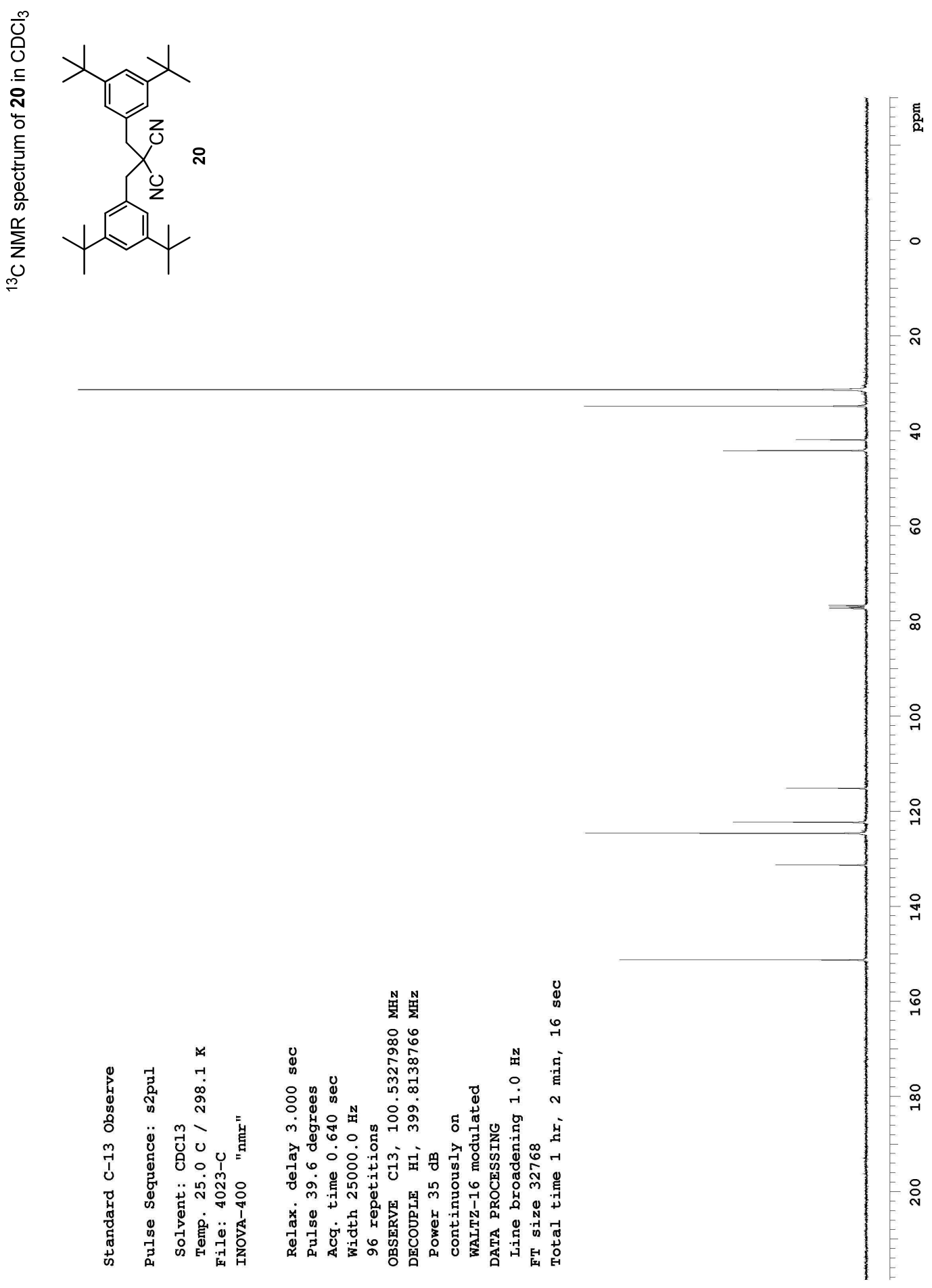

Figure C.27: ${ }^{13} \mathrm{C}$ NMR spectrum of 20 


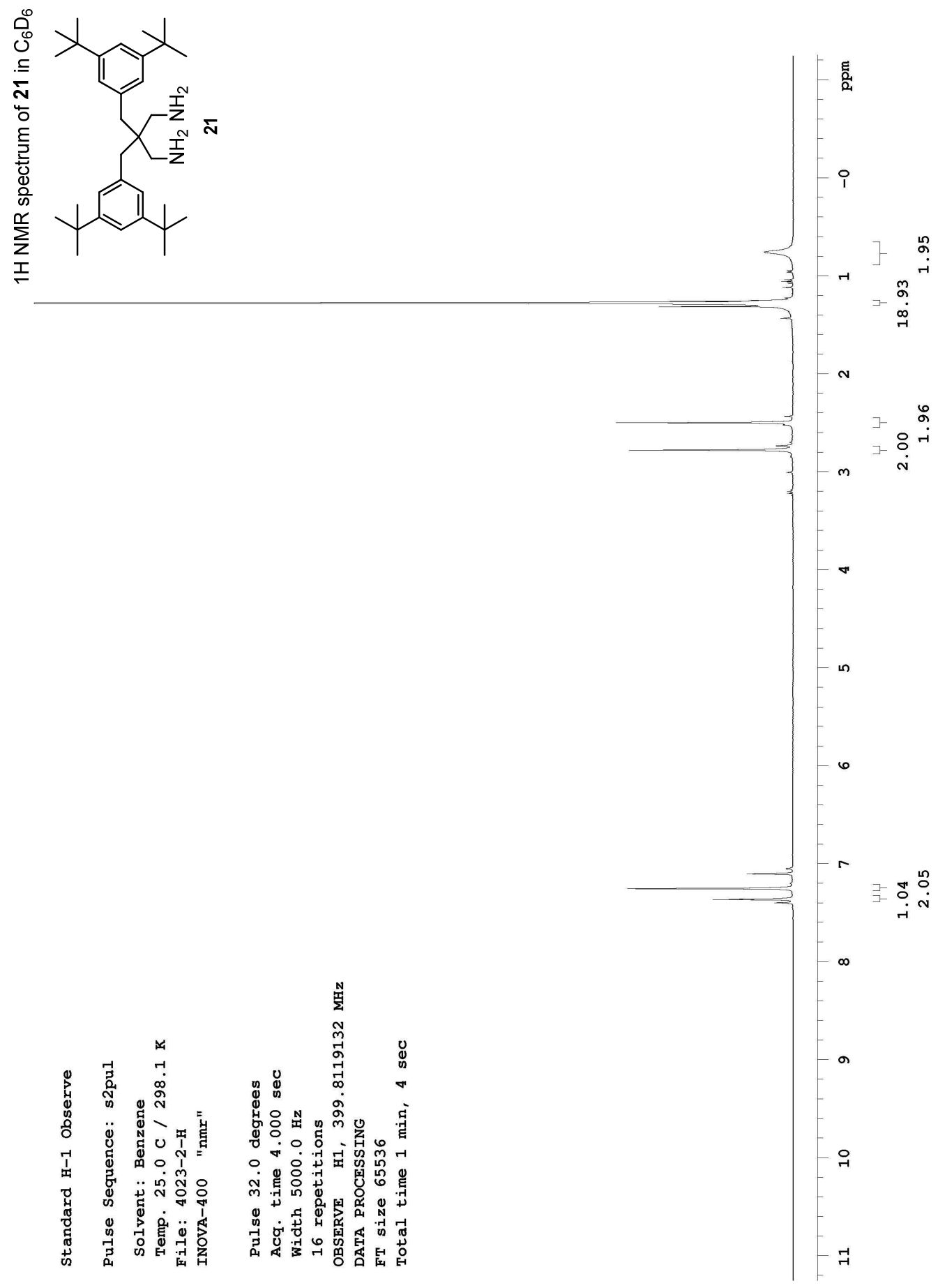

Figure C.28: ${ }^{1} \mathrm{H}$ NMR spectrum of 21 

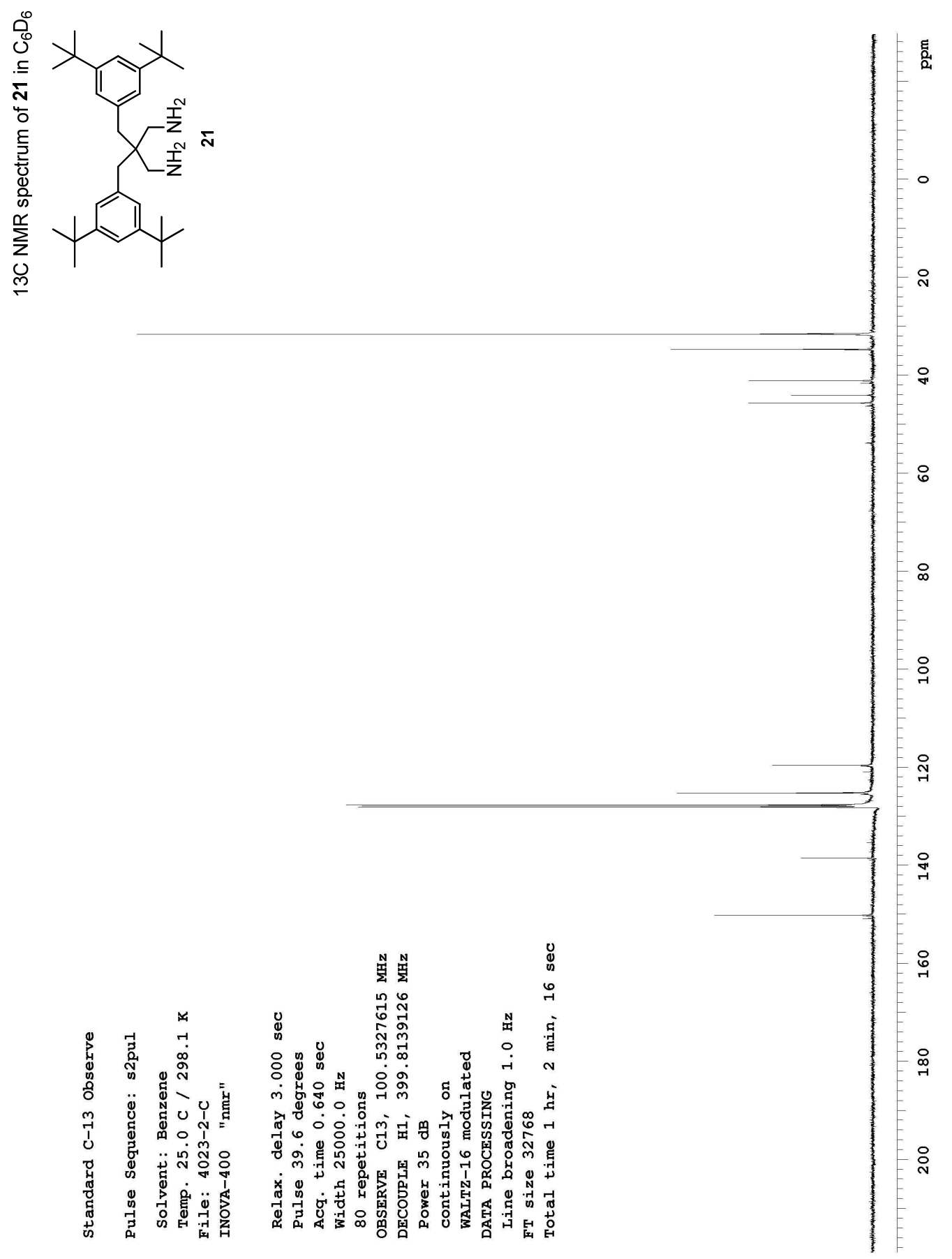

Figure C.29: ${ }^{13} \mathrm{C}$ NMR spectrum of 21 

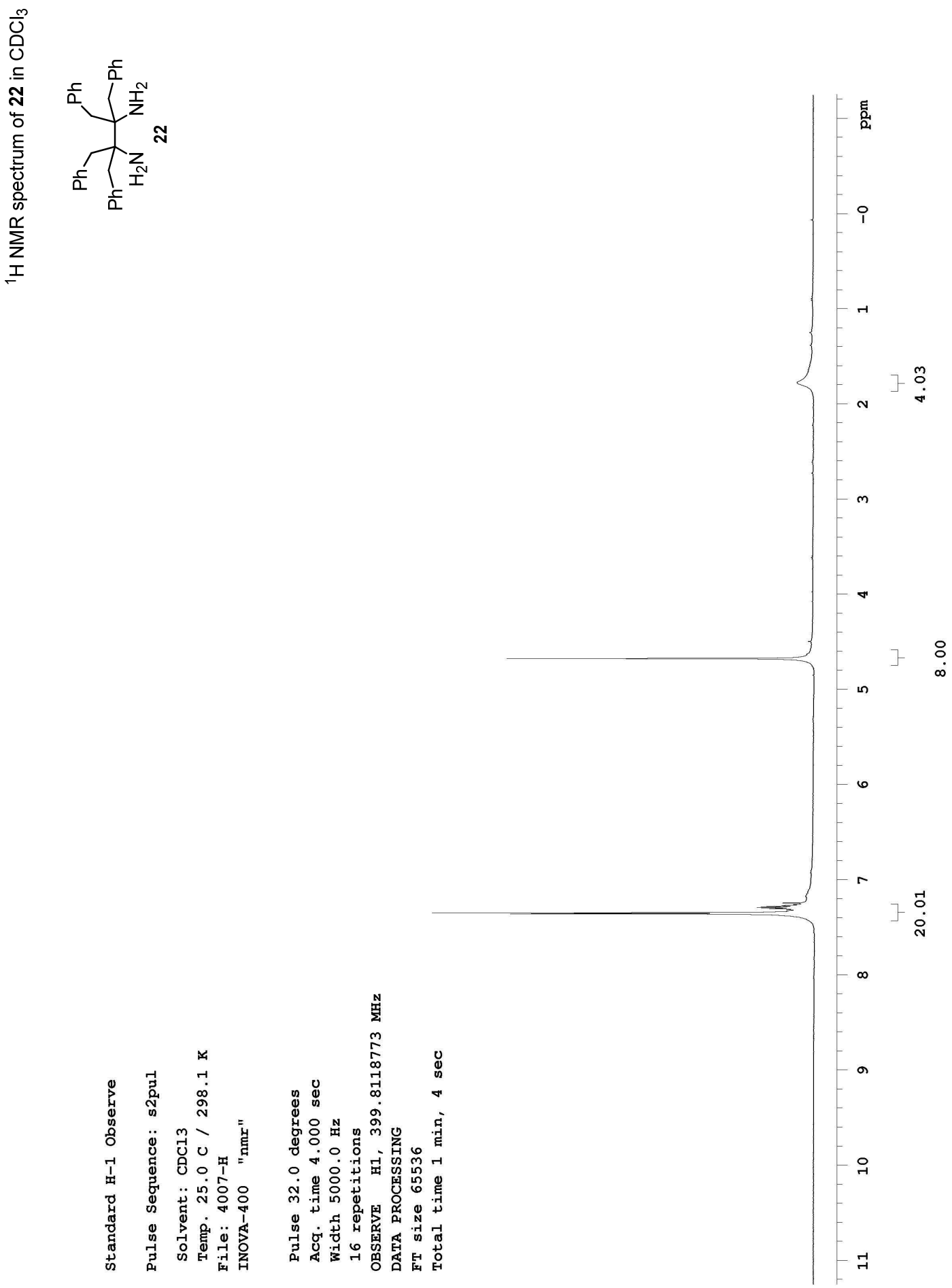

Figure C.30: ${ }^{1} \mathrm{H}$ NMR spectrum of $\mathbf{2 2}$ 

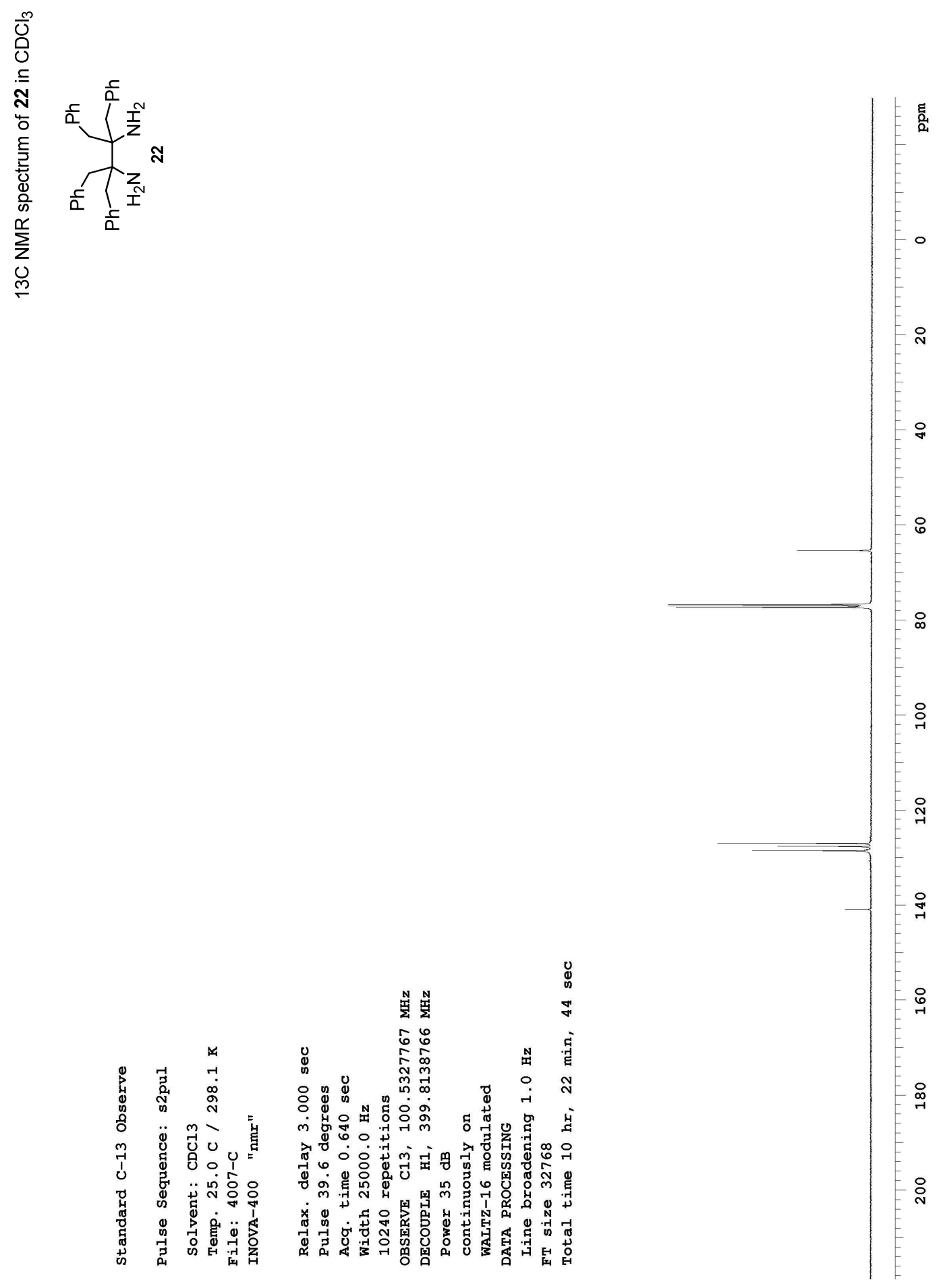

Figure C.31: ${ }^{13} \mathrm{C}$ NMR spectrum of 22 


\section{Appendix D}

\section{Permission from the publishers}

\section{D.1 License of reproduction for Chapter 2}

\section{Table D.1}

License of reproduction for Chapter 2

Copyright
Clearance Righter
Center
Home s My Orders s View Your Rights Link Od
Lice nse Details
This is a License Agreement between xiar
the payment terms and conditions.
Get the printable license.
License Number
License date
Licensed content publisher
Licensed content publication
Licensed content title
Licensed content author
Licensed content date
Licensed content volume number
Licensed content issue number
Number of pages
Type of Use
Format
Are you the author of this Elsevier
article?
Will you be translating?
Order reference number
Tittle of your thesis/dissertation
Expected completion date
Estimated size (number of pages)
Elsevier VAT number
Permissions price
Value added tax $0.0 \%$
Total

Welcome zxiang@mtu.edu Log out I Help

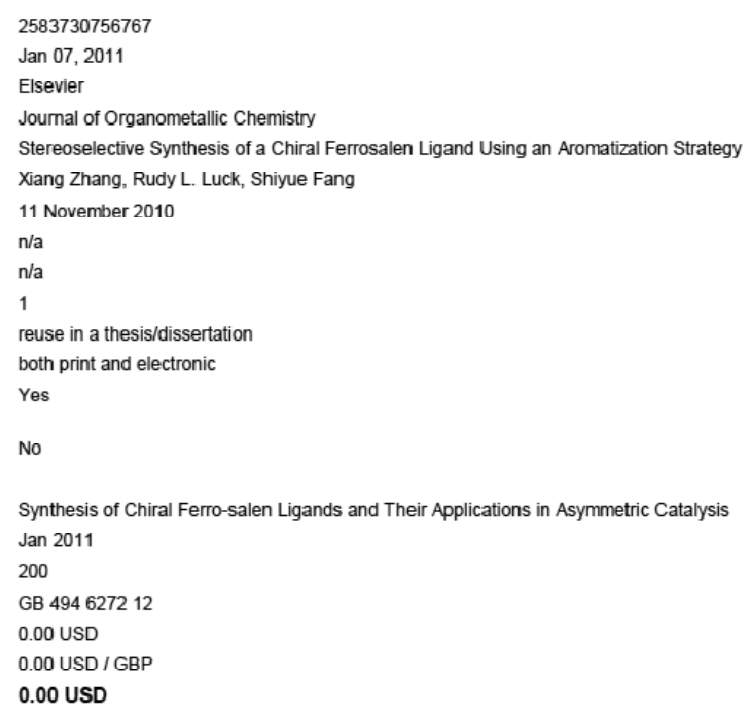




\section{D.2 License of reproduction for Chapter 3}

\section{American Chemical Society's Policy on Theses and Dissertations}

This is regarding request for permission to include your paper(s) or portions of text from your paper(s) in your thesis. Permission is now automatically granted; please pay special attention to the implications paragraph below. The Copyright Subcommittee of the Joint Board/Council Committees on Publications approved the following:

Copyright permission for published and submitted material from theses and dissertations

ACS extends blanket permission to students to include in their theses and dissertations their own articles, or portions thereof, that have been published in ACS journals or submitted to ACS journals for publication, provided that the ACS copyright credit line is noted on the appropriate page(s).

Publishing implications of electronic publication of theses and dissertation material

Students and their mentors should be aware that posting of theses and dissertation material on the Web prior to submission of material from that thesis or dissertation to an ACS journal may affect publication in that journal. Whether Web posting is considered prior publication may be evaluated on a case-by-case basis by the journal's editor. If an ACS journal editor considers Web posting to be "prior publication", the paper will not be accepted for publication in that journal. If you intend to submit your unpublished paper to ACS for publication, check with the appropriate editor prior to posting your manuscript electronically.

Reuse/Republication of the Entire Work in Theses or Collections: Authors may reuse all or part of the Submitted, Accepted or Published Work in a thesis or dissertation that the author writes and is required to submit to satisfy the criteria of degree-granting institutions. Such reuse is permitted subject to the ACS' "Ethical Guidelines to Publication of Chemical Research" (http://pubs.acs.org/page/policy/ethics/index.html); the author should secure written confirmation (via letter or email) from the respective ACS journal editor(s) to avoid potential conflicts with journal prior publication*/embargo policies. Appropriate citation of the Published Work must be made. If the thesis or dissertation to be published is in electronic format, a direct link to the Published Work must also be included using the ACS Articles on Request author-directed link see http://pubs.acs.org/page/policy/articlesonrequest/index.html

* Prior publication policies of ACS journals are posted on the ACS website at http://pubs.acs.org/page/policy/prior/index.html

If your paper has not yet been published by ACS, please print the following credit line on the first page of your article: "Reproduced (or 'Reproduced in part') with permission from [JOURNAL NAME], in press (or 'submitted for publication'). Unpublished work copyright [CURRENT YEAR] American Chemical Society." Include appropriate information.

If your paper has already been published by ACS and you want to include the text or portions of the text in your thesis/dissertation, please print the ACS copyright credit line on the first page of your article: "Reproduced (or 'Reproduced in part') with permission from [FULL REFERENCE CITATION.] Copyright [YEAR] American Chemical Society." Include appropriate information.

Submission to a Dissertation Distributor: If you plan to submit your thesis to UMI or to another dissertation distributor, you should not include the unpublished ACS paper in your thesis if the thesis will be disseminated electronically, until ACS has published your paper. After publication of the paper by ACS, you may release the entire thesis (not the individual ACS article by itself) for electronic dissemination through the distributor; ACS's copyright credit line should be printed on the first page of the ACS paper.

$10 / 10 / 03,01 / 15 / 04,06 / 07 / 06,04 / 07 / 10,08 / 24 / 10,02 / 28 / 11$ 